\title{
Talking You Through
}

Citation for published version (APA):

Dieker, M. L. R. (2020). Talking You Through: The Shifting Socio-Technical Practices of Radio Traffic News, 1950s-now. [Doctoral Thesis, Maastricht University]. Proefschriftmaken.nl || Uitgeverij BOXPress. https://doi.org/10.26481/dis.20200116md

Document status and date:

Published: 01/01/2020

DOI:

10.26481/dis.20200116md

Document Version:

Publisher's PDF, also known as Version of record

\section{Please check the document version of this publication:}

- A submitted manuscript is the version of the article upon submission and before peer-review. There can be important differences between the submitted version and the official published version of record.

People interested in the research are advised to contact the author for the final version of the publication, or visit the DOI to the publisher's website.

- The final author version and the galley proof are versions of the publication after peer review.

- The final published version features the final layout of the paper including the volume, issue and page numbers.

Link to publication

\footnotetext{
General rights rights.

- You may freely distribute the URL identifying the publication in the public portal. please follow below link for the End User Agreement:

www.umlib.nl/taverne-license

Take down policy

If you believe that this document breaches copyright please contact us at:

repository@maastrichtuniversity.nl

providing details and we will investigate your claim.
}

Copyright and moral rights for the publications made accessible in the public portal are retained by the authors and/or other copyright owners and it is a condition of accessing publications that users recognise and abide by the legal requirements associated with these

- Users may download and print one copy of any publication from the public portal for the purpose of private study or research.

- You may not further distribute the material or use it for any profit-making activity or commercial gain

If the publication is distributed under the terms of Article $25 \mathrm{fa}$ of the Dutch Copyright Act, indicated by the "Taverne" license above, 



\title{
Talking You Through
}

The Shifting Socio-Technical Practices of Radio Traffic News, 1950s-now

\author{
Marith Dieker
}


Copyright (C) 2020, Marith Dieker

Cover design: (C) Sveya Dieker \& Dion Dieker

Lay-out: Marith Dieker \& Michiel Boer

Printing: proefschriftmaken.nl

The printing of this dissertation has been financially supported by the Netherlands Graduate Research School for Science, Technology and Modern Culture (WTMC) 



\title{
Talking You Through
}

\section{The Shifting Socio-Technical Practices of Radio Traffic News, 1950s-now}

\author{
Dissertation \\ to obtain the degree of Doctor at Maastricht University, \\ on the authority of the Rector Magnificus, Prof. dr. Rianne M. Letschert \\ in accordance with the decision of the Board of Deans, \\ to be defended in public on Thursday, 16 January 2020 at 10.00 hours \\ by
}

Marith Loudine Renée Dieker 


\section{Promotors}

Prof. dr. Karin Bijsterveld

Prof. dr. Wiebe Bijker

\section{Assessment Committee}

Prof. dr. Cyrus Mody (chair)

Dr. Anique Hommels

Prof. dr. Peter Peters

Prof. dr. Erik van der Vleuten (TU Eindhoven, the Netherlands)

Prof. dr. Heike Weber (TU Berlin, Germany)

This dissertation is the result of an individual research project funded by the Netherlands Organisation for Scientific Research (NWO) [grant number PGW-14-02] 



\section{Table of Contents}

\section{ACKNOWLEDGEMENTS}

\section{INTRODUCTION}

Talking You Through

Brief Historiography of Car Radio and Traffic Information

Radio, Traffic Information and Strategies for Traffic Management

Research Design: Case Selection, Sources, Observations and Interviews

Overview of Theoretical Frameworks

Outline of this Dissertation

\section{MAPPING MOBILITY: GATHERING, PROCESSING AND}

\section{BROADCASTING TRAFFIC INFORMATION}

Tracing Technological Trajectories

New! Radio Traffic Information at the Push of a Button

Changing Practices of Gathering Traffic Data

Momentum and the Merging of Broadcasting Technologies in Europe

Traffic Reporting Traditions across the Atlantic Ocean 58

Conclusion: A Theoretical Shock of the Old

\section{BROADCASTING FLOW:}

\section{PRESENTING TRAFFIC INFORMATION ON THE AIR}

Flow in and through Radio Traffic Reports

Studying Flow in Radio Broadcasts

Weather Alerts and Other Dangers in Early Broadcasts for Motorists

Scaling Up While Sizing Down

Persisting Presentation Practices in the New York Area 
4. LISTENING WHILE DRIVING:

APPREHENDING TRAFFIC INFORMATION ON THE ROAD 101

Listening along with Motorists $\quad 101$

Studying Automobile Habitation through Sound Recordings 103

Sounds and Technologies in a Car on the Move 109

Choosing Media in Search of Useful Traffic Information $\quad 113$

Traffic Reports as Hopeful Messages of Misery $\quad 120$

Alternative Forms of Autonomy on the Road 124

$\begin{array}{ll}\text { Conclusion: Searching for Solace inside the Automobile } & 127\end{array}$

5. CONCLUSION: ENRICHING THE DEBATE ABOUT AUTOMOBILITY 133

Returning to the Research Objectives 133

Zooming in on the Meaning of Traffic Reports in Practice 136

Envisioning New Trajectories 138

Conclusion: Where the Past, Present and Future Meet, Again 141

$\begin{array}{ll}\text { BIBLIOGRAPHY } & 145\end{array}$

ARCHIVES, FIELD VISITS, INTERVIEWS AND CORRESPONDENCES 155

$\begin{array}{ll}\text { ILLUSTRATIONS } & 159\end{array}$

THE VALORISATION ADDENDUM 171

Sharing Expertise and Experience 171

Explicating the Relevance of my Research 172

Past and Planned Dissemination and Outreach Activities 173

Traversing into new Trajectories 176

$\begin{array}{ll}\text { References } & 178\end{array}$

$\begin{array}{ll}\text { NEDERLANDSE SAMENVATTING } & 181\end{array}$

$\begin{array}{lr}\text { CURRICULUM VITAE } & 187\end{array}$ 




\section{Acknowledgements}

Researching the car radio and traffic information's role in the context of our everyday automobile travelling has been nothing short of a journey in itself. My time as a $\mathrm{PhD}$ candidate at Maastricht University has been filled with moments of curiosity, joy, insight, surprise, gratefulness, and a few uncertainties. Fortunately, I was joined by many great individuals in my quest, some of whom I hereby want to thank for their help along the way.

First, my sincere gratitude goes out to my supervisors, Karin Bijsterveld and Wiebe Bijker. Karin has guided me throughout every phase in this project, and I am truly grateful for her continued and careful supervision. I can safely say her involvement has shaped me as a professional and as a person. Wiebe has been a mentor from the moment I enrolled in the Research Master Cultures of Arts, Science and Technology, back in 2011. I am fortunate to have been able to draw upon his knowledge of our scholarly discipline and thank him for his sensitivity for all the things that make us human.

I received helpful comments from Gijs Mom, Thomas Zeller and Bruce Seely at the start of this project. I would like to thank them again for supporting my research during its initiation.

The research presented in this dissertation has been conducted at various places. In the Netherlands, I would like to thank the following individuals for their time and willingness to share their knowledge with me: Arnoud Broekhuis, Erwin de Hard, Dennis Mooij, Cees Quax, René Passet and Jolanda van den Velde at the ANWB; Theo Kamalski at TomTom; Jurgen van den Berg, Hans van Raaij, Lara Rense, and Frits 'Spits' Ritmeester at NPO Radio 1. Marianka Louwers and Miriam Lengová were of great help to get me started with my archival research at the Philips Company Archives. Bas Agterberg guided me into the fascinating databases of the Dutch Institute for Sound and Vision. Mark Beekhuis of BNR Radio enabled me to share my first findings on the air.

Arnoud Broekhuis (ANWB), Jurgen van den Berg (Radio 1) and Karel Brookhuis (University of Groningen) also provided valuable comments on my main findings during the two expert meetings in the final phase of the project.

During my fieldwork in Germany I had the pleasure to meet Tobias Fasora and Andrea Phillipp at the SWR archives, located on the lower floors of the SWR broadcasting centre in Stuttgart. On the higher floors of the same building I was welcomed by Birgit Wächter, Corvin Tondera-Klein and Julia Raizner, who were so kind to show me around in the SWR 1 radio studio. Jochen Stöckle, Thomas Schmidt and Janet Pollok provided more insight into their experiences as radio hosts during very engaging telephone calls. In the Bosch/Blaupunkt company archives I received support from Bettina Simon and Dietrich Kuhlgatz. At the Landesmeldestelle fur den Verkehrswarndienst in Stuttgart I enjoyed a very informative conversation with Bernd Mayershofer. I am also grateful to Mr. Peter Brägas, who answered some technical questions about Blaupunkt's innovations back in the early 1970s. Finally, 
during both of my four-week stays in Stuttgart in 2016 and 2017 Frau Regine Höll was very kind to take me in her home.

In the New York metropolitan area, I could rely upon the expertise of Danielle Cordovez at the Rodgers and Hammerstein Archives of Recorded Sound. Mike Weinstein and Andrew Kaplan welcomed me for a visit at the Port Authority of New York and New Jersey. I am also grateful to the traffic reporters and radio hosts at WCBS880, 1010WINS, and Total Traffic and Weather: Wayne Cabot, Kelly Dillon, Anthony Gatti, Tom Kaminski, John McLaughlin, Greg Rice, Tim Scheld, Steve Scott, Pete Tauriello, Michael Wallace, and Matt Ward. David Fein and Jerry Lebow also shared their past experiences with New York traffic news with me. I am especially indebted to Bernie Wagenblast for being the first American traffic reporter I had the pleasure to interview all the way back in 2013, and I am grateful for his support of my project ever since. Bruce Slutsky, Neil Weiser, Ed Salvas, Nick Sarames and Bob Gilmore gave helpful comments and assisted in finding historical radio broadcasts via forum posts at the New York Radio History Board and various New York radio tribute sites.

Chapter four of this dissertation could not have been written without the participation of 22 motorists. I am incredibly grateful for all their efforts to make my research possible, and I hope this dissertation reflects my appreciation in return.

At Maastricht University, and particularly at the Faculty of Arts and Social Sciences, many people have inspired, stimulated, and reassured me, in my work and beyond. Claudia was a fantastic classmate during CAST and wonderful officemate during the $\mathrm{PhD}$. Simone, Hortense, Lisa, Karlijn, Linnea, Andreea, Valentina, Karlien, Willemine, Afke and others: you have each made my time in Maastricht a real pleasure, and I am grateful for the good and occasional tougher times we shared. Many thanks also to Charles, Gladys, Sarah and Lea for the good conversations and moral support in the office.

I am also indebted to my colleagues in the department of Society Studies and the MUSTS research group for providing feedback during several seminars and work in progress meetings. Also, thank you for making me feel part of a strong academic community. I also received much support from the two secretaries of the department, Sabine Kuipers and Cindy van Montfoort, and the team behind the FASoS Graduate School, in particular Christine Neuhold, Cyrus Mody and Alexandra Supper. Finally, Vincent Lagendijk has been the most conscientious UTQ mentor, fellow history of technology enthusiast, and life-in-and-outsideof-academia sparring partner. A special thanks goes out to you!

At the national research school WTMC I met an entire cohort of young scholars who, with their sharp minds as well as kindness, evaluated my work in progress during workshops, summer schools and writeshops. I am especially thankful to Jorijn and Tessa, with whom I crossed the finish line. Coordinators Bernike Pasveer and Govert Valkenburg: thank you for your guidance and feedback throughout my $\mathrm{PhD}$ trajectory. 
Furthermore, I would like to thank the attendants of my presentations at 4S/EASST conference in Barcelona, 2016, the Mobile Utopia conference in Lancaster, 2017, and the International Perspective on Radio Centenary in Hilversum, 2019, for their questions and suggestions. Similarly, gratitude goes to Frank Schipper (TU Eindhoven) and Alec Badenoch (UvA/Beeld en Geluid) for inviting me to present at one of their seminars.

I am indebted to Ton Brouwers, who never ceased to provide helpful comments on my texts, and Rhoda Gieske and Jorinde Wilbrink for their help with transcribing some interviews.

Then, there are a bunch of friends and loved ones who reminded me there is a life outside of work. You have made my travels more exciting and my heart considerably bigger! Thanks!

Finally, I feel fortunate that I always had a home to return to. Ellen, Clemens, Dion, Sveya, Sjoerd and Chloé, I am proud when I think about all the adventures we have committed ourselves to as individuals and as a family. Your never-ending love and support has definitely helped me to complete this $\mathrm{PhD}$.

Michiel and Naud, I am so very happy to have you as my companions in life. I look forward to every next step of the way, together.

I dedicate this work to you. 



\section{Introduction}

\section{Talking You Through}

In the last week of May 2015, when I found myself in the middle of my research project on radio traffic reporting, Dutch media unexpectedly carried headlines and news items which were highly relevant to my topic. Some of these stories indicated there was reason for a party: to celebrate the sixtieth anniversary of the traffic jam in the Netherlands (e.g. Van den Akker, May 29, 2015). On the sunny Pentecost Sunday in late May 1955, this 'first' traffic jam took place at the highway junction Oudenrijn, just south of the city of Utrecht, right in the centre of the country (Buiter \& Volkers, 1996). If many cars got stuck in traffic on that particular Sunday, the history of traffic congestion in the Netherlands started at least several decades earlier. In fact, newspaper articles testify that Dutch motorists had to deal with lengthy queues of waiting cars as early as in the 1910s and 1920s (Boon, 2015; see also illustration 1.1). It is true, however, that as a phenomenon traffic jams became more common on Dutch roads and highways as of the second half of the 1950s, despite major efforts on the part of the Dutch authorities to expand and improve the country's traffic infrastructure.

Early 2019, a traffic jam-related record was realised: on January 22, around the peak of the evening rush hour, Dutch highways were clogged and a staggering total of 2287 kilometres of slow and stagnant traffic was reported (Wassens, January 22, 2019). Motorists who listened to the radio at that time will have heard the efforts of radio hosts and traffic reporters to inform and entertain their captive audience. At regular intervals, reporters provided information about developing jam lengths, informing listeners on where traffic had come to a standstill and where it sluggishly started to get going again. Meanwhile, the radio hosts tried to provide moral support to those who were stuck, also by putting things into perspective through playful jokes.

In the Netherlands, as in many countries, the car is still the preferred means for travelling from A to B, regardless of the efforts of public campaigns and travel information services to convince people to use public transport instead. For many years, the car radio has been considered an important means for informing drivers about the situation on the road. In the Netherlands, traffic news items with the latest updates about ongoing congestions have been aired since at least the mid-1960s. Numerous studies have meanwhile been conducted to explore the use of these reports by motorists. A mid-1990s survey among drivers in the Amsterdam region, for example, showed that 38.3 per cent of motorists listened to radio traffic information regularly while 37.9 per cent did so frequently, which implies that 76,2 per cent of the listeners in fact used traffic radio (Emmerink et al., 1996, p. 140). In 2013, over half of the commuters interviewed in the region of The Hague responded that "radio remains the most common way ... of obtaining traffic information" (Tseng et al., 2013, p. 199). And, significantly, in 2014 the European Commission considered Traffic Message Channel, a feature of radios and navigation systems equipped with RDS (Radio Data System) technology, as "the most successful traffic information service" in Europe (2014).

Despite the rise of Advanced Traveller Information Services (ATIS) — such as dynamic message systems, in-car navigation, and sources of information accessible through 
the smartphone - traffic information via car radio has continued to be an important source of information for motorists to this day. This is remarkable because radio has long been viewed as a relatively old-fashioned medium. Already in 1979, a Dutch expert in the field of traffic and transport, Ron Hendriks, referred to "good old radio" in a discussion about new radio traffic information technologies, seeing it as a technology of the past (Hendriks, 1979, p. 1135).

That radio traffic information has been in use for a long time, however, does not imply that it has had the same character or ascribed role as it appears to have today. In fact, the format of radio traffic news shifted substantially over time, in the Netherlands as well as in other countries. The format of traffic information may also vary considerably from one country, or even from one radio station within a country, to the next. Dutch radio traffic reporters today commonly present traffic jams in terms of delays they imply for drivers, and only occasionally specify the cause or length of the jam. American reporters, by contrast, often explain the situation in a congested area in detail, and add information on alternative routes to avoid a traffic jam. The means for gathering traffic information have also changed over time, ranging from aerial traffic reporting from helicopters to the use of citizen band radio and automated road sensors. The responsibility for providing the information is organised in varying ways in different places, and it may be in the hands of public traffic authorities, commercial service providers or private motorist organisations.

This dissertation deals with the range of ways in which traffic information has been gathered and presented over the years and in various countries. I explore how particular practices originated, and how the shifts and differences in these practices across countries can be explained. Although present-day European research and policy documents generally presume a significant contribution of traffic information to traffic flow management, there are also drivers who do not use it at all and who rather listen to their mobile phone, fellow passengers, navigation technology, music, audiobooks or nothing in particular. Obviously this freedom of car drivers to listen to whatever they like best does not agree well with the purpose of traffic control and potential driver compliance with implicit or explicit advice on alternative routes whenever a road is jammed.

To gain a better understanding of the dynamics involved, this dissertation will address the following question in particular:

How and to what extent have practices of gathering, presenting and listening to radio traffic information evolved into practices aimed at traffic flow control?

To trace the shifts in gathering traffic information, presenting it and listening to traffic radio, I will explore the following three questions in more detail: 


\section{Which technologies and organisational forms have been developed to gather and transmit traffic information across radio? \\ How has this information been presented to drivers and embedded in radio programmes? \\ How do drivers today appropriate traffic information amidst competing listening activities?}

In order to understand the international differences in the ways traffic information has been gathered and presented, my study will draw on historical comparison and focus on three countries in particular: the Netherlands, Germany and the United States. The rationale of this selection will be explained below in the section on research design. In the conclusion of this dissertation I will address how my historical-comparative analysis of the rise and appropriation of traffic radio can contribute to high-quality traffic information and sustainable mobility today.

The aim of my project is twofold. First, this research is meant to help experts to enrich their experiments on and strategies for reducing traffic jams and promoting an efficient flow of traffic, which policy documents often conflate with sustainable forms of mobility. To this end, I rely on historical and in-car ethnographic research - to be elaborated upon belowand concepts from the History of Technology, Media Studies and Mobility Studies. Secondly, I hope to contribute to these scholarly disciplines by unravelling the history of an understudied topic - radio traffic news - by showing the relation between transportation and media technologies, and by exploring how existing (media) technologies seem to retain their practical relevance once new technologies are introduced. This latter notion has been forcefully put forward by historian of technology David Edgerton in The Shock of the Old: Technology and Global History since 1900 (2006). Edgerton reminds the readers of his study that many old technologies may well retain functional relevance after the introduction of new ones, and why this is important to keep in mind. In line with this position, I will argue for the relevance of studying conventional traffic radio, even though contemporary policy reports on smart transport appear to put all their eggs in the basket of Advanced Traveller Information Services.

\section{Brief Historiography of Car Radio and Traffic Information}

When in-built car radios were introduced in the US in the 1920s, informing drivers on traffic situations was not exactly on the agenda of car radio manufacturers. On the contrary, they had to defend their new technology against concerns that it threatened road safety. An accident in which a pedestrian was hit by a New York taxi whose driver was presumably distracted by his car radio provoked a debate about this recent invention's negative effects on driver attention. In the United States, a lobby of radio manufacturers even had to prevent a ban on the use of car radios (Bijsterveld et al., 2014, p. 94). The potential (un)safety of radio listening while driving also became an issue in other countries. In the 1930s, for instance, the Dutch radio manufacturer Philips recommended drivers not to play their car radio in dense urban traffic, and to tune in only during long drives in the country. On a lonely 
country road, car radio might actually prevent drivers from falling asleep (Bijsterveld et al., 2014, pp. 95-96).

By the 1960s the traffic situation in both the US and Europe had changed dramatically. In 1960, 64 per cent of all employees in the US used a car in order to get to work. A dissertation citing this information opened with the claim that in "most of the large US metropolitan areas, a monumental traffic jam signals the arrival of a work day" (Aangeenbrug cited in Bijsterveld et al., 2014, p. 99). Traffic reports informed motorists about the most congested areas and invited them to consider alternative roads to reach their destination. Around the same time, traffic news became a more widespread European phenomenon. By the early 1970s, several German radio stations had begun to offer broadcasts especially for motorists. They offered music to "cheer up" motorists during "rush hour" and offered drivers information on, for example, the need for snow chains. ${ }^{1}$ A Dutch car mechanics handbook from 1971 explains that "reports on the weather, roads broken up, and traffic jams" were indispensable for the "realistic" motorist (Hinlopen, 1971, p. 174, cited in Bijsterveld et al. 2014, p. 102). From 1980, traffic reports also warned motorists for wrong-way drivers (so-called 'ghost drivers'). These emergency messages were broadcast instantly, regardless of the programme or time of day (Blokpoel \& De Niet, 2000, p. 11).

It was far from easy, however, to find broadcasting stations with traffic news amidst the myriad of stations on the radio dial. In the early 1970s in Germany, a joint venture of car radio manufacturer Blaupunkt and automobile club ADAC (both Stuttgart-based), together with the German radio and traffic authorities, tackled this problem by setting aside a particular range of radio bands as index frequencies for traffic radio. ${ }^{2}$ This ARI system (Autofahrer Rundfunk Information, also translated as Automatic Road Information) was officially adopted by the Federal German State in 1974. It assisted the driver, Blaupunkt claimed, in spending time with his family instead of being stuck in traffic jams (see also Weber, 2008, p. 149).

Soon after its introduction in Germany, the ARI system was taken up in other parts of Europe and, after its success, Blaupunkt also tried to promote it in the United States. ${ }^{3}$ In 1983, a team of Blaupunkt ambassadors went to various cities to promote their invention to traffic authorities and radio manufacturers. Armed with the slogan "ARI steers you clear of traffic," their first visit was to New York. ${ }^{4}$ At that time, a number of large radio stations in the New York area received their traffic information from a service provider called Shadow Traffic. The reporters at Shadow gathered information for their traffic reports from "a network of airplanes, helicopters, spotter cars, direct phone lines to the tunnel and bridge authorities and police departments, and ... 'regular citizen-type people' who take the same

\footnotetext{
${ }^{1}$ Bosch Company Archives, file 1601069 Autoradio 1968-1972 (Prospekte, Preislisten, Handelsunterlegen), unnumbered documentation, "Blaupunkt Autoradio," 1972, p. 2.

${ }^{2}$ Bosch Company Archives, file 1601078 Autoradio 1975-76 (Kataloge, Händlerinformationen), unnumbered documentation, "Blaupunkt Autofahrer-Rundfunk-Informations-System," 1977, p. 7; file 1601623 ARI Autofahrer Rundfunkinformation, unnumbered documentation, "Blaupunkt Moderne Verkehrslenkung durch den Rundfunk," 1977, pp. 5-6.

${ }^{3}$ Bosch Company Archives, file 1601623 ARI Autofahrer Rundfunkinformation, unnumbered documentation, "Blaupunkt Moderne Verkehrslenkung durch den Rundfunk," 1977, p. 7.

${ }^{4}$ Bosch Company Archives, unsorted files held by Mr. Kuhlgatz, document reference A/02/86/05/SM8, Blaupunkt Press Release "ARI Erfolgreich auch in den USA. Verkehrsfunk-Service schon von 24 UKW-FM-Sendern in Nordamerika," May 1986, p. 1.
} 
routes each day to their jobs and call in two-way radio reports to Shadow" (Angus \& Harrys, 1983, p. 3). Blaupunkt's liaisons in the United States developed a strategy to create an operational system for broadcasting and receiving traffic information in moving cars. They were not completely successful, however. Despite the cooperation of the participating popular radio stations, the ARI system proved less successful in the United States.

As I explain in chapter two, this failure can be largely attributed to differences in the organization of radio and radio traffic news between the United States and Europe. In addition, the emergence of new information and communication technologies in the 1980s, such as fully automated information gathering system and navigation devices, was a factor as well. Yet despite the rapid adoption of these traffic information systems, radio broadcasters still include traffic reports in their programmes, in an effort to improve the safety and efficiency of road travel. It is therefore interesting to investigate the relationship between traffic information, automobility and the situation on the road more closely.

\section{Radio, Traffic Information and Strategies for Traffic Management}

In the previous section, I referred to strategies put forward by car radio manufacturers to promote the benefits of car radio. They advocated that listening to car radio helped drivers to feel less lonely, stay awake, remain good-tempered and receive up-to-date information so as to avoid traffic jams. Today, the last issue in particular seems as timely as in the twentieth century, if not more so. After all, the number of vehicles on the road at any given moment has increased in virtually all Western countries and road infrastructures have grown more complex. Also, in many countries the different stakeholders - policymakers, car companies, the car radio industry, traffic authorities-have joined efforts to make people's daily commute faster and more efficient, which is, at least in documents on traffic information, often considered as more environmentally sustainable as well.

Indeed, the definition of sustainability is dependent on the precise context in which the term is used. The first discussions in which the term popped up emerged in the domains of ecology and environmentalism in the 1970s. Researchers sounded the alarm bell because of the rapid depletion of the earth's natural resources. Exemplary work from that time are the Limits to Growth report (1972) and A Blueprint for Survival by Edward Goldsmith and Robert Allen (1972). These researchers were concerned with sustainable development in a global context: if humans wish to survive on earth, rapid changes in production, consumption, and use of natural resources are required. Goldsmith and Allen summarise this need explicitly as an attack on industrial society:

The principal defect of the industrial way of life with its ethos of expansion is that it is not sustainable ... Radical change is both necessary and inevitable because the present increases in human numbers and per capita consumption, by disrupting ecosystems and depleting resources, are undermining the very foundations of survival. (1972, p. 15)

In the decade that followed, professionals in other disciplines like economics and ethics adopted the focus on sustainable development. This influenced the meaning of the term 
as discussions progressed (see Wheeler, 2013, pp. 25-26). This also comes to expression in the evolving definition of the term. For example, in a review article from 1987 in the journal Environmental Management, Becky Brown, Mark Hanson, Diana Liverman and Robert Merideth conclude that

The contexts [of most definitions of sustainability] range from a social or cultural perspective, where quality of life is emphasized, to an economic perspective, with emphasis on a steady-state economy, to a biological perspective, where the emphasis is on the management and maintenance of ecosystems and species survival. (1987, p. 718)

This summary illustrates how the concept of sustainability evolved to cover concerns about sustaining life on earth by balancing natural resources with the growth of human population and consumption rates, to more specific social, economic and ecological considerations. It is commonly accepted today that these three pillars of sustainability necessarily have to be taken into account when developing and assessing strategies for sustainable development (see United Nations, 2005; Morelli, 2011). This multisided character of the term is also reiterated in the problem definition of the European Commission in its search for more sustainable mobility as laid down in the Mobility for Growthprogramme. Here, the general aim of new developments in traffic and transport is taken to be a "resource-efficient, climate- and environmentally-friendly, safe and seamless [transportation system] for the benefit of all citizens, the economy and society" (European Commission, 2014, p. 5). The concept of sustainability, also when applied in the domain of transport and mobility, thus captures more than the ecological dimension of environmental pollution and climate change. It also refers to the wellbeing of those who make use of the various means of transportation, including the automobile.

In policy reports and research agendas concerning the transportation of people and goods, however, sustainability-related innovations focus predominantly on reducing the negative impact of traffic on the environment by improving resource efficiency. To attain this objective, improving traffic flow is an important strategy for fluently moving traffic creates less exhaust emissions than stagnant vehicles. Much effort is therefore going into the development of information technologies that calculate the most efficient route based on realtime information about road capacity, in order to maintain traffic flow. This objective also features prominently in the Mobility for Growth research agenda, exemplified by "MG3.5: Cooperative ITS for safe, congestion-free and sustainable mobility" (2014, p. 27). Basically, the idea is that information and navigation systems exert control over traffic flows by influencing drivers' route choice, thereby reducing the queueing of vehicles on congested roads.

In discussion about mobility, the negative effects of congestion feature prominently. The Frankfurter Allgemeine Zeitung of August 24, 2014, for instance, devoted an entire page to discuss a variety of causes and effects of traffic problems in Germany. In 2013, the country witnessed 830.000 kilometres of Stau (traffic jams), which represents an average of 60 hours of delay per year for every German resident. This was estimated to result in financial losses of 100 up to 300 billion euros (Siedenbiedel, 2014). Four years later, by the end of 2017, the 
total annual jam length on German roads had risen to almost 1.5 million kilometres, leading to even higher average delay times and, consequently, great financial losses and high levels of dissatisfaction amongst drivers (ADAC, 2018). Similar trends in terms of the number, length and duration of traffic jams are reported across the globe, and are currently expected to continue to rise in the foreseeable future (see CBS, 2018; INRIX, 2018).

While such numbers may shock people who are rarely caught in a jam, others will know too well what it is like to be stuck in traffic. Many of these motorists are keen to acquire precise traffic updates or to be entertained by listening to their radio. Researchers from various disciplines have sought to understand the effects of traffic information and aural entertainment on driver behaviour. For example, Warren Brodsky (2002), an expert in the field of music and listening, and social scientists like Ayça Ünal have studied the effects of music on driving performance (Ünal et al., 2013). Listening to music while driving, so these scholars conclude, can positively affect drivers' responsiveness to their environment on the road, either through a sense of relaxation or through a heightened arousal. Other researchers have focused more specifically on drivers' responses to traffic and roadside information, claiming, for instance, that prescriptive information has a larger behavioural impact on drivers than descriptive information. This insight has implications for the form and content in which information about a traffic situation ahead is communicated to drivers (e.g. Ettema \& Timmermans, 2006). Other publications, like those of data processing experts HongCheng Gan, Yang Bai and June Wei (2013) and traffic psychologists Eran Ben-Elia, Roberta Pace, Gennaro Bifulco and Yoram Shiftan (2013), demonstrate that past experiences on a certain route matter for a driver's response to incoming traffic updates.

These are just three examples of the vastly expanding field of research on the specific effects of aural entertainment on driving, and of traffic information on route choice decisions. These studies' findings also affect the domain of traffic and transport policy. Caspar Chorus, Joan Walker and Moshe Ben-Akiva, who have backgrounds in political science and civil engineering, have examined those implications and argue that the knowledge generated in studies on driver behaviour is often used to serve two ends: first, to promote newly emerging Advanced Traveller Information Services and, "perhaps more dominantly," to aid in transport policy. Here, the focus is on traffic information as a means to change traveller behaviour in ways that are deemed beneficial to the transport system. "Examples of such behavioural changes," the authors continue, "are a modal shift from car to transit and a more efficient use of the available road capacity due to route and departure time choice adaptations" (2013, pp. 62-63). The European Commission's Horizon2020 work programme on Mobility for Growth can be seen as an embodiment of the interconnected evolvement of the latest technological advances in traveller support, and the formulation of new policy perspectives that aim to enhance traffic flow control.

The abovementioned studies certainly contribute to our understanding of the ways in which auditory input (like music or traffic information) affect drivers and their driving behaviour. But most of them hardly investigated the ways in which drivers choose what they listen to in the first place, and how such choices are situated in the ways in which drivers inhabit their cars. Moreover, in their studies on radio traffic reporting, traffic psychologists, engineers and economists rely heavily on regional surveys for understanding how radio traffic information affects drivers' route choice behaviour 'universally'. They do not take 
into account potential sociocultural differences in the apprehension of traffic information. Yin-Yen Tseng, Jasper Knockaert \& Erik Verhoef (2013), for example, extrapolate conclusions from findings in a thirteen-week Dutch research project on commutes during rush hours on a specific motorway section to drivers in general. While insightful for this specific trial, the parameters upon which those conclusions are based are presented irrespective of the place, time, or personal characteristics and preferences of the individuals who participated in the trial. A similar approach can be identified in many other studies in this same field (e.g. Emmerink, Nijkamp, Rietveld \& Verhoef, 1996; or Gan, Bai \& Wei, 2013).

One of the premises of my study on listening-while-driving, however, is that people's habits and responses to traffic information may well differ across geographical regions and cultural settings, if only because of differences in gathering, processing and presenting such information. This is important to consider, because if traffic reports are to fulfil their intent and purpose as facilitators of more optimal traffic flows in support of more sustainable mobility, not only the form and content of the information matters, but also how people apprehend and respond to the various way(s) in which this information is broadcast. All of these elements are influenced by local, social and cultural practices. Of course this is hardly a new insight. At the end of the 1950s, Dutch psychologist Theo Walbeehm explicitly argued against the universal validity of the conclusions of studies in the, then newly emerging, field of traffic psychology. He claimed that discussions on the psychology of drivers should always be specified in local, or at most national, terms, given the influence of specific cultural markers and social behaviour on the use of traffic information by drivers (Walbeehm, 1959, pp. 66-68).

It is intriguing that contemporary studies on traffic management, traffic psychology and mobility studies engage with these cultural differences way less explicitly, despite the early reflections on those differences at the time in which those fields were still emerging. To fill this gap in our knowledge and thinking about the intentions and effects of radio traffic reports, we need studies of the car radio and/or traffic information from a more constructionist point of view. These are studies of how people interpret and give meaning to the world they inhabit, like the car's interior space in this case, and the artefacts they use in their daily routines, like their car radio. Neglecting these qualitative experiences of drivers, especially of those who commute every working day, can lead to an impoverished understanding of what automobility means in practice. Knowing more about those everyday practices can contribute in turn to efforts of scholars in other domains.

So far, only a small number of qualitatively oriented scholars, especially from the fields of Sound Studies and Mobility Studies, have investigated the personal experiences of motorists during their average commutes in depth. In some of these studies, specific attention has been paid to the role and meaning of listening to car radio while driving. Karin Bijsterveld concluded in one of her enquiries into listening while driving that "car radio's meaning shifted from an artefact that brought companionship to lonely drivers, to an instrument that helped drivers to mentally block out their fellows on the road" (Bijsterveld, 2010, p. 189). One can ask the question, then, whether this 'acoustic cocooning', together with the increased precision and availability of traffic information, plays a role in the way(s) in which drivers experience their aural surroundings in the car. How do drivers deal with the possible tensions 
between hearing traffic reports, possibly even seeing their route being adjusted real-time on their navigation system toward less crowded roads, and their autonomy as listener and motorist?

The issue of freedom, or autonomy, and driving emerges in different domains concerned with automobility. Car manufacturers, for example, increasingly strive to stimulate 'sustainable' or 'smart' driving through technological advancements, such as the introduction of "eco-feedback" technologies. One illustration of this development is the Nissan Eco-Pedal, which increases the accelerator's resistance when the driver suddenly and excessively accelerates. This stimulates a gradual increase of speed, which is more environmentally friendly (Nissan, 2014). While this may appear desirable, philosophers of technology have asked how these so-called 'nudging' or 'persuasive' technologies affect the autonomy and self-control of the drivers (e.g. Smids, 2012; Verbeek, 2006). After all, such technologies have the aim of directly altering human actions (see Thaler \& Sunstein, 2008, p. 8), so that negative externalities such as environmental pollution or potentially unsafe situations can be averted.

Interestingly, most contemporary scholarly work on the influence of travel information on drivers' route decisions by traffic psychologists and engineers rarely discusses this issue of autonomy and self-determination in their scholarly publications. BenElia and colleagues are exceptional in referring to this issue explicitly. They conclude that not knowing the response to travel information by drivers "is a drawback in the state-of-theart, since at the network level ATIS [Advanced Travel Information Services] requires a high degree of compliance to be effective" (Ben-Elia et al., 2013, p. 148). The promotors of radio traffic information, on the other hand, have been much more vocal about the issue of compliance. For example, the report of the EUROTRAVEL '88 conference-a recurrent conference hosted by the European Broadcasting Union (EBU) on developments in the field of traffic and travel information technologies - in the EBU Review - Programmes, Administration, Law states that "traffic information by radio is only useful if the audience is willing to accept it and be guided by it" (1989, p. 29). My historical-comparative analysis of the emergence and appropriation of traffic radio aims to contribute both empirically and reflexively to this discussion of the relation between (aural) traffic information and sustainable mobility. In doing so I wish to enlarge our awareness of where such strategies come from, in order to develop grounded, constructive and durable mobility practices in the future.

All of the above is based on one important supposition: we are constantly on the move, we travel increasingly across large distances, and we are not likely to reduce our personal mobility any time soon. The concept of mobility is not without ambiguity, however. In an essay on the history of mobility as a social science concept, sociologist Vincent Kaufmann argues that the difficulty as well as the usefulness of the concept of mobility comes down to its versatile applicability. A "traffic engineer for whom mobility refers to transport flows" uses a different definition of 'mobility' than a "sociologist for whom it refers to change of social position or role" (Kaufmann, 2009, p. 41; italics in original). This underlines that our mobility is not only made possible by traffic and transport technologies such as cars, trains or airplanes, or by technologies of communication, but also by the new forms of social organisation that are required for the use of these technologies. In the words of sociologist 
and mobility scholar John Urry: "[in] a mobile world there are extensive and intricate connections between physical travel and modes of communication and these form new fluidities that are often difficult to stabilize" (2007, p. 5).

Urry continues that the twentieth century has been particularly 'productive' regarding the number of such 'mobility systems' as the "car-system, ... mobile phones, [and] networked computers" (p. 14). What these different perspectives have in common, is their attention for the role of new technologies in our options for travel—spatially, socially and virtually. In my research I follow the objective of Urry and other scholars in the fields of media, transport history, and mobility studies in order to understand how mobility systemsin my case that of car radio and traffic information-have played out in the "principal contours of life in a world that combines exceptional freedom (at least for some on some occasions) and exceptional system dependence" (Urry, 2007, p. 15). In this way, this project is connected to ongoing research in the (sub)field of mobility history that is particularly interested in the interconnections between transportation networks and media. The car radio has long been, and still is, an important medium in this context.

\section{Research Design: Case Selection, Sources, Observations and Interviews}

To address my first sub-question, on the history of the technologies and organisation of gathering and processing traffic information, I will start my analysis in the 1950s. In this decade, automobility grew more popular and radio broadcasts for motorists became increasingly common in both the United States and many countries in Western Europe. To focus my research I will consider three countries in particular. The United States are relevant for their pioneering role in the development of car radio and traffic news. At first, car radios in taxi cabs were primarily used for point-to-point communication to share traffic updates, in order to help taxi drivers save "time and mileage" ("Space Speaks," June 29, 1929). By 1937, a Newark radio station had started broadcasting traffic reports with data collected by an airplane, and by the 1950s, "aerial traffic reporting by radio" had become "a regular service during the weekday rush hours in major cities" (McDonald quoted in Bijsterveld et al., 2014, p. 102). For a study on the shifting socio-technical practices of radio traffic news, Germany is also important. This country, like the United States, has a long and strong history of automobility. Moreover, in Germany the first experiments with encoded traffic information were conducted, marking the start and subsequent heart of a new technological trajectory.

Within these two countries, I have narrowed down my analysis of traffic reporting practices to two specific regions: the New York Metropolitan area (including New York City, Newark and the New Jersey suburbs to the west, and the adjacent area of Long Island to the north and east) and the state of Baden-Württemberg (of which Stuttgart is the capital). The New York area has a particularly long history with radio traffic reporting as a response to local traffic density, while the selected German region has been central to the country's car industry and the collaboration between Blaupunkt and the ADAC in the development of ARI. Stuttgart and New York are also significant regions in the history of traffic radio for another reason. After the successful adoption of ARI in Europe, Blaupunkt sought to export its technology to the United States. Considering the longstanding practice of live radio traffic reports on several of the nation's most popular radio stations, Blaupunkt aimed to introduce 
ARI in the New York area first. The focus on these two regions therefore provides an interesting possibility to understand the emergence of new traffic broadcasting technologies, and the eventual unsuccessful implementation of ARI in the United States.

The Netherlands, by contrast, will feature here as a case study of a region that motorized relatively late but developed a very strong mobility culture. While initially cars were adopted fairly slowly, the speed at which the car subsequently developed into the most preferred means of transport in the post-war period was unprecedented. Historians Gijs Mom and Ruud Filarski even refer to the Dutch adoption of the car in the late fifties and early sixties as a 'mobility explosion' (2008, p. 265). This trend continued throughout the remainder of the twentieth century, and currently the Netherlands is one of the most densely populated and travelled areas in the world (INRIX, 2015; Kerncijfers Mobiliteit, 2018). Along with the highly institutionalised activities of the influential motorist association ANWB (Algemene Nederlandsche Wielrijdersbond, Royal Dutch Touring Club), the intense efforts to inform motorists on Dutch radio about ongoing developments on the roads, and the general public interest in mobility, the Netherlands - and particularly the highly urbanised and heavily travelled 'Randstad' area in the western part of the country - are an interesting context for studying the development and apprehension of traffic reporting technologies and practices as well.

For my study of the roles of radio and car manufacturers in the emergence of technologies for gathering and transmitting traffic information, I could in part rely on earlier scholarly work. A study by Karin Bijsterveld, Eefje Cleophas, Stefan Krebs and Gijs Mom, entitled Sound and Safe: A History of Listening Behind the Wheel (2014) provided a good starting point for understanding the socio-technical history of car radio and traffic information technologies. In their book, Bijsterveld and her colleagues draw from a wide range of archival sources. For my study, I was able to make use of the same company archives of manufacturers, such as Philips in Eindhoven, the Netherlands, and Bosch-Blaupunkt in Stuttgart, Germany. Because of the rather fragmented car radio and traffic data industry in the United States, however, there is no single similarly relevant archive of a major industrial stakeholder available in that country. For this reason, I drew on historical sources from a range of radio broadcasting stations (for more on this, see below).

In order to gain a better understanding of the policies and political interference with respect to traffic problems I used materials from archives of public authorities. For this, I accessed publications and digital archives of Rijkswaterstaat (the executive department of the Dutch Ministry of Infrastructure and Environment), Statistics Netherlands, the Ministries of Transport and Infrastructure (and their predecessors) in Baden-Württemberg, and the Port Authority of New York and New Jersey. Additionally, I analysed a selection of newspaper articles, publications in professional and trade journals in the fields of traffic management and broadcasting, corporate journals of Bosch (Bosch Zünder) and Philips (Range Telecommunication Journal and Philips Technisch Tijdschrift), and publications by the European Broadcasting Union (especially editions of the EBU Review). Finally, I checked all issues of the popular magazines published by of the Dutch motorist association ANWB (De Kampioen) and the German association ADAC (Motorwelt) from the years between 1950 and 2000. 
The regional focus also helped me to select a manageable sample of radio programmes for my analysis of the ways in which traffic information was embedded in radio formats, which pertains to the question explored in chapter three. I focus my analysis of radio programmes on the heydays of traffic radio: the years between 1965 and, roughly, 2000. The analysis here could not begin in 1950 - the year I chose to start my historical analysis - because I did not manage to trace any recordings of those early years in the archives. Between the mid-1960s and 2000, drivers barely had any other option for acquiring traffic information beyond radio. Advanced traveller information systems were not yet widespread, nor could drivers use a smartphone for access to internet sources. For each area, I selected the radio broadcasting stations most significant for airing traffic news. In Baden-Württemberg, this was the state's principal radio broadcaster, the Südwestrundfunk (SWR). As the main broadcaster, SWR is in charge of several public stations. The most important station for news updates is SWR 1. Car radios switch to SWR 1 when traffic reports are broadcast. In Stuttgart, Germany, the SWR has its own radio archive, which is largely accessible to researchers. Many old radio tapes have been digitised, which has made the listening and transcription process much easier.

For the Dutch Randstad area, I selected the most significant station for news and traffic information in the Netherlands: Radio 1. This is again the station that radios tune into when drivers select automatic reception of traffic information. The archives of Radio 1 are stored at Beeld en Geluid (Sound and Vision), in Hilversum. After I was granted access to the largely digitised radio collection, I was able to transcribe hundreds of traffic reports (for a discussion of my methods of analysis and my selection of transcribed recordings, see chapter three).

With respect to my case study of New York, the selection of radio stations involved a slightly more complex process. Here, the most popular radio stations are commercial. Unlike the public broadcasters in the Netherlands and Germany, the radio enterprises in the United States have very few archives, if any, of their own. At the same time, public archives have not widely collected ordinary radio broadcasts either. This is why I could not use the same strategies for collecting research materials as in my European case studies, while I was also unable to find large sets of radio recordings that could potentially include radio traffic reports from a single New York station. I therefore decided to broaden the search, and include three radio stations from the New York metropolitan area in my study. After my requests to various public archives - such as the Paley Center for Media and the Rodgers and Hammerstein Archives of Recorded Sound (a division of the New York Public Library) proved to generate very few accessible radio recordings with traffic reports, I contacted private collectors of American radio recordings for access to their 'airchecks'. Through these contacts I managed to trace and listen to several more historical radio fragments - enough at least to include New York as a case study in my chapter on changing traffic reporting practices.

The New York radio stations I listened to and whose traffic reporting I include in my sample are WCBS880, 1010WINS, and 77WABC. WCBS880 is an all-news station owned by the Columbia Broadcasting System Corporation, better known as CBS. It is one of the largest, most popular radio stations in the New York area, broadcasting on AM frequencies. According to Fred Jacobs, a media strategy consultant, WCBS is also one of the 
few American radio stations that has managed to keep radio traffic information as a prominent feature in its programme, in the age of smartphones and personalised applications (Jacobs, November 17, 2015). Another station that has managed to do so is a WCBS rival: 1010WINS. WINS is the oldest operating all-news station in America, broadcasting in this format since 1965. Moreover, in 1989 it was the first of two stations to introduce a circular format that includes traffic information every ten minutes around the clock. This format was quickly copied by WCBS. When WINS later began to promote their strategy of presenting "Traffic and Transit on the 1's," WCBS soon introduced the ad line "Traffic and weather together on the 8 's." These taglines illustrate the importance these radio stations ascribe to traffic information as part of their programming.

In addition to these two all-news stations, I decided to include a station with a more mixed format on the AM dial as well: 77WABC, located in New Jersey. This is one of America's oldest radio stations overall, and currently broadcasts a combination of news and talk radio. The frequency of traffic reports on this station is comparable to the Dutch and German radio stations. 77WABC is therefore an interesting addition to WCBS880 and 1010WINS. The three stations together nicely cover the most important formats in New York commercial news radio on the AM dial.

Amongst the archival materials of each of the radio stations in the three selected regions, I searched for traffic reports broadcast during the winter months (November, December, January and February). This selection allowed me to transcribe comparable traffic reports across the stations in times of heavy traffic due to weather conditions. This decision also created symmetry with the selection of historical radio programmes, as well as comparability across the areas studied. The second step was selecting reports broadcast during morning and evening rush hours; between 06.00 and 09.30 in the morning, and 15.30 and 19.00 in the afternoon and early evening. Recordings that matched these criteria I subsequently transcribed. To comprehend the lived experiences of traffic reporters and radio hosts themselves, I also visited the radio stations of Radio 1, SWR 1, WCBS880 and 1010WINS, and I conducted interviews with hosts and reporters at these four stations.

For my research on the apprehension of traffic information by drivers, which concerns the third sub-question (addressed in chapter four), I started with reviewing existing studies on the reception of various kinds of traffic information. Yet unlike the stimulus-response type of research that is typical for traffic psychology and traffic management, I studied motorists' experiences with automobile habitation, the role of listening while driving, and the meaning of traffic reports. To this end, I collaborated with twenty motorists in the Netherlands and Germany, whom I asked to make ten audio recordings of their commute, divided over five subsequent working days. ${ }^{5}$ In a trial session I conducted in December 2013, it appeared to be possible to make good recordings of the auditory events in the car while driving by using a professional sound recorder. In the actual research project, participants also had the option to make use of their own smartphones with a recording application. These recordings helped to

\footnotetext{
${ }^{5}$ This research was preceded by a report in which I specified my research project and strategies for safeguarding the participants' safety as well as privacy. This document was reviewed positively in accordance with the criteria for ethical research conduct set by the Ethical Review Committee of Maastricht University, in February 2016 (document ERCIC_003_01_02_2016).
} 
understand the sonic surroundings of contemporary motorists, and provided the starting point for interviews about the participants' use of traffic information technologies and their listening-while-driving experiences.

This part of my study was conducted in the autumn and winter months to create symmetry between the analysis of the historical radio programmes and the experiences of drivers today. The participants all commuted in the selected geographical areas: the Dutch Randstad region and the south-west region of Germany near Stuttgart. In the Netherlands, I was able to collect audio recordings and interview people in the fall of 2016 until early spring 2017. In Germany, I repeated the process throughout the autumn and winter of 2017-2018. Other selection criteria were the participants' age (between 25 to 60), and a minimum commute of 30 minutes one-way. Additionally, I aimed to include an equal number of men and women in my research in order to prevent a gender bias in my findings. The recordings commenced before the start of the trip and stopped after the participant reached their workplace. The audio files were subsequently transferred to me for analysis via a file-sharing platform of the participants' choice. From these sound files, I selected four files per participant for transcription and further analysis. For more details about the analysis of the audio material, see chapter four.

Many participants were enrolled through the snowballing method. I asked friends, acquaintances and interviewees whether they knew people who would fit the criteria and could be interested in my project. Due to this principle, many of the participants had a higher education background-like myself and many people in my social network. This is a common effect of snowballing: "there is a tendency for people to know and introduce you to others who are broadly similar to themselves" (Byrne, 2004, p. 188). To include people outside of my own network, I also reached out to a range of organisations whose commuting employees I thought might be interested in my research. Examples of such organisations were university and polytechnic departments of history, science and technology studies, media studies, and automotive engineering, as well as related corporate companies within my focus areas. Finally, I received a few responses to my announcements on car-sharing platforms like BlaBlaCar and car-sharing and commuting groups on Facebook, as well as one reply to my call for participants in a radio item about traffic information on the Dutch station BNR (Dieker, 28 September 2016). Respondents did not automatically become participants, because sometimes they did not fit my selection criteria. In one case a participant, while initially fully engaged and having submitted all ten recordings, suddenly no longer responded to any communication. The recordings of this person were excluded from the sample, and a new participant was enrolled. The final set of participants was quite diverse in terms of their gender (13 male; 7 female), age (25 to 60; mean 43), occupational sector and daily commuting distances.

In the fall of 2017, I started to prepare for participant research in the New York area. However, after numerous enquiries with juridical experts, I was advised not to include audio recordings of drivers' commutes in the United States. This advice was based on experiences with the vigorous American litigation system. In case of an accident in which a participant might be involved while recording, I might be held accountable — and thus be liable - for causing a safety hazard. This issue could for example be raised if a driver would adjust the position of the recording device while driving - a situation that Dutch and German 
participants were explicitly instructed to avoid. Given the focus of American lawyers on liability, however, I decided to not gather audio recordings in the United States. To collect some experiences of American motorists who regularly listen to car radio nonetheless, I interviewed two American drivers. Although I did not include these interviews in the systematic analysis in chapter four, the experiences reflected in the interviews did provide some background information on the organisation of radio traffic news in the New York region.

Finally, in the last stage of my research, I organised two expert meetings to discuss my findings with professionals in the field of traffic information. The first meeting was with Dutch Radio 1 host Jurgen van den Berg and expert in the field of traffic and transport Karel Brookhuis. The meeting was also attended by my supervisor, Karin Bijsterveld. For the second meeting, I visited the ANWB traffic information centre in The Hague. Here, I spoke at length with the manager of the traffic information centre, Arnoud Broekhuis. We were later joined by five traffic reporters who, based on exemplary fragments of radio recordings, engaged in a discussion about changes in the form and content of Dutch, German and American traffic reports. All experts provided interesting feedback on my findings, which helped to refine parts of the reflection that will be presented in the following chapters, and contributed to the discussion in the conclusion of this dissertation.

\section{Overview of Theoretical Frameworks}

Although contemporary policy reports on smart transport are geared towards the development of Advanced Traveller Information Services, conventional traffic radio is still an important source of real-time information for motorists. Historian of technology David Edgerton has underlined the relevance of the continued use of pre-existing alternatives for the latest innovations, such as horse-drawn agricultural vehicles in the age of the automobile. Often, in his view, both the sustained use of older technologies and creative combinations of old and new technologies are unjustly written out of history, while they are not taken into account when thinking about the process of innovation. He therefore proposes we should be cautious of a "futurology of the past," in which recent innovations would appear to be the inevitable result of earlier technological developments (2006, p. xvii). This emphasis on historical sensitivity in studies on socio-technical innovations motivated me to trace how incar listening practices evolved over time, and to investigate the continued relevance of radio even now that digital information and communication technologies seem to have permeated every aspect of our lives.

Several other theoretical notions have helped me to sharpen my understanding of changes in radio traffic reporting. In chapter two, where I trace the technologies and organisational forms of radio traffic reporting, I use the notion of 'technological trajectory' as developed by evolutionary economist Giovanni Dosi (1982) to explain how in industrial settings a particular framing of problems and solutions concerning a technology under production dominates the further trajectory of that technology. A path dependency between early conceptions and later developments may thus emerge. Another concept I use in my analysis is 'momentum'. With this notion, historian of technology Thomas Hughes tried to capture the evolution of a new technology into a large technological system. In this 
developmental process, a novel technology becomes part of a growing network of people, organisations and other technologies. The larger the size of this network, the more momentum a technology appears to gain (see Hughes, 1987/2012). In chapter two I discus several examples of intertwined network elements, such as radio technology and car radio systems, information gathering institutions, broadcasting corporations and various forms of governmental agencies.

In the second empirical chapter, I build on work by media scholar Raymond Williams. In his study on television broadcasting in the 1970 s, Williams introduced the concept of 'flow'. This notion opened up new approaches for investigating how broadcasting companies planned their programmes in such a way that they kept their audience's attention and had them experience a continuous flow of programmes, commercials and trailers (Williams, 1974, pp. 86-120). The notion of flow was later adopted to study radio broadcasting as well (e.g. by Andrew Crisell, 1994; see also Hendy, 2000, pp. 179-183). In my research, this analytical concept helps to unravel the strategies which past and present radio hosts and traffic reporters developed for incorporating traffic information into their shows and to keep drivers tuned in amidst competing listening activities.

The use of certain media is related not only to the available technologies, but also to broader social and cultural contexts. To capture this dimension, I use another insight put forward by Williams: his concept of 'mobile privatisation', which follows from the observation that people who watch or listen to the media were increasingly doing this by themselves, in the comfort of their private home or automobile. As Roger Silverstone explains in the preface to the new edition of the book Television (2003) "Williams' notion of 'mobile privatisation' elegantly captures the particularity of the newly social, one might say suburban, world which radio and television were to engage. This was a world of increasing individualisation and fragmentation" (2003, pp. iix-ix). In this dissertation, the concept of 'mobile privatisation' will help us to understand the relation between the rise of automobility, new forms of broadcast media, and the desire of individuals to stay informed about events in the world from within their own, personal surroundings.

For the last part of my analysis, which addresses the question of how drivers deal with traffic information in the context of in-car listening practices, I build on existing research on automobile habitation from the fields of Mobility Studies and Sound Studies. Automobile habitation is a concept that helps researchers to focus on the situated experiences of motorists when they spend time in their cars on the road. According to Sound Studies scholar Michael Bull, the installation of radios inside cars has played a pivotal role in transforming the experience of driving, and contributed to a sense of wellbeing and control within the enclosed environment of the automobile (Bull, 2001). The sonic environment and the role of sound in the car are therefore essential elements to study if one is to understand the listening-whiledriving experiences of motorists.

\section{Outline of this Dissertation}

This study, then, provides an investigation of the phenomenon of traffic reporting in Germany, the Netherlands and the New York Metropolitan area since the 1950s. The three specific research questions, which will be addressed in the following chapters, are formulated 
in such a way that they allow the reader to travel along with a traffic report's narrative, as it were, and develop a sense of the thematic discussions of the main components of radio traffic reporting from its inception and up to contemporary user experiences linked to this practice. Each of the chapters illuminates radio traffic reports from another angle, and is informed by different methodological as well as theoretical approaches. Moreover, each chapter combines knowledge about the contemporary situation in each country with historical research. In this way, the significance of radio traffic reports can be studied from different vantage points.

Chapter 2, "Mapping Mobility: Gathering, Processing and Broadcasting Traffic Information," focusses on the development of traffic reporting systems in Germany, the Netherlands and the New York area. Using 'technological trajectory' and 'momentum' as major concepts, I study the interrelations between the aims of prominent stakeholders-most importantly motorist associations, car radio manufacturers, policymakers, and broadcasters - and the technologies they supported.

In chapter 3, "Broadcasting Flow: Presenting Traffic Information on the Air," the focus shifts to the broadcasters. Employing Williams' concept of 'flow' and his analysis of form and content in broadcast media, the analysis of transcribed radio recordings and interviews with radio hosts and traffic reporters indicate alternating strategies for traffic reporting in each of the three countries. Here I also develop the trend towards 'mobile privatization', another concept from Williams.

In chapter 4, "Listening while Driving: Apprehending Traffic Information on the Road," I approach the act of listening while driving through the framework of automobile habitation. Based on sound recordings and interviews with twenty individuals, my analysis reveals more about the ways in which they inhabit their cars and listen to their media devices, while I also discuss how traffic information is part of their overall driving experience.

Finally, the concluding chapter brings together insights from the three preceding chapters for a discussion of how the historical-comparative analysis of traffic news I presented throughout the dissertation can contribute to high-quality traffic information today. In so doing, I return to the concerns of policymakers and engineers linked to radio traffic information as an instrument for facilitating smooth(er) traffic flows on the increasingly congested roads and highways. How can we enrich such discussions by going beyond the somewhat limited focus on traffic flow control? And what are the implications for the 'good old' ideal of automobility as the best means of transport for the experience of a sense of freedom and autonomy while travelling? 



\section{Mapping Mobility: Gathering, Processing and Broadcasting Traffic Information}

\section{Tracing Technological Trajectories}

This chapter engages with the emergence of privatised mobility and the interrelated rise of technologies, infrastructures, information systems and problem-solving paradigms for traffic management in Germany, the Netherlands and the New York metropolitan area. In particular after World War II, the popular imagery of the car's association with freedom, modernity and youthfulness, as vividly promoted in North American media, gained a strong foothold in Western Europe as well (Bosch \& Van der Ham, 1998, p. 166). The automobile soon evolved into the most favoured means of transport on both sides of the Atlantic Ocean. Even more, American idea(l)s about the importance and construction of an elaborate network of motorways heavily influenced the construction of a European road network after the Second World War. According to Pär Blomkvist, researcher on economic history,

Interlinking European motor roads was intended not only to boost trade and commerce; the E-roads [the motorways connecting countries across the European continent] also carried a simple and straightforward vision: the linking of infrastructures between European countries, and thereby the linking of markets as an effective means of preventing future wars-roads for peace! (2004, p. 275)

Yet the more cars were entering the roads, the less they in fact could move around freely. Instead, congestion rates went up and the car lost its "magic aura of freedom and mobility" (Weber, 2011, p. 26). The tension between the reality and the myth of automobility, however, did serve to underpin a range of technological solutions aimed at facilitating such mobility within the context of frequently recurring traffic jams. These solutions partly pertained to the central topic of this chapter: practices of gathering, processing and broadcasting traffic information. To explore the historical development of these practices, this chapter addresses the question of which technologies and organisational forms for gathering and transmitting traffic information across radio have been developed since the 1950s, and what motivations drove those developments.

The account presented here is based on different kinds of archival sources and interviews with stakeholders involved in the (past) organisation of traffic information. Most of the historical sources I found in the archives of key corporations in the field of car radio and traffic information in Germany and the Netherlands: Blaupunkt and Philips. Additional source materials were gathered in public libraries and the digital repositories of public authorities in each of the three countries I study. Furthermore, I selected a range of published articles, opinion pieces and other publications on radio traffic reporting including magazines of motorist associations and, when available, materials by the companies under study. I also looked at professional, academic and governmental publications on traffic engineering and 
traffic management. In addition to analysing these sources, I conducted in-depth qualitative interviews with reporters and technicians who are working or have worked in the field of car radio and broadcasting technologies. These interviews helped me to gain a better understanding of both past and contemporary practices of gathering and reporting radio traffic information.

While the Dutch and German historiography of radio traffic information is dominated by a few corporate, institutional and governmental players with accessible archives, this is not true for the United States. In this country, various small commercial parties - with small or no (accessible) archives - had more impact on the development of traffic information systems than the public authorities did. For this reason, my investigation of the history of radio traffic reporting in the United States relies more on (oral history) interviews with experts in the field. In total, I conducted twenty-two interviews with (former) traffic reporters and experts in local traffic information technologies: ten in the New York metropolitan area, seven in Germany, and five interviews in the Netherlands.

Theoretically, this chapter is informed by evolutionary economics, innovation studies, and the history of science and technology. In particular, I employ the concept of 'technological trajectory' to interpret and understand the emergence of radio traffic information systems in the three countries under study. This concept was developed by the economists Richard Nelson and Sidney Winter in the late 1970s and early 1980s. They claimed that existing economic theories and policies were inadequate to understand and shape innovation processes. To move towards a broader, more "useful theory of innovation," they advocated identifying and studying "natural trajectories" within so-called "technological regimes" (1977, pp. 56-57). Such a regime, as Nelson and Winter explain, comprises "the sense of potential, of constraints, and of not yet exploited opportunities [that] focuses the attention of engineers on certain directions in which progress is possible, and provides strong guidance as to the tactics likely to be fruitful for probing in that direction." (p. 57).

To illustrate their point they give the example of innovations of the DC3 aircraft in the 1930s. Because the engineers working on this airplane were convinced of its potential, the entire research and development strategy was geared towards improving that type of aircraft for more than two decades. The engineers' commitment prevented them from venturing into other directions. "In other words," Nelson and Winter conclude, "a regime not only defines boundaries, but also trajectories to those boundaries. Indeed these concepts are integral, the boundaries being defined as the limits of following various design trajectories" (ibid.).

Economic theorist Giovanni Dosi expanded on the work by Nelson and Winter. In his Technological paradigms and technological trajectories (1982), he underlines how economic theory has a problem to apprehend "the direction of causal relationship, the degree of independence of technical change vis-à-vis endogenous market mechanisms - both in the short and the long run - the role played by institutional factors, [and] the determinants of the 'rate and direction' of innovative activity" (p. 147). He therefore proposes to advance the notions of technological paradigm and trajectory. An industrial paradigm, Dosi explains, is "a 'model' or 'pattern' of solutions for selected technological problems, based on selected material technologies" (italics in original, p. 152). A technological trajectory is "the pattern of 'normal' problem solving activity (i.e. of 'progress') on the ground of a technological 
paradigm" (ibid.). Like Nelson and Winter, Dosi concludes that paradigms inevitably generate an exclusion effect, as the "efforts and the technological imagination of engineers and of the organizations they are in are focussed in rather precise directions while they are, so to speak, 'blind' with respect to other technological possibilities" (p. 153).

Dosi illustrates the practical use of the concepts of paradigm and trajectory with the example of the internal combustion engine. When investigating existing mobility ideals in the early 1900s, he argues, one can identify a need for flexible transportation of people and goods. This need spurred engineers and businesses to improve motorised transportation, which resulted in the creation of the combustion engine. The paradigm - the need for motorised vehicles and the dedication of technicians and businesses towards this idealcontinued to shape the technological trajectory: as new combustion engines proved successful, further research and development was invested into that particular machinery (1982, pp. 152-153). Accordingly, as he concludes, "the idea of paradigms and trajectories can account for the often observable phenomenon of cumulativeness of technical advances (within an established trajectory)" (pp. 158-159; italics in original).

Identifying the paradigm and trajectory of a new technology helped Dosi to understand in more detail than his predecessors the issue of which processes shape the process of innovation and stimulate further research into economically profitable innovation processes. Indeed, as Dosi and Winter together conclude in a review article about evolutionary theory in economics in 1994, they "used the term technological trajectory to refer to the path of improvement taken by that technology, given technologists' perceptions of opportunities, and the market and other evaluation mechanisms that determined what kinds of improvements would be profitable" (p. 161).

This does not, however, imply technological determinism. Rather, my use of the concept of technological trajectory and path dependency will be informed by constructivism: understanding technological change in the field of car radio and traffic information gathering as a process that is inherently part of the wider socio-technical environment in which the technologies are being developed and introduced into other systems (including cars, information gathering services and institutions). In the words of John Staudenmaier:

Far from having an independent and necessary dynamism of its own, technical design has no force whatever unless it has become embodied in the choices and commitments of some set of cultural institutions or individuals. Thus the technology-culture relationship is intrinsically mutual. (Staudenmaier, 1985, p.134)

'Trajectory' is thus a tool to help understand the origins, adaptation to and embedding of technology in a broader, societal context - a process also known as the emergence of 'sociotechnical systems' (see Bijker, Hughes \& Pinch, 1987/2012). STS scholars who build upon the notion of trajectory are not so much interested in the potential economic effects of models of innovation, but they share the economists' and organisational theorists' evolutionary perspective on processes of innovation.

In line with this view, historian of technology Thomas Hughes introduced the concept of 'technological momentum' to capture the evolutionary expansion of technologies, 
in particular in large technical systems (LTS). There are no concise definitions of a large technical system, as they are "often defined by example" (Van der Vleuten, 2006, p. 282). In the first collection of chapters on a variety of large technical systems, however, editors Renate Mayntz and Thomas Hughes state that these systems are "spatially extended and functionally integrated socio-technical networks" (1988, p. 5). Famous case studies in the field of history of technology are electrical power systems, the railroads, and telephone systems. In his book Networks of Power: Electrification in Western Society, 1880-1930 (1983), for example, Hughes presents an elaborate historical reconstruction of three phases of transition in the development of the electricity supply systems in the United States, the United Kingdom and Germany.

Hughes in fact argues for a generalised model of the emergence of large technical systems as evolving in three phases. Sociologist Bernward Joerges has provided a concise summary of these phases, indicating that the first phase "goes from radical invention, culminating in new technological systems, through development, which especially involves providing technological systems with the economic and political embeddings needed for survival, to innovation - putting the system into efficient use." The next phase is that of transfer, when the emergent systems have to fit in, or adapt to, their broader environments. Finally, the third phase "proceeds from growth through competition and consolidation" (Joerges, 1988, p. 12; italics in original).

This, admittedly, dense summary of Hughes' idea of the developmental process of a large technical system sets the stage for introducing the concept of 'momentum'. In a chapter entitled 'The evolution of large technological systems' (1987/2012), Hughes argues that "modern technological systems seem to evolve in accordance with a loosely defined pattern" (p. 50). Acquiring 'momentum' is, in the case of successfully developing systems, one stage in such a pattern. Although Hughes admits that his concept of momentum resembles the process that is captured in the concept of trajectory $(2012$, p. 70$)$, he prefers to use metaphors from physics rather than economics - such as momentum and mass - as heuristics to capture the patterned evolution and potential weight of new technologies. $\mathrm{He}$ states that "the large mass of a technological system arises especially from the organizations and people committed by various interests to the system" (ibid.). Despite Hughes' metaphorical use of physics terminology, it is important to stress his belief in the inherently social foundation of any technical system. He was quite vocal about both the social nature and the enormous societal importance of the large technological systems that he invited historians of technology to investigate (see also Van der Vleuten, 2006, pp. 280-282).

The concept of momentum, however, made it possible to move away from the focus on individual actors - the starting point of Hughes' analysis of new technologies, which he calls 'system builders'. As Joerges has explained, momentum is a concept that

brings together several notions: that of giant mass, made up of innumerable technical and organizational components; of velocity, in the sense of expansiveness and rate of growth; and of goal-directedness ... It is momentum what gives LTS the appearance of "autonomy" and deterministic power, and the concept is meant to prevent social science research on LTS to take these appearances at face value. $(1988$, p. 14) 
Momentum, as a concept, thus helps to recognise and explain the gradual process through which the initial malleability of a technology's design and use diminishes, how an innovation becomes more and more embedded in pre-existing environments, and thereby becomes obdurate (see also Bijker, 1995, pp. 13-16; Hommels, 2001, pp. 35, 40). Hughes' book Networks of Power is one lengthy illustration of the ways in which artefacts, organisations, resources and materials, scientific and experiential knowledge, corporate strategies, legislation and policy all become integrated to form the large socio-technical system of networked electricity.

Yet there have also been scholars who disapproved of these theoretical concepts to understand processes of socio-technical change. Trajectory and momentum have both been criticised for simplifying the innovation process and ignoring local and national particularities (Hommels, 2001, p. 42). In the view of innovation scholars Henk van den Belt and Arie Rip (1987/2012), the concept of trajectory in the "Nelson-Winter-Dosi model" does not sufficiently account for the processes that shape technological change. Concluding that the original works contain too much ambiguity when it comes to the operationalisation of the concept (pp. 132-133), they also criticise the narrow focus of Nelson, Winter and Dosi on the internal operations within the walls of a company or research laboratory. To remedy these shortcomings, Van den Belt and Rip propose to develop the concept of 'selection environment': the context that shapes the successful adoption of an innovation. Based on an investigation of the synthetic dye industry in the nineteenth century, they emphasise the importance of studying the nexus between the technology and the individuals who are part of the selection environment (ibid.).

The concept of momentum has also been criticised precisely for the "appearance of 'autonomy' and deterministic power" that Bernhard Joerges refers to in the quote above (1988, p. 12). This criticism, however, seems to be based on a misconception of the notion's purpose - as part of the theoretical model of large technological systems - in the study of socio-technical construction processes. According to David Hounshell, expert on technology and social change, Hughes himself ultimately concluded that his concept of momentum can be interpreted as being softly deterministic (Hughes in Hounshell, 1995, p. 215). But instead of stressing this connotation of the term, momentum should primarily be understood as a concept $-\mathrm{a}$ tool - to help understand the dynamics of the large technological system, and especially the processes in which the system develops ties with and roots in society, acquiring momentum, and generating social implications as a result. Moreover, the concept of momentum can supplement, for example, knowledge about the kinds of impact a decision made by an individual actor has on that system, which is a common topic of enquiry in social constructivist studies of technology.

Acknowledging these concerns, and in line with the focus of STS research on context and contingency, social and cultural factors, as well as materiality, I examine the trajectories of a number of radio traffic information technologies in their (inter)national social, cultural, economic, political, technical and material contexts. I will argue that in the 1970s and 1980s the increasing collaboration between various European countries, propelled primarily by political and economic motivations, led to the production of a set of international traffic information transmission technologies. Many of these were built on, or compatible with, the German Autofahrer Rundfunk Information system (Broadcast Information System 
for Motorists, or Automatic Road Information, as it was called in the United States). ARI was launched in 1974, and developed by Blaupunkt, a German car audio company that became part of the Robert Bosch Group in 1933, in collaboration with several other actors in the German automobility and radio broadcasting sector. Soon thereafter, it became the blueprint for a range of traffic information systems in Europe and, later, the world.

As I will demonstrate, the concepts of technological trajectory and momentum are helpful to understand why certain practices for gathering and processing traffic information thrived in some countries, while these were rejected in others. In taking up this approach I follow an old, but still under-researched, agenda setting question formulated by Renate Mayntz and Thomas Hughes in 1988. They asked what difference national contexts make in the development of a given type of technological system (1988, p. 7). In this chapter, I will show how national, or even more local, contexts mattered in the development of radio traffic information systems. In particular in the United States, metropolitan areas such as New York, Los Angeles and Chicago have a long tradition of informing drivers about congestions on the radio, going back to the 1930s. Contrary to the increasingly automated way in which traffic information was being gathered and processed in Europe after the 1970s, however, several large American radio stations and traffic information companies sustained their old reporting practices. They relied on traffic reporters in helicopters hovering above dense urban areas to report about their latest observations live on and from the air.

On the basis of a comparative history of traffic information gathering and reporting practices, I therefore suggest that it is important to take the local path dependencies of traffic radio into account. By identifying these locally situated trajectories, one can begin to explain the similarities and differences between the strategies that emerged in response to the increasingly suffocating problem of traffic congestion in the second half of the twentieth century. Understanding both the similarities and diversities in traffic reporting practices in the past, in turn, contributes to more constructive discussions about the relation between media and mobility in the present and future-which is the topic of the last chapter of this dissertation.

\section{New! Radio Traffic Information at the Push of a Button}

I will begin my investigation into the history of traffic reporting in the Federal Republic of Germany. ${ }^{6}$ In 1969, the German motorist association ADAC contacted Blaupunkt, a company specialised in improving and manufacturing car radios. ADAC was searching for a solution to a huge societal problem at the time. The number of traffic accidents on German roads and highways, as well as jams caused by such accidents, had risen to an unacceptable level. In 1970, the death toll on German roads reached its peak, with more than 21,300 fatal traffic incidents in one year (Hütter, 2013, p. 36).

These dreadful quantities did not seem to affect the popularity of the car at that time. After World War II, Germany's citizens quickly adopted the car as their preferred and primary mode of transport. The growing use of the private automobile in post-war Germany is well captured in statistics on that period. The number of privately owned vehicles grew

\footnotetext{
${ }^{6}$ FDR, indicating West Germany in the years between 1949 - 1990; henceforth referred to in this dissertation as 'Germany'.
} 
from almost 2.5 million in 1951 to over 16 million in 1970. By that time, individuals born at the beginning of the baby boom-period (1946-1964) were old enough to own their own cars (Von Erich, 1958, p. 120; "Radioprogramm für Autofahrer," 1970; Mom, Schot \& Staal, 2002, p. 72).

Unlike contemporary drivers on the German Autobahn, however, motorists in the late 1940s to 1960 s were confronted with severely impaired infrastructures. The poor state of the German roads and highways contributed significantly to the country's high accident totals. These had been damaged during the war and were only incrementally repaired after 1945, despite the overall post-war economic growth and various forms of taxation and financial support structures, such as the allocation of parts of the American Marshall Aid to recover Germany's infrastructures (see Eichengreen, Uzan, Crafts \& Hellwig, 1992). This frustrated automobile enthusiasts who already in the early 1950s complained in the ADAC magazine Motorwelt about "ill traffic flows" which partially resulted from insufficient investments in infrastructure ("Kranker Verkehrsfluss," 1952, p. 10). Yet it was not until the mid-1960s, after considerable public commotion and lobbying by the Automobile Association ADAC, that the government of the Federal Republic invested in expansive restoration of existing roads and the construction of new highways, in order to facilitate the increasing number of vehicles ("Zukunfstmusik für Autofahrer," 1968; McShane, 1997, p. $125)$.

In the meantime, while authorities were negotiating the maintenance and construction of the roads and many private individuals bought their first cars, research and development by car manufacturers led to major improvements in the overall convenience and utility of motorized vehicles. In that process, considerable attention was paid to the performance of the car radio and in-car sound systems. Based on extensive historical research, Bijsterveld and her colleagues have illustrated how ideals about the sounds in and of the car changed over time (2014). Due to technological innovations, such as the use of new insulating materials and increasingly mobile radio technologies, the automobile became an "acoustic cocoon": a space that enables the driver "to relax by controlling the car's interior acoustic environment." This, Bijsterveld and her colleagues argue, becomes especially important "in traffic situations that allow only limited freedom in other aspects of driving" (p. 2; see also Weber, 2008. The phenomenon of acoustic cocooning will be explored in more detail in chapter four).

The study of Bijsterveld and her co-authors, which is illustrated by many wonderful images of car and car radio promotion materials, describes the process of shielding off the car from outside noises. This process was accompanied by the effort to fill the car's interior space with carefully designed and selected sounds. As a result, public opinion on the comfort of private car usage changed. Bijsterveld and her colleagues refer to this process as "civilizing the automobile," whereby the car was converted from "adventure machine to family commodity" (ibid., p. 25). Technically, the machinery inside the car became more reliable and easy to handle, transforming the car from a hobby for upper-class men-as in the years prior to World War I - to a means of transport that could be used by virtually anyone with the appropriate experience.

Between the early 1900s and the late 1960s, the car radio played an important role in the massive adoption of the car as preferred means of transport. After the construction of 
the first solid, stable and mass producible car radios, it was argued by radio proponents that listening while driving would make the journey more pleasant and entertaining, and even stimulate the attention of drivers during dull drives, thus preventing them from falling asleep behind the wheel ${ }^{7}$ (see Bijsterveld et al., 2014, pp. 94-98). In some early advertisement brochures of Blaupunkt, the radio was even portrayed as a guardian angel. ${ }^{8}$ Additionally, radio was the only medium through which drivers could be informed about the ongoing situation in the world, or the road ahead, while driving.

In an article in the British newspaper The Observer of January 21, 1973, Gordon Wilkins emphasises just how welcome car radio is. As he opens the article: "In the world today there is probably no one more lonely than the man blocked in a motorway traffic jam. There is nowhere he can go; nobody he can ask about the problem and no way he can inform anybody about his delay." Next, he claims that "the German autobahns suffer the worst holdups of any motorways in the world." But, as he continues,

the Germans are doing something about it - trying to get information to motorists so that they can be warned off jammed sections or told about bad weather conditions. Various methods have been tried [in Germany], including special curtained signs which open up to the traffic on to detours and wire loops in the road surface which activate warning receivers in each car. But these methods are both costly and long term. (Wilkins, 1973, p. 25)

The parties involved in the development of traffic information gathering, transmitting and reception technologies agreed with Wilkins. There were other options to communicate information to drivers on the road, like the dynamic road signs and special induction loops in the road surface that could transmit aural announcements, also referred to by Wilkins in the excerpt above.

These technologies, however, were not considered to be as advantageous as car radio. Road signs, for example, were installed in large boxes on the curb of some important highway sections and could be operated from a distance in a nearby police office. When required, an officer could rotate a sign in such a 'box', or signpost, ${ }^{9}$ thereby notifying drivers about a dangerous traffic situation. However, such signs were very static, and could not be used to inform drivers precisely enough in advance to offer them the opportunity to take another route. The second example Wilkins refers to, the induction loops that send out messages, also had its downsides. These messages could be listened to only with a special receiver and, again, the reception range was very limited. In a corporate note of Blaupunkt,

\footnotetext{
${ }^{7}$ Bosch Company Archives, file 1601003 -1 601020 Autoradio 1949-1956 (Prospekte, Preislisten), folder 1601 004, unnumbered documentation, brochure "Blaupunkt Autosuper verschönt die Fahrt" [1949/1952].

${ }^{8}$ Bosch Company Archives, file 1601003 - 1601020 Autoradio 1949-1956 (Prospekte, Preislisten), folder 1601 005, unnumbered documentation, leaflet "Schutzengel schweben über uns..." [1953].

${ }^{9}$ Despite the historical documentation, it remains unclear whether each signpost had one or more signs that could be put on display.
} 
engineer Hans Duckeck additionally argued that such structures require high monetary investment and a long construction time. ${ }^{10}$

Despite such drawbacks, the general discussion and physical fabrication of such equipment for informing drivers about dangerous traffic situations continued. In 1967, one of the Philips Company divisions started to produce a radio signalling system that "will be placed next to the main roads, and [should] broadcast frequent messages about delays and weather. The motorist with the radio turned on will have to hear these messages, because the transmitters along the roadside will overrule and suppress the other stations." 11 Next to these complex technological systems, less advanced means of communication were also used to inform drivers on the road. The German motorist association ADAC, like the Dutch motorist association ANWB, distributed leaflets with information about ongoing roadworks or expected hindrances. Such paper leaflets, however, could only be helpful for projects planned way in advance, because they could not be updated for the latest, or ongoing, changes on the road.

Due to the improved transmission and reception of radio signals, even in a moving vehicle, car radio quickly became the authorities' medium of choice for communicating important information to drivers. In the corporate magazine of Bosch, the Bosch Zünder (Zünder meaning tinder or spark), car radio was frequently described as an essential piece of in-car equipment: "All in all, it is in the interest of every single driver to have a car radio at his disposal during his journey. This will provide him with information-information that in certain circumstances might even be vital"12 ("Wer hört, fährt besser," 1969). Not only radio manufacturers were enthusiastic about listening while driving. By 1970, approximately one quarter of the 16 million cars in Germany had been fitted with radio equipment ("Radioprogramm für Autofahrer," 1970), and this number was expected to rise steadily. Also in the Netherlands and other parts of Europe, car radio sales were intensifying. According to a report by the Dutch research institute TNO, 55\% of all Dutch cars had been fitted with a car radio on July 1, 1974. This percentage had risen from $27 \%$ on November 1 , 1966. ${ }^{13}$ These sales numbers illustrate the rapid integration of radio in cars in Western Europe during the late 1960s and early 1970s. By the turn of the twenty-first century, virtually all cars came with at least a radio device, and car radio manufacturers offered a large range of additional information, communication and sound systems. ${ }^{14}$

This widespread acceptance of car radio did not evolve successfully without any discussion, however. In the early days, the potential negative effect of radio listing on the attention of drivers was an issue of debate (see Suchman, 1939, for an illustration of those

\footnotetext{
${ }^{10}$ Bosch Company Archives, Blaupunkt Technische Berichte TB 1-18; file TB1-100, November 1972, unnumbered documentation, "Verkehrswarnfunksystem Blaupunkt ARI" by Hans Duckeck, pp. 2-3

${ }^{11}$ Philips Company Archives, file 822 PTI/NSF krantenknipsels, unnumbered documentation, newspaper clipping "Van der Heem meer werk door verschuiving" in Haagsche Courant, September 8, 1967.

12 Vital is a translation of the German word "lebenswichtig."

${ }^{13}$ Philips Company Archives, File CA Dossierkamer 811.215 - 822 Dossier volgnr 1 va 1973-1974 (Nipo enquête), unnumbered documentation, Jaarrapport Autoradio Enquêteperiode: 8-10-1973 t/m 1-10-1974, no pages section “Penetratie autoradio op basis van autobezit," December 1974.

${ }^{14}$ Philips Company Archives, File 811.215 (cassette) 1986 - ..., unnumbered documentation, catalogue Philips Car Systems in cooperation with Mannesmann VDO, 1998.
} 
debates in the New York area). Nevertheless, motorist associations and police officials considered information for motorists to be a significant contribution to the safety of drivers. In Germany, broadcasts specifically tailored to motorists, known as Verkehrswarnfunk or Polizeiwarnfunk ('traffic warning radio' or 'police warning radio'), were presented on German radio by the police and the ADAC since 1972. At the occasion of the second anniversary of the Polizeiwarnfunk in Baden-Württemberg, a journalist of a local newspaper in southern Germany even called the police officers who reported on traffic "the unseen angels of the streets." 15 The police, ADAC and radio engineers commonly argued that traffic reports could help drivers to avoid traffic jams or additional rear-end collisions, simply by informing them about any dangerous situation on the road ahead. Consequently, motorists could reach their destinations "safer and faster."16 Moreover, because radio was a quick, simple and low cost medium for distributing traffic information, it was seen by engineers as the most optimal means to inform drivers. ${ }^{17}$

These reasons and concerns also motivated the collaboration between ADAC and Blaupunkt in 1969. Together with a range of other institutions, such as the Institut für Rundfunktechnik (Institute for Radio Technology), the German postal service, the Federal Transport Ministry and Germany's national radio station Deutschlandfunk, it was decided to create a broadcasting system that would allow drivers on the road to easily tune in to the most recent traffic report. This idea marked the inception of the Autofahrer Rundfunk Information, or ARI. ${ }^{18}$ Motorists first got to experience ARI in so-called Infotheken, ${ }^{19}$ which were small booths installed in the Raststätten (fuel stations and roadside restaurants) along the German Autobahn, and in the ADAC headquarters in Munich. These stations were fitted with a device that could record the latest radio traffic report as it was broadcasted on Deutschlandfunk. The first ARI equipment thus allowed motorists to listen to a recording of the latest traffic report, on demand, in Infotheken (see illustration 2.1). There were envisioned to serve two types of users: drivers without car radio, and motorists who had a car radio but were unwilling to tune in to entire radio shows just to pick up the traffic report (see Forgber, 1972, p. 47).

To record the most recent report effectively, the recorder needed to switch on and off at the exact right time. In the first experimental set-up of the machinery, the recorder in the Infothek would switch on after the decoder picked up the transmission of three consecutive tones: D-F-sharp-A. This tune, however, was not uncommon in some musical compositions, causing the recorder to switch on unintentionally whenever the tune was played on radio. Nevertheless, the experiment proved that a sound signal could be used to set off the recording device. This became the start of a new technological trajectory. Engineers were convinced of the potential usefulness of the technological principle and continued their search for another, more suitable trigger to turn on the recorders. In this process the physics

\footnotetext{
${ }^{15}$ Landesmeldestelle Baden-Württemberg Archive. Press release folder "VWD Presse Historie LMS - Personal LMS - 601a," unnumbered documentation, article "Ein Engel hat Geburtstag" from the Waiblinger Zeitung, June 15, 1974.

${ }^{16}$ Bosch Company Archives, File 1601 072, unnumbered documentation, booklet “Ein Beitrag zur Verkehrssicherheit."

${ }^{17}$ Bosch Company Archives, unsorted files held by Mr. Kuhlgatz, unnumbered documentation, report "Moderne Verkehrslenkung durch den Rundfunk. Eine ausführliche Beschreibung des Autofahrer-Rundfunk-InformationsSystems," 1977, pp. 4-5.

18 Ibid., p. 6.

${ }^{19}$ The German word 'Infothek' may loosely be translated as 'information counter'.
} 
of radio wave technology as well as the hearing range of the human ear, for which frequencies between 20 hertz and 20 kilohertz (or $20 \mathrm{kHz}$ ) are audible, had to be taken into account.

After extensive research, engineers considered a high-pitched tone of $2,35 \mathrm{kHz}$ that was frequency modulated with 123 Hertz to be the best option (Brägas, [1974], p. 2). Because of the modulation, these rapidly alternating high sounds were slightly disharmonic and anything but common, which solved the problem faced by the ARI technicians of unintended recording. To humans, the sound resembles that of a slightly out-of-tune, and almost vibrating (trilling) whistle. This technology became known amongst radio experts as the Hinz-Triller, after the technical director of the German federal radio station Deutschlandfunk, Werner Hinz, who first suggested to mark the start and end of the traffic reports with the a special signal (Meyer, 1999, p. 3). The signal was transmitted between 0.5 and 1 second before the start of a traffic report, allowing the recorders in the Infotheken to switch on and start recording right at the beginning of the traffic-related message on air (Brägas, 1973, p. 5). When the equipment was considered solid enough to be introduced to the public, the construction of the Infotheken took off. Between 1971 and 1976, motorist association ADAC installed 25 of these Infotheken at various frequently visited Raststätten throughout Germany ("Hilft-Autofahrern unterwegs," 1976; see illustration 2.2).

But the people involved in building the first ARI systems had larger ambitions. To increase motorists' awareness of the most recent changes in the situation on the road, they should listen, ideally, to all radio traffic reports. This was in itself not a novel idea. Already in 1967-68 there had been a discussion within the Technical Commission of the Department of Broadcasting and Television, which was part of the Zentralverband der Elektrotechnischen Industrie (ZVEI; Germany's Electrical and Electronic Manufacturers Association), to create a special scheme or radio frequency for transmitting traffic reports. ${ }^{20}$ This initiative was stalled by the Postal Authorities. They voted against making the required frequency range available for the sole purpose of traffic reporting. Moreover, the radio stations that aired traffic reports were unwilling to pay for the additional efforts they would have to dedicate to creating such traffic radio station. ${ }^{21}$ For them, the biggest advantage of ARI was that it did not require much effort from the broadcasters' side. They only needed to install the transmitter of the ARI signal, and did not have to make any changes in their programming, let alone set up a whole new programme just for traffic updates.

Yet the relatively simple technological principles upon which ARI was based propelled engineers to look for its applicability beyond the ADAC Infotheken. From a technical point of view, Blaupunkt engineer Hans Duckeck argued, it was possible "to connect one of these [ARI] decoders to a car radio." 22 In this phase of ARI's technological trajectory we see the emerging of the technology with existing car radio systems. From here onward, it became possible for individual motorists to tune in to traffic information from within their own automobiles. Despite improvements in car radio technology in the early 1970s, however, the tuning process was still considered to be rather cumbersome. In an article

\footnotetext{
${ }^{20}$ Bosch Company Archives, unsorted files held by Mr. Kuhlgatz, unnumbered documentation, report "Moderne Verkehrslenkung durch den Rundfunk. Eine ausführliche Beschreibung des Autofahrer-Rundfunk-InformationsSystems," 1977, p. 5

21 Ibid.

22 Ibid.
} 
about the early design process of the German traffic radio, Peter Brägas, another Blaupunkt engineer and promotor of the ARI system, reflected that "since every broadcasting network in the Federal Republic of Germany (FRG) transmits at least three programs on the FM band, but announces traffic information in only one of those, it is difficult to tune the car radio to the 'right' station" (Brägas, 1973, p. 180). The next objective of the Blaupunkt engineers was therefore to make it easier for drivers to tune their car radio to the stations that featured traffic reports.

This led to a new set of innovations that furthered ARI's integration into car radio design. The basic principle at the technical level was to conjoin the frequencies of traffic reporting stations with a special carrier. Technically, this was already possible and in use in the United States. Since the late 1950s, the so-called Subsidiary Communications Authorization system, or SCA, facilitated the transmission of background music in places like shopping malls (Brägas, 1973, p. 180; "Subsidiary Communications Authorization," 2010). In October 1970, after negotiations with broadcasters and authorities such as the German Postal Office and the Institute for Radio Technology, Blaupunkt commenced trials with a special frequency modulated inaudible subcarrier - a sideband of the range of audible radio frequencies - of 57 kilohertz. ${ }^{23}$

In some ways, the technology of the later ARI technology remained the same. Similar to the high-pitched tone of the Hinz-Triller, the $57 \mathrm{kHz}$ signal triggered a decoder. The first radios with such decoders were trialled and sold in 1972 (Schneider, 1973). These trials were quickly deemed successful, and between 1974 and 1976 three types of ARIdecoders and ARI-equipped radios were introduced on the German car radio market. The launch was presented with considerable clamour. The technology was initially marketed as the ARI-Travelpilot. Through the German word Pilot, Blaupunkt ascribed the role of travel guide, or even controller, to the decoder: the listening driver would surely follow up on the updates and advice presented in the latest traffic report. The first and simplest ARI devices were only fitted with the so-called Senderkennung (SK: Station identification feature). When tuning in to a radio station that transmitted the $57 \mathrm{kHz}$ subcarrier, a small lightbulb in the ARI add-on or ARI-fitted radio would switch on. ${ }^{24}$ As a result, drivers could see in a blink of an eye whether they could expect announcements for motorists on that station (see illustration $2.3)^{25}$

The slightly more advanced ARI-radios also had a Bereichskennung feature (BK: Range Identification). This enabled the radio to recognise regional radio stations for more localized, and therefore more relevant, traffic reports. To make sure drivers would tune into

\footnotetext{
${ }^{23}$ Bosch Company Archives, unsorted files held by Mr. Kuhlgatz, report no 03/77/HDR “Radio Broadcast Information. A detailed description of the ARI-System" [1977, p. 6], published by Blaupunkt-Werke GmbH. Italics added; see also Brägas, 1973, p. 182.

${ }^{24}$ Bosch Company Archives, File 1601 072, unnumbered documentation, document reference WEB/AK/1.91/501D (VOD373), promotion prospect Blaupunkt “Autoradio 73," 1973, p. 2, published by Blaupunkt-Werke GmbH.

${ }^{25}$ To alert drivers about an upcoming traffic report, several radio stations broadcasted the tone of the Hinz-Triller or composed a different tune to signal the beginning and end of the traffic report to the listening audience. These strategies for gaining and retaining the attention of driving motorists for the radio traffic reports will be discussed in chapter three.
} 
a radio station from the region in which they were traveling, BK radios were accompanied by a special map that indicated the transmission regions and the letter codes that signposted each geographical broadcasting area (see illustration 2.3). For this system to work, no letter could be assigned to two neighbouring regions, as the transmission range of one station might overlap, and thus possibly interfere, with that of another station in an adjacent region. This could jeopardize the efficacy of the designated codes. Finally, the most advanced ARI radios had the so-called Durchsagekennung option installed (DK: Announcement Identification). This feature "allows even switched off radios to make the traffic announcements audible." 26 Motorists who owned such add-on decoder or radio device would surely never miss another traffic update while driving.

In the company archive of Bosch/Blaupunkt, one can find many leaflets, pamphlets, retailer information booklets and reports in which the company's marketing and technical departments explain why ARI was such an important technological innovation. First and foremost, the early documentation about ARI centres on the discourse of its "contribution to traffic safety." 27 This positive impact could be accomplished because drivers would be informed at very regular intervals about hindrances and delays. In 1975, one year after its launch, ARI won the ADAC Sicherheitspreis ('safety award'; "Preis für das ARI-System," 1975). ARI's usefulness did not end with its implications for drivers' safety, however. The promotion materials of the early 1970s also referred to its potential to help motorists reach their destination "safer and quicker." 28 This is where ARI's role as an instrument for improving traffic flow first comes to the fore; a conceptualisation of the technology's usefulness that rapidly gained momentum in the years that followed, as I will explain below.

Following its launch in Germany in 1974, authorities and broadcasters in other European countries also expressed an increasing interest in adopting the system. In 1975, it was rolled out in Austria, Switzerland, Yugoslavia and, later on, in Luxembourg, Denmark, (part of) the Netherlands, and several other European countries. ${ }^{29}$ This interest was not only expressed by broadcasters. The German Institute for Radio Technology proposed ARI to the working group Broadcasts for Motorists of the European Broadcasting Union, as a new standard for European traffic broadcasting. ${ }^{30}$ The working group specifically studied traffic congestion and risks in traffic safety and was chaired by Gerhard Bogner. Bogner also worked at the agglomerate of German public radio stations ARD, as well as the Bayerischer Rundfunk. In his view, the working group's "main concerns, of which listeners hear nothing, [were] the establishment and harmonization of new sources, the organization of

\footnotetext{
${ }^{26}$ Bosch Company Archives, File 1601 072, unnumbered documentation, document reference WEB/AK/1.91/501D (VOD373), promotion prospect Blaupunkt Autoradio 73, 1973, p. 1. Published by BlaupunktWerke $\mathrm{GmbH}$.

${ }^{27}$ Bosch Company Archives, File 1601 071, unnumbered documentation, promotion prospect "BlaupunktVerkehrsfunk-Dekoder. Ein Betrag zur Verkehrssicherheit" [1972].

${ }^{28} \mathrm{Ibid}$. I will return to this multifaceted rationale in the next section of this chapter.

${ }^{29}$ Bosch Company Archives, File 1601 086, unnumbered documentation, folder Blaupunkt Autoradio-Marketing, 1977, p. 5. See also Bosch Company Archive, File 1601 101-II, unnumbered documentation, American Blaupunkt retail brochure, 1985, p. 1.

${ }^{30}$ Bosch Company Archives, unsorted files held by Mr. Kuhlgatz, unnumbered documentation, report "Moderne Verkehrslenkung durch den Rundfunk. Eine ausführliche Beschreibung des Autofahrer-Rundfunk-InformationsSystems," 1977, p. 7.
} 
communication activities and cooperation, overcoming the obstacles of language, distance, mentalities and technical questions" (Bogner, 1979, p. 18).

To come to a good recommendation for solving those problems, the Broadcasts for Motorists working group evaluated several possibilities for informing motorists about ongoing developments in traffic. They eventually concluded in that "only the German system ARI [could] be realised at once." 31 This was considered a crucial advantage compared to the other information systems that were part of the explorative study. Through the working group's recommendation of ARI, it became a broadcasting system with international fame, and affected the paradigm of those involved in developing traffic radio focussed on the standardization and (technically facilitated) communication between the stakeholders involved in gathering, processing and broadcasting traffic information.

Its successful adoption in Germany and German-speaking regions in Europe did not go unnoticed in the Netherlands either. In 1979, Ron Hendriks, an expert journalist on traffic and transport issues in the Netherlands, published a review on large-scale, advanced radio traffic information systems that were in use at the time. He concludes that "the Netherlands is simply too small to introduce a car-information system on its own, if other [countries] in the rest of Europe would choose for a different system" (pp. 1135-1136). Doing so would not make sense in the context of increasing inter-national traffic, communication, and collaboration. These statements illustrate the subordinate role of the national level within the evolving European techno-political context regarding the construction and organisation of traffic information after the mid-1970s. According to historian Christian Henrich-Franke, radio traffic reports can therefore be seen as a good, early example of efforts to harmonise radio broadcasting transnationally across Europe (2016). I will return to this development shortly.

The success of ARI also significantly narrowed the focus of engineers on the further development of car radio technology for the distribution of traffic information. Alternative ways to communicate information to motorists were considered too expensive, too complicated to implement or reaching too small an audience to be beneficial to both the providers and users of the information. Nor were other, more bottom-up initiatives - such as interactions between private individuals (both drivers and non-drivers) via Citizen Broadband (CB) radio - part of the envisioned trajectory, as this was incompatible with the objective to harmonize the sources and communication channels to improve the speed and accuracy of traffic reporting. As a result of these dynamics, ARI became the blueprint for transmitting radio traffic reports in the whole of Europe.

The construction of traffic information systems did not end with ARI, however. On the contrary, public authorities and traffic managers increasingly tried to influence traffic flows. One way in which they did so was reaching out to drivers to affect their route choice. They aimed at redirecting traffic flows in order to reduce the growing problem of congestion. Apart from the technical aspirations of engineers and experts in the field of radio technology, other aims and motivations also played a role in the construction of new ways for gathering and broadcasting traffic information. For example, traffic managers and infrastructural engineers investigated ways to facilitate the growing numbers of motorists and professional

\footnotetext{
${ }^{31}$ SWR Archives, file 30 SL 40544 Technische Direktion Verkehrsfunk 74-80, document number 11.12/014, information letter by Paul A. Becké of the ADAC, dd. April 5, 1974, p. 3.
} 
drivers. Changes in those practices and motivations were, at least in part, stimulated by insights and technical advances in the emerging field of information and communication technologies (ICTs) and new collaborative initiatives that were set up at the European level. These interrelations will be explored in the following section.

\section{Changing Practices of Gathering Traffic Data}

By the late 1960s, the police, motorist associations and traffic authorities actively tried to reach out to motorists in order to provide them with the latest traffic-related information and updates. In Germany, this was technically facilitated through the ARI system, but also in the Netherlands traffic reports were more frequently broadcast on the air. In terms of the local politics, geology, economy, demography and the speed at which the automobile became the preferred means of transport, there were differences between Germany and the Netherlands. Nevertheless, the first structures and practices in place for collection and processing traffic information were very similar, and by the early 1970s traffic updates during rush hours had become a standard feature of several Dutch radio programmes. In the process of gathering information and compiling those reports, the national motorists associations played key roles in both the Netherlands and Germany. Together with the police traffic departments, they shared a lasting concern about the high, and increasing, number of (fatal) accidents at the time. In 1970, when the number of deadly casualties peaked, the issue of traffic safety grew more urgent still, and motorist associations and public authorities, including police officials, considered radio traffic reports as one means to reduce those fatality rates (CBS, 2000; Hütter, 2013).

Traffic reports were not only envisioned as a means to improve traffic safety. While this was the most dominant discourse, some of the very first German leaflets promoting ARI decoders made reference to the enhancement of traffic flow as well. A 1972 brochure on the 'Blaupunkt-Verkehrsfunk-Dekoder' carried as headline "Ein Betrag zur Vekehrssicherheit" (A contribution to traffic safety): a tagline frequently repeated in the promotion materials of ARI-radios in the years that followed. Interestingly, however, the first lines of the brochure from 1972 read as follows:

Jammed streets and motorways, kilometres of car queues, hours of waiting time. ... This now belongs to the past. With the Blaupunkt-Traffic radiodecoder you find those streets on which you get through. Because you will miss no traffic reports or traffic warning of the radio stations anymore. With this device you will immediately recognise those FM stations that regularly broadcast traffic announcements. That is to your advantage. Timely and reliable warnings for congestions, necessary detours and danger due to motorcades or suddenly changing weather influences mean that you will be 
safer and faster at your destination. Blaupunkt has therefore developed a traffic radio-decoder as a contribution to traffic safety. ${ }^{32}$

ARI was thus introduced not only as "a contribution to traffic safety," 33 but also as a way to avoid slowly moving traffic on one's route.

In the Netherlands, the discourse around radio traffic was quite similar to the discussions and concerns in Germany. The author of an article in De Kampioen (The Champion), the magazine for members of the largest Dutch motorists association ANWB, captured the underlying motivations like this: "traffic information means that road users are 'informed'. [Hence] they can adjust their behaviour on the road, upon which we can all drive more safely, flow faster, and use the capacity of our road network better" ("Verkeersinformatie in Nederland," 1975). Another article in the same magazine, published three years later, put forward three other main objectives for providing radio traffic information. This time, the phenomenon was considered in a broader, more action-oriented context. Traffic reports, the author argues, allow travellers to take an alternative route, to change the time at which they leave and/or to choose for travelling by public transport ("Zo werkt de radioverkeersinformatie," 1978). The article concludes saying that "[a] fourth reason [for providing traffic information], even though this is considered to be only an additional advantage, is that a car driver who hears of congestion on his route, will adjust his behaviour to prevent his crashing into the tail end of a jam" (ibid.).

These two quotes indicate the slight but meaningful change in the principal motivations behind the development of information and communication tools tailored to traffic reports in the Netherlands. The quote above, from 1975, first addresses the issue of traffic safety, after which it goes on to raise the issue of efficient traffic flows. The second account, a review of the ways in which radio traffic information was organised in the Netherlands in 1978, puts the issue of traffic safety as the "additional advantage." The primary objective of traffic reporting had become (more) speedy travel times for all commuters. In both accounts, however, radio traffic information is considered a valuable means to facilitate more optimal movement of traffic. This subtle alteration from the objective and discourse centred around traffic safety to that of efficiency also comes to the fore in another publication from 1983 in De Kampioen: "The ANWB holds the opinion that its contribution to traffic information is in the interest of traffic safety and as such considers it its task as service provision to the benefit of its members, the road users." In the same article it is then stated that the national police considered traffic information to be a major part of their task to "maintain traffic order and ensure the daily traffic management." ("Verkeersinformatie," 1983).

The objectives of safer and more efficient traffic flows were shared by the collaborating institutions and individuals that gathered, processed and presented traffic reports, as they continued their collaboration in the years ahead. In order to facilitate the

\footnotetext{
32 Bosch Company Archives, File 1601 071, unnumbered documentation, document reference WEB/AR/1.91/465D (772 HDV), promotion prospect "Blaupunkt-Verkehrsfunk-Dekoder. Ein Betrag zur Verkehrssicherheit" [1972], published by Blaupunkt-Werke GmbH.

${ }^{33}$ For the further continuation of the safety discourse, see also Bosch Company Archives, File 1601072 , unnumbered documentation, document reference WEB/AK/1.91/501D (VOD373), promotion prospect Blaupunkt Autoradio 73, 1973, p. 2, published by Blaupunkt-Werke GmbH.
} 
gathering of data, new, automated technologies were built to monitor, calculate and map traffic flows. These were crafted by traffic experts in co-operation with commercial companies such as Siemens, Bosch and Philips. In 1957, in an early attempt to literally keep an eye on the road at all times, the Dutch highway authority Rijkswaterstaat, in collaboration with local police and the special traffic department of Philips, installed optical surveillance systems using CCTV (closed circuit television) to monitor traffic flows in the Eindhoven region during rush hours ("Politiedeskundigen in Eindhoven," 1957).

Later, other techniques were developed, such as punch tape recorders, inductive loop detectors ${ }^{34}$ and radar (see Fuller \& Lambell, 1970). These helped to monitor traffic as well as to alert traffic experts at the police departments and in the newly emerging discipline of traffic engineering and management about the most congested areas on the highways. In response, traffic management research and studies in infrastructural engineering aimed at optimizing traffic flows, for example by investigating new designs of highway entries and exits to facilitate the most efficient flow of traffic on those crucial points of the road network. ${ }^{35}$

In a report entitled Philips en het Wegverkeer (Philips and road traffic) written by A.J. Steer (1977), the close collaboration between the Dutch Rijkswaterstaat and Philips, including their common goals with regard to the issues of traffic safety and efficiency, was defined explicitly as follows by one of the project members from Philips:

The principal philosophy for our company must continue to be that we are willing and able to contribute to achieving a safer and more efficient use of the road network. [This entails a] further application of, amongst other things, electrical engineering, to solve traffic problems. Continuous dialogue will be needed between our traffic and electro-technical experts and those of [Rijkswaterstaat $]$ and other governmental authorities, in order to realize [the agreed upon objectives]. ${ }^{36}$

This related to the above-illustrated discussions on the technical process of putting together the features of ARI. In fact, the quote reveals similar concerns in Germany and the Netherlands about traffic safety, as well as, later on, traffic flows. This underscores that the general socio-political contexts in which traffic reporting became embedded in these two countries were quite similar at the time.

The very first radio traffic reports, however, as I will show in detail in the next chapter, did not refer to any traffic jams, nor was the efficient flow of traffic a primary concern for the reporters. The broadcasts for motorists in the 1960s primarily contained information about local conditions that might affect the motorists' driving experience, such

\footnotetext{
${ }^{34}$ Philips Company Archives, File 811.39, folder 25, Verkeerssystemen, unnumbered documentation, brochure Philips Traffic Systems, issued January 1972.

${ }^{35}$ See Leisch (1993) for a historical overview of American highway design, and Lamm, Psarianos, Choueiri \& Mailaender (1993) for a discussion of international-including American and German-perspectives of motorway design.

${ }^{36}$ Philps Company Archives, File 814.9, folder 1, Verkeersregelapparatuur, unnumbered documentation, report "Philips en het wegverkeer" by A. J. Steer, 1977, p. 3.
} 
as particularly dangerous weather conditions or local construction sites. In the Netherlands, the information gathered through these various sources was accumulated at the headquarters of the highway and traffic division of the state police department in Driebergen. In Germany the Verkehrsbundesamt was in charge of monitoring the situation on the country's main roads and highways. At these road information service centres, incoming reports and quantitative sources of information were assembled, analysed and updated, and subsequently compiled into a report that was forwarded to the (local) radio station(s) to be read on air.

This information was initially gathered and distributed through a network of individual observers that made use of the telephone, and later Telex (a precursor of the Fax machine). The traffic police would call to other police and border control offices, district offices of the road and waterway authorities, the meteorological institutes, the roadside assistance workers of the motorists associations (ANWB in the Netherlands and ADAC in Germany) and fuel stations to receive information about the situation on roads and highways in their respective areas. Individual motorists and professional drivers also called in at their own accord to share information about slow traffic (see "Gecoördineerde verkeersinformatie," 1969; "Wer hört, fährt besser," 1969; Ministeriële Werkgroep Radioverkeersinformatie, 1982, p. 4).

Additionally, employees of the motorists association in the Netherlands would receive phone calls from stranded motorists next to the main highways. They informed the traffic reporters about ongoing traffic situations. Sometimes employees of the ANWB would even listen in on emergency telephones that used to be installed at regular intervals next to the motorways. If they heard a reduced flow of traffic, they marked the location of the emergency telephone as part of an ongoing traffic jam (Klijnhout, 1972, p. 288). In exceptional circumstances, for example when it was extremely busy on the roads, the police would employ a helicopter to survey specific geographical areas and report, sometimes live on the air, on the situation down below ${ }^{37}$ (see Oei, 1976, p. 225; see illustration 2.4 for a visual representation of the traffic information flows in Germany in 1977).

Of course, the traffic situation on roads and highways is always in flux. When traffic became denser in the early 1970s, automation and the use of computers to collect and communicate traffic information from one organisation to another were still emerging disciplines. One can only imagine, then, the hectic job of individuals in the traffic information communication chain on days with heavy congestions. Traffic reporters were constantly in conversation with their informants on the latest developments via telephone, they monitored visual information sources, received incoming messages via Telex, and they were not yet equipped with digital technologies to keep track of all those evolving updates. Several sources in the SWR archive remark upon the heavy workload of the traffic data collectors and reporters. In a communication between an employee of the 'Car and Traffic Desk' (Redaktion Auto und Verkehr) and the station director of Südwestfunk, the traffic reporter makes "an urgent plea" for a seemingly small matter, yet one which had great impact on his job. Rather than placing the traffic reporter in studio 4 , he asks if he can retain studio 10 as his main broadcasting cubicle. He backs up his request with the following reasons:

\footnotetext{
${ }^{37}$ Bosch Company Archives, unsorted files held by Mr. Kuhlgatz, unnumbered documentation, report "Radio Traffic Broadcast Systems: A detailed description of ARI," 1977, p. 19.
} 
The walk from the traffic office to studio 10 is significantly shorter compared to studio 4 . Due to the shorter route it is possible to report on a traffic announcement before the musical piece announced by the host is actually played; with some breathing exercises [this can be done] even after a run [from the traffic reporters' office to the radio studio]. In practice, this means that the traffic report can be presented more up-to-date, and this saves delays of three minutes or more for the listeners. A quick report after a run to studio 4 , which is located further away, is, even with the best breathing exercises, not possible anymore. On days with heavy road traffic and with many radio reports, frequent queries and personal returns of the reporter to the traffic office are essential. Also here the significantly longer way to studio 4 means more time delay, and an additional complication of the work. ${ }^{38}$

This quote illustrates the pressure traffic reporters experienced to be both accurate and as quick as possible with their most recent updates, while at the same time trying to present the announcement eloquently on the air. When the information was still collected from a range of sources and had to be noted down on paper by hand before heading into the studio, every second spent walking or running up and down the corridor was considered one too many.

With the increased availability of computing technology and networking between data gathering and processing systems, the job of traffic reporters would increasingly take place behind a computer screen. Visiting the offices of traffic reporters in the twenty-first century, one sees how - if all systems operate well—computer monitors constantly provide a 'live' look on the road. The operationalisation and shared use with police and governmental road authorities of CCTV cameras, the introduction of crowdsourced real-time data provided by smartphones and navigation devices, the automatic processing of statistics gathered through induction loops in the road surface - all of these technologies allow the present-day traffic reporter to track and trace any congestion on roads and highways and present the most up-to-date traffic report on the air at all times.

Knowing more about these innovations in the field of gathering and processing data will help us to understand the next part of the trajectory towards today's global radio traffic information systems; a step that involved the introduction of digital equipment into car radios. In the following section of this chapter I will explain how car radio manufacturers and broadcasters increasingly integrated the existing radio technologies with new, digital information and communication systems. These enabled new ways of gathering data about the position and speed of automobiles, that could inform traffic reporters about the ongoing situation on the road. For motorists, these new technologies were also deemed useful, because they enabled the quick transmission of traffic alerts. In order for these new systems to operate without error, however, they had to be compatible or at least co-operable with the existing information and communication technologies in place. This brings us to the next phase in the trajectory of traffic reporting. In what follows, the ongoing innovation processes and

\footnotetext{
${ }^{38}$ SWR Archive, File 30 / 40544 Technische Direktion Verkehrsfunk '74-'80, unnumbered documentation, notification by Matthias Schneider to Dr. Lüke, January 13, 1977.
} 
integration of broadcasting technologies will be explained using the concept of technological momentum.

\section{Momentum and the Merging of Broadcasting Technologies in Europe}

The ARI system, while a success in Germany and several other European countries by the late 1970s, was not adopted in the Netherlands with the same fervour. In part, this can be explained by the Dutch radio landscape and the radio broadcasting authorities' hesitance to allocate the required broadcast band as a traffic report identification signal. But there were also other, commercial reasons to resist the immediate adoption of ARI. The co-developer of ARI, Blaupunkt, was the main competitor of the Netherlands-based equipment manufacturer Philips in the Dutch car radio market. ${ }^{39}$ While Bosch/Blaupunkt worked on the improvement and promotion of ARI, Philips invested much research and development in the innovation of other electronic and digital transmission systems. In 1979, the company presented, according to its marketing brochures, the "first radio that tunes itself" by using Micro Computer Control (MCC) technology. ${ }^{40}$ This technology was sold with the argument that "without you having to pay any attention, MCC stays tuned to the FM programme you selected - while you keep your hands on the wheel and your eyes on the road." Moreover, "a single button touch instructs the microcomputer to ignore [unwanted local news updates or traffic reports] until further notice, while the automatic tuning system will immediately search for another transmitter broadcasting the programme you were enjoying. We call this useful feature 'Station Kill'.,"41

The introduction of MCC into Philips car radios illustrates two trends. First, it is an example of the continuous attempts of Philips to innovate car radio and outcompete other players in that market. Any of the company's marketing brochures testify to the newest, stateof-the-art technology that was built into the latest radio models. At the same time, an investigation of the released models and their technical features clearly illustrates the ways in which these innovations were built upon the principles of earlier radio systems. Here, the concept of trajectory and Thomas Hughes' theory of technological momentum help to understand the way in which the network of people, organisations, companies and material objects and technologies became entangled and grew into a large technological system.

In the previous section I explained on what grounds the various parties involved in the development of ARI came together, and how it became the foundation of a technological trajectory. The market introduction of Philips' MCC technology further illustrates the momentum of the ARI technology. Philips radios equipped with MCC were in essence similar to, but more advanced, ARI-BK radio: radios that helped to tune into the best radio frequency of a station in a certain region. The 'Station Kill' feature might come across as a

\footnotetext{
39 Philips Company Archives, File 811.215:822 Nipo-enquete (I) 1967-1968, unnumbered documentation, NIPO report “Continu onderzoek: Autoradio. Periode 30-1-1967 - 22-1-1968," April 23, 1968.

40 Philips Company Archives, Cassette 811.215 ... - '79, unnumbered documentation, brochure "The basics Philips MCC: The first car radio that tunes itself," 1979.

41 Ibid.
} 
break with that trajectory. After all, it enabled drivers to tune out of messages on the radio, rather than automatically tune in.

However, Philips did not reject ARI principles completely. Car radios they manufactured in the early 1980s were equipped with a 'SDK info' button, which was "an automatic decoder (SDK) for receiving traffic information in Germany, Austria and Switzerland." ${ }^{42}$ This appears to have been a (commercial) necessity for Philips to offer their customers car radio models that were compatible with ARI, as it was already so widely used in the German speaking countries in Europe by that time. These examples of Philips technologies illustrate how ARI, as one of the first successful radio information systems, had gained so much momentum that it became almost by definition part of car radio technology in other parts of Europe as well. Despite the competition between Blaupunkt and Philips as big and profitable car radio manufacturers, they shared the objective of offering their customers state-of-the-art car radio technologies that would make the drivers' journey as pleasant, safe and smooth as possible. ARI was considered part of that strategy. This stipulates ARI's prolonged trajectory.

The technological system around ARI thus continued to expand and it moved rapidly from a primarily national level to an international level. Facilitated by various international working groups, the collaborations between engineers and authorities in Europe were increasingly formalised. In order to build a system that could be employed by motorists all over Europe, engineers as well as policymakers called for more standardized, and thus compatible, traffic information systems. They sought to align the technology, but also-in line with the later phases of large technical systems as explained by Hughes - aimed to collaborate across the different organisations involved in the construction of a large-scale traffic information system (see Hughes, 1987/2012, p. 70). Through a shared, uniform traffic information system, it was argued, the efficient flow of increasingly more international traffic could be accommodated. ${ }^{43}$

In the first half of the 1980s, a lot of anticipation surrounded a system that was supposed to fulfil those aspirations and homogenize radio traffic information broadcasting technologies in the whole of Europe: the Radio Data System (Kopitz \& Marks, 1999, p. 7). Of course, such an expansive system required the support of many stakeholders; this time not only at the national level, but across the whole of Europe. Key moments in the developmental process of this (and other) new, Europe-wide traffic systems were the EUROTRAVEL conferences of 1980 and 1983. Here, broadcasters, car radio manufacturers, engineers in radio and traffic management, and public authorities came together to discuss the importance of traffic and travel information, compare existing information sharing structures, and agree on objectives for the future of (international) traffic flows. Their recommendations were subsequently widely distributed, and at times disputed, at the places where they would affect ongoing work, such as the local radio broadcasting stations. ${ }^{44}$

\footnotetext{
42 Philips Company Archives, file 811.2151980 - '85, unnumbered documentation, booklet "Philips Auto-Audio. Dat hoort u goed," 1985, p. 22.

${ }^{43}$ SWR Archive, file 10 / 28893 WP Broadcasts for Motorists, unnumbered documentation, communication by Gerhard Bogner "“Broadcasts for Motorists" - Euroradio Verkehrssendungen in der Union der Europäischen Rundfunkanstalten UER / EBU," 1982, p. 2.

${ }^{44}$ See SWR archive, file 10 / 28893 WP Broadcasts for Motorists, unnumbered documentation, a critical response by SDF traffic reporter Nägele to the recommendations of the EUROTRAVEL 80 conference, dd. January 20, 1982.
} 
Despite the difficulty to align all stakeholders in the field, some of the people involved in the central organisation of those European traffic information systems - not only for transmitting radio traffic information, but also for gathering and processing traffic datawere highly motivated. One of the principal spokespersons of the mission towards European traffic information systems was Gerhard Bogner. Being the first chair of the Broadcasts for Motorists working group of the EBU, he pointed out in the article "Radio on European Routes" in an EBU Review of 1981 that

Standing midway between the nothing of 20 years ago and the unknowns of tomorrow, the EUROTRAVEL conference in 1980 made it clear, through close cooperation between radio and its partners, that today's western industrial society - and perhaps society in other parts of the world too cannot and will not live without information and that traffic information occupies a prominent position as a service to the public.... To this extent the two different radio objectives of informing and entertaining overlap and mingle as social and political purposes which are intrinsically helping to shape a European society. (Bogner, 1981, p. 13)

The writings of Bogner, in all their enthusiasm, might not represent the opinions of all people involved in the working groups on radio traffic information at the time. Radio presenters and traffic reporters, for example, had to find ways to make sure the "objectives of informing and entertaining" were maintained around and during the traffic reports on the air. And what, exactly, was relevant traffic information? This was hardly self-evident and therefore heavily discussed in the broadcasting world. In 1982, Sibylle Nägele, an employee of the German station SDR (a predecessor of SWR in the Stuttgart-area), responded with scepticism to the recommendations that followed after the EUROTRAVEL ' 80 conference. In response to the proposed internationalisation of on-air traffic reports, she stated that

the SDR does not transmit a signal other than the Hinz-Triller and is also not planning to introduce another signal ... [Moreover,] the SDR is not interested in a daily exchange of traffic announcements out of EasternEuropean countries. Still, those contacts should be maintained. ${ }^{45}$

This response illustrates the established practice to broadcast the Hinz-Triller, the hesitance of broadcasters to introduce another identification signal of radio traffic reports, and a-possibly politically inspired - scepticism towards all-out internationalisation of onair traffic announcements. Still, the increasing scale of operations and the number of people involved in the development of the new traffic information systems, as referred to by Gerhard Bogner, illustrate how those new networks gained more momentum at an increasingly international level. Illustrative in this respect is the European Parliament's effort to formalise the research and development of new traffic and travel technologies to explore ways for

\footnotetext{
${ }^{45}$ SWR archive, file 10 / 28892 WP Broadcasts for Motorists, unnumbered documentation, communication by Sibylle Nägele in response to the 14 recommendations of EUROTRAVEL80, dd. January 20, 1982.
} 
improving road safety across the European continent. Through the COST (European Scientific and Technological Co-operation) funding scheme, the first DRIVE programme commenced in 1988. Within this programme, 72 exploratory projects were instigated in the field of traffic engineering and the communication of traffic information to drivers. The European Commission considered the initiative successful, and in June 1991 DRIVE I was carried forward as DRIVE II, with "56 projects involving 512 partners and amounting to about 18,500 man-months of work," and supported by the European Free Trade Association. All these people, based in very dissimilar institutions and companies, shared one key objective: the expansion of the use of telematics in the field of traffic engineering and traffic management (Keen \& Murphy, 1992, p. 1).

However, despite the emphasis on the newness of the information and communication technologies, and the integration of those in the physical infrastructure, it was also paramount for all those involved that the "new, more flexible and responsive forms of traffic management and traffic safety systems" had to be compatible with existing equipment and organisational structures in the field (Keen \& Murphy, 1992, p. 5). "Such cooperation is essential in supporting the close-to-market activities of European industry and ensuring that incompatibilities or unnecessary duplication of efforts do not occur" (ibid.). The section on 'The need for European collaboration' in the 1992 DRIVE report even concluded that "a common conceptual framework and agreement on basic principles at European level is a prerequisite for meeting user requirements, fair competition and the management of risks of the considerable investments required." (ibid., pp. 4-5). In other words: at the European level, policymakers and engineers strongly communicated the need for a shared road transport telematics paradigm that would obtain enough momentum so as to become a Europe-wide radio traffic system, and they allocated a vast amount of resources to achieve that aim.

The Radio Data System was envisioned by the involved European corporate researchers, manufacturers, broadcasters and policymakers - who collaborated in research programmes such as DRIVE and gathered at conferences like EUROTRAVEL - as a great new technology that could contribute to that vision of a European standard. RDS became officially operational on April 1, 1988 and according to Johnny Beerling, EBU RDS Programme Group chairman and controller at BBC Radio 1, it provided "the key to troublefree radio selection, increased safety on the roads, and a better travel news service" (Beerling, 1989, p. 30). Andrew Crisell, a British expert in the history of radio, was one of the first media scholars to also reflect on the new possibilities of RDS for radio listeners: "it is likely to modify the way in which the listener uses the medium [radio]," he almost prophetically concludes his book Understanding Radio (1994, p. 40). The time had come that new technologies would complement the traditional AM and FM bands, adding new features to radios and radio listening. Especially with regard to the transmission of radio traffic information, it was proposed that RDS would "replace ARI after a transition period." 46

Technically, RDS allowed for more functionalities than the most advanced ARI radio models. These features have been explained in various publications by Dietmar Kopitz

\footnotetext{
${ }^{46}$ SWR archive, file 10 / 33530 Verkehrsfunk in Europa, unnumbered documentation, message by Dieter Hoff communicated by the press office of the Westdeutscher Rundfunk, BEVEI - BEssere VErkehrsInformation, dd. May 3, 1993, p. 2.
} 
and Bev Marks, two EBU engineers closely involved in the advancement and marketing of RDS in the course of the 1980s and 1990s. In their view, the biggest contribution of RDS to existing broadcasting technologies was its so-called flexible data transmission channel (Kopitz \& Marks, 1999, p. 1). This enabled broadcasters to send small pieces of information along with their audio signals on the FM range. These signals could be decoded by a RDS decoder, and this had two main functions. In the crowded radio transmission landscape, with a growing number of radio stations vying for a frequency to broadcast on and with different frequencies in adjacent geographical regions for one station, RDS signals - like the ARI-BK signals - made it possible for car radios to tune automatically to the strongest signal of a station even when the car crossed radio transmission ranges.

This 'Alternative Frequency' protocol guaranteed the seamless changing between frequencies while continuing to listen to the same station. Additionally, because of the condensed nature of the RDS signals, several other types of information could be broadcast as well, such as the name of the station one is tuned into (the 'Programme Service' code), or the type of station one hears (the 'Programme Type' code; e.g. news, sports, or pop-, jazz- or classical music). ${ }^{47}$ This information was displayed visually through text or small icons on a LED-screen that was fitted into a radio or navigation device's interface. ${ }^{48}$

Concerning the distribution of traffic information, RDS engineers created new transmission types: the EON-protocol (Enhanced Other Networks), which was subdivided into the 'Traffic Programme' and 'Traffic Announcement' features. ${ }^{49}$ The content of the latter two functions was principally the same as the ARI Senderkennung and Durchsagekennung. Traffic Programme entailed the automatic notification when the radio was tuned in to a radio station that aired traffic reports by means of illuminated signs, while Traffic Announcement facilitated the automatic pushing of those traffic reports so the driver would never have to miss a single update about the situation on the road (see Riley and McParland, 1991, p. 1). An important innovation in the (sub)field of RDS traffic information was the introduction of RDS-TMC, or Traffic Message Channel. TMC was first proposed in 1984, developed as part of one of the DRIVE projects, and tested in field trials in 1993. Kopitz and Marks claim that TMC

was soon recognised by traffic management experts in Europe as a potentially very valuable feature since it permitted the delivery of coded traffic messages which, in-car, could be interpreted in a driver's native language regardless of the visited country. ... [M] any new standards were developed about messages, dictionaries for all the languages needed, and the management issues concerning these elements. (1999, p. 20)

In 1997, the large technical system of RDS-TMC was finally complete and operational. The aim of TMC was to reduce the tensions "between traffic, traffic safety and

\footnotetext{
${ }^{47}$ Philips Company Archives, File 811.215 cassette 1985 - ..., unnumbered documentation, promotion booklet "The new standard in sound and design," published by Philips Car Systems, 1993, p. 6.

${ }^{48}$ Philips Company Archives, File 811.215 cassette 1980-'85, unnumbered documentation, promotion booklet "Philips CARIN TM Navigation System," no date.

${ }^{49}$ Philips Company Archives, File 811.215 cassette 1985 - ..., unnumbered documentation, promotion booklet

"The new standard in sound and design," published by Philips Car Systems, 1993, p. 6.
} 
the environment, especially in the core of Europe" (Everts, Olberding \& Schneider, 1994, p. 1; see also Meyer, 1999, for similar conclusions). Thus, RDS-TMC was explicitly envisioned as a follow-up of ARI that was supported throughout all of Europe.

The principles behind the operation of TMC did not rely only upon radio signal transmissions. It also made use of a memory card and synthetic speech to inform the driver about any traffic-related incidents via the car radio and/or navigation set. For motorists, this offered several uses. The memory card and speech function enabled motorists to listen back to the latest, digitally processed traffic news. What was more, as the messages were codedrelying on the new standardised catalogue for indicating specific places of the European infrastructural network and the type of incident that Kopitz and Marks referred to in the excerpt above - they could be decoded and subsequently translated into any drivers' preferred language. The principle of coded and stored data allowed for the improved "delivery of accurate, timely, and relevant information without the need to interrupt the radio programme - just the opposite of the common practice today with spoken traffic messages" (EBU, 1998, p. 6). In this way, RDS-TMC also offered a solution to the linguistic problems faced by traffic reporters. This had become an increasingly pressing issue when international traffic flows intensified. Whereas reporters wished to service all driving listeners, including foreign ones, it had long been impossible to present radio traffic reports in any language other than the language of the radio station (see recommendations of EUROTRAVEL '88 in EBU Review, 1989, p. 35).

The possibility to decode information digitally thus affected the design and use of car radios. Motorists got access to new sources of traffic information while driving. The development of new information and communication technologies also contributed to an expansion of the range of technological possibilities in the realm of gathering and processing traffic data. I will not explain in much detail all innovations that taken up in this realm, but one development is important for a good comprehension of the traffic information systems in these two countries. This is the establishment of so-called Traffic Information Centres, or TICs. Illustration 2.5 presents a concise, visual overview of the entire network of organisations and - albeit unspecified - technologies that made radio traffic reports possible. The Traffic Information Centres were central hubs in these networks. Here, data from both public and private institutions, such as the road authorities, traffic police and motorist associations, came together and were bundled in order to be communicated to the broadcasters or traffic information service providers. They, in turn, decided what reports to present on the air (see Vanderschuren \& Sijstema, 2000; Kirschfink, Poschmann \& Ziegler, 2002).

After the introduction of these more advanced information and communication technologies, monitoring traffic flows has considerably improved, both in terms of the detail and overall accessibility of the information. It would surpass the topic of this chapter to map out the entire technical system that lies at the foundation of those new technological means to gather and present traffic information. Yet they added a new dimension to the practices for gathering and transmitting details about ongoing traffic flows. For example, based on crowdsourced GPS data generated through cell phones and other mobile devices, Google Maps is currently able to indicate real-time traffic flows using a colour-coded scheme. 'Green' traffic means there is no delay, orange road sections indicate minor delays, and red 
areas imply severely congested roads. These technologies aid traffic experts in their effort to monitor traffic flows in the blink of an eye.

When traffic reporters began using these technologies as well, they were at least in part relieved of their laborious personal contact via phone, radio, fax, telex, or whichever other manual and more labour-intense forms of communication. Moreover, once the standardized map and lexicon of virtually the entire European road network was finished as part of the efforts of engineers, traffic managers and policymakers to introduce RDS-TMC, coded information could be sent $24 / 7$ to every device with a TMC-decoder. For these reasons electronic gathering, processing and communicating technologies for traffic information were welcomed by all parties involved (see Van Rees, 1995; Bartsch, 1997).

The introduction of the Radio Data System can thus be seen as the starting point of a new range of devices and data broadcasting systems. Moreover, RDS, which started as a European endeavour, was soon exported to countries all over the world. Kopitz and Marks remark about the exportation of RDS to the United States that "in the U.S. radio environment, radio networks and relay transmitters, or transposers as they are called in the United States, are more infrequently [sic] found, which is quite different from Europe. So, RDS clearly needed some adaptation" (1999, p. 21). This is an interesting remark that invites questions like: how did the system in the United States operate, how did this differ from the German and Dutch context, and how influenced those practices the trajectory of traffic reporting technologies on the other side of the Atlantic Ocean? These questions will be explored in the following section of this chapter.

\section{Traffic Reporting Traditions across the Atlantic Ocean}

In the introduction of this chapter I explained how the phenomenon of radio traffic reporting was no European invention. The first references to announcements for motorists on the radio were aired in the United States, and date back to the late 1930s. Already in 1929, a British newspaper item remarks on the use of radio in taxi cabs to inform taxi drivers about ongoing difficulties in traffic, enabling them to save "time and mileage" by avoiding those streets ("Space Speaks," June 29, 1929). The first radio traffic reports for a wider audience were broadcast soon thereafter. The way in which the reports were collected and aired, however, was very different from what became common in Europe. Instead of a large network of communication technologies, helicopters played — and continue to play — an important role in the traffic reporting practices of several large American radio stations.

Considering the enormous number of motorists, the potential audience of traffic reports in the United States was huge. In 1949, around fifty percent of all cars sold in America were already equipped with a radio (McShane, 1997, p. 99), and this number would continue to go up consistently. The combination of the potential interest in traffic information, along with growing car radio sales, was interesting for broadcasters and car radio manufacturers. Blaupunkt saw a commercial potential in the United States as well. After the success of ARI in Germany and the leading role of Blaupunkt in the development of European traffic information systems, this company was keen on expanding its technology beyond Europe. In 1983, a team of Blaupunkt engineers and spokespersons flew to New York to promote ARI 
technology at several radio stations. ${ }^{50}$ The aim was to make American broadcasters enthusiastic for transmitting the $57 \mathrm{kHz}$ signal along with the traffic reports, which could be picked up and activate Blaupunkt ARI car radios that would be sold by local retailers. ${ }^{51}$

The article "ARI gives radio traffic a "boost" "by Judith Gross, writer for the journal Broadcast Management \& Engineering, describes that ARI entered the US radio domain "after a dazzling launch," and could "be heard in 24 cities covering eight radio markets, with some seven more areas set for launch before the end of the year" (1985, p. 27). The author concludes her laudation of ARI by stating that "for radio stations which get a certain smug thrill out of [the prospect that ARI radios always switch to every traffic broadcast], Blaupunkt has the ultimate radio manager's fantasy already waiting in the wings" (p. 30). This bright and exciting vision of the future of ARI in the United States, however, did not fully come to fruition.

In the archives of Blaupunkt, very few references to this expedition can be found, and none of those sources explains why ARI did not become a commercial success in the United States. To understand why this was the case, then, it is relevant to look at the ways in which traffic information was gathered and broadcast across the Atlantic Ocean. This is why I followed Blaupunkt's employees, and focused my research on American traffic radio in the New York metropolitan area, including New Jersey to the West and parts of Long Island to the East of the City. This is one of the most densely populated regions in the United States, and even though New York itself has a relatively low number of car commuters compared to many other American cities, the infrastructure still lacked capacity to accommodate all automobile travellers (see McShane, 1997, pp. 128, 167). Consequently, congestion rates in the New York region continued to go up during the second half of the twentieth century. In the 1960s, the heyday of the environmental movement in the United States, voices were raised to ban cars from Manhattan altogether in order to reduce congestion and its negative impact on air quality. But the activities to realise those idea(1)s were largely discontinued by the 1970s, and New York became one of the most jammed cities on our planet (Renn, 2016; INRIX, 2018). For these reasons, the New York region provided a relevant research site for my research into traffic reporting practices.

In the previous sections, I explained how the emergence of traffic information practices in Germany and the Netherlands was shaped through the collaborative efforts of several public and commercial organisations. They remained key players in the later development of new technologies, which is why the innovation process could be explained satisfactorily using the concepts of technological trajectory and momentum. Unlike in Europe, however, the American car radio market was not dominated by a few large corporations. Instead, a large number of companies competed to get their product into America's cars, without one of them gaining a substantial share of the market (see Bijsterveld et al., 2014, p. 89). This is an important contextual factor to take into account, because it limited the room for car radio manufacturers to expand their businesses in a national context,

\footnotetext{
${ }^{50}$ Bosch Company Archives, unsorted files held by Mr. Kuhlgatz, unnumbered documentation, document reference A/02/86/05/SM8, Blaupunkt Press Release "ARI Erfolgreich auch in den USA. Verkehrsfunk-Service schon von 24 UKW-FM-Sendern in Nordamerika," May 1986, p.1.

${ }^{51}$ Bosch Company Archives, File 1601 099, unnumbered documentation, document reference 10/83, prospect

"Travel ARI" published by Blaupunkt Werke GmbH, Hildesheim Presse und Information.
} 
like Blaupunkt and Philips had been able to do in the German and Dutch car radio sector. It was therefore more difficult for Blaupunkt, once it sent liaisons over to the United States, to generate the necessary momentum the company needed to make ARI as popular and successful in America as it had become in Europe. However, as I will explain below, it is insufficient to follow the operations of businesses alone. One also needs to consider the overall traffic reporting system that was already in place in the New York metropolitan area by the time ARI's technological trajectory evolved in Europe.

The starting point of New York traffic reporting practices can be traced back to a large New York radio station with enough financial means to make use of mobile radio transmitters and a flying airplane or helicopter. This was common practice at several large radio stations at the time. In the United States a Newark radio station started broadcasting traffic reports on the basis of data collected by an airplane as early as in 1937, and - as mentioned earlier in the introduction - by the 1950s, "aerial traffic reporting by radio" had become "a regular service during the weekday rush hours in majors cities," now with the help of helicopters" (McDonald in Bijsterveld et al., 2014, p. 102). The reporter in the air was able to inform the listening audience on the traffic activity on any road or highway he could see from his aerial viewpoint. ${ }^{52}$

Apart from traffic flows, the aerial reporter oversaw an infrastructure that was governed and maintained by different organisations. This segmented organisational and judicial structure of New York and New Jersey's infrastructural network is the first element that helps to understand and explain the difference between the American traffic reporting system and the one prevailing in Germany and the Netherlands. This can be illustrated by a comparison of the construction and maintenance practices of highways in Germany and the United States. Whereas German governmental authorities have full power to make decisions on the country's Autobahnen, the jurisdictions in the United States were much more dispersed. As Michael Fein remarked in an article about the history of the New York State road network: "American road building has always been a contested process: constrained by a political system that aimed to preserve community control over local roads, while drawing on the centralized authority necessary to direct a public works project national in scope." (2007, pp. 63-64). States, counties, towns, the federal government, all had a say in the regulation of road and traffic. Moreover, the US knew a strong automobile lobby (see Flink, 1988, pp. 368-375). There was no interaction amongst these various authorities, however, about providing data on the evolving situation on the road as a service to motorists, as was common in several European countries.

The second biggest difference when mapping the interconnected systems for traffic reporting in the New York region, concerns the means for gathering and processing relevant sources of information. In Germany and the Netherlands, the motorist associations and the road and highway police departments had acted as central hubs in the collection and processing of traffic data since the late 1960s. In New York, no such centralisation of information flows was realised until 1979. Across the United States traffic news was gathered by for-profit companies who sold their updates to radio stations who had no helicopter of their own, as well as to other parties interested in such information. The first company that

\footnotetext{
52 In sources and recollections of the early history of traffic radio in the New York area, I did not find any references to female traffic reporters until the 1970s.
} 
facilitated this service in the New York area was named Shadow Broadcast Services, better known as Shadow Traffic, or even just 'Shadow'. Shadow started out as a voluntary initiative in 1975 in Philadelphia, where its founder used a remote controlled Citizen Broadband (CB) radio called 'Shadow box' to contact passing motorists in order to receive updates on the local flow of traffic. Soon, however, he sought help to commercialise his concept, and the company expanded to New York in 1979. Here, Shadow Traffic became the principal traffic information company. By 1983, it facilitated the traffic reporting for as many as fifty-six New York radio stations (Bornstein, 1983).

Its operations were similar to the Traffic Information Centres in Germany and the Netherlands, the difference being that Shadow was completely for-profit. Moreover, reporters at Shadow could rely much less on the early adopted automatic traffic data generation technologies that were used in Europe. To gather information, Shadow's reporters used the telephone a lot. According to an article in the magazine Billboard, Shadow had a monthly phone bill of 15,000 dollars and additional overhead costs of close to a million to maintain five aircrafts, a phone monitoring service that included calling each local police department every 45 minutes, and another set of 'shadow boxes' to be in touch with motorists on the road who had a CB radio in their car (Bornstein, 1983). Moreover, traffic employees were driving up and down the streets of New York and New Jersey to call in any congestion they encountered (interview Tom Kaminski, March 5, 2018). To earn revenue, Shadow had two sources of income. They asked a fee for its services from every station, but more important were the advertisers who sponsored the traffic news and whose commercials were read aloud by the reporter during a report (Bornstein, 1983). With this revenue model, Shadow took the New York radio market by storm.

Similar to the situation in Europe, however, these commercial traffic reporters gathered their information from a range of sources; several of which were facilitated by public authorities, such as the Port Authority, patrollers and emergency services at the Department of Transportation, police departments, and workers at the highway and toll agencies (interview Bernie Wagenblast, March 16,2018). Unlike in Europe, the police was not on the air to report on traffic. This elaboration on the business model of Shadow Traffic demonstrates how the techno-political and economic landscape in the New York area influenced the practices and possibilities for sourcing and sharing information about road conditions. The fragmented jurisdiction over roads and highways, the various dispersed and time consuming systems for gathering traffic data, the lack of centralized and collaborating public authorities or public interest organizations, and the commercial nature of American broadcasting were all factors that played a role in shaping the technological trajectory of traffic information reporting in that area.

In light of these insights, it becomes possible to explain why Blaupunkt's ARI system gained less popularity in the United States than in Europe. When Blaupunkt's liaisons began their efforts to generate interest for their technology, they essentially had to expand the socio-technical system that was already in place for traffic reporting, by introducing a new technology that required the cooperation of broadcasters, broadcasting authorities like the Federal Communications Commission (FCC), and local car radio retailers who were willing to sell Blaupunkt radios. This was no easy task as such, and proved even more complicated because there was already a longstanding, albeit dispersed system for gathering 
and broadcasting traffic information in place. Moreover, the actual transmission technology that was the basis of ARI's operationalisation in Europe had to be adapted to American broadcasting protocols. ${ }^{53}$ To make this possible, Blaupunkt's liaisons had to come to a constructive agreement with broadcasters and the FCC, in order to develop new standards for radio transmission in the United States and secure the necessary frequency for transmitting the ARI-signal. According to Jerry Lebow, one of Blaupunkt's spokespersons in this process, it took a long time to align all those stakeholders (interview Jerry Lebow, December 12, 2018).

Nevertheless, by 1986, after two years of trials, Blaupunkt had equipped twentytwo American radio stations, including stations that spanned part of the American northeastern coast from Long Island to Washington, DC. ${ }^{54}$ Via these stations, and with the necessary ARI decoder for their car radios, millions of people could automatically tune in to the latest traffic report about their region. At the same time, however, the development of new information and communication technologies, like the Radio Data System, had also progressed significantly. Following the decision in Europe to implement RDS as a new broadcasting standard across the continent, American broadcasters, the FCC, and car radio manufacturers were supportive of the decision to introduce the protocols of the Radio Data System in the United States as well. Technically, these protocols had to be adapted slightly to fit the existing American broadcasting system, but the technical standards for the Radio Broadcast Data System, as the American version of RDS came to be called, were accepted by the National Radio Systems Committee in 1992 (Beale \& Kopitz, 1993, p. 7).

Thus, timing appears to be another factor in explaining the inability of Blaupunkt to market their ARI radios at a scale comparable to their success in Europe. By the time they had all relevant stakeholders aligned, the development of the Radio Data System - which drew on the idea of ARI, but was at the same time technically incompatible with ARI because it made use of exactly the same frequency band - superseded the ARI system altogether. The successful and more rapid implementation of the American Radio Data System nevertheless illustrates that automatic transmission systems for radio traffic information, for which RDS offered more elaborate and advanced technical possibilities, had gained enough momentum to be taken into consideration in Europe as well as the United States.

In general, American broadcasters were indeed very susceptible to the idea of including traffic information as part of their programmes. This can be explained in part because most American radio stations were, and are, commercial and decentralised, rather than being financed (at least partially) by governmental funds as was common in Europe. This had an impact on the paradigm of the broadcasters, and the role ascribed to traffic reports in the overall radio programme. When talking to traffic reporters and radio anchors at the two New York radio stations that I visited for this research project, 1010WINS and WCBS880, it was easy to observe that good traffic reports were a major asset for the station. According to the headline of an article by a media consultant in the trade magazine Radio \& Records, traffic information should even be treated as a "top priority," after which it is added: "regular,

\footnotetext{
${ }^{53}$ Bosch Company Archives, unsorted files held by Mr. Kuhlgatz, folder ARI, document number A/15/83/06/Sm6, Blaupunkt Press Release “Fortschritt aus den alten Welt: Amerika entdeckt ARI," dd. August 1983.

${ }^{54}$ Bosch Company Archives, unsorted files held by Mr. Kuhlgatz, folder ARI, "ARI Verkehrsfunksender in den USA, stand Januar 1986," 1986.
} 
accurate reports are the key to success. Years of research about news, traffic, and sports have shown that the audience cares predominantly about weather and traffic. They consider traffic to be 'the news'. It's their news" (Sabo, 1997, p. 32; italics in original).

The article in Radio \& Records is tailored to traffic reporters, so we would do well to take the headline and claims about the unquestionable value of traffic reports with a grain of salt. Nevertheless, the example shows how the economic model behind radio broadcasting in New York worked, constituting a very different socio-technical system compared to Europe. Traffic reporting was, and is, a commercial product; paid for by advertisers who get their name mentioned on the air through sponsored reports. This marks a rather sharp contrast with all the talk about traffic safety and, later, efficiency, in European documentation on the motivations for transmitting broadcasts for motorists.

Another marked distinction between the American and European paradigms for gathering, processing and transmitting traffic reports is the American focus on personal observations of the live traffic situation. In several interviews, traffic reporters in the New York metropolitan area indicated the long tradition in their profession of looking at local traffic flows, which they consider a crucial element of their work. These reporters relied on their own perception of any unfolding traffic situation, as seen by them from a helicopter, from their car, by driving around as spotter, or, later on, by looking at CCTV footage on a television or computer screen. However, spotters or CCTV did not always guarantee perfect oversight of any given traffic situation. Cameras did not necessarily show the cause or entire length of a jam, and many roads were out of view because no cameras were installed. Consequently, while the traffic reporter might have some evidence of an ongoing jam, he or she still needed to interpret what could be seen on the computer screen.

According to Matt Ward, a senior traffic reporter at Total Traffic and Weather, the company into which Shadow Traffic merged after a couple of corporate takeovers, the experience to deliver trustworthy reports based on the CCTV cameras is based on several ways of triangulating camera images with other sources of information, such as the police radio scanners, incoming or additional phone calls, employed drivers on the road, and the reporter's own experience. Ward explained that once you become familiar with the local infrastructure and frequently recurring problems, you learn to see patterns and over time you will be able to anticipate congestions based on past experiences (interview Matt Ward, March $12,2018)$. Also, in addition to the information from CCTV cameras, various other tools and sources may help to get a fuller picture of a traffic situation, such as data from the local toll systems within the New York and New Jersey road network, Google Maps, and information shared with reporters via social media and the telephone. All the available pieces of information may help to puzzle together an update of particular information and add to the value of the radio traffic report. After all, according to the interviewed traffic reporters in New York, too, this is what the entire system of radio traffic reporting is geared towards: to provide listeners with useful traffic information, in order to make their drive more safe and more efficient. 


\section{Conclusion: A Theoretical Shock of the Old}

In this chapter, I explored the technologies and organisational forms that have been developed to gather and transmit radio traffic information since the 1950s. This led me to investigate the Autofahrer Rundfunk Information system, or ARI. This was the first system in the world that enabled the automatic tuning of a radio to the latest traffic report, thus enabling drivers to be up-to-date about the ever-changing situation on the road and give them the possibility to 'find the empty roads'. The growth of the ARI system, from the information booths in the service stations alongside the German highways in the early 1970s to the groundwork of a European-wide information and communication system by the $1990 \mathrm{~s}$, has been explained by looking at the role of Blaupunkt in the process of building the technological system required to make ARI work.

The concept of technological trajectory, developed by Giovanni Dosi and others to make sense of the kinds of technologies that are developed within a corporate paradigm, helped to understand which processes and dynamics facilitated the development of ARI and study its merging with newer, computer-driven information and communication technologies at the European level. To capture this growth, it proved useful to combine the notion of 'technological trajectory' with theory on large technical systems and Thomas Hughes' concept of momentum. This allowed me to show how ARI - through the expanding number of ARI radio users, related radio reception technologies and car radio devices, and a surge of radio stations with traffic information using ARI transmission signals - evolved into a single network of connected social and technical elements. As the system continued to grow larger, I concluded, the mass and momentum of the expanding socio-technical network prolonged ARI's trajectory.

To gain insight into the role of differing technologies and organizational forms in the domain of radio traffic information I also studied the New York metropolitan region. Here, I aimed to find out why Blaupunkt's effort to export ARI to the US was not as successful in terms of the wider adoption of the technology, even though radio traffic reports were already frequently part of several American radio programmes. To account for this discrepancy, it was necessary to look at the traffic reporting system that was already in place in the New York region. My investigation, in other words, resulted in the study of a different socio-technical system - one that had enough mass of its own to withstand the efforts of Blaupunkt to introduce ARI, which did not allow for the smooth integration of a new technological system in the existing practices for gathering and broadcasting traffic reports on New York radio stations, let alone replace these practices. Still, the efforts to introduce ARI in the United States did result in more communication between relevant stakeholders in the broadcasting and car radio industries, which helped to roll out RDS at a quicker pace and with a broader supplier and user base. This illustrated the importance of local actors' receptivity for any technology to successfully become part of a broader system of operations.

In order to develop this kind of 'Hughesian' analysis of a large technical system, it is paramount that the analyst conducts in-depth historical research in order to be able to interpret and reconstruct the emergence of the technological system under study. Other theoretical frameworks applicable to studying technological change, such as those with a focus on niches and landscapes (Kemp, Rip \& Schot, 2001; Geels, 2002) or with an emphasis on relevant social groups and interpretative flexibility in the Social Construction of 
Technology (SCOT) approach (Pinch \& Bijker, 1987/2012; Bijker, 1995) have their own merits. Still, for understanding the rise of traffic information and broadcasting technologies I want to argue in favour of the systems approach. This was one of the founding approaches in the emerging field of technology studies in the 1980s, but apart from the work in which Thomas Hughes was involved himself there are only a few examples of critical, full-fletched empirical studies of large technical systems today. Exceptions are the various studies that emerged from the Tensions of Europe project, such as the edited volume by Erik van der Vleuten and Arne Kaijser (2006) in which the contributing authors demonstrate how transnational infrastructures shaped contemporary Europe between 1850 and 2000.

More work has been written over the years that use LTS as an approach to theoretically investigate specific dynamics in governing change in large technical systems, using empirical case studies. Examples of this work can be found in the volumes edited by Jane Summerton (1994) and Olivier Coutard (1999). Few scholars, however, have aimed to contribute to the theoretical framework of LTS as such. One recent attempt to revive and expand LTS is the article by Benjamin Sovacool, Katherine Lovell and Blanche Ting (2018) in which they propose to add the concepts of 'reconfiguration', 'contestation' and 'decline' to our vocabulary to understand the dynamics in established large technical systems and thereby expand insights that can be gained from LTS theory - as is common in much LTS literature - that focusses on the emergence of a large technical system.

Methodologically, researchers who aim to present a combination of new empirical and theoretical knowledge within studies on large technical systems are confronted with a few difficulties. Compared to the helpful ready-to-use toolbox of SCOT, the researcher attempting to use LTS necessarily faces a wide variety of potential sources and has to make many decisions on which leads to follow as the research unfolds. This complexity may have contributed to the fact that internationally comparative studies of large technical systems are rare, and it may also explain why systems research, if applied, is nowadays often done by groups of researchers rather than by a single individual scholar.

Having expressed my support for the systems approach in studies on the history of technology, I want to return to the accusation that concepts as 'mass' and 'momentum' implicate technological determinism. In a review of two decades of studies on large technical systems, Erik van der Vleuten convincingly dismisses these accusations. He invites fellow historians of technology to use LTS to demonstrate precisely the nuance and complexity of the interrelations that come into play once a large technical system takes shape (2006, p. 294). With the study presented in this chapter, I have contributed to this mission by illuminating how the first traffic information technologies, ARI in Europe and aerial traffic reporting in the New York region, gained momentum. This was not because these were indisputably the better options, but because their makers were able to link up with other stakeholders and technologies.

Altogether, this chapter thus demonstrates that it is useful to revive a set of early theoretical concepts in the field of Science and Technology Studies to investigate sociotechnical systems in the past as well as the present. Borrowing the notion of 'the shock of the old' as coined by historian of technology David Edgerton, I argue my investigation of evolving traffic reporting practices flags a theoretical shock of the old. I claim it is worthwhile to occasionally dust off some of the original works in our field as a way to reopen 


\section{Chapter 2}

our analytical senses and answer questions about why technologies successfully evolve in particular countries or even continents, yet are seriously stalled when first introduced in other places.

In the following chapter I will address a tension in the relation between the ideal image of automobility and the everyday reality of many motorists which media scholar Heike Weber captured succinctly by stating that "the vehicle's magic aura of freedom and mobility has faded ... [but] our society seems to worship more than ever before the potential to move" (2011, p. 26). Now that we have an understanding of the development of the technologies to gather, process and transmit traffic information, the next chapter will address the work done at the radio stations and offices of the traffic reporters. In those locations, the various actorsreporters and radio hosts primarily - in fact witnessed all the technological changes discussed in this chapter first-hand and adapted their professions accordingly in an attempt to contribute to the potential of automobile drivers to move ahead. To carry my investigation of traffic radio forward I will next investigate the ways in which these individuals attempted to help motorists in their search for open roads, and, when stuck in a jam nonetheless, tried to talk them through. 
Mapping Mobility 



\section{Broadcasting Flow: Presenting Traffic Information on the Air}

\section{Flow in and through Radio Traffic Reports}

This chapter is devoted to an investigation of the ways in which the presentation of radio traffic reports in the Netherlands, Germany and the New York metropolitan area has developed and changed since the 1950s. I address the following main question: how was traffic information presented to drivers and embedded in the overall radio programming? I will also consider the underlying question of how radio hosts and traffic reporters tried to win and retain their listeners' attention. To answer these questions, I not only studied documents about radio traffic information from the 1950s onward, but also systematically analysed the form and content of traffic reports broadcast between 1960 and the early 2000s, while I also interviewed various (former) traffic reporters and radio hosts in each of the three countries included in my research. I studied these historical radio broadcasts on the basis of manually written transcripts of their recordings, which were coded by using the software programme ATLAS.ti.

To study traffic reporting practices in the Netherlands, I focussed on broadcasts by news station Radio 1, which are archived at Sound and Vision, a Dutch knowledge institute in the domain of media-culture and audio-visual archiving in Hilversum. ${ }^{55}$ I selected radio recordings from 1960 to 2000 . I looked specifically at the morning and evening drive time hours in the months November to February because I expected to find more regular traffic reports during these months due to their instable weather conditions. Because the total number of radio broadcasts in line with these criteria was still high, I decided to transcribe all broadcasts for drivers from the $1960 \mathrm{~s}^{56}$ and a subset from the 'complete recordings' (integrale opnames) for two years per decade after 1970: 1977, 1982, 1987, 1993, 1997 and 2000. These 'complete recordings' are records of one full week of radio programming. In most cases, the Dutch broadcasting organisations made these 'complete recordings' in calendar week 50, except for the year 2000, when this was done in calendar week 1 . In the end, my selection resulted in more than 150 pages of transcripts and notes.

Furthermore, I conducted two interviews with the traffic information manager of the ANWB, the principal provider of radio traffic information in the Netherlands on public radio stations, and I interviewed three (former) radio show hosts of Radio 1, as well as one radio technician responsible for the switching between the radio host and traffic reporters (and other media such as incoming calls, sounders or commercials). Finally, in the fall of 2018 I organised two expert workshops. The first meeting in September was attended by a Dutch radio host and a traffic psychologist. The second meeting took place in early November at the ANWB traffic information department, where I spoke at length with the manager of the department and was joined for one hour by five reporters who were at work that day. Together

\footnotetext{
${ }^{55}$ For more information about the selection of radio stations, please see the research design section in the introductory chapter. For an analysis and discussion of the Dutch materials gathered for the purpose of this chapter, see also Dieker (2018).

${ }^{56}$ The recordings from the 1960s were aired on Dutch station Radio 2. Because of programming similarities between Radio 1 and Radio 2 in this decade, I decided to include these broadcasts in my research as well. All broadcasts from 1970 onwards were aired on Radio 1.
} 
with these experts, I discussed the main findings of my research. These conversations also contributed to the final reflections presented in this chapter.

For my German case study, I documented broadcasts from the Stuttgart-based public broadcaster for the Bundesland of Baden-Württemberg: Südwestrundfunk (SWR). This included broadcasts from its local predecessors, Süddeutscher Rundfunk (SDR), which aired in the southern and western part of Baden-Württemberg, and Südwestfunk (SWF), whose broadcasts were aired in the northern and eastern region of this same German Bundesland. These broadcasters operated various stations (e.g. SDR 1, 2 and 3). I focussed my analysis on SDR 1, SWF 1 and - after the merger of these two stations in 1998-SWR 1 because these are the most prominent news channels in this part of Germany and most comparable to Dutch Radio 1 and the news stations in the New York region. My selection of recordings from the SWR archive resulted in approximately 130 pages of transcribed research material. Although the first actual traffic news for drivers dates from 1967, earlier radio items about traffic problems covered discussions about more general infrastructural and regulatory difficulties in Germany at the time (see below).

I also conducted several interviews with various individuals on radio traffic information in the state of Baden-Württemberg. I spoke with three SWR traffic reporters, and three radio show hosts of current morning and afternoon programmes. Moreover, the Landesmeldestelle für den Verkehrswarndienst (a division of the state's police department concerned with traffic information) in Stuttgart welcomed me for a conversation with one of their senior employees. In addition to this interview, they granted me access to their archival collection of press coverages. This provided additional insight into the activities and involvements of the Landesmeldestelle in the field of traffic information gathering, their communication with the radio traffic reporters, and their development towards becoming the central traffic information centre in Baden-Württemberg.

Finally, for my case study on traffic reporting in the New York metropolitan area, I collected historical audio materials in a variety of places: the Rodgers and Hammerstein Archives of Recorded Sound, the Paley Center for Media, and online information portals and air check repositories that are available on websites such as www.nyradioarchive.com and www.musicradio77.com. Most of the materials from the New York and New Jersey region presented in this chapter, however, were provided by WCBS880 radio anchor Wayne Cabot from his personal archive. Retrieving American radio recordings proved considerably more difficult than in Europe. Although the New York metropolitan area has a long tradition of radio broadcasting, the most important radio stations have always been commercial stations which had - and have - little interest in archiving everyday broadcast materials (see chapter two).

Recent efforts to combine inventories of radio archives, like the database of the Radio Preservation Task Force, National Recording Preservation Board of the Library of Congress and the Association for Recorded Sound Collections, provided additional radio collections to search for relevant source materials. Unfortunately, unlike broadcasts covering major events, such as the assassination of John F. Kennedy or the explosion of the Challenger airspace shuttle, traffic reports are rarely saved. An additional complication I encountered in the United States is that many historical radio recordings are 'scoped'. This means that ordinary items such as traffic reports are cut out of the tape or the digitally stored recordings. 
As a result, my search for radio traffic reports left me with relatively few useful recordings. Even the most engaged collectors of American radio airchecks I contacted were unable to help me find radio recordings with traffic reports, even though traffic news used to be part of some of the historical radio recordings they owned. As one of the collectors, the editor of the online appreciation site of Newsradio88 (the former name of the station WCBS880), explained to me:

[One] reason you're having difficulty in locating complete traffic reports in airchecks is that such reports are perishable and retain little or no historical value - unless the traffic reporter observes, say, the attack on the World Trade Center on 9/11, a major fire, or flooding. Otherwise, the reports, from a historical standpoint, are almost useless due to their immediate and passing nature, similar to weather forecasts. (Salvas, personal communication, July 24, 2018)

Although I certainly hope to show that past broadcasts of traffic news are of historical interest, the sample of recordings from the New York metropolitan area is considerably smaller compared to that of my Dutch and German case studies. To gain additional insight into the development of New York traffic reporting beyond the recordings I was able to transcribe, I conducted interviews with eight radio show hosts and (former) traffic reporters from the two most important New York all-news stations in the period between the 1950s and the present: WCBS880 and 1010WINS. Additionally, I spoke with employees at the New York division of the corporate service broadcaster Total Traffic and Weather Network (TTWN, the successor of Shadow Traffic in the New York region) and the Technical Center of the New York and New Jersey Port Authority. Finally, I conducted three interviews with senior traffic information experts who worked at these radio stations or TTWN's predecessor, Shadow Traffic, in the past.

In order to develop an analysis of changes in the form and content of the historical radio traffic reports, I selected stations that are somewhat comparable in terms of format and popularity in the three geographical regions covered. While I found radio broadcasts from several other radio stations in the wider New York metropolitan area, I focus my analysis in this chapter exclusively on the three New York news- and talk stations (with occasionally some music) that rank amongst the most listened to stations in the area: 1010WINS, WCBS880 and 77WABC. With the additional help of Bob Gilmore, a private collector of airchecks, I was able to analyse sixteen recordings with one or more traffic reports aired by these stations from the years between 1978 and 2001. These stations are comparable in terms of their formats and are also akin to the Dutch and German formats I studied. The format of the stations defines the kind of show presented to listeners. For example, a pop music station - a genre commonly broadcast on the FM dial — would sound and was organised differently from an all-news station. Typically, the latter was found on the AM dial. 


\section{Studying Flow in Radio Broadcasts}

My approach is theoretically informed by the concept of flow, as developed by Raymond Williams in the field of media studies. Williams was one of the first scholars who coined the concept of flow to analyse changes in media broadcasting. His scholarly contribution was not limited to his media analyses, however. Williams is known for the ways in which he connected his observations in media with a broader cultural analysis. One example of this is his reflection on the relation between media and mobility. In Television: Technology and Cultural Form (1974/2003), Williams engages with these two, related phenomena. With respect to broadcast media, he argues on the basis of a comparative analysis of television broadcasts at three British and two American stations in March and June 1973, that broadcasting corporations moved away from offering standalone programmes (one show or item after the other), and instead had begun to present a continuous and carefully programmed flow of images and/or sounds. He claims this development is closely related to the "apparently paradoxical yet deeply connected tendencies of modern urban industrial living: on the one hand mobility, on the other hand the more apparently self-sufficient family home" (2003, p. 19). In other words, Williams observed new means of being 'mobile'. Physically, this mobility was made possible by new forms of transport, in particular people's individually owned cars. Mentally, broadcast media enabled people to explore the world from within the privacy and comfort of their own, personal space.

Williams goes on to explain how, due to increasingly nuclear and geographically dispersed families, as well as changing professional relations and working hours, broadcast media helped to fill the need for "new kinds of contact" (p. 22). Through continuous newscasts and other forms of informative broadcasts, media helped people to stay connected, if only mentally, to other individuals elsewhere. The way in which the programming was set up, 'flowing' from one item to another in a continuous stream of information and entertainment, contributed to catching and maintaining the audiences' attention at all times (see Williams, 2003, pp. 93-95).

The connection between media, flow and the different forms of mobility come together in Williams' concept of mobile 'privatisation', which entails 'an operative relationship between a new kind of expanded, mobile and complex society and the development of a modern communications technology" (Williams quoted in Packer \& Oswald, 2010, p. 312). The concept of mobile privatisation has been taken up predominantly by other scholars because Williams himself presented only a limited account of his definition of the term. Media scholar Shaun Moores has written more extensively on the topic and explains that mobile privatisation "refers, on the one hand, to the dramatic retreat of social life into privatized settings ... On the other hand, it signals far greater opportunities for travel and a vastly expanded sense of community" (1993, p. 365). Indeed, when Williams published his book in 1974, people amplified their physical mobility, mostly by using their cars. Jeremy Packer and Kathleen Oswald, both media and communication scholars, conclude in a reflection on Williams' work that in 1974, when he

first discussed mobile privatization, the network in which the automobile and broadcast communications was oriented was that of work, home, and nation. The automobile rovided the connective technology that linked the 
home to circuits of consumption and production while broadcast television maintained links between the nation and the increasingly disparate suburban homes. (2010, p. 329)

As Packer and Oswald argue, "Williams was describing a period in which space, time, and capital came to be organized by suburbanization, commuting, broadcast, and bureaucratic corporate industrialization" (2010, p. 313). In this sense, the automobile was, literally, a prominent node in the process towards mobile privatisation. It involves a means of transportation that allows people to drive back and forth between suburban homes and urban workplaces in a physically secluded space, while at the same time connecting them to the world through the car radio.

To secure the attention of the audience, which travelled longer distances more frequently than ever before, broadcasters had to find ways to maintain the audience's attention. This is where Williams introduces the study and importance of broadcasting flow. To study the role of radio traffic reports in this chapter, Williams' concept and analysis of flow is useful not only because he linked media to mobility, but also because he concretely points to three different levels at which flow can be identified within media broadcasts: the long, medium and close range. Indeed, as Oswald and Packer note in an article about the relation between media and mobility in which they also rely on the work of Williams, "flow offered a holistic account ranging from the broad understanding of weekly programming to a focused textual analysis" (2012, p. 280).

Some contemporary media scholars, like Henry Jenkins, consider research using Williams' framework for studying flow overdue, now that we have many more media than just traditional broadcasters (Jenkins, 2006). Indeed, some more recent analytical concepts, like 'convergence', can also be used to investigate how broadcasters try to maintain the attention of their audience. Convergence, however, is used to study the "flow of content across multiple media platforms, the cooperation between multiple media industries, and the migratory behaviour of media audiences who will go almost anywhere in search of the kinds of entertainment experiences they want" (Jenkins, 2006, p. 2). The concept of convergence, then, directs the attention of the researcher towards the content and underlying dynamics of multi-media. For an analysis of the presentation of radio traffic news, a medium still frequently used despite the emergence of other sources of traffic information, it is important to thoroughly analyse the precise form and content of the reports. For this, Williams' concept of flow is most useful.

The long-range in Williams' framework pertains to the 'timetable' of a particular broadcasting channel. At this level, the analyst looks at the sequence of programmes offered on any respective day or time (Williams, 2003, pp. 97-100). Medium-range analysis helps to identify how items in a single programme are connected, as in the transition from one newscast item to the next (pp. 101-113). An investigation of the close range shifts the analytical focus to the level of the discourse: what language and vocal tricks do people use on the radio to alternate between items, and create and sustain an interconnection, or flow, across the various topics within a single show? Here, Williams refers to certain cue formulas to connect one item to another, and the use of words to create a sense of instantaneous, or simultaneous, happenings (pp. 113-120). 
This sense of events happening as they appear on radio is generally false, for much of what we hear on the air has been recorded prior to the moment of broadcasting. This paradox is discussed more elaborately by radio scholar Andrew Crisell in Liveness and Recording in the Media (2012). Crisell explains how words can communicate a sense of actuality, even urgency. This is in fact a strategy that radio producers and hosts use to bind the listener to the broadcast. In that way, Williams also argues, they retain the attention of their audience, even if the item or information provided is not directly relevant to listeners or when they are engaged in other activities. Media scholar John Ellis argues that the latter, in practice, is often the case, and that media users commonly divide their attention between a (television) broadcast and another activity (1982, pp. 112-116; 137-138).

The "distinctive characteristics of radio" and the role of the medium for its users and producers are discussed by Crisell in his Understanding Radio (1994, p. xv). Like Ellis, Crisell concludes that radio ultimately serves two main ends: it is a source of information and, in a more subordinate role, an accompaniment during other activities (2012, p. 14). The integration of radio into people's lives started quite early in radio history (Volek, 1993). Susan Douglas argues similarly in her book Listening In that "radio listening as a craze, and then as a daily pastime, swept through America in the 1920s and '30s" (1999, p.29). In that time period, she concludes, radio "became interwoven with the ritualized routines of everyday life" (pp. 31-32). These studies all highlight the importance of attention as an element that co-constructs the overall listening experiences for listeners. This is of great importance to broadcasters as well, for they seek to attract as many listeners for as long possible.

Radio traffic reports, however, are examples of radio items that are not always relevant to everybody who is tuned in. To understand how they relate to the overall programme, and the ways in which radio hosts and reporters try to capture the attention of the listeners, I apply Williams' analytical framework for studying flow in broadcasting. According to media scholar Jostein Gripsrud, Williams himself was convinced that his study of flow in television broadcasting could also be applied to a study of radio (2002, p. 212). To this end, I will investigate in detail the form and content of the transcribed traffic reports.

Form, as employed in this chapter, is informed by Williams' medium-range analysis of broadcasts. It refers to the ways in which traffic reports are embedded in the overall radio programming, and the style of presentation of radio host(s) and traffic reporters. Regarding the study of the form of such reports, I explore the following questions at the medium range: how is the traffic report embedded in the overall radio programme? What is the role of sounders, jingles, and other aural elements in the programme? How can we describe the type of interaction between the radio host and the traffic reporter? The changing content of traffic reporting involves the informative substance of the announcements, as well as the narrative strategies that can be identified in the transcribed historical and contemporary recordings of traffic jam updates. This resembles Williams' close-range study of flow. My study of the reports' content was guided by the following questions: how is the character of a traffic jam defined (e.g. in jam length or in delay time)? Does the reporter present a jam's causes or consequences and possible alternative routes? Do the reporters or radio hosts communicate their own take on the traffic news? These questions informed the codes I developed in ATLASti to analyse the transcribed recordings. 
Through analysing the content and form of the reports, including the way in which traffic reports were embedded in the overall radio programme, it becomes possible to comprehend the role of traffic reports from the broadcasters' point of view, and the way in which reporters and radio hosts aim to create a sense of flow throughout their on-air performances. Following Williams' theories, then, it is possible to study radio traffic reporting practices to investigate how information about the world beyond the horizon has been brought to the attention of drivers in such a way that they not only adapt their travel plans but also stay tuned to the radio. The empirical core of this chapter is therefore constituted by the historical radio traffic reports I collected and transcribed, and the considerations of reporters and radio hosts regarding their own professions. Because I studied only recorded radio shows that included traffic reports, Williams' long-range focus in the study of flow—which merely confirms that traffic reports are broadcast—will not feature in the analysis.

Based on the medium and short-range investigation of flow within the conceptual framework of mobile privatisation, and the reflection on the changes in traffic reporting in light of developments in broadcasting technologies, I claim that there is a relationship between the emergence and changes in everyday traffic reporting practices and the efforts of public authorities to reduce the rising pressure of traffic congestions. This comes to expression in two, seemingly contradictory, dynamics. The form of traffic reports, including their embedding and presentational style, changed from rather formal and clearly segmented announcements in the early days to more informal and interactive reporting formats in later years. This dynamic is most clearly identifiable in Dutch and German traffic reports. The content of traffic reports shifted in similar ways across all three countries, from local and culturally informed information to standardised summaries of traffic data. Those standardised reports in later decades aimed at facilitating drivers' effective appropriation of the most recent traffic news, thereby exerting a controlling influence on traffic flows as the number of automobiles on the road increased. As these shifts evolved, it became even more important for the traffic reporters and radio hosts to retain their audience's attention both in and beyond the car.

\section{Weather Alerts and Other Dangers in Early Broadcasts for Motorists}

In the previous chapter, I discussed the development of various technologies for gathering and broadcasting information about problems in traffic. The first European broadcasts for motorists, however, were not about ongoing traffic jams. Instead, they focussed on potential dangers on the road-most notably the weather. Like many countries, Germany and the Netherlands may see quite capricious weather conditions, especially in autumn and winter. These conditions can have a big impact on the safety of drivers on the road. Slippery, icy or broken road surfaces, or dangerous conditions due to fog or heavy rain, may hinder motorists or cause accidents, and were recurring items on the radio. An article in the magazine for ADAC members, Motorwelt, by an employee of the weather service provider in Munich, discussed these messages of the Straßenwetterdienst (road weather service). Together with the Straßenzustandsmeldungen (road condition messages), which were radio reports on the location of construction sites and other obstructions, the weather reports for motorists were 


\section{Chapter 3}

seen as a valuable "service in the interest of road safety" (Schneider, 1952, p. 15). This explanation of the importance of broadcasts for motorists strongly resembles discussions of policymakers and authorities in the realm of automobility, as we have seen in chapter two, that also underlined the significance of traffic safety.

Especially in the Netherlands, the early broadcasts for motorists devoted much time to changing weather conditions in local areas of the country. These were stipulated elaborately at the end of the national newscast, or delivered on the radio as a special item for drivers. The following fragment, broadcast on Saturday November 27, 1965, well exemplifies this level of attention and detail for local conditions on national radio:

Host: 'Risk of slippery roads.'

Hostess: 'The KNAC-ANWB road information service announced the following. With the exception of southern Limburg and the uppermost northern [parts of the] provinces of Groningen and Friesland, road traffic throughout the country encounters difficulties due to slippery roads. Especially in the coastal regions extreme caution should be exercised, for clinker brick roads, entries and exits, and overpasses (...) might locally become very slippery. Road users in the Achterhoek should be particularly attentive as well.'

* Sound of a doorbell. ${ }^{57}$

In this passage, we see how the KNAC-ANWB, a collaboration between the two motorist associations in the Netherlands at the time, explicitly warns drivers to "exercise extreme caution." Words like 'danger', 'warning', 'caution', 'care(fullness)' and 'attention' are relatively common in these early years of Dutch broadcasts for motorists. The emphasis on the safety of drivers, and of other individuals on or next to the road, was a prominent element in these reports. Motorists were alerted, for example, about unexpected events like sudden sidewinds or the possibility of deep puddles due to broken frozen surfaces. ${ }^{58}$

Another example of this kind of early, cautionary traffic reporting on Dutch radio in the 1960s, is the lengthy announcement on Saint Nicolas' eve, 1962. This is the evening of the Saint Nicolas (Sinterklaas) celebrations: a traditional holiday that involves gift-giving and eating particular sweets, such as gingerbread-like pepernoten and speculaas. That evening the influence of the ghastly weather on local traffic was the most prominent feature at the start of the evening radio program 'Radiokrant' ('Radio newspaper'). For as long as six minutes the hosts paid attention to twelve traffic-related miseries caused by incidents earlier that day. The radio hosts were also in contact with local police forces and providers of public transport, who reported their latest updates live on the air. Together, the hosts and informants of the different authorities informed listeners thoroughly about the situation on the roads and the operation of public transport services in different parts of the country. ${ }^{59}$

\footnotetext{
${ }^{57}$ Beeld en Geluid Archives. Recording source ID 652351. "Radiokrant," 27 November 1965. The sounds that mark the separation of a programme item are called 'sounders'. I discuss their role in more detail elsewhere in this chapter.

${ }^{58}$ Beeld en Geluid Archives. Recording source ID 652346. "Radiokrant," 29 November 1965.

${ }^{59}$ The geographical focus of many of these reports, however, is on the densely populated areas in the west of the Netherlands.
} 
Special time was also allotted to a traffic reporter of the motorist association KNAC. His report starts with the following two sentences:

'Good evening listeners. Unfortunately I come to spoil your 'Sinterklaas' evening for a few hours, but you should not blame me, because it is all about your own safety. Because in a large part of our country the fog is extremely dense and many roads in foggy areas are slippery, I must urgently advise all those who live in these areas to stay put, unless you have a pressing reason to be on the road. I now provide you with an update on the situation as we took stock of it about fifteen minutes ago. ${ }^{60}$

After almost two and a half minutes of detailed descriptions of local weather conditions, the KNAC reporter ends his monologue by saying:

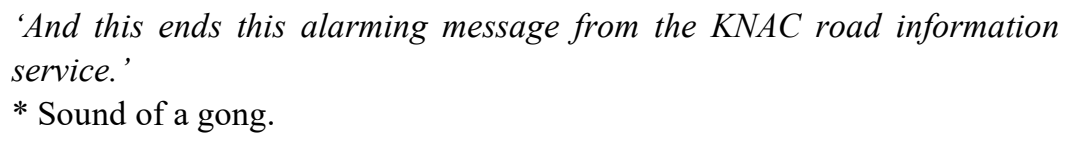

These excerpts indicate how the radio hosts and traffic reporters combined information about particular local areas, meteorological situations and personal and culturally rooted stories and events, with explicit concerns about the safety of drivers on the road. They also illustrate the lengthy, cautionary reporting style in the Netherlands. Imbuing the reports with details and speaking to motorists directly as if they were standing or sitting next to the drivers, the broadcasts for motorists served a specific function: they accompany and help drivers to arrive at their destination safely. It is a mode of representation that resembles the frog perspective as distinguished in the study of photography and art (see Vogel, 1875, p. 326). In the traffic reports, the reporters adopt the drivers' frog perspective: a position close to the ground, looking upwards to the scene in front of the viewer and reporting on what is to be seen ahead. The importance of this perspective, and the shift of the reporters' perspective after the 1970s, will be discussed below.

The concern with driver safety is articulated in other radio items as well. The earliest example of an on-air discussion about motorised traffic in the German SWR archive after 1950 is the episode on traffic problems (Verkehrsprobleme) broadcast on July 15, 1952. ${ }^{61}$ In this episode, a traffic expert and the radio host respond to the letter of a listener about traffic education (Verkehrserziehung), and the issue of how to inform everyone - motorists as well as, for example, cyclists and pedestrians - about the new traffic rules coming into effect at the time. Other topics discussed in those early broadcasts about automobility, rather than for drivers, are the development of the new motorways, ${ }^{62}$ the increasing traffic density, ${ }^{63}$ and the possible overstraining of drivers' attention whilst on the road. ${ }^{64}$

\footnotetext{
${ }^{60}$ Beeld en Geluid Archives. Recording source ID 653864. "Radiokrant," 5 December 1962.

${ }^{61}$ SWR Archives. Archivnummer W0097370. "Verkehrsprobleme," 15 July 1952.

${ }^{62}$ SWR Archives. Archivnummer W0114409. "Autobahn - in diesem Augenblick," 3 March 1959.

${ }^{63}$ SWR Archives. Archivnummer W0549789. "Der Verkehr - Heute und Morgen," 13 January 1961.

${ }^{64}$ SWR Archives. Archivnummer W0549788. “Ist der Verkehrsteilnehmer überfordert?," 20 January 1961.
} 
As automobility became more common, radio stations in southern Germany allocated time to discuss traffic beyond the socio-technical, economic and didactic problems associated with the rise of private automobile ownership. German informants of traffic information (a combined effort of the police, the motorists' association ADAC, and the road authority) started to broadcast information on local conditions that could affect traffic in the different regions that were part of the station's reception area. In so doing, they also talked to drivers. An example from such broadcast for motorists on the SWF is the following fragment from April 26, 1967:

Hostess: 'We ask your attention for two announcements by the traffic police.

On Tuesday April 25 between eight and seventeen o'clock [there will be] repair work in the right lane on the federal highway Karlsruhe-Mannheim between the junctions Bruchsal and Kirrlach-Kronau. During this period, northbound traffic will use the [left] fast lane. Traffic congestion is expected.'

* short moment of silence

'And federal highway 9 will be closed for traffic between Sinzig and Cologne from eight-fifteen until nineteen o'clock tomorrow, on the occasion of the burial of the late former chancellor Konrad Adenauer. The diversion starts at Sinzig via Bad Neunenahr, Gilsdorf and Anskirchen to Cologne. We recommend long-distance traffic from Rheinland-Pfalz in the direction of Cologne to reroute from Koblenz or Neuwied to the Frankfurt to Cologne highway.'

* Hostess continues with programme. ${ }^{65}$

This announcement for motorists is comparable to the KNAC-ANWB information service announcement of November 27, 1965, referred to above. The announcement on behalf of the German traffic police was read in a similar calm and formal tone. In terms of its content the German report is somewhat more neutral — it contains no explicit words of warning — but was equally aimed to inform motorists about foreseeable disturbances of local traffic flows.

In the 1970s, traffic news became an integral part of the official newscasts in Germany as well as the Netherlands. An exemplary, regular report on Dutch radio that was part of the news is the following excerpt:

* Countdown to 8.30 AM news

Newsreader: 'It is eight-thirty. Radio news service provided by the ANP.'

[Newsreader continues with the news]

Newsreader: 'The weather' [continues with weather report]

Newsreader: 'And now traffic information. On the following motorways there are jams. A16 Breda towards Rotterdam there are four kilometres [of jams] in front of the Van Brienenoord-bridge. A2 The Hague towards

\footnotetext{
${ }^{65}$ SWR Archives. Archivnummer W0557517. “Verkehrsmeldungen; An- und Absagen U-Musik-Sendungen,” 26
} April 1967. 
Utrecht in front of the Lek-bridge, three kilometres. A8 Zaanstad towards Amsterdam in front of the Coen-tunnel, six kilometres. The congestions on the A15 Gorinchem towards Ridderkerk and the A29 Hellegatsplein towards Rotterdam have almost cleared. Fog banks with a view of 100 to 200 meters occur locally in the provinces of Utrecht and South Holland, in the Gooi region and in the Betuwe region. The fog may persist for several hours. This was the news.'

* Sounder indicating the upcoming commercial break. ${ }^{66}$

For comparison, the next item is from the German station SWF. This example comes from the afternoon show on September 5, 1972-the first day of the massacre that took place during the Summer Olympics in Munich that year. While this was certainly not an ordinary day in German (radio) history, the presentation of the radio traffic reports followed the regular proceedings, while also showing that traffic reports basically had the same format on German and Dutch radio in that period:

* Sounder.

Voice-over: 'Südwestfunk News.'

Newsreader: reads the news.

* Short moment of silence.

Newsreader: 'The weather.' [continues with weather report]

Newsreader: 'Traffic information. On the federal motorway Frankfurt towards Cologne a traffic jam has formed of approximately three kilometres after an accident between Raunheim and the intersection at Wiesbaden. We cannot recommend any alternative route. This was the news. [It is] Three past five.'

* Start of song. ${ }^{67}$

The rigid format and neutral tone of these reports are characteristic of traffic reporting from this period. At the same time, the reports' content accompanied the driver on the road, warning the motorist for what was upcoming. In terms of their form and content, German and Dutch reporting practices were thus quite similar in these years. As they were part of the newscast, they did not contribute much to the liveliness of the radio show. Yet the fact that Dutch and German traffic reports were included in the newscast indicates the importance broadcasters ascribed to these regular updates.

Not all German broadcasts for motorists in the late 1960s were neutrally read out by the radio host or newsreader, however. On days that were notoriously busy on the roadwhich was often the case during holidays - some radio stations would allocate special attention to traffic. On Friday March 23, 1967, the start of the Easter holiday weekend, the SDR provided such extensive traffic reports. They dispatched multiple reporters to different

\footnotetext{
${ }^{66}$ Beeld en Geluid Archives. Recording source ID 581479. “Integrale opname Hilversum 1, week 50 1977," 13 December 1977.

${ }^{67}$ SWR Archives. Archivnummer W0664570."Münchner Überfall (Olympische Sommerspiele 1972)," 5 September 1972.
} 
locations to broadcast live reports, using mobile broadcasting technologies. For the radio host, moderating such special traffic information item was very challenging. In the case of the following example, the host managed to handle a live connection involving as many as five different locations. First, there was a connection between the studio and a radio reporter at the Police Traffic Centre of the Nord-Baden region in Karlsruhe-Durlach, who interviewed a police officer about the ongoing traffic situation in his area. Another SDR reporter transmitted live from a roadside restaurant near Mannheim-Seggenheim. A third radio reporter was stationed with mobile radio equipment next to the motorway near the city of Bruchsal. Another reporter was sitting in a helicopter and reviewed traffic flows from the air in the village of Walldorf, near Heidelberg. Finally, there was a live connection between the studio and a reporter who interviewed the principal of the road authority (Autobahnmeisterei) in Karlsruhe. Similar to traffic reporting in the Netherlands at the time, potentially dangerous weather conditions were the starting point of the report:

Host: 'In the early afternoon, drizzle caused accidents on various highway exits, which resulted in most cases in damage to vehicles' exteriors. At the Mannheim-Heidelberg stretch as many as seven accidents occurred in heavy traffic. Two individuals were injured. For more extended reports on Easter traffic on the motorway, we now report via a direct transmission. For this purpose, we move to our headquarters in the Federal Police Traffic Commissariat in Karlsruhe-Durlach. ${ }^{68}$

This introduction was followed by a traffic report lasting more than fifteen minutes, during which the various reporters and invited traffic experts communicated the latest details about the location and the length of traffic jams in their region.

Characteristic for these incidental live, on-site reports on German radio is the extensive personal and reciprocal interaction between the various individuals who contributed on the air. The following excerpt from the same broadcast indicates this reciprocity. The radio host tries to contact the police helicopter which was supposed to report on traffic conditions. Unfortunately, there were some difficulties establishing a stable radio connection:

Host: 'Brusschart' [this is the nickname of the helicopter], please report.' Reporter: [noise, no words]

Host: 'I call again, 'Brusschart', please report?'

Reporter: [noise, but finally some words can be identified. Reporter asks whether he can be heard.]

Host: [addressing the listeners] 'Well, this helicopter is currently heading in the direction of Waldorf. It has an altitude of 50 to 80 meters, and does not quite come through to us. I call the helicopter 'Brusschart' again, please report. You certainly have a good view from the air looking down, but you have a bad [connection]. Please report once again.'

68 SWR Archives. Archivnummer W0104387. “Osterverkehr auf der Autobahn,” 23 March 1967. 
Reporter: [noise. Then the noise clears a bit and a male voice can be heard] 'Can you hear me?'

Host: 'Thank you, this is tolerable. Please try to continue.'

Reporter: 'Yes, we are just over the intersection at Walldorf, and I notice that traffic to the north is much heavier towards [... interrupting noise] than in the southern direction. In the south very fluent traffic at the construction sites, and here in the northern direction [it is] stagnating. That is because traffic in today's [... interrupting noise] right at the entrances of Waldorf [noise ... then loses connection].'

Host: 'Thank you for the message from the helicopter. The helicopter will continue to fly for another half an hour and will then return to the headquarters. ... And now we will move away from the police in the control room for a moment, and take up another issue. Colleague, Mr Nibbel, may I ask you [to continue]? 69

One of the interesting features we can identify in this excerpt is that each informant is addressed by their (last) name, which makes the interaction personal, despite the overall formal tone. As a listener one feels transported along with the radio host and the various reporters (a feature I discuss below in more detail regarding New York traffic reports). Moreover, even though the language used by the men is somewhat formal, it is clearly not scripted: the reporters do not read aloud from written notes. The form and content-both the way the information was presented, and the details presented in the report—of such live reports was thus considerably more dynamic than a regular radio traffic report that was aired on a day with less exceptional traffic.

A final observation with respect to the first radio traffic reports in the Netherlands and Germany relates to the use of aural markers, such as 'sounders', 'beds', and caesuras or silences. 'Sounders' are short musical pieces that contain information about the programme one is listening to; their function is like that of a brand logo, to enable quick identification of the radio station or programme. 'Beds' are also musical compositions, but their function is mainly to accompany people's speech. Nowadays, radio stations often choose to allocate a bed to a specific part of the programme. The transcripts of radio broadcasts presented so far include various types of aural markers that indicated changes in the radio programme. The sharpest caesura in this respect is, perhaps paradoxically, a moment of silence. A silence indicates a static move from one radio item to the next. Other examples from the excerpts above are the use of a gong and, in the late 1970s, the first use of a sounder that indicated the change towards the next item of the radio show.

Over time, these beds and sounders became more prominent parts of radio broadcasts, while the more rigid silences and sounds like that of a gong or bell were less frequently used. In the context of radio traffic reports this can be identified most clearly in the course of the 1980s, when radio stations frequently played beds to mark the start of the traffic update, or had it run throughout the entire traffic report. This is not without reason. According to Dutch radio host Jurgen van den Berg, these beds or short pieces of energetic

${ }^{69}$ SWR Archives. Archivnummer W0104387. “Osterverkehr auf der Autobahn,” 23 March 1967. 
sound function as the "cement that binds the programme together" (Van den Berg on Radio 1, September 26, 2018; expert meeting, September 28, 2018). Similarly, a producer of the Radio 1 morning show claimed that a station's sounders and jingles significantly contribute to the station's profiling (interview Van Raaij, June 22, 2017). These aural elements assist broadcasters in their effort to create a flow from one item to the next, which - they hoperesults in gaining and retaining the attention of their listeners by livening up the broadcast, and improving the listeners' experience. This also became increasingly important as the media landscape changed in the course of the second half of the twentieth century, when many new radio stations began broadcasting. In this context, sounders and beds helped broadcasters to create their own character and distinguish themselves from their competitors.

\section{Scaling Up While Sizing Down}

By the time broadcasters enthusiastically used sounders and jingles as part of their shows in the 1980s, radio traffic reports had gained a strong foothold in specific radio programmes. This development was propelled by the ongoing rise of traffic accidents and mortalities in the decades before and the continuously growing number of traffic jams. Because more and more commuters also covered longer distances in their car, the form and content of traffic reports were gradually adapted. In this section, I will show that these changes express the shifting function of traffic news. The paternalistic and localised messages of the $1960 \mathrm{~s}$, in which the reporter was almost accompanying drivers personally and warning them about possible dangers up ahead, became more standardised and geared towards more centralised forms of traffic management.

The degree to which traffic reports reflected a 'real-time' overview of traffic flows depended in part on the systems that were in place to gather and transmit traffic information. As explained in chapter two, during the 1970s and 1980s the number of available information sources increased with the introduction of automated, and later digital, information and communication technologies. This did not result in more extensive traffic reports, however. On the contrary, the opposite happened. Whereas reporters had more traffic information at their disposal, the allotted time for traffic reports on the air became more and more restricted. This development can be identified especially in the Netherlands and Germany.

The limitation of airtime affected the way in which traffic news was presented. Formally, the presentation of traffic news reveals a fairly steady move away from traffic reports' separation from overall radio programming. The silent caesuras and gong vanished, and the mode of presentation shifted towards more seamless and informal interaction between the radio show host and the traffic reporter, which created a more smoothly integrated radio show, meant to be more captivating as well. The reports' content, as noted above, increasingly became standardised. One alteration in traffic reports' content that demonstrates the shift towards standardised reporting practices involves the way reporters referred to specific road sections. In traffic updates from the 1960s and early 1970s, there were few references to roads by means of their letter-number combination. Reporters could technically do this, because the basic road network connecting the Netherlands, Germany and other countries in Europe was put in place by the first half of the twentieth century already (see 
Mom and Filarski, 2008, p. 251). Yet despite the international agreements on these road codes, traffic reporters often mentioned the entire trajectory of a certain motorway.

For example, motorway A12 in the Netherlands was for some years referred to as "motorway The Hague - Rotterdam - Utrecht - Arnhem."70 This stretch covers the 120 kilometres from the west coast of the country to the German border in the east. No traffic jam has ever been this long, so the reporter specified the exact location of the bottleneck: "dense traffic in both lanes of the section Waddinxveen - Woerden over a distance of five kilometres." Similarly in Southern Germany, even though road numbers were occasionally used to indicate the smaller ('B') roads, the main motorways were indicated on the basis of the travellers' trajectory or the most nearby city, as in the following example, where the newsreader explains to the listener that "on the motorway [near] Frankfurt between Frankfurt-West and Bad Homburg towards Kassel [there is] a jam with a length of two kilometres due to a restricted lane."71

The practice of reading out entire stretches of motorways changed in the second half of the 1970s, however. To provide the most precise information in the quickest way possible, a more concise strategy for reporting on a jam was developed that relied heavily on the standardised letter-number combinations. The following excerpt from 1982 is a simple example of such highly standardised content in a Dutch traffic report:

Newsreader [after having read the news and weather forecast]: 'Now follows traffic information. Jams on the following roads. A8 Zaanstad towards Amsterdam in front of the Coen-tunnel four kilometres, and on the A12 Utrecht towards The Hague there is a jam between Zoetermeer and Voorburg of five kilometres. This was the news. ${ }^{72}$

This excerpt also shows a modification in Dutch traffic reports that became more common in the 1970s, namely the separation of weather and traffic news. The traffic report became just that: an item that no longer provided information about local conditions, but prioritised information about disturbed traffic flows on the main Dutch motorways.

The two main stations serving Germany's southwest region, the SDR and the SWF, developed slightly different presentation practices. Traffic reporters on SDR 1, a station transmitting the ARI signal and serving the most southern regions close to the Alps, continued to devote quite some time to local weather conditions. This is reflected in the following example from the 1980s:

* Short silence after the news and weather forecast was read by the radio hostess.

Hostess: 'And now on to the traffic overview.'

* Sound of the Hinz-Triller indicating start of the traffic report

\footnotetext{
${ }^{70}$ Beeld en Geluid Archives. Recording source ID 692678. "VPRO-Vrijdag," 5 November 1971.

${ }^{71}$ SWR Archives. Archivnummer W0664570. "Nachrichten / Verkehrsmeldungen / Reisewetter," 5 September 1972.

72 Beeld en Geluid Archives. Recording source ID 578524. “Integrale Opname Hilversum 1 week 50 1982," 14 December 1982.
} 
Hostess: 'Six minutes past seven o'clock, Südfunk Stuttgart, and this is the traffic overview, as communicated to us by the police: On the B35 Germersheim towards Buchheim considerable delays because of a military column. On the A5 Karlsruhe towards Frankfurt between KarlsruheDurlach and Bruchsal after an accident, one to two kilometres dissolving traffic with standstills. And the State traffic warning service reports the following on the road conditions in Baden-Württemberg: fresh snow in the high-lying areas of the Black Forest, locally mixed with sludge, snow, or slippery frost or ice. There is some traffic hindrance. The state motorways are currently free of snow and ice.' [Continues with more detailed weather information for motorists]

* Sound of the Hinz-Triller indicating end of the report. ${ }^{73}$

This more elaborate information for motorists on SDR 1 differs from the traffic report on its neighbouring station, SWF 1. The reports on SWF resemble more closely the format common in the Netherlands at the time. The following fragment illustrates how the emphasis shifted towards attention for traffic jams on the main motorways:

Host: 'SWF 1 with the hourly traffic overview for the motorways of Rheinland-Pfalz and Baden-Württemberg. A81 Stuttgart towards Singen between Geislingen and Engen [an] accident, delays. A81 Stuttgart towards Heilbronn between intersection Stuttgart and Stuttgart-Feuerbach, accident, two kilometres jam.'

* Sounder indicating the end of the newscast and introducing the weather update next. ${ }^{74}$

Although SDR 1 continued to report in a more lengthy and cautionary manner on weather forecasts than SWF 1 or Dutch Radio 1 at the time-which illustrates that stations could tailor their traffic reports to their own priorities and ideas about their listeners' needsthe three examples above have one new feature in common: they all convey a shift towards less detailed and descriptive, and more standardised messages. Along with this change in the content of the reports, the focus of the reports moved away from the frog's perspectiveaccompanying the driver - to a bird's eye perspective: a perspective from above, overseeing or covering a wider geographical area. This was the second content-related change in traffic reporting on Dutch and German radio. Owing to the increased availability of traffic data, the reporting moved away from specifying very local conditions and towards providing more abstract, generic information which addressed clustered regional areas or even focussed on the national traffic situation. The traffic reporter's perspective thus resembled more and more that of a bird high up in the sky, overlooking traffic from a distance. This mode of monitoring traffic flows implied a more general and abstract approach, rather than that reporters were able to tell what, exactly, was happening on any specific road.

\footnotetext{
${ }^{73}$ SWR Archives. Archivnummer W0624648. "Morgentelegramm Radio Stuttgart 7.00 Uhr, Nachrichten, Wetter, Verkehr," 14 January 1985.

${ }^{74}$ SWR Archives. Archivnummer W0653690. “Nachrichten - Wetter - Verkehr,” 5 November 1985.
} 
This transition towards more standardised reporting in terms of the reports' content and the shifting perspective of the traffic reporter in the late 1970s and 1980s was accompanied by a change in the reports' embedding. As more people were caught up in traffic and traffic reports became a familiar item on the radio, traffic experts with a name and style of their own began to appear on live radio to inform motorists of the latest events on the roads. Through their more informal interaction with the radio hosts, many of these reporters became a household name on the air indeed. For example, in the Netherlands, where all traffic reports were broadcast from the police traffic information centre in the town of Driebergen, the name of the reporters and the village of Driebergen became synonyms for, and implied the authority of, the latest traffic information. For radio hosts, this provided new strategies to introduce the upcoming traffic report and integrate it into their programme. An example from the Netherlands that illustrates the search for flow between various items is the following excerpt from Tuesday December 8, 1987:

Host: 'We are not just going to Washington on this memorable December 8. There is also something going on in Driebergen, Theo Gerritsen!'

Reporter: 'And that concerns one traffic jam. On the A10 Amsterdam towards Zaandam there is a jam in front of the Coentunnel with a length of 3 kilometres.'

Host: 'Well this is not too bad, this morning the number of jams amounted to a total of 151 kilometres. Now on to Meteoconsult in Wageningen! On to John Bernhard. John, go ahead. ${ }^{75}$

This short interaction took place right after the 4 p.m. news. The radio host gleefully refers to the recent news of the signing of the Intermediate-Range Nuclear Forces Treaty by Ronald Reagan and Michael Gorbachev in Washington, which is used as a bridge to the headquarters of the Dutch traffic police in Driebergen where Mr Gerritsen is ready to read the next traffic update. This is an example of creating flow amongst at least four different topics: the headline news, the newest traffic update, the heavy congestion on the Dutch roads earlier that day, and the subsequent weather forecast. Because of this flow, listeners are informed and mentally transported to very different places in just a matter of seconds. Moreover, this kind of embedding contributes to a sense of urgency. The listeners become part of things that are going on right now. As explained, this sense of 'liveness' adds to the perceived importance and usefulness of this radio programming item.

Another way to stress the 'live' character of the reports and create an additional sense of flow could be realised through prior contact between the radio host (or the technical producer) and the traffic reporter right before coming on the air. Knowing one detail of the traffic report enables the host to create a smooth or playful transition, as in this traffic report on Dutch Radio 1 on Monday morning, 13 December 1993:

\footnotetext{
${ }^{75}$ Beeld en Geluid Archives. Recording source ID 577853. “Integrale opname Hilversum 1, week 50 1987," dd. 8 December 1987. For an image of the alarm center of the Dutch Police Traffic Centre in Driebergen, see illusration 3.2.
} 
Host: 'It is now three minutes past eight-thirty. There is a total of two hundred kilometres of jammed traffic.'

* Traffic information sounder.

Host: 'Klaas Hofman' [name of the traffic reporter]

Reporter: 'Distributed across a total of thirty-one jams, Govert. It is exceptionally busy this morning. Here they come. ${ }^{76}$

These kinds of interactive exchanges on the air between traffic reporters and radio hosts helped to increase the interest in and the attention for the upcoming traffic report, having the dual effect of binding the listener to the programme and increasing the responsiveness of listening drivers. Indeed, the changes in the form and content of Dutch and German traffic reports contributed not only to a greater sense of flow on the radio; they were also meant to improve the movement of traffic. Initially, the reports were mostly geared towards motorists' awareness of dangerous traffic conditions. Later, the meaning of radio traffic reports shifted and they became a means for impersonal traffic control, monitoring abstract traffic flows from a bird's eye perspective and influencing traffic flows through easy to apprehend information with implicit and explicit travel suggestions.

A final transformation in traffic reporting strategies, which precisely captures this tension between the rising quantity of congestions and the limited amount of airtime reporters have, pertained to the greater emphasis in radio traffic news on extraordinary traffic problems. Whereas the reporter in the above example from 1993 listed all thirty-one jams, this format changed in 1998, when the reports were no longer presented by the Dutch traffic police in Driebergen but by the traffic information centre, a coordinative effort of the highway authority and the motorist association ANWB in The Hague. This organisational change was accompanied by a new reporting format. As explained by the manager of the ANWB traffic information centre, Arnoud Broekhuis, radio traffic news started prioritising traffic problems that did not occur on a daily basis, such as jams which were exceptionally long or problems caused by a remarkable event (interview Broekhuis, November 2, 2018). This prioritisation of irregular traffic problems helped to shorten the radio reports, and it implicitly signalled to drivers that they could also expect delays on stretches where jams or slow traffic occur on a daily basis.

In the effort to create more flow in traffic reporting, Dutch and German traffic news increasingly began to resemble the embedding of traffic reports that had been common practice on several New York radio stations for a long time already. As I will show next, the particularities of New York traffic reports can be explained well when analysing these reports in the context of their local and temporal socio-technical context, and when comparing this context to that of the Dutch and German traffic news reports.

\section{Persisting Presentation Practices in the New York Area}

Compared to the rigid and formalised template of Dutch and German traffic reports in the 1960s and 1970s, the embedding and presentation of traffic reports was considerably

\footnotetext{
${ }^{76}$ Beeld en Geluid Archives. Recording source ID 675248. “Integrale opname Hilversum 1, week 50 1993,” dd. 13 December 1993.
} 
different in the New York metropolitan area in those years. In the previous chapter I explained how commercial radio stations in New York, and in the United States more generally, relied on their own reporters to monitor traffic flows. For decades, they did so primarily from helicopters or airplanes. As a result of this greater physical mobility of the reporters, their updates involved more interactive exchanges between the radio host and reporter. The following quote from the morning after Halloween, 1 November 1978, on the radio station WCBS880 illustrates this liveliness:

Host: 'It's eleven minutes to seven o'clock on Wednesday morning, and good
morning Neal Busch, trick or treating in the traffic watch helicopter, put
down your candy bars.'
Reporter: 'Great, good morning Jim and Lou, and I certainly hope
everybody's car made it through last night without too much of a problem.
Good luck to you. And as you're driving in this morning very very good
conditions as you're coming inbound. As a matter of fact the Long Island
Expressway approaching the Midtown tunnel, look at the Midtown area,
look at that new Citicorp building some sort of futuristic gantry for a rocket
launch pad, that silvery orange building. And by the way, I am at upper
Brooklyn-Queens expressway we're all cleared up southbound. Remember
yesterday morning we had a tie-up there all rush hour long. We're ok now.
Emptying into Brooklyn from Queens. We have the full report right before
seven.'
* End of recording. ${ }^{77}$

This fragment demonstrates the fluent, chit-chatty introduction of the incoming traffic report by the radio host, the reporting coming live from the station's aerial traffic reporter, Neal Busch. Having quite a presence, Busch worked for WCBS880 in this job for over three decades, from 1967 to 1999 . Unlike many other aerial reporters before and after him, he controlled his own helicopter while reporting on the air. In practice, this meant that he operated the helicopter and communicated with the air traffic control tower, while at the same time looking out for traffic problems, listening to the police scanner for any police intelligence, and reporting at very regular intervals on the latest traffic developments throughout the day (see illustration 4.1 for an information leaflet of WCBS880's morning programme in the late 1970s).

Because of the more interactive embedding of the traffic reports, and the speed at which the traffic reporter was moving - physically, between his sources, and his live on-air performances - the form and content of the aerial traffic reports in New York strongly differed from the neatly compiled traffic reports on Dutch and German radio at the time. Whereas Dutch and German traffic reports were mostly read from an office desk, the quick, ad-hoc and very localised aerial traffic reports in New York were much less scripted; the radio host and the traffic reporter, it seemed, constantly improvised the way in which they

\footnotetext{
77 Personal archive of Wayne Cabot. WCBS880, "AM Drive," November 1, 1978. This fragment can also be listened to on http://www.nyradionews.com/wcbs/media/Martin\%20Hardee\%20-\%20WCBS\%20\%20John\%20Wheeling.mp3 (accessed August 30, 2018).
} 
introduced and concluded the traffic report. Focussing on the reports' form-following the analytical framework of Raymond Williams - it becomes clear that this had implications for the medium-range flow of the traffic reports. Because the traffic reports were part of the ongoing radio programme, rather than a separate item, the radio host played an important role in actively embedding the traffic report into the radio show. This was also demonstrated in the previous example: the host's personal introduction and reference to last night's Halloween celebrations ensures a fluent transition between the studio and the traffic reporter, thereby creating a flow between himself and the reporter who is ready to be on the air.

It is possible to identify dissimilarities between the American and European radio traffic updates at the level of their content as well. Unlike the reports read out on Dutch and German radio in the 1960s and 1970s, New York's aerial traffic reporters primarily referred to what they could see (immediately prior to) the moment they were on the air. Phrases such as "I see," "looking at" and "I am currently at," constituted the core of any New York aerial traffic report. When zooming in on those reports for a close-range analysis of flow, it becomes clear how the host and reporter accentuate the liveness and actuality of the latest traffic update. It is almost as if the listener is sitting in the helicopter with the reporter, circling over Manhattan and the neighbouring boroughs and looking down at the perpetually fluctuating traffic flows below. At that moment, the audience can have an instantaneous experience of momentary traffic, but, as the reporter in the excerpt above is keen to remind us, the next report will follow in merely a couple of minutes. This is yet another way, of course, in which the reporter creates a sense of flow and binds the listener to the radio: even if you are not going to drive yourself, you are teased with the next 'full' report, to which you might also want to listen. Even today, this strategy for creating flow is hardly deployed to the same extent on Dutch and German radio.

Despite the various differences in form and content, the traffic reports in my three case studies have one element in common throughout the period from the early 1960 s to the late 1970s: they all provide information on fairly local traffic conditions. In this sense, their content is remarkably similar, sharing a focus on informing drivers within their frog perspective on local circumstances ahead.

The introduction of Shadow Traffic in the New York traffic information market in 1979, and the subsequent changes in the local socio-technical system for gathering and processing traffic information, led to a number of changes in the form and content of New York traffic reports. In many ways, Shadow's daily operation from a more centralised traffic information centre resembled the everyday work practices of Dutch and German traffic reporters. Moreover, by the 1980s new information and communication technologies offered traffic reporters new possibilities for gathering and processing their information. While the practice of reporting live from a helicopter continues to this day, reporters began to supplement the information from the helicopter and airplanes with various other sources, like CCTV cameras and induction loops, and routine phone calls to police stations and local spotters. The physical shift of the traffic reporter's locations, from a helicopter or car into a studio, affected the form and content of New York traffic news. The form of studio-read traffic reports in New York in fact became more similar to the reporting practices in the Netherlands and Germany. Also, the reports' content became more alike across these 
different countries, as New York traffic reporters began to operate from a traffic information centre.

The increase of similarities can be illustrated by the following example from New York station WABC, 1987:

Host: 'And Pete Tauriello is covering Shadow Traffic. We kind of have a problem on Route 3.'

Reporter with sounder in the background: 'That's right. Route 3 westbound is now closed at Main Avenue and Clifton by a jack-knifed tractor-trailer. Eastbound near ... for a mile and a half. And in Edison New Jersey, southbound on Route 1 an overturned tractor-trailer with tanker leaving only one lane open south of two-eighty-seven. This has not been a good morning for the most part. We have just one problem after another. Inbound Lincoln and Holland Tunnel delays are running at ten minutes delays. GWB is under the five-minute mark, and the alternate side parking is in effect and we still have fifteen minutes delays at the Lexington Avenue line. Scattered delays on the L-trains between Manhattan and Brooklyn.'

Host: 'It has been a tough morning for some people.'

Reporter: 'It sure has.'

Host: [comments on the insufficient subway connections to the City] 'It is nine thirty-eight, WABC. ${ }^{\text {"7 }}$

This quote captures two dynamics in a single traffic report. First, the noise of the helicopter in the background has been replaced with a special 'bed' to accompany the traffic reporters' talk. This formal change results in a sense of rhythm and liveliness in the way the update is presented. Moreover, in terms of the report's embedding, the dialogue between the radio host and traffic reporter helps to integrate the report. Through the phrase "we kind of have a problem," the show host even makes the upcoming traffic a concern to all of the station's listeners. This sense of drama and urgency is reinforced by the reply of the traffic reporter, who responds positively to the radio hosts' introduction, and even extends it by stating "this has not been a good morning for the most part. We have just one problem after another." Second, this example reveals how the content of traffic reports from the Shadow Traffic studio differs from aerial reports from a helicopter. The geographical area covered by the reporter has been broadened, while in this particular instance he also included some transit information for the listening commuters who use the trains and subways to get into New York City.

Listening closely to New York traffic reports broadcast from a studio, then, a similar shift in the reporters' perspective can be observed as the one I identified in the Dutch and German recordings. Along with the use of new information and communication technologies, the literal but limited bird's eye view of New York aerial traffic reporters shifted towards a more generic overview of traffic flows: a more abstracted bird's eye view. This view was mediated by direct and indirect glances on the road through CCTV cameras, incoming phone

\footnotetext{
${ }^{78}$ Personal archive of Wayne Cabot. WABC, show and date unknown, 1987. GWB is an abbreviation used to refer to the George Washington Bridge.
} 
calls, statistics that came in through automated data processing systems, and, in later years, real-time information sources like Google Maps. In contrast to the development in my two European case studies, however, New York traffic reporters continued to explain some details of specific incidents or causes of delays to their listeners. Although their reports covered a broader geographical area, the reporter still created a sense of accompanying drivers on particular selected roads, which illustrates the perseverance in their discourse of helping New York drivers to cope with local traffic problems. In the course of the 1980s, Dutch and German traffic reporters actually began to standardise their reports in order to mention as many congestions as possible in their limited amount of time.

If it is a common practice of New York traffic reporters to provide their listeners with alternative routes, this appears not as common on the selected German radio stations and even less so in the Netherlands in the period between 1970 and 2000. ${ }^{79}$ This longstanding practice in New York can be explained by taking local context and existing socio-technical systems for gathering traffic information into account: by providing listeners with alternative routes across the main rivers or ways to avoid blocked roads of the Manhattan grid-like roadmap, the aerial traffic reporters of the commercial New York radio stations helped their driving listeners in very concrete ways. This was considered a valuable practice in the early days of radio traffic reporting, and it has remained part of their mission to this day. 1010WINS reporter Greg Rice, for example, said that part of his daily business to contribute to local traffic management is directing people away from certain areas (interview Greg Rice, March 15, 2017).

Another difference in traffic reporting practices that relates directly to the setup of the socio-technical system pertains to their financial aspect. Due to the highly privatised system in New York, the radio stations as well as commercial enterprises like Shadow Traffic and its later mergers, had to find ways to generate revenue directly out of their broadcasts. New York traffic reports are therefore sponsored, and the name and advertisement of the sponsor is read out a couple of times every hour prior to or during the traffic report. These sponsorships pay for the traffic reports (interview and studio visit WCBS880, Steve Scott and Mike Wallace, March 5, 2018). This practice is illustrated by the following excerpt, dated September 11, 2001, from a regular traffic report aired approximately one hour before the first airplane crashed into one of the towers of the World Trade Centre:

Host: 'WINS news, time: eight o-one. Traffic and transit on the 1 's sponsored by Boston Market! Here's Pete Tauriello.'

Reporter [starts with sounder, which fades away after a couple of seconds]: 'Well as we expected we got delays on the Major Deegan again coming in this morning down south out of the 2-30's right on down to Yankee stadium due to the rough road surface. And Mark calling in to the phone for us, says Henri Hudson Parkway is pretty bad too from the Cross County Parkway all the way down to the tolls. That is probably everybody trying to get away

\footnotetext{
${ }^{79}$ Today, Dutch and German traffic reporters more frequently propose alternative routes. In the Netherlands, the ANWB traffic reporters do so only after consultation with the traffic experts of the highway authority Rijkswaterstaat.
} 
from the Major Deegan. Cross Bronx is loaded up pretty much from the Bruckner all the way up to the GWB Jersey-bound upper deck with construction work again underneath the apartment building. City-bound Lincoln tunnel has a 40-minute delay. ... I am Pete Tauriello, Shadow Traffic on 1010WINS.'

* Advertisement voice-over: 'Right now on Boston Market! Try ...' [continued advertisement].

Host: 'WINS news, time: eight o-two ...' [continues with programme]. ${ }^{80}$

In terms of the traffic reports' embedding and flow, it becomes clear that the report is very much connected to the sponsor. The sponsor's name is mentioned prior to the traffic update, which is subsequently followed by a short advertisement. As a result of this practice and the interrelated business model, the overall embedding of the traffic reports is very different from Dutch and German public radio, where traffic reports are not linked to any commercial party and hosts can decide more freely how to integrate updates into their programme.

The excerpt above also illustrates a final important difference between the form and content of traffic reporting in New York when compared to the Netherlands or Germany. On the Dutch and German radio stations featured in this study, traffic reports were broadcast approximately every 30 minutes, with some exceptions during special drive time programmes (when there might be additional reports) or at moments when traffic is low and no reports are broadcast. At the New York stations WCBS and WINS, however, traffic reports became an increasingly more prominent part of the programme, being broadcast every ten minutes throughout the day. Once this format was introduced in 1989, WINS introduced a special slogan that emphasises the prominence of the traffic report as part of the station's programme: "Traffic and transit on the 1's." This slogan had three main functions. First, it was a cue for the traffic reporter to come in. Second, it became a recognisable part of the station's identity. Finally, like other beds and sounders, it provided yet another means for broadcasters to create a sense of flow in their programme, the slogan serving as a structuring element of the radio show.

Shortly after WINS introduced their traffic and transit slogan, WCBS - the biggest competitor on the New York radio market — created a similar tagline of their own: "Traffic and Weather together on the 8's." Both slogans refer to the ten-minute cycle of traffic updates on each station. The decision to broadcast traffic reports this often was made after several focus group interviews had been done, which indicated New York listeners wanted traffic updates throughout the day, also outside of drive time. According to Tom Kaminski, traffic reporter at WCBS880 (and a commercial television station), this change fitted within the overall aim of the broadcasters to provide listeners with useful and up-to-date information at all times. Within the highly competitive, commercial radio broadcasting context in New York, traffic reports have become a selling point, or even an asset (interview Tom Kaminski, March 5, 2018; similar views were expressed by Bernie Wagenblast, interview, November

\footnotetext{
${ }^{80} 1010$ WINS, 11 September 2001. The recording can be found online via the link https://www.youtube.com/watch?v=oPNPzrom18U. This traffic report starts at the 1:17 minute mark (accessed November 12, 2018). 'Major Deegan' refers to the Major Deegan Expressway in the Bronx, a New York borough. 'Bruckner' refers to the Bruckner Expressway, also in the Bronx.
} 
$14,2013)$. In this rationale, 'good' traffic reports are one way to bind the commuting listeners to the radio station and they are a selling point for attracting sponsors and advertisers.

This focus on slogans and selling points reveals the immediate relationship between the local socio-technical system of radio broadcasting and the specifics of traffic reporting in the New York region. The need for sponsorships, in a commercial radio system that does not rely on public radio funding, directly influences the traffic reports' form and content. At the same time, it is argued that the opportunities for generating revenue are increased by the quality of the traffic reports. Of course, this system has particular implications for broadcasters and listeners. As explained in the previous chapter, many European drivers could rely on the ARI-technology to receive traffic reports automatically whenever they were broadcast (at certain radio stations), even if they were listening to another station. Drivers in New York, like in the rest of America, did not have this option. As a result, it was important that people would tune in to a station that aired its own traffic reports. To make sure that motorists would do so, radio stations tried to attract listeners by broadcasting frequent reports at regular intervals. In this way, they hoped to help motorists to find the empty roads, while at the same time trying to keep them tuned in to their station. The absence of a technological system like ARI thus stimulated the largest New York radio stations to broadcast traffic reports frequently, in order to secure the attention of their driving audience.

In the next section of this chapter I will explain in more detail how professional traffic reporters themselves perceive their work and their reports' usefulness. In my conversations with traffic reporters from the three countries that feature in my case studies, several elements came to the fore that influenced the form and content of the reports beyond the socio-technical systems in which they were gathered and broadcast. These elements are difficult to identify on the basis of historical knowledge of the systems in which the reporters operate, nor can they be recognised easily through close listening to changes in traffic reporting practices and analysing them within the framework of Raymond Williams' media analysis. Reporters themselves frequently refer to their experiential knowledge and intuition as important foundations for doing their job well, and they put much effort in developing those tacit skills in order to improve their on-air reports. After all, time 'on air' has always been considered a precious commodity, in public as well as commercial broadcasting systems, and broadcasters want every second to matter for their audience. To explore how traffic reporters themselves appreciate their contribution to radio programming, the last section of this chapter concentrates on the work performed off air, which is pivotal in making radio traffic reports useful for driving listeners.

\section{Reporters' and Hosts' Reflections on Radio Traffic Reports}

Traffic reporters are well aware of the developments in information and communication technologies, and the impact these have, or may have, on their profession. Broadcasters continuously search for formats that fit their station(s) best. Especially after the introduction of (real-time updated) navigation devices and smartphones, which assist drivers in choosing their personal routes via other media technologies than (car)radio, the role of radio traffic reports has come under discussion. In some cases, this has resulted in changing or abandoning on-air traffic reports. But the opposite occurred as well. Stations such as WINS or WCBS in 
New York turned their traffic reports into a core element of their programming and developed a fixed and frequent format for airing radio traffic news. Of course, traffic reporters and radio show hosts are involved in these discussions as well.

During the interviews I conducted with twenty-six (former) traffic reporters, radio show hosts and producers, some interviewees expressed concerns about the value of radio traffic reports in the nearby future, in part due to the massive use of smartphones and other digital technologies to obtain real-time traffic information. If more and more people will use these other technologies, radio stations may decide to refrain from airing traffic information altogether. Dutch Radio 1 host Lara Rense, however, expressed a more nuanced opinion on the value of traffic reports, arguing that it is still unthinkable, today, to take the 'newsweather-traffic' tripartite out of the regular programming. She motivates this claim by referring to this cluster of recurring items as structuring and even "calibrating" moments for the radio hosts as well as the listeners (interview Lara Rense, June 22, 2017). These items, she concluded, can be a means for the radio hosts to connect with their listeners by offering an aural look outward: responding to events that are going on in the world, which can be surprising or fun or have some news value to listeners. Similarly, for Dutch radio veteran Frits Ritmeester, traffic information is a kind of "soft news." Ritmeester is known on and off air as Frits 'Spits' (spits is the Dutch word for 'rush hour') after his popular radio show De Avondspits ('evening rush hour'), which he presented in the years 1978-1988 and 1990-1995. For all those people stuck in a jam, he argued, radio traffic reports can be a very helpful source of information, which makes it a 'soft' yet relevant item to address on radio (interview Frits Ritmeester, June 22, 2017).

Indeed, one of the first motivations mentioned by reporters and hosts in support of traffic reporters' continued presence on air is the possibility that traffic reports present an audible overview of the major or most unexpected delays; as such they add to the liveliness as well as the news value of the radio show. Apart from providing content, the focus on (extraordinary) problems in traffic became an additional service. This may explain why reporters in all three countries referred to traffic reports as a service: verkeersservice in Dutch ('traffic service'), Hörerservice and Verkehrsservice in German ('listener service' and 'traffic service'), and especially in the New York area interviewees used the word 'service' to describe their contribution to the programme. Kelly Dillon, one of the reporters of WCBS880 remarked that this element of traffic reports make it the most fun. As she explained, she enjoys the idea that she can "help [the driving listeners] out" (interview Kelly Dillon, March 5, 2018). Moreover, Dillon argued, the frequency of the traffic reports (every ten minutes), in combination with the twenty to thirty-second bridge and tunnel updates that are also broadcast on WCBS four times every hour during the morning and afternoon drive time hours, have the effect that traffic updates "keep [the listeners] wanting to listen."

The practice of suggesting alternative routes or directions in New York is much in line with the more sensational style of traffic reporting in this region, the localised focus of the traffic reports, and the objective to help listening drivers avoid (really bad) jams. New York reporter Matt Ward, a senior employee at the Total Traffic and Weather centre and coach of less experienced traffic reporters, provided a succinct summary of the relevance of live radio traffic reporting, and the importance of the reporters' character and style for the way in which the reports are presented on air. First, he argued, to become a good traffic 
reporter one needs empathy for listeners who are driving and for those who are not. In the effort to be of interest to both types of audience, the reporter should be entertaining, without being ironic, and should try to be helpful at all times. To accomplish this, the reporter needs to be trained well as a presenter and be able to communicate in a clear and amiable way. Moreover, the reporter must be thoroughly knowledgeable about the movement of normal and abnormal traffic flows, and should at all times feel emphatic towards the listener and try to contribute to their safety whenever possible. If the reporter is able to fulfil all those criteria, traffic reports are the ultimate kind of "news that you can use." And this, he concluded, is the real valorisation of traffic reporters' expertise (interview Matt Ward, March 12, 2018).

The importance of expressing empathy with their listeners, especially those stuck in a jam, was repeated by almost all traffic reporters I interviewed for this research project. In line with the remarks of Matt Ward, WCBS880 reporter Kelly Dillon reflected on her personal strategies for keeping her listeners captivated and informed. She concluded that there are various ways in which she uses her voice to accomplish those aims, and stated that:

I also like to use empathy in my voice during reports. If there's a really horrible backup, I know listeners are upset and frustrated, so I like to share that frustration in my voice so they have someone they can relate to and so they feel like we understand what they are going through. (Personal correspondence, September 26, 2018)

Dillon also argued she uses her voice in a different way than in a normal conversation, in order to make sure driving listeners will pick up her report amidst all other sounds and distractions in a car. That way she tries to make sure "to try to get the point across" (interview Kelly Dillon, March 5, 2017). "One way I do this," Dillon later replied in a written correspondence, "is changing my fluctuation. When there is something big or breaking happening, I tend to go a little bit higher and louder [with my voice], to express urgency. If things aren't bad on a roadway, I will use a more relaxed, laid back tone" (Dillon, personal correspondence, September 26, 2018).

In many of my interviews, reporters also reflected on their strategies for gaining and retaining the attention of their listenership. This is yet another type of flow that Raymond Williams identified in a medium-range analysis of flow. He argued that "the overall emotional tone" of a programme can also be considered an element of the show's flow (1974/2003, p. 113). Sometimes, however, this can be a delicate matter, because the presentation styles of radio stations tend to differ depending on the identity of the station and the audience. It is therefore important for the flow of a programme that the traffic report fits into the rest of the show. This was most clearly revealed to me in the headquarters of the Dutch ANWB traffic information centre. Today, this centre is equipped with several small radio booths that serve various stations. The reporters are familiar with the style and preferences of the stations for which they work, and they will adjust their presentation style to each station. As the centre's manager explained to me, traffic on news station Radio 1 is a bit more formal than on popular music station 3FM or classical music station Radio 4 (interview Arnoud Broekhuis, June 16, 2015). The style of a traffic reporter is thus dependent on the individual, but also on the station. Moreover, the style may even depend on the 
programme or time of day. German reporter Birgit Wächter mentioned how she and her colleagues at the SWR decided to have slightly more chit-chatty traffic reports during the morning shows, to help their listeners ease into the day, and slightly more serious reporting during the early afternoon, when most listeners are engaged in their work or other activities (interview Birgit Wächter, February 22, 2017).

Nowadays, however, most radio stations - and certainly the ones I researchedhave adopted a format in which there is generally a very colloquial exchange between the radio show hosts and the traffic reporters on air, with a friendly and positive tone. While such dialogue can help to create flow within the programme, German radio host Thomas Schmidt noted that hosts sometimes have to be careful not to be too chit-chatty with the traffic reporters, nor should they be too laconic. If a reporter comes with news about a serious traffic safety hazard, for example, the tone of the introduction by the radio host should match the content of the report (interview Thomas Schmidt, April 20, 2017). Schmidt's SWR colleague Jochen Stöckle agreed with this position. He mentioned it is up to the show host how to best embed the traffic report into the programme, and colloquial interactions are part of that format. Within the report, however, it is up to the reporter to maintain a good flow from one item to the next (interview Jochen Stöckle, April 20, 2017).

Stöckle's remark underlines the changing role of traffic reports as more integral part of a radio show. Over time, traffic reporters became more and more professional radio presenters. Matt Ward shared some of his experiences about that process, and the way in which he sees the evolving professionalism of radio traffic reporters in relation to the radio stations at which they present. As he explained:

I found that most of this job for a broadcaster is: you're walking this fine line between reading a script and ad-libbing. Because you're looking at information that is inputted into a screen. But you also don't want to read it [just like that]. You want to make it your own style and present it in your own way. (Matt Ward, March 12, 2018)

This quote captures the shared experience of many traffic reporters that they have their own way of 'doing traffic' within the boundaries set by the radio stations.

The issue of personal style is illustrated in its most extreme form by the case of some New York traffic reporters who report under different names on different radio station. Two interviewed traffic reporters also explained how, in the past, some stations asked them to present their reports by using an alter ego. Bernie Wagenblast was known at WABC as 'Jack Packard', and Matt Ward presented some reports using 'Thom Rivers' as his name. Wagenblast said his pseudonym was given to him by one of the station's famous DJ's, Dan Ingram. Ward reported elsewhere that the name Thom Rivers was a playful take on a New Jersey town, 'Toms River' (MacFarquhar, 1997). Both men explained that operating under a pseudonym was interesting to certain radio stations, because the names were exclusively bound to those stations and fitted the style or identity of those stations. In these cases, then, the personal identity of the reporter was subjected to the interests of the radio station management. Considering the highly competitive, commercial broadcasting system in the United States, such strategic approaches to traffic information are an important part of the 
overall radio system. Former Shadow Traffic reporter David Fein concluded that traffic reporters are evaluated by two parties: their listeners, who judge the usefulness of their reports, and the broadcasters or media groups of which the radio stations are part. Their ultimate concern are listener ratings, and traffic reporters' airtime is critically reviewed in light of their contribution to the radio programme (interview David Fein, March 13, 2017).

Part of a radio traffic reporter's personal style is informed by the reporter's knowledge about traffic in their region. Many reporters explained during the interviews how they gained experiential knowledge about traffic flows on certain roads, and learned to interpret the various sources of information they have at their disposal. German traffic reporter Corvin Tondera-Klein, for example, explained that a message about a twelvekilometre jam might be deleted in the system they use to share information between the police and road authority and the traffic reporters once the cause of the accident was resolved. This does not mean that a lengthy jam will instantly vanish. In such case, Tondera-Klein believes it to be his job to double-check with other sources, such as Google Maps or live camera footage, to verify whether the congestion has really disappeared. If not, he will still include the jam in the next report, adding the extra information about the road's being open again (interview Corvin Tondera-Klein, February 22, 2016; for a visual impression of the present day workplace of SWR traffic reporters, see illustration 4.3).

Various other reporters made similar remarks, which brings us to another putative advantage of listening to a traffic reporter compared to automated information from a device. The reporter has a lot of experience, and is able to look at the raw traffic data or singular sources with a "healthy scepticism" (interview Tom Kaminski, March 5, 2018). Because of their experience-based knowledge, and the possibility to double-check certain data which sometimes even resembles the work of a journalist, traffic reporters are also able to add nuance or context to a jam reported on the air (interview Greg Rice, March 15, 2017). German traffic reporter Julia Raizner told me that she also liked the situation in which she can inform her listeners about an urgent safety-related issue of which she just received a notification, for example when parts of a tire pose a risk on a busy motorway (interview Julia Raizner, February 23, 2016). All in all, the radio traffic reporter is more qualitatively informed than any (currently existing) technology. Their knowledge is based on experience, and they are able to triangulate between different sources of information. This translates, so traffic reporters argue, into more useful traffic information on the air (interview Bernie Wagenblast, March 6, 2018).

During my interviews on the role of radio traffic updates, read aloud by a real reporter, two words frequently returned: trust and appreciation. These notions appeared to capture the main concerns of traffic reporters and radio hosts alike, when it comes to the overall value of radio traffic news. If the abovementioned conditions-providing good service, having empathy and attention for the listeners, developing a professional yet engaging personal style, obtaining experiential knowledge, and ensuring the quality of a report through triangulation-are all met, traffic reporters become trustworthy and appreciated contributors to any radio programme. Trust and appreciation, however, must be earned, and listeners - especially those stuck in a jam — can be a very critical audience (as I will illustrate in the next chapter). Yet reporters and the people working at the radio stations 
share a profound awareness of the potency of good traffic reports for the public's evaluation of their programmes.

\section{Conclusion: Flow on the Radio and on the Road}

In this chapter I set out to investigate how traffic information has been presented to drivers, as well as embedded in radio programmes. I concluded that a seemingly contradictory shift can be identified in the form and content of traffic reports. The form of Dutch and German traffic reports changed from segmented announcements to more colloquial updates, brought to the listeners by traffic reporters with an on-air personality. Nowadays, traffic reporters are really part of the radio show's crew, regardless of whether they work on the same floor as the radio hosts - as is the case at the German station I studied — or operate from traffic information centres elsewhere. The latter is the modus operandi for Dutch and several American radio traffic reporters. In the New York area, in fact, traffic reporting always took this interactive form. The tradition of live traffic reports coming in from a flying helicopter evolved into a longstanding, lively presentation practice that continued even when traffic information was gathered and presented indoors, from the traffic centre of Shadow Traffic and its successors. The reports' content, however, developed in similar ways in each of the countries featured in my case studies, from detailed and locally sourced messages of warning, to increasingly routinized and standardised updates based on a surveillance of general traffic flows, and geared towards effective traffic management.

Raymond Williams' media theory on broadcasting flow, which originally pertained to television shows, was adopted for the analysis of radio traffic reports, and this proved to be useful for a better understanding of radio broadcasting. Especially the medium-range and close-range analysis of flow allowed me to investigate the strategies developed by radio hosts and traffic reporters over time to facilitate the apprehension of traffic information while (ideally) retaining the attention of all their listeners. This was done primarily by constructing two aural senses of flow. Musically, flow was accomplished through the use of sounders and beds. Verbally, the spoken interactions between the radio host and the traffic reporter on the air (and at times off the air) contributed to the smooth integration of reports into radio shows.

Regarding the content of the reports, the perspective of the traffic reporter on problems on the road shifted as new information technologies became available to map and monitor traffic flows over a larger area. In that process, the focus of the traffic reports' content moved away from local conditions to a more comprehensive bird's eye perspective. Thisand this is my last substantiation of radio flow-resulted in new discursive practices that at once illustrate the broadened outlook on the road network, and highlighted the shifting meaning of traffic reports towards their role as a means of traffic management. Through discourse that connected one jam to another-for example via phrases like 'and then further toward ...' or 'because of that delay it is also jamming on ...'-the traffic reporter created verbal flow within a single update and was able to communicate efficiently about the interdependent motion of traffic flows on the road. In this way, the reporter simultaneously sought to retain the attention of the audience, even though the summarized listing of traffic jams itself had become highly standardised through having to fit within a very small timeframe. Interestingly, while New York traffic reporters also adopted new information and 
communication technologies in their effort to monitor traffic flows and cover wider areas, they largely kept the localised focus in their reports. Discursively, this is reflected in phrases like 'I see...', which imply the close view of the traffic reporter-be it live from a helicopter or mediated by traffic cameras - on selected sections of the road network.

Part of the reporters' efforts to gain and retain listeners' attention is shared with the radio host with whom the reporter is interacting, and bound by the preferences of the station's management. To understand the differences in the ways flow is attained over time and across the various radio stations, it is important to look beyond the form and content of the reports, and see the evolving changes within the local contexts in which they were broadcast. My analysis revealed that the form and content of traffic reports co-evolved with the rising congestion rates in this study's three countries, and I also uncovered how changes in the form and content of the reports were introduced in order to create and sustain a sense of flow both on the radio as well as on the road.

At the most practical level, the relation between flow and radio traffic information is expressed in its function within the overall radio programme. As a regularly recurring item, which is broadcast at predefined moments in time, traffic reports act as a structuring element. An explanation provided by journalism scholar Stuart Allan, in his book News Culture (2010), is relevant here. Allan argues that newscasts, including radio traffic information, "provide the scheduler with a means to facilitate the structuration of programming flow, namely by serving as points of transition between routines of daily life and between different genres of entertainment" (p. 135). When formulating this conclusion, Allan was inspired by Raymond Williams' study of broadcasting flow. But Williams did not only study flow in broadcast media. He also connected the phenomenon he observed in the media to a wider cultural change. As argued by Williams in a posthumous publication from 1999:

This general trend, towards an increasing variability and miscellaneity of public communications, is evidently part of a whole social experience. It has profound connections with the growth and development of greater physical and social mobility, in conditions both of cultural expansion and of consumer rather than community cultural organization. (p. 232)

Williams, in other words, felt that 'flow' captured a change in the media in which all programme items were increasingly connected in a continuous flow, rather than presented in a sequence of strictly separated parts, as used to be the case before. But he also connected this shift in the presentation of broadcast media to new conceptions of and possibilities for being physically and mentally mobile.

As argued in this chapter, my study of radio traffic reporting practices contributes to the work by Williams and others on the development towards privatised mobility, the notion of mobile privatisation and the role of 'flow' in radio broadcasting. This contribution is threefold. First, radio traffic reports can be understood as an important illustration of the integration of broadcast media along with, and even into, people's increasing use of their private car in the course of the twentieth century. Traffic news has actually supported this new mobility paradigm of suburbanisation and increasing distances between home and workplace. In this sense, traffic updates reflect that broader cultural change and capture the 
essential tension privatised mobility caused for society at large: in search for a sense of freedom, motorists have come more frequently to a standstill.

Second, it is in this capacity that traffic reports can also be understood as being part of the process that Raymond Williams aimed to understand using the concept of mobile privatisation. Especially in America, as illustrated by the New York reporting practices discussed in this chapter, traffic news was at once catering to and used by individual drivers. Broadcasters expected the reports to be listened to by drivers who enjoyed the radio show from the comfort of their own, private automobiles. In this sense, traffic reports can be seen as a result and, perhaps, a driver of the cultural tendency towards increasing individualisation - in this case through individualised automobility. Initially, traffic reports were a response to the rising number of traffic problems and congestion rates in urban areas. When the focus shifted from alerting drivers about danger to the avoidance of back-ups, however, the overall mobility paradigm in which private automobile use became reinforced. This confirms claims by mobility scholar John Urry about the prevalence of the focus on the automobile as "the predominant global form of 'quasi-private' mobility" (2006, p. 18).

The relation between radio traffic information and the overall mobility system, however, has not been frequently investigated. My analysis, then, also sheds light on traffic reporting as an understudied element of the experience of everyday automobility. In this way, this chapter contributes to the call by Urry and others (see Bull, 2001, 2004; Bijsterveld, 2010, 2014; Kent, 2014) to pay attention to the senses when studying automobility, including the experiences of listening while driving. The importance of hearing and listening while driving will be discussed more in-depth in the next chapter. 



\section{Listening while Driving: Apprehending Traffic Information on the Road}

\section{Listening along with Motorists}

In the previous chapters, I discussed the interdependencies between the (semi-)governmental authorities, corporations, associations, institutions and individuals involved in gathering, processing and presenting radio traffic information. I also traced the ways in which radio traffic reporters and hosts articulated traffic information, and which strategies they employ to inform as well as retain the attention of their listeners. Some of these listeners will be drivers, who have a range of options with respect to their auditory entertainment. Yet even with the radio switched off, motorists are constantly surrounded by sound. Perhaps they converse with fellow passengers or engage in a phone call, their navigation system may give directions, they may hear the wailing of an emergency vehicle's siren that passes by, and there is the constant rushing of the wind or the sound of their car's tires rolling down the road. Driving, in other words, implies a wide array of aural stimuli, of which a radio programme or traffic reports via the car radio are but two examples. In order to understand how motorists are talked through their commute, and to complete the study traffic information's trajectory from its inception to its use by recipients, I shall investigate how motorists experience radio traffic reports as part of their daily commute and amidst all the (other) sounds that surround them while driving. This chapter, then, addresses the question: How do motorists today apprehend traffic information amidst competing listening activities?

The study of motorists' responses to information, or other (aural) phenomena, while driving is central to the fields of traffic engineering and traffic psychology. Traditionally, researchers in these fields focus on the relations between various forms of stimuli, and the responses of drivers while driving (or as simulated in experiments). For example, many studies have investigated motorists' most optimal responses to visual and/or aural information. An early example is the work by Job Klijnhout, published in a 1972 issue of Verkeerstechniek, a Dutch professional journal on traffic-related technologies and engineering. Klijnhout discusses various ways of providing information to drivers. He discerns tactile, visual and aural forms of communication. Tactile means of communication are not very useful for conveying complex messages, he concludes (p. 268). Signs can be used to transfer information visually. The car radio, then, is one means to convey messages aurally. Once the fields of traffic engineering and psychology professionalised, new technological systems were developed for informing drivers visually as well as aurally. In turn, various studies investigated the effects on users of the new, so-called 'Advanced Traveller Information Services' (e.g. Emmerink et al., 1996; Emmerink \& Nijkamp, 1999; Chorus, Molin \& Van Wee, 2006). As I have explained earlier, an important effect pursued by these engineers and researchers was to minimise jam length and travel or delay times, by increasing the efficient use of the capacity of the road network. By means of information 
distribution, they sought to influence drivers' decision-making, in order to maintain optimal traffic flows. Richard Emmerink and his colleagues motivated their research stating that

Obtaining a greater understanding of the impact of Road Transport Informatics (RTI) on drivers' behaviour is extremely important for judging the performance and market success of telematics. Since traffic flows are simply an aggregation of individual decisions, road users' behaviour will completely determine whether these new technologies are able to meet their objective of using scarce road space in a more efficient manner. (Emmerink et al., 1996, p. 135)

Despite the introduction of those 'advanced' information technologies, more 'oldfashioned' radio traffic reports continued to stay on the agenda as well. Using predominantly quantitative surveys, researchers have tried to map the interest in and appropriation of traffic information via radio. An exemplary Dutch study (Van Dammen \& Overste, 1976), presented an overview of various statistics. They calculated the percentage of motorists that have a car radio, specified the number of people who listen to certain radio stations, and what proportion of them listens to the radio traffic reports. This research was followed up by Simone Akerboom. In her dissertation she addressed the question of how people apprehend radio traffic information, and how the reports could be optimised in order to obtain the best positive effect in terms of apprehension and response, so as to reduce congestion rates $(1988,1989)$. When innovations such as RDS-TMC were first introduced, these were, of course, also tested for their efficacy in terms of distributing clear, up-to-date and relevant traffic information. Underlying motivations for this were to contribute to "the traditional aims of traffic control: increasing traffic safety, improving traffic flow, reducing environmental pollution, and reducing operation costs" (Everts, Olberding \& Schneider, 1994, p. 35).

Much research on motorists' responses has been biased towards the visual dimension of driving and possibilities for information intake. Signals and signs, or the use of short phrases or words, are commonly considered easy ways to inform drivers on the road, and the efficiency of such media for communicating messages to drivers has been proven in trials. Yet the relation between aural information or music, and driver behaviour, has been a topic of research as well. In the introduction of this dissertation, I explained that car radios were initially a contested new technology, and that some taxi drivers in New York reported in a 1934 survey that radio was a source of distraction (Suchman, 1939, p. 149). Gradually, however, this position lost support, and researchers began to investigate the effect of the car radio in more detail. Examples of early work in this field is by Ivan Brown $(1961,1965)$, who studied the effect of car radio listening on driver performance.

More recently, various music psychologists, such as Warren Brodsky (2002), Nicola Dibben and Victoria Williamson (2007), and Ayça Ünal and her colleagues (2013), have all investigated the influence of music on the attention of drivers. The findings in this subdiscipline share the observation that music has a positive effect on drivers' response times to what happens on the road. In a review article (2015) that was supported by the British Transport Research Laboratory and the Institute of Advanced Motorists, experts in traffic safety Neale Kinnear and Alan Stevens present an overview of distractions while driving. 
Their aim was specifically to understand "how drivers engage with technology when driving," what impact this has on driver behaviour and safety, and how distracted driving can be reduced (p. 4). "Adjusting an entertainment system or climate control" is the first activity that the authors mention that can cause driver distraction (p. 5), like searching for a specific song (p. 20).

While searching for music can be a distraction and can have a negative effect on driver performance, music itself can also be uplifting and thereby contribute to drivers' level of attention. In her dissertation Music Directs Your Mood (2012), Marjolein van der Zwaag provided a synthesis of research on the positive effects of listening to music, concluding that "intelligent music selection systems could be envisaged to improve driving performance and decrease physiological stress while driving” (p. 94; see also Van der Zwaag et al., 2012).

This stimulus-response type of inquiry, which characterises existing research on listening while driving in the fields of traffic management and traffic psychology, helps us to understand the relation between certain stimuli and driver behaviour. In my own research, however, I take a step back from this search for causality or correlations. In this chapter, I investigate drivers' experiences of car radio as part of their overall listening while driving experiences, in order to learn more about the meaning they ascribe to radio traffic reports as part of that practice. I will do so by studying the ways in which drivers 'inhabit' their car. The focus on people's automobile habitation implies a detailed study of their everyday listening and driving habits. Attention for motorists' everyday experiences occasionally recurs in, and at times bridges, research in the fields of mobility studies, sound studies, and traffic psychology. Through my elaboration of drivers' experience of sound inside their car, and of the meanings they ascribe to traffic information, I aim to connect and contribute to these three different disciplines.

\section{Studying Automobile Habitation through Sound Recordings}

Automobility has been studied in different ways. Several researchers have looked at it as a phenomenon and as a practice from an abstract level of perspective. A good example is the work by John Urry on the socio-technical system of automobility, in which he explicates reasons for the dominance of the car as our most favoured means of mobility (2004), or Peter Merriman's detailed analysis of the many interdependencies and co-constructive developments within such automobile system (2009). Other researchers have investigated the emotional dimension of automobility. In 2004, Mimi Sheller published an influential article, entitled 'Automotive Emotions: Feeling the Car', on the emotional dimension of automobility. She used insights from various disciplines to explore how the 'dominant culture of automobility', as Urry (2000) put it,

is implicated in a deep context of affective and embodied relations between people, machines and spaces of mobility and dwelling, in which emptions and the senses play a key part. ... Car cultures have social, material and above all affective dimensions that are overlooked in current strategies to influence car-driving decisions. (Sheller, 2004, pp. 221-222) 
Following this line of research, other scholars have aimed to unravel elements that constitute the affective relationships between motorists and their cars. Jennifer Kent, for example, followed up on Sheller's research and investigated the relation between the physical comfort of automobile travel and the car's persistent importance as our preferred means of transport (2015). She concludes that comfort and personal space play an important role in the positive evaluation of the car that go beyond mere sensory experiences while driving. Over time, the attributes of bodily comfort and mental relaxation inside the private and secluded space of a car have led to a broad cultural appreciation of automobility that plays out at the societal level—automobility has become accepted as normal-through very personal understandings of self-care. In the words of Kent:

For some, car comforts are experienced as a logical way to nurture the self. The avoidance of the feeling of discomfort is a practice of self-care which maintains a sense of self-pride and appeals to culturally inculcated desires for freedom and security. Driving the car, avoiding the rain and hot weather, the sweaty people on the train, the danger of riding a bike and the inconvenience of waiting, are all practices of self-nurture - they have become what it means in modern life to look after oneself. (Kent, 2014, p. 739)

The car and ideas about the self are thus intimately connected. Richard Randell has recently synthesized work on the emergence of the "automobile self" (2017). This is a state of being, in which the car, the physical infrastructure, the driver, and shared routines and behaviours on the road merge into a single entity for the duration of the time on the road. The 'autoself' thus differs from the conceptualisation of the driver. The driver, Randell specifies, is "the person who is understood within everyday automobility to be an autonomous, not imputed, self; who drives an object - a car - that is assumed to be separate from the subject-driver" (p. 669 ; italics in original). The concept of 'autoself', in contrast, aims to capture the assemblage of driver, car, infrastructure and interactions with fellow drivers while on the road (p. 669). This is important to take into account in discussions about the detrimental impact of the car on the environment, because such a philosophical approach toward automobility may help to unravel the precise factors that play a role in people's choice for the automobile as their preferred means of mobility. Randell also concludes that such a broader understanding of the 'autoself' is necessary if one aspires to shift the hegemonic position of automobility in our mobility systems towards more sustainable transportation options (p. 673).

Characteristic of much research in the field of mobility studies, regardless of its level of analysis, is the acknowledgement of the importance of drivers' everyday experiences. By analysing the experiences and practices of motorists, it is possible to get a better understanding of 'automobility' as such and people's motivations for continued use of their car even when other means of transportation are available. To investigate the context of the commute, both in terms of the experience as well as the aural environment, I use the concept of 'automobile habitation'. In his article 'Inhabiting the Car' (2006), John Urry has provided a comprehensive reflection on automobility as a phenomenon and daily experience for millions of motorists. He considers automobility to be "a complex amalgam of interlocking 
machines, social practices and especially ways of inhabiting, dwelling within, a mobile, semiprivatized and hugely dangerous auto-mobile capsule" (p. 18; italics in original).

As such, automobile habitation aims to capture the act of dwelling inside a car, emphasising the spatial as well as temporal and affective, or emotional, dimensions of driving. By focussing on these various dimensions, scholars have aimed to understand the qualitative effects and dimensions of the rise of our contemporary system of privatised automobility, or, as Daniel Miller (2001) coined it, our "car culture." Because of the comprehensive approach towards the practice of driving, the concept of automobile habitation helps me to frame and interpret the general and the more detailed listening while driving experiences of the participating motorists that I explore in this chapter.

If car driving has become a routine practice, listening to car radio is an equally common element of that practice. Whereas car radio technology did not exist yet at the start of the twentieth century, at the turn of the twenty-first century virtually no car was built without (the possibility to install) a radio. Michael Bull, expert in the field of Sound Studies, was one of the first researchers in the humanities to publish on the role of sound inside the car using the concept of automobile habitation. In 'Soundscapes of the Car: A Critical Study of Automobile Habitation' (2001) and its follow-up publication 'Automobility and the Power of Sound' (2004), Bull investigated the relation between sound technologies, such as car radio, and drivers' ways of dwelling inside their cars. To motivate the relevance of this topic and his approach to study the relation between automobility and sound, he writes that

the historical turning point between 'dwelling on the road' and 'dwelling in the car' can be located in a very specific technological development: the placing of a radio within the automobile. This has radically transformed the nature of driving and the driver's experience of space, time and place. Thus, an understanding of automobile habitation should focus upon the mediated aural nature of that experience. ... By focusing upon the auditory and the technologized nature of everyday experience of automobile users, I explain their attempts at creating manageable sites of habitation. (2001, pp. 188-189)

The ability to select the sounds one wants to listen to, by means of the available sound technologies, has an important effect on the way drivers experience their own automobile habitation. As argued by Bull, "[t]he mundane activity of the day is transformed into a personally possessed time. Listening to music/radio enhances the drivers' sense of time control/occupancy" (2001, p. 193). In 'Automobility and the Power of Sound' (2004), Bull captures this process using the term 'mobile solipsism': through their in-car sound technologies, people are able to control their environment and thereby re-appropriate the time they are captive in their car. This sense of control is crucial, because, as he concludes, "[ $t]$ ime possessed is more likely to be time enjoyed" (2004, p. 248). In other words, by choosing a specific listening activity, motorists are able to reinterpret the time they spend in their car, and driving becomes a meaningful activity that involves some level of autonomy despite the restrictions of the car's confined space and the limited views and manoeuvrability on the road. This position opposes the common, economic model of time - the framework that also precedes the objectives behind providing radio traffic information - in which "journey time 
is formulated in terms of cost and is, broadly speaking, 'lost' (Lyons and Urry, 2005)" (Laurier et al., 2008, p. 19). Similar to Lyons and Urry, Eric Laurier and his colleagues conclude that for many drivers, regardless of the company and means of entertainment, "travel time is time spent; it is not time savoured, hated, shared, enjoyed or recollected" (ibid.).

In order to come to a more positive evaluation of the time motorists dwell inside their cars, they must feel at ease in that space. In-car media can contribute to creating this sense of comfort, in particular because they can be enjoyed in the car's sealed-off space. This space has been characterised by some scholars as a 'bubble' or 'sonic envelope' (Bull, 2001, 2004), a 'capsule' (Urry, 1999; 2006) or a 'cocoon' (Weber, 2008; Bijsterveld, 2010). According to Karin Bijsterveld, who has used this concept most elaborately, the car is a perfect example of an acoustic cocoon: a "domain in which people experience privacy and relaxation because they consider the interior acoustics of cars pleasant and controllable" (2010, p. 192). She continues to argue that we should "have an awareness of the symbolism of sound in order to understand how the car became a place in which to unwind by the enablement of sonic control" (ibid., p. 204; italics in original); a claim she bases on her investigation of the changing meaning of the car radio, shifts in the ways drivers relate to the mechanic sounds of their cars, and the construction of so-called target sounds.

In the book Sound and Safe (2014), Bijsterveld and her colleagues also elaborate on the topic of sonic control inside the vehicle. They explain changing conceptualisations of automobile sounds in the course of the twentieth century, and highlight motorists' search for auditory privacy on public roads (p. vii). They do so by tracing the socio-technical history of innovations in car design and sound technologies. Through these innovations, automobile drivers at once became "both secluded from and thoroughly connected to the surrounding world" (p. 1). This entails a process "of shielding the car's interior acoustic space from outside noises, and of filling this space with the sound of audio equipment" (p.7; italics in original). The seclusion is thus twofold. Outside the car, sound-cancelling measures such as noise barriers and special sound-deadening asphalt helped to keep the noise of a driving car at a minimum. Inside the car, improvements in insulation and car design enabled an even deeper sense of isolation from the outside world. The authors aim to understand this move towards 'acoustic cocooning.' This "refers to control over a sonic environment-feeling sound and safe — which implies seeking both isolation and connection through sound" (p. 7).

In line with earlier work on sound and automobility, Bijsterveld and her colleagues emphasise the importance of car radio in the automobile's acoustical and metaphorical shielding effect. This is no straightforward result from the installation of a radio inside the car, however. The meaning of car radio, they argue,

would hardly remain stable over the years. Manufacturers such as Philips introduced car radio as a way to draw people into cars, both literallyattracting admirers - and virtually: the company of radio voices. From the 1960s, however, car radio was increasingly presented as a device assisting motorists to tolerate their fellow traffic participants and keep them, emotionally, at a distance. (Bijsterveld et al., 2014, p. 99; italics in original) 
This culturally informed interpretation of the socio-technical process of 'shielding' car passengers off, while at the same time allowing (mostly) controlled sounds to enter the car's interior by means of the car radio, is central to my own understanding of the historical developments regarding sound and media use inside the automobile.

Indeed, there have been many innovations that help to shield the car's interior acoustic space. Yet in this chapter I explicitly emphasise the permeability of the car's exterior. Based on the sound recordings provided by the research participants, I can only conclude that 'the outside world' is, in varying degrees, still very much part of the car's interior acoustic space. This includes the ever-audible presence of outside noises such as the wind, tires, the engine, and surrounding traffic. I therefore suggest that the automobile listening experience can be better understood in terms of a 'bubble', as used by Bull and, before him, Georg Simmel (1997) and Jean Baudrillard (1989). The illustrative metaphor of a bubble helps to remind us of the permeability of the car's exterior body, while at the same time it captures the car's shielding effect-without the connotation of a "locus of transformation" that is connected to the cocoon metaphor (Groening, 2016, p. 133). This understanding of inhabiting the car serves as the foundation for developing my investigation of drivers' personal experiences of sound and media technologies, and their relation to traffic information.

In terms of the empirical research that informs this chapter, I have taken up the joint call by Mimi Sheller and John Urry (2006) for a new mobilities paradigm. This new approach towards studying mobility should enable different branches of social sciences, the humanities, and transport studies to come and work together. More recently, Peter Merriman and Lynne Pearce (2017) have explicitly invited humanities scholars to join this field of research. This interdisciplinary attitude, they all argue, should result in new theories and innovative methodologies for studying (auto)mobility. In the words of Sheller, the new paradigm "advocates for a realist ontology for contemporary social science capable of transcending old debates and bridging disciplinary boundaries" (2014, p. 790). One of the innovations in research methods developed in the wake of this call is using video registrations of drivers and passengers in order to study the peculiarity of everyday drives. One of the first studies with this set-up was published by Eric Laurier and his colleagues in the article 'Driving and "Passengering": Notes on the ordinary organization of car travel' (2008). They researched the lived realities of automobility, or as they put it: "view the backseat of the car in all its banana-skinned, half-empty drink carton glory, and better attune ears to Wogan in the morning rush hour as a queue begins to back up on a sliproad" (p. 2).

To the literature just discussed, I will add the use of sound recordings and qualitative interviews as a new and exploratory way of researching everyday driving. My approach does not primarily rely on looking at people driving, but on listening to them, and inquiring into their own reflections about the role(s) of sound during the time they inhabit their cars. To gain more insight - the visual bias of the word is somewhat ironic - into the practice of listening while driving, I collaborated with twenty individuals, ten of whom were living in the Netherlands and ten in Germany. These participants were asked to make ten audio recordings of their commute on five days in the winter periods (November to March) of 20162017 and that of 2017-2018. The Dutch participants were all living in or commuting to the densely populated and highly urbanised Randstad region covering the cities of Rotterdam, 
The Hague, Amsterdam and Utrecht, and their surroundings. The German participants were all living and working in Southern Germany, in the region between Karlsruhe and Munich. The participants were all aged between twenty-five and sixty and commuted for approximately thirty minutes or longer one-way.

After collecting these ten recordings per participant, I selected the audio of four recordings for transcription and further analysis. The selection of the analysed recordings is based on the length of the recordings. For each participant, I selected two shorter and two longer recordings, in order to explore potential differences in drivers' behaviour during varying commute lengths. The shortest recording amounts to approximately twenty minutes, while the longest transcribed commute took over 2,5 hours. Transcribing the audio meant writing down all (changing) audible events discernible on the recording. The selection of recordings for further analysis was based on the length of the recordings: many participants had one or two significantly longer commutes and some shorter ones. To create a distribution, I focussed on two of the longer and two of the shorter recordings among the sample. The transcriptions of the recorded audio typically looked like this:

00.00 Start recording. Sound of reverse-beeps + airco or fan steadily whooshing.

00.23 End of reverse-beeps, radio volume turns up but barely audible.

Airflow is much louder. Car is moving.

01.42 Low rumbling sound in the background. Wind or tires?

01.58 Pulling up to higher speed. Some fumbling in the car.

02.16 Radio voice audible intermittedly. Pulling up to higher speed.

$02.42 \mathrm{Airco} /$ fan is turned down. Radio suddenly much better audible. Radio reception does not appear very stable?

03.08 Some rustling in the car

03.11 Shortly blinkers are on

03.31 Blinkers on + car slows down

03.45 Blinkers turned off, car continues driving

03.54 Blinkers turned on

04.00 Blinkers off + on again

04.03 Soft fumbling in the car

04.05 Car pulls up to higher speed

(Audio Mira, January 15, 2018. Morning commute)

Finally, these transcriptions together with a topic list provided the basis for a qualitative, semi-structured interview with each participant about their experiences with listening while driving and the search and apprehension of traffic information as part of their commute. This provided the second main type of source material for this chapter. The interviews lasted from 35 minutes up to almost three hours. The difference in duration of the interview had to do with the time each participant had available. The shortest interview was conducted via phone during office hours; the longest interview took place during a Sunday morning brunch at the interviewee's home. All interviews were subsequently transcribed ad verbatim and coded using the qualitative research software programme ATLASti. Finally, in 
writing up this chapter, I decided to give every participant a pseudonym, in order to safeguard their anonymity.

The aim of this examination was to acquire more insight into the ways motorists appropriate radio traffic reports amidst other, competing, listening activities. What exactly do drivers hear during their commute, and how does their aural environment change while driving? Additional questions with regard to the topic of traffic information were: what sources do participants make use of to gather information about traffic jams, and how are traffic reports part of this more contextual practice of listening while driving? These questions provided a basis for coding and analysing the interviews. To keep track of the participants' considerations, I developed a total of 39 codes, belonging to five categories: contextual information about the participant, the participants' listening while driving behaviour, the process of making travel decisions on route, considerations about safety and distractions on the road, and their reflections on the topic of sustainable mobility. These categories provided me with a means to structure the analysis, and connect topics within a single interview and amongst the twenty interviews analysed for this chapter. Moreover, the categories helped to relate findings between this part of my research project and issues addressed in other parts of this dissertation.

In this chapter, I will also use the insights from the empirical research and knowledge from the literature in the fields of traffic psychology, mobility studies, and sound studies to address the proverbial elephant in the room. This is the tension between drivers' autonomy to control their own route and listen to their own preferred media, and the implicit and explicit appeals in traffic information updates to comply with diversions that lead them away from their travel plan or favourite source of aural entertainment. In this sense, traffic information asks drivers to give up their control over their travel itinerary. As I argue, traffic information can ultimately be understood as a spoiler of the motorists' prospect of a free, smooth and entertaining commute. By spoiler, I mean a message that has the potential to diminish drivers' anticipation of a pleasurable commute, without hindrance or delay. At the same time, traffic information offers the possibility, or hope, of a way to avoid the congestion ahead.

As we will see in this chapter, however, drivers deal with this tension in many different ways as they negotiate between their own preferences, routines, concerns, and sensory capacities in the car. The personal practices of obtaining and responding to traffic information are thus part of drivers' attempts to cope with the excess of traffic and (regain) control over their time on the road. They act in search of some sort of solace, knowing the spoiler of delays ahead. But their choices do not necessarily align with the aims of the traffic report providers, whose intentions and technological interventions I explained in the previous two chapters. To arrive at this conclusion, I will first briefly illustrate the rich soundscape in which motorists find themselves when driving their car, and explain how they obtain traffic information through various media both before and during their trip.

\section{Sounds and Technologies in a Car on the Move}

One of the aims of this chapter is to gain a more thorough understanding of the sounds that motorists hear when they are driving, and how they relate to those sounds. Careful listening 
to the recordings of the participants in my study reveals that the aural surroundings of each motorist vary endlessly in accordance with the driver's specific location, driving mode and vehicle design. For example, the engine of an old diesel car sounds very different from an electric vehicle, which even at high speed hardly produces any noise. New or more expensive car models tend to be better insulated, limiting the amount of noise inside. Hence the volume level of sounds one hears while driving — such as the engine, tires, or wind - will vary substantially for every car, and even differ in changing weather or road conditions.

To delve a little bit deeper into the wide range of sounds one can hear inside a car, let us move to the front seats. Here, motorists can clearly see the road ahead. In most cases, they also have easy access to one or more in-car entertainment and information systems, such as car radio, a navigation device and a (smart)phone. These devices often produce sounds at the driver's command, for example by turning on the radio set. But they may also come with built-in sounds, like the default settings of the software are configured in a way that every touch comes with a short sound. Some devices are interactive in more elaborate ways, such as voice-controlled navigation systems that are meant to assist drivers in finding their way and respond to drivers' commands while they can keep their eyes on the road. Other common sounds inside a car are the result of turning on the blinker lights, opening up food packages, shifting position in one's seat, the occasional siren or honking of a fellow driver, coughing, et cetera. Finally, of course, there are the incessant sounds of tires on the road and the wind rushing past the car's exterior.

If this short overview of sounds on the participants' recordings is by no means exhaustive, it underscores the complexity of the sonic environment inside a driving car. One never simply hears 'the car' or 'the radio'. Moreover, as every car design is different, it is impossible to present a single characterisation of the aural environment of drivers. While this may seem obvious, past studies have barely acknowledged this variation in soundscapes of vehicles yet. But it turns out that motorists' qualitative experience of sound while driving depends on much more than their car stereo's number of speakers. It is also highly subjected to the involuntary sounds that enter the car while driving. The participants in my study were all to some extent aware of the range of the soundscapes in their car, and the effect of their car's insulation on their experience of sonic comfort. After we discussed my analysis of her recorded audio, one of the first observations Phoebe shared in the interview was that she no longer perceives particular outside noises that she did hear right after she had bought her current car:

In the beginning you are aware of everything that is different. The window in the back [of the car] closes properly, but there appears to be a bit of a flow of incoming air there. ... Because of that I noticed in the beginning that more noise was coming in from the back left side. While waiting [in front of a red light] I could overhear bicyclists chatting or calling. I would consciously hear that, too. But, well, now I consider it to be quite normal. (Phoebe, December 10, 2016)

Andrew told me that he had a similar recollection about the 'normal' levels of noise inside his car. As he laughingly explained during the interview: 
I think my car is nice and ...*laughs* rather silent. ... I find that a great good and I love it because I can better listen to the radio. I also notice this when I get into other people's car, which is often more noisy. (Andrew, December 23, 2016)

At the end of the interview, Andrew underlined that recently he realized the importance of the comfort of low-level in-car noise:

Now I would not buy a 'tin' [noisy car] anymore. That's important, I believe. If it is not such a silent car, then, this could be a reason to buy something else. But I only realised that after I bought this [new car], haha. (Andrew, December 23, 2016)

Another participant, Uri, noted that the recent increase in noise inside his car was even a reason for him to start looking for a new one:

It's actually important to me that it's as quiet as possible, and it's actually one of the reasons that make me sell my car because it just got louder and louder over the last maybe 6 or 12 months, mostly due to its ageing probably. So it's normal. ... But it has gotten a little too loud. And my first car was so loud that when you had a long distance drive with someone else and you had a conversation, your throat was sore after the drive and that's-I will never ever want to have that again, so as quiet as possible is better. (Uri, April 4, 2017)

These examples show how motorists are aware of the sounds produced by their car or that may come from the outside and influence their sense of comfort. In some instances, however, 'annoying' sounds actually contribute to safety in traffic, like the siren of an approaching emergency vehicle or an uncommon sound by the car itself. The latter may be an indication something is wrong with the car. One of the interviewees, Alex, shared a recent recollection of such event:

A few weeks ago I had a flat tire. At first I could hear it. Next, you also feel it in the car's performance, but initially you hear something is wrong, you know, and you realize "okay, it's better to stop." (Alex, February 23, 2017)

In every interview, participants referred to their experience of noise, of normal and abnormal sounds. Despite the pervasive presence of 'normal' sounds, like the rushing wind or the tires on the road, those sounds do not fit well with the idea of the car as a space of comfort. They can hardly be regulated by the driver. At most, they can be masked through the volume of audio devices. In this sense, several participants confirmed the argument of Bull (2004) and Bijsterveld (2010) that the car's sonic space is appreciated most when people experience a sense of acoustic control by using certain sound technologies. If the car does 


\section{Chapter 4}

not have more advanced insulation, the volume of one's audio devices thus becomes an important means to create such acoustic control. Paul confirmed this observation. He regularly changes the volume of the radio in the car he uses to drive to work, and commented on this habit:

Yeah, probably because of the speed. Less speed means that my car produces less noise, so naturally I turn it [the volume] down. Because it [the noise in the car] feels louder than it actually is. It's ok at a speed of $100[\mathrm{~km} / \mathrm{hour}]$ or something, but then it feels too *short pause* silent. You just don't hear the music anymore. That's what it feels like. I know it's not like that, but it feels like the music is vanishing, so I'm raising the volume level and I'm also lowering it again when I slow down. What I almost always do, is turn it really down when I have to park. I think this is something everyone will do ... You just need that concentration ... It's actually bothering me, like, in the middle of an awesome song, when I'm just starting to back [parking into a space] and I say to myself "shit I can't park yet, because of the music" *grins*. Yeah, it's a thing. (Paul, February 27, 2017)

For Paul, the volume of his radio is closely connected to specific details pertaining to his drive, like his speed or the manoeuvre he has to complete. This example also indicates the importance of the radio's volume when it comes to feeling comfortable inside the car: too loud is distracting, whereas too low is not enjoyable either. Sound technologies that entertain or inform the driver thus come with a measure of ambiguity. Many interviewees acknowledged, in line with academic literature and recent prohibitive policy, that the technologies they use have the potential to distract them from the task of driving. They therefore argued that, apart from their own responsibility, in-car information systems should be 'easy' to operate, without diverting too much attention away from the act of driving itself: "In the end, you still have to pay attention to the road" (Chris, November 08, 2016).

Such easy operability is not always self-evident. In newer cars, the most popular incar devices - radio, navigation, smartphone - are increasingly integrated into one large, centrally built-in computer that provides access to a variety of functionalities. While this ought to make operation easier, drivers must still learn how to operate such devices. Consequently, they need to navigate not only the roads, but also learn to find their way through the car's computer software. For some participants, this causes too much distraction from driving. Benjamin, who because of his age (58) and annual mileage (60.000 kilometres) can be considered a veteran on the road, concluded that the distraction from built-in digital systems inside the car has increased over time:

At first, you just had a radio tuned in to a station and you immediately had sound. Now you have to press something, then the device starts to search and may ask for example a follow-up question. Then you have to press something again. You are really looking at the screen too much. And now I notice that, with this system [in current car], I am much more distracted from the road than before. Before it was just ' $1,2,3$,' and it worked. Now it is 
much more difficult. Or, rather *short pause* complex. More actions are needed. (Benjamin, January 21, 2017)

In this respect, two participants, Alice and her husband Edward, even invented their own term to capture the overload of options and information on the car's dashboard: "Klickibunti," a word that can be loosely translated as "clicking extravaganza" (Edward \& Alice, February 26, 2017).

Some participants voiced similar concerns about the continuous stream of sound coming from the car radio. It is common that the car radio switches on the moment the engine starts. At times, this can be experienced as an information and entertainment overload that leave motorists longing for silence rather than talk or music radio. In order to (re)claim control over their aural environment, some drivers intentionally switch off their media every now and then. Choosing to surround oneself momentarily with silence, then, is also a strategy motorists have to comfortably situate themselves in their cars. In the words of Cathy:

Sometimes when I come from work I want just music and nothing else. And sometimes when it has been a very hectic day, then I also like to just have nothing on my mind, and then I consciously do not turn the radio on. (Cathy, April 21, 2017)

Next to the search for silence, the radio is also occasionally switched off, or turned to a very low volume, to create a safer situation. This has reportedly been the case for some participants when, for example, an ambulance is approaching:

Yes, when I think "Oh! I have to be careful now," I turn the [volume] down, of course. Or if I see a police car or an ambulance coming from the back, I turn it down just to be sure. To see if everything is ok, [to make sure that I know] what is happening. (Jim, April 7, 2017)

As these examples show, motorists have a range of possibilities to surround themselves with auditory and other technologies during their drive. Sometimes, however, these technologies can have an overwhelming or distracting effect. To reclaim a sense of control over their sonic environment, some participants occasionally choose to do without any source of information or entertainment. Of course, this has implications for the media's possibility to get traffic information across.

Now that I explained in some detail what technologies and sounds surround drivers during their commute, I will continue the discussion about the apprehension of traffic information - and specifically about the considerations that play in role in choosing for a certain source of information - in the next section of this chapter.

\section{Choosing Media in Search of Useful Traffic Information}

With respect to the appropriation of traffic information, one of the first findings that resulted from the collaboration with the participating commuters was that many of them do not, or 
not solely, listen to radio traffic reports to inform themselves about ongoing changes in the traffic situation ahead. Instead, a range of devices and mobile applications are used, some of which are located outside of the car. Variable road signs and matrix signs display symbols as well as text to inform drivers about temporary speed reductions, accidents or congestion in the upcoming section(s) of the road network. Back inside the car, navigation systems and smartphones provide yet other sources of information motorists can use to predict, confirm or avoid congestion up ahead. Especially smartphones offer a wide range of options to become informed about traffic-related issues on the intended route.

The latter forms of digital, real-time traffic information are relatively new, but all motorists in my study were aware of digital technologies to inform themselves before or during their commute. Based on the feedback by the twenty individuals in my study, then, it is safe to conclude that the smartphone has become the most regularly used source of traffic information. Some participants checked a website or mobile phone application prior to departure. Others used Google Maps on their mobile phone during their trip. This application functioned as their navigation system, with the added benefit that it simultaneously keeps them updated on delays and the expected time of arrival. In fact, out of the twenty participants, only a few reported that they do not make use of a navigation system or their mobile phone while driving. Jessica, the youngest participant in my study, reported she sometimes checks Google Maps prior to her departure, to see if she should expect any delays, but not during the trip itself. About using her mobile phone to access traffic information when on the road, she said:

I do have my phone within reach, but I rather not look at it unless traffic has come to a complete standstill. Because *short pause* I would want to quickly look up something. But to open the app and look where I am and where the jams are, and then also see what would be a smart alternative route, I think that is a bit dangerous while driving. So then I just stick to the radio [traffic reports]. (Jessica, November 28, 2016)

Many other participants, however, almost always use their smartphone - in most cases the application of Google Maps - to navigate and stay informed on the situation on the road. Paul is a passionate user of Google Maps. When we discussed different traffic information technologies during the interview, he remarked:

TMC, right. I saw that. It does kind of work, so you do get information like: 'you are going to hit a traffic jam'. But it is, as I said, it's just not very precise. And I want to really know exactly where [a jam] starts, where it ends, and how bad it is. That's what I like about Google Maps. I really know that when it's dark red, almost black, you're bound to end up in a standstill, and when it's orange or something you are in dense traffic but you can still drive on slowly. (Paul, February 27, 2017) 
Several other participants made similar remarks about the advantage of Google Maps and other Real-Time-Traffic services that show them not only the location and length of a jam, but also how slow traffic is moving through the changing colours of the road on the screen.

While driving, however, the situation in which information is apprehended is literally much more dynamic than when someone is stationary. It is therefore highly important how the information is presented to driving motorists. In the interviews, participants made various comments about their preferred medium and format for obtaining traffic information. It appears that the decision of drivers to make use of a particular source of information is primarily related to the accessibility of the information. Here, many participants, as well as the scholarly literature on traffic management and in-vehicle information provision, refer to the issue of aural versus visual input while driving. In chapter two, I explained that traffic engineers, psychologists and the motorist associations in the 1960s and after were cautious about diverging drivers' eyes off the road, and argued it would be safer if information about traffic conditions was communicated to drivers aurally. But there are downsides to aural information as well. Verbal information takes more time to be communicated, and it is more difficult to be consulted again after the moment's passage. In practice, both aural and visual information provision have their own affordances, which drivers will evaluate based on their own preferences and prior experience.

The second element that plays a significant role in the choice for a particular source of traffic information, is the source's being abreast of the road conditions and level of detail it provides. The precision and frequency with which the reports are updated therefore matter a great deal. So-called 'advanced' traffic information technologies are experienced by participants (and considered by researchers) to be especially beneficial when it comes to the actuality and accuracy of the reports. The most recent technologies in the field of traffic information stress their 'real-time' representation of the situation on the road. Even though radio traffic reports aim to be as much up-to-date as possible, I have explained in the previous chapter that many radio stations only broadcast traffic updates at set times in the programming. This may reduce its usefulness for motorists who entered their cars right after a traffic report has been aired. Additionally, due to the limited time allocated to the reports on air, the traffic reporters often need to make a selection of jams that will be mentioned in their item. As a result, the reports do not necessarily serve as the most complete source of information, and may be helpful to motorists on the listed highways only potentially. This can cause frustration for those motorists who are stuck elsewhere. As one participant who regularly finds himself in an unreported jam put it:

It is sometimes very frustrating, because you are never mentioned. The jam I am in is apparently not important enough, [or it is] slightly too short to become important, so actually it is almost never mentioned. (Harold, November 7, 2016)

It is possible to obtain more locally specific information via radio. To this end, motorists can choose to listen to a local radio station, instead of the stations that service a wider geographical area. These local stations often provide more regional (traffic) news. Yet many participants explained they do not employ this strategy. This was notably the case in 
the Netherlands, where local stations generally cover a very small geographical region and offer programming that strongly differs from that of the national stations. In Germany, the broadcasters that address a specific Bundesland seem to provide a more optimal 'middle range' in this respect. They are more localised than the national broadcasters, but are not so local they only provide news from one small area. Yet many drivers' reluctance to use local stations for obtaining traffic information did not relate to the nature of the traffic reporting per se, but to the content of the overall programming on those local stations. One participant was especially vocal when it came to the quality of local radio programming. After saying he barely listened to local stations, he added that he did

actually try to catch the traffic information. That's the only situation where I would listen to it [local radio], and otherwise I honestly just really hate it. I really hate it. (Uri, April 5, 2017)

But even the more local focus of the content of the traffic reports could not fully please Uri and tempt him to tune in to a local station. He continued:

The way they present traffic information on the local stations is absolutely awful. They try to make it funny or interesting and it's just terrible. And their ... talk radio they present seriously, but it is also terribly boring. (Uri, April 5, 2017)

Other participants were less deterred by the quality of the shows and traffic information on local radio stations, and would actively switch to a local station to obtain the latest traffic report in their region. In doing so, they temporarily stopped their preferred source of aural entertainment in favour of traffic reports that are more focussed on their particular region, and thus more applicable to their commute. As another participant explained about the traffic information on his radio station of choice:

It is not very detailed for my region, so [for traffic information] I always switch to this local radio which is called SWR, Südwestrundfunk, ... which includes detailed traffic information. New traffic information is issued every half hour. At eight, eight-thirty, nine, nine-thirty, and so on. And in between I switch to this news channel. This is how I spend ... 90 percent of the time during my ... ride to work. (Shane, March 13, 2017)

Mira also preferred to listen to a national radio station (Deutschlandfunk), but as she explained as well:

They only have traffic information on jams of, I don't know, four kilometres or more. And such jams hardly occur here. But when I know something is going on, I will check or listen to another station, SWR, for example. (Mira, February 16, 2018) 
As we can see, these participants developed different preferences and practices for obtaining 'useful' radio traffic information. In this process, they aim to balance their interest in the overall programme of a specific station with their search for traffic news that is most relevant for their own geographical area.

Additionally, some participants indicated that their search for traffic information depends on the nature of their trip. William made the following remark, in which he differentiates his commute from trips in his free time, and also identifies different strategies for obtaining traffic information prior or during those drives:

I certainly listen to [radio traffic information] ... yes I do. Maybe not so much for commuting. But when we go to Maastricht to visit relatives, and you're driving and then you suddenly hear about the A2 [motorway] ... Then I certainly listen to it. What I actually always do in the afternoon before I leave the office is to check on the computer: what is the state of affairs right now, and is there a way to anticipate [jams] already? (William, December 15, 2016)

For his commute, then, William uses online sources like Google Maps prior to his departure to check the current situation on the road. He explained how he has several routes to get to his office or go home, and rather "drive around for 10 minutes than be in a jam for 10 minutes." To this end, real-time, visual traffic information helps him to evaluate the traffic situation when he departs, and allows him to choose a route with no, or minor, delay at that moment in time. During longer journeys, like the two-hour trip to family in the south of the Netherlands, William prefers radio traffic reports to stay informed about delays further down the road. Those jams, he argued, may well have disappeared by the time he would pass the location of a reported jam. Would the congestion be heavier in the next report, he might still have time to look on the map and consider an alternative route.

The final dimension that affects the apprehension of radio traffic reports ties in with Williams' anecdote about considering alternative routes, and relates to motorists' knowledge of the infrastructural network on which they travel. When a motorist is familiar with possible alternative routes, the decision-making process will be easier. This familiarity with and knowledge about the local environment can be captured in the concept of a 'mental map'. This concept is commonly used in research that focusses on people's environmental perception, such as in geography and behavioural geography (e.g. Lynch, 1960; Gould \& White, 1974/2012). In these fields, a mental map is what prompts people's perception of and interaction with their surroundings. Regarding the importance of mental maps in order to navigate the roads, Robin noted:

Well, I am quite good in topography of the Netherlands. But that also has to do with the fact that I lived in different places in the Netherlands. ... so I know the regions quite well *short pause* Yes, and still ... when I have to go somewhere I have never been before, I look it up. To see where it is. It is not that I enter it into my navigation system and then see where I end up. I want to know ... where it is. (Robin, December 21, 2016) 
This tacit knowledge about the local layout of roads and highways also enables motorists to better interpret radio traffic reporting. Some participants remarked how their mental mapstheir own representation or memory of the infrastructural network in their minds - are as a prerequisite for responding to the traffic report. In this respect, Chris claimed to be very aware of his own knowledge of the roads and the importance of his mental map:

Yes, if you drive a lot you have a map inside your head after a while. But if you ... [have] no idea of which A or N-roads are found [in a particular region], you will neither be helped by the [traffic] information. Because you do not have that map inside your head. (Chris, November 8, 2016)

I will come back to the participants' reflections on the importance of mental maps later in this chapter, but essentially, these comments underscore the importance for drivers to have some basic geographical knowledge in order to be able to interpret the traffic information that comes to them.

Of course, the more advanced traffic information systems, such as navigation devices with a RDS-TMC decoder or devices with a live internet connection, can also help drivers to evaluate traffic reports and come up with alternative routes. In principle, these information technologies would require no need for a mental map, because they offer a visual representation of the road network-Including the location, length, and sometimes even details about the cause of some congestion. Many participants expressed their fondness of the quick accessibility and apprehension of visualised traffic information. Still mental maps are considered useful. Harold, for example, liked the fact that he could interpret the radio traffic report and understand it quickly because of his own mental map. He appreciated the colour coded congestions in Google Maps as well, claiming that such visual information is

a finesse that radio, or let's say a spoken message, less easily *short pause* ... this visual information is a bit - I find that easier to interpret. If you would for example list all jams in numerical order, [it takes quite some time to go from] the A2 to the A15 and A27. And I do not know if by the time we arrive at 27 I can still remember the [data on the] A2. But in visual information I can see [what the situation is like on those specific highways] in a single glance. (Harold, November 7, 2016)

Nevertheless, several participants also expressed some scepticism concerning navigation devices that provide alternative routes based on incoming traffic information. Phoebe even concluded laughingly: "We are completely dependent on technology [for navigation directions and traffic information]. That's really bad" (December 10, 2016). Another participant, who works at a company that draws up maps of various kinds, was also careful not to trust his navigation system blindly. He recalled how the device directed him to take unnecessary detours along difficult local roads in the past. He also concluded that one always has a better, broader overview of the infrastructure on a paper map compared to a digital device, because the displayed geographical region is always smaller on such a device, 
and this makes overall orientation more difficult. A few moments later in the interview he remarked:

Having some geographical knowledge comes in rather handy as well. And often I check in advance to see where I have to go. ... And then also on holidays I quickly write down some keywords on how to drive and which highways to take on a sheet of paper in the car.... Because this allows you to drive almost without a map. ... Also when once I had to go to a town called Zundert, I checked its location briefly: 'Where is it? Oh, somewhat south of Breda.' Alright, so I know [the way] to Breda, and afterwards I have to pay attention. (William, November 15, 2016)

William's sceptical attitude towards his navigation device and the automatic rerouting did not go as far as to mistrust the technology in general. On the contrary, like many other participants, he appreciated the technology's potential to warn him about unexpected delays ahead. Several participants even commented that time is often the most important factor they take into account when searching for, or responding to, traffic information. Benjamin, for example, showed a great awareness of the meanings of the colour-coded route options in his navigation system. The system suggests the shortest, fastest, and most optimal (in terms of travel time in relation to the distance) route, and he must decide at the start of his commute which factor will determine which travel plan he will follow that day. Most often, he concluded, he opts for the fastest option. He explained:

I always have three options. I first look at the time: how long [the suggested route] takes. ... I usually do not take the green route [shortest travel distance], because it takes 20 to 30 percent more time. (Benjamin, January 21, 2017)

Some participants, then, continuously searched for the quickest routes to get to their destination. For Shane, it was even "purely time" that determines what route he takes:

The only question is what is the fastest option to come from $\mathrm{A}$ to $\mathrm{B}$, and then I take this [route] no matter if I have to drive a detour which is 20 kilometres or 20 percent [longer]. [As long as] it brings me faster to where I want to go. (Shane, March 13, 2017)

The same rationale also turned out to motivate people's decision to take the car, rather than public transport, to get to work. Harold, Andrew, Jim, Aubrey, Edward, Alice, Jessica and Paula all indicated how it would take them (considerably) more time to reach their workplaces by bus and train. Some were aware of the negative effect their choice has on the environment, but the decrease in speed and comfort of their journey resulted in their decision to go to work by car. Mira was very aware about the negative effect of her commute on the environment, but for her yet another reason motivated her to choose for the fastest means of mobility available to her, namely her own car: 
I would like to travel to work with public transport, but then I would spend a good hour extra on the way. That is simply - that would be ok for me when I would be responsible just for myself, but I have to pick up my child [from childcare]. That is one hour more at daycare every day and I don't think that is *short pause* that aspect outweighs the environmental aspect. (Mira, February 16, 2018)

For these participants, their experiences with long travel times ultimately led to their automobile travelling, even though they also all acknowledged the possibility of serious delays on the road. In the following section I will therefore look in more detail at how drivers evaluate the meaning of traffic information for their commutes and how, despite the undesirable and at times even gloomy content, traffic reports may also serve to spark some hope in drivers who are (not yet) stuck in traffic.

\section{Traffic Reports as Hopeful Messages of Misery}

As we have seen thus far, the possibility to actively, and effectively, act on traffic information is not simply a matter of listening to the radio or checking a navigation tool. The possibilities of many drivers to use traffic information as a means to avoid a jam is in fact limited various conditions. These will be explored in this part of the chapter. One of the policy aims behind traffic reports, as I argued before, is to provide motorists with the possibility to take an alternative route. The mental maps of drivers help to facilitate this process. This is not the only condition for responding effectively to traffic information, however. As it turned out, for several participants in my research the layout of the infrastructural network itself is crucial for their option(s) to avoid a jam. They reported they have few, if any, possibilities to change routes. Yet even in these circumstances, traffic information can be a source of hope. Alice experiences this on a daily basis. She explained during the interview:

Before I leave in the morning, I already listen to what is said on the radio. Yes, I find that important. Because for me there is often a jam, or accidents, and because it is only one straight road, without alternatives, it is not possible to drive around it. And when I then drive into such a traffic jam it is usually quite bad. (Alice, February 27, 2017)

For Alice, it is thus very important to obtain traffic information prior to departure. Only by postponing her departure is she able to avert an already existing jam, and therefore she uses the radio reports as a means to evaluate her chances to get to work on time, and calls in to her office if she knows she will be leaving a little bit later because of a jam on her road. Her husband, who has a company car with an advanced navigation system that integrates updated information about delays during the drive, subsequently explained that for him radio traffic reports 
were more important when I did not have this Live Traffic yet. Since I have Live Traffic the only problem I have, is that I must decide in the first 10 kilometres ... do I drive that way or that way? And ... Live Traffic, this always takes 1 to 2 minutes until it has processed all the information and then I must look quickly across the map to see [what route to take] *short pause* it would take away some stress if I have heard the traffic report before. (Edward, February 27, 2017)

So even for Edward radio traffic information is a valuable source of information that can complement his navigation system, which automatically reroutes on the basis of incoming data about ongoing traffic flows. Having heard the radio traffic news, he is able to check whether his navigation is already up to date with the large jams that were mentioned in the radio report. In that case he trusts the route his device suggests to him. In both the cases of Alice and Edward, however, the layout of the infrastructure is an important factor in their decision-making process.

In addition to their dependency on the road network for their possibilities to change routes, the experiences of Alice and Edward indicate it is very important that traffic information can be consulted in time to change the travel plan. Only then can these bad news reports be effective and fulfil their function as a positive, or at least hopeful, means for reducing congestions. Another participant who also actively seeks for traffic information before he starts the car is Robin. During the interview he remarked:

What I often do before I leave is check my phone. Look on Google Maps ... because Google Maps is reasonably reliable in terms of traffic. How busy it is at that moment *short pause* and must I take another route? (Robin, December 21, 2016)

Similarly, Shane stated that

For me it is important that I check the traffic information before I start, or at the beginning of my ride, right? It doesn't help me if I'm in the middle of the Autobahn and then I'm informed 'oh there is some traffic jam.' So I need to know it in advance ... [If I'm too late for the radio traffic report I check] the traffic information on my smartphone in advance to avoid that I have no information before driving. (Shane, March 13, 2017)

These participants highlighted the importance of traffic information before the start of their commute, but several participating motorists were also convinced of the positive effects of delay notifications during their commute, via either their own devices or in-car navigation with real-time traffic updates, or a radio traffic report. In this case, traffic information serves a primarily psychological function. Unlike the proactive goals mentioned above, these participants explained how traffic information helps them to anticipate delays, and consequently deal with the loss of time and ideal prospect of speedy travel. One participant came to the following conclusion: 
... for the acceptance [of a delay] it sometimes helps to know how bad the delay is. And that is where traffic information of course also helps. That you know what you can expect, because nothing is as frustrating when you think you are [going to be] fast and you are not. (Maude, January 21, 2017

This excerpt is indicative of several participants' sentiments with regards to the value of (radio) traffic reports. Even when the information cannot be actively put to use, for example to make an informed decision on a different route or time of departure, traffic reports are appropriated by many of the participating motorists to manage their expectations about the flow they will be able to sustain whilst on the road. In the words of another participant: "Well, because you kind of want to know 'can I drive nice and smoothly, or should I expect congestion'? That is actually the only reason [to obtain traffic information]" (Cathy, April 21, 2017).

Drivers, thus, use traffic information not always, or not only, to safeguard their own free and smooth flow on the road, but it also functions as a tool to manage expectations. This appears to be the case especially for motorists who choose to make use of (the contemporary equivalent of) ARI's functionality to let traffic reports 'break in' whenever they are broadcast. Harold, the oldest participant and an enthusiastic user of radio traffic information as well as Google Maps and the traffic app of the Dutch motorist association ANWB, added that he listens to traffic reports to prepare or adapt his commute. If 'his' highways are not mentioned in these information sources, "then I assume [...] that [the jam] causes less delay than the other [mentioned] traffic jams" (Harold, November 7, 2016). In his reasoning, if a jam he encounters is not listed in any of his information sources, he assumes he will not be confronted with very serious delays.

During the interviews with the participating drivers, several also referred to instances when a radio traffic report served as a source of information, not only for themselves, but for non-drivers as well. Examples were shared about family members who listened to the traffic news to estimate whether their loved ones would arrive home on time. The wife of Jim, for instance, sometimes calls her husband to notify him about a jam on his route (Jim, April 7, 2017). William also mentioned he would sometimes call home to inform his family he would be delayed (William, December 15, 2016). Traffic information thus also has a function towards the people who are not travelling but are, socially speaking, are near and dear to the people on the road.

Some participants even indicated they sometimes like to listen to the traffic report as source of social engagement in its own right. Especially on holidays or during the winter and summer holiday seasons, when there is often a lot of traffic on the road, the traffic report can be fun to 'see what is going on in the world' (Edward, February 26, 2017) or, in the words of Ethan:

Sometimes it's just interesting, right? It is not that I [draw] any conclusion for my own route, but it is interesting to listen to it. What is going on. It was [recently] of course the beginning of the Easter holidays and that list of traffic jams would not stop, right? ... That was just interesting. 
To hear that for some reason going [from] north to south is difficult. All these Dutch people going skiing. Right? (Ethan, April 2, 2018)

This recollection demonstrates how Ethan also has a general interest in the traffic updates, even if he is not about to travel himself. Sometimes, traffic news can simply be an interesting radio item that people can relate to beyond its function as a traffic jam alert. For Ethan, the report of heavy holiday traffic also invokes more social and culturally informed imageries of the large numbers of people who drive to the Alps for their winter holiday. This shows that even radio traffic reports can contribute to the radio's capacity to transport people mentally to other places, and - more intimately — can help to create a sense of community amongst the listeners. According to many radio and media scholars (e.g. Williams, 1974; Moores, 1993; Douglas, 1999) this is one of the characterising features of radio as a medium of communication.

Not all participants were equally enthusiastic about the value of traffic information, however. Especially radio traffic information occasionally stirred participants' emotions, and some expressed explicit reservations when it comes to the overall usefulness and value of this particular source of traffic information. This negative evaluation was generally the result of past experiences, when warnings about delays ahead or suggested alternative routes had not resulted in a smooth drive after all. Alex concluded that

Very often you follow that information or change the roads and sometimes it's not working out at all, so [now] I decide to stay on the highway and I really don't care if I need 10 minutes longer. (Alex, February 23, 2017)

Because of his bad experience with route advice from the radio traffic reporter, the whole item no longer interests him: "I think that most of the time I don't hear it or I don't follow it," he stated. Alex' experience was shared more widely amongst the people who joined my research project. Others remarked for example how they frequently miss information to judge whether a congestion that is mentioned in a radio traffic update will soon dissolve, or not. Mira, for example, noted:

Quite often there is no information about the cause of the traffic jam. I think it makes a difference whether I am waiting in front of a construction site, and this is the reason for the jam, or whether there has been an accident ... for which rescue workers need to clear a track. Yes. Often this information is missing in a radio traffic report. (Mira, February 15,2018 )

Thus, drivers are sometimes confronted with information that bypasses its goal of more efficient flow of traffic, or lacks the level of detail to help motorists make up their own mind about their travel plans. During the interviews it became clear that drivers often develop their own strategies to cope with such disturbance of their free and fluent commute. They develop their own individual and context-dependent ways to apprehend and respond to traffic information, which will be discussed in the final part of this chapter. 


\section{Alternative Forms of Autonomy on the Road}

Sometimes, when drivers are unable to assess the possibility or necessity of changing their itinerary in order to save travel time, or when the traffic reports do not provide the required information to estimate what the impact of an impending traffic jam will be on their trip, drivers may also decide to simply join the queue. In these cases, drivers may have to come to terms with the fact they will be delayed. This reconciliation, or the decision to do 'nothing,' can in fact also be a strategy motorists employ in response to the jam. In those instances, motorist may find other things to do. In order to maintain a sense of control over their commute, despite their impeded travel plan. These strategies provide insight into the ways drivers inhabit their cars when they are truly a captive audience, ${ }^{81}$ and how-following Michael Bull's (2004) explanation of automobility in relation to people's use of sound technologies - they re-appropriate their environment and time spent inside their cars in case of an (impending) traffic jam. In the following pages, I will argue that these strategies help to reclaim a sense of autonomy, despite the physical constraint of just sitting in a car, strapped in a seatbelt.

Reclaiming control or a sense of autonomy can be done in a number of ways, both inside and outside of the car. One way in which drivers exert control within the confinement of their cars is by choosing what they listen to. In some of the participants' recordings, this could be heard very clearly. Especially the younger drivers switched comparatively often between different stations, in search of interesting information or music of their preference. Right before the 7 o'clock morning news on Tuesday October 27, 2016, Jessica even switched 12 times during a 66-minute commute, with a peak of switching stations seven times in a period of less than 15 minutes. The moments at which she changed stations illustrate her lack of interest in certain songs or advertisements. Instead of listening to the commercial break, for example, Jessica explained: "I rather listen to the news [at another station]." Another reason she might change stations is to check "whether I missed something of the traffic report." Following this statement, Jessica continued to describe how she knows from experience that radio stations have their traffic report broadcast at slightly different moments in time. Some have it before the news, for example, whereas other stations 'do traffic' after the newscast. In case she misses the traffic report at the station she is initially listening to, or if she is uncertain about whether her route has been mentioned in the report, she could switch to another station to double-check her chances for a swift commute.

Finally, as some sort of final solution, Jessica explained she has a USB stick permanently plugged into the car's sound system, which she listens to "only when there is really nothing else" (Jessica, November 28, 2016). On top of these diverse listening practices, Jessica's recording also indicated she changes the volume of the radio several times; turning it up when she likes a song, turning it down again when the song is over or when she is driving slowly. Both through her choice of entertainment medium and the volume of the car radio, Jessica, like Cathy who was quoted before, maintains a sense of acoustic control over her drive, even when she cannot actively evade the slow traffic around her. At those moments, the car radio, with its various options that can cater to the preferred type of entertainment and

\footnotetext{
${ }^{81}$ The metaphor of a 'captive audience' has been used before in the work of, amongst others, McLeish (1994), Bull (2001) and Bijsterveld \& Dieker (2015).
} 
listening experiences of one's choice-including a moment of silence-is able to provide some solace to drivers who are otherwise caught in a disheartening traffic situation.

For some participants, the car radio not only provided a means to stay entertained during their drive, or when stuck in a jam. They even found ways to make the time in the car 'productive' time, by consciously engaging with a technology that gives them a sense of satisfaction. For example, Aubrey concluded in general terms that

Usually I hear a book during my drive time. But I did not have one the last weeks *laughs*, and so I used the radio sometimes and sometimes not. ... Always the same channel, because it is cultural-it's a more cultural station. Not so much popular music. It is more talking and news, and it's, well, everything I am interested in, on this channel. ... For me it is more [important] to get food for the brain, and I get that at this [radio] channel. (Aubrey, January 11, 2018)

In many interviews, listening to audiobooks was a recurring strategy to make travel time inside a car more useful. Aubrey concluded with regards to her preference for audiobooks that:

I like reading, and the time to go to Munich is a little bit wasted time and when I am not able to read, I try to read with my ears, you know. And then the distance is a very short one, because I am always very quick in Munich when I hear a book. Sometimes too quick! *laughs*. (Aubrey, January 11, 2018)

Uri, another enthusiastic listener of audiobooks, was even more explicit about the advantage of audiobooks as a means to appropriate the many hours he spends on the road:

I spent about $15 \ldots$ hours every week in the car, which is more than two working days for me. ... so it's a lot of time, and to me it felt like a waste of time. Also boring, but mostly a waste. And ... at some point I made a conscious decision: I want to use that time as well as possible and ... I listened to audiobooks occasionally before and I had such wonderful experience with audiobooks. (Uri, April 4, 2017)

Other participants were less inclined to see the time in the car as time well spent. Ethan, also a fan of audiobooks, made the following observation:

Well, the problem is: I'm an engineer, right? It is for me hard to be productive on the phone. ... I have friends who are in, like, in corporate, or so, and for them being on the phone, that is their work. So that could be productive. ... But I'm not productive when I'm sitting in my car with my hands tied. (Ethan, April 2, 2018) 
These experiences of motorists illustrate their search for ways to make their travel time somehow more meaningful than travelling from point A to B. Such reappropriation of their drive time through 'productive' activities helps to avoid experiencing this time as merely spent and therefore lost; a finding that supports earlier reflections on automobility by Lyons and Urry (2005) and Laurier (2008).

In addition to their sense of sonic control by means of their in-car sound technologies, some motorists also try to maintain in control of their route even when they make use of navigation devices or applications on their smartphones. In the previous section I referred to Phoebe and William who expressed explicit concerns about their reliance on navigation systems. Their comments demonstrate the intention of some people to check and prepare their routes prior to departure in addition to their use of aural and visual traffic information. This indicates their unwillingness to rely completely on the navigation and information technologies they have at their disposal during their commute. The technology is there to help them navigate most efficiently, yet they continue to want some level of control. This is obtained and maintained through their experiential knowledge, beliefs about swift routes, willingness to follow the automated advice, and their mental map. Because of their mental maps, these participants feel capable to choose for themselves whether they follow the automatic rerouting of their navigation system, or not. Chris noted the following about the importance of mental maps in relation to traffic information and detour directions via the radio:

Often I check the map in advance to see 'ok, this is the route', I plan that in advance, 'but I want to drive this and that way.' And then I know in advance the route as a map inside my head, and I use that to navigate. And then I also very quickly have the idea: 'ok, it is jammed here, if I go this and that way I am also travelling south,' for example. ... I think that is kind of strange, if you go somewhere for the first time, then traffic information is not very useful because you do not know the roads so well. If you always travel the same route then you just know exactly 'there and there it is always jammed.' (Chris, November 8, 2016)

These experiences indicate the importance of mental maps as a prerequisite, if a motorist is to effectively appropriate, and possibly respond to, radio traffic information. Interestingly, Chris also uses his preparation and mental mapping in order to decide whenever he is going to divert from the route that is indicated on the computer as the most optimal one. His mental map thus helps to navigate and interpret the traffic information, but also enables him to consciously move away from the suggested routes whenever he chooses to do so.

Mental maps may also play a role in a final, radical strategy for avoiding traffic jams, namely to completely change one's travel plan after having been informed about an impending delay on their route. Several participants argued they sometimes abort their trip, in order to spend their time in a completely different way. Chris, for example, declared: 
I think driving in jams is simply annoying, irritating. Driving slow, standing still, driving slow, standing still. Next to the time it takes. Then I rather consider to stop for a moment at Ikea and drink a coffee - or something like that - and continue half an hour later, instead of losing that same half hour by standing still. Or I just pass by the Albert Heijn [grocery store] and get some groceries and then continue. (Chris, November 8, 2016)

Getting a meal or doing some shopping are two examples of alternative activities participants engage in to avoid joining the queue of cars on the road. Visiting acquaintances who happen to live nearby is sometimes also an option. Participant Benjamin remarked that he prefers to make an additional stop, if he knows he will otherwise enter a jam:

Well *short pause* if it is not too cold, and it is only fifteen minutes or half an hour [of expected delay time] then I stay in the car. If I pass a nice establishment that I know, then I will sit inside for a moment. I would not change my route. Except when I say '[friend's name], I am going to drop by, because I am stuck in a traffic jam. Stopping by in Apeldoorn to drink a cup of coffee.' Then I am also really in touch and visiting a friend. That is something different from killing that time, so to say. (Benjamin, January 21, 2017)

In these instances, when the motorist decides to interrupt his drive, the straightforward commute has also ended. By altering the reason why someone is in the car altogether, the commute becomes a different, more special kind of journey. It becomes travelling for its own sake, like going on local explorations or enjoying certain amenities (see Salomon \& Mokhtarian, 1998; Ory \& Mokhtarian, 2005). By opting out of their commute, and choosing for a radically different way to spend their time, these motorists show how traffic information can actually stimulate people's autonomous decision making in such a way that they redefine what they were doing in the first place. This may in turn may lead to entirely unanticipated activities and unexpected, enjoyable experiences - in addition to the positive effect of escaping another traffic jam.

\section{Conclusion: Searching for Solace inside the Automobile}

In this chapter, the experiences of contemporary motorists were explored. I addressed the question of how drivers today apprehend traffic information amidst competing listening activities. To answer this question, I adopted a research method that combines analysis of sound recordings of specific driving experiences and semi-structured interviews about these recordings and experiences. In addition, I reviewed literature from the fields of traffic psychology and traffic engineering on Advanced Travel Information Systems. I also studied literature on automobile habitation to provide a more comprehensive understanding of motorists' response to traffic information than is commonly promoted in the (sub)fields of traffic management and traffic psychology. 
The research presented in this chapter revealed that motorists develop individualised practices and preferences that shape their personal automobile habitation. None of the participants in my research conveyed the exact same experience on the road as their peers. While this may seem obvious - we are all individuals, after all-earlier research on the apprehension of traffic information does not take this diversity of practices and preferences into account. Moreover, listening to the participants' recordings of their commutes as part of my approach to study people's apprehension of traffic information, very quickly led to the realisation that no soundscape in the car is the same. In fact, soundscapes have a tendency to change permanently while travelling on the road. The audio recordings provided by the twenty motorists who participated in my study hardly begin to cover the range of sounds that surrounds motorists inside their vehicles. For many participants, these sounds generally recede to the background of their conscious processing. But when prompted, the drivers were quite aware of the effect of those sounds on their driving tasks, including their processing of traffic news. Based on these insights, I firstly want to argue for more sensitivity to the diversity of the aural surroundings of motorists in studies on the efficacy of traffic information. Only when this sonic dimension of drivers' experience is explicitly part of researchers' approach towards studying automobility can researchers develop a comprehensive understanding of people's habits and preferences for information intake while driving.

In stating this, I do not mean to question the value of research into traffic information as such. On the contrary, many participants indicated an interest in information during their commute. In their reflections, a specific tension came to the fore regarding the ways people apprehend this information. Drivers make use of various technologies to access the latest traffic updates, and most of these technologies rely on visual representations of the relevant information. Through smartphones, drivers can access these services before or during the drive to get an immediate, visual overview of their route and travel time. Route planners, for example, have the advantage that they help to create a mental map of the route. This helps drivers to orient themselves quickly while on the road. The most advanced services also indicate real-time or even anticipated future traffic flows. In this way, visual information generally facilitates easy apprehension of route-specific traffic information. This type of visual information has one main disadvantage, however. Several participants indicated the potential risk of distraction, not only when glancing at the screens on which the information is presented but also when trying to navigate the software programme itself in order to find the right information.

Aural information, in contrast, does not have this risk or drawback. Radio traffic reports are usually broadcast at regular, even foreseeable intervals, which makes it easy for listeners to tune in to the reports around the moment they are broadcast. The predictable, or at least familiar, format also helps people to apprehend the content of the reports and take out the information that is relevant for their own travel plan. Precisely because of their familiarity with the form and content of the reports many participating motorists appreciate radio traffic news as a useful medium and source of information to plan or adjust their commute.

Yet despite these advantages of radio reports, the participating motorists did not consider radio traffic information to be ideal. The timing of the reports is crucial if drivers are confronted with the decision to continue their initial travel plan, change their route or 
interrupt their commute altogether. Because automobile trips are not scheduled according to the rigid schedule of the radio programming, it often happens that motorists have just missed an update when they start the engine of their car. This, of course, does not contribute to the reports usefulness for the people whom they are intended for. Moreover, several participants concluded that radio traffic information cannot help them to change their route, simply because they (hardly) have alternative roads to choose from. The value of radio traffic reports is thus dependent on the timing it is broadcast, and on contextual factors like the layout of the concrete infrastructure.

Even though participants generally found it easy to explain the shortcomings of radio traffic reports as a source of information during their commutes, many also attributed positive roles to this element of radio programming. Specifically, they suggested three main advantages. First, radio traffic reports help to manage people's expectations. If their planned route or destination is mentioned in a report, they are mentally prepared for a delay, and more likely to accept additional travel time. Secondly, traffic reporters may provide a brief explanation of the cause of the delay. This contextual information, which hitherto has often been absent in popular navigation systems or applications, contributes to the acceptance of (impending) slow traffic. Thirdly, and perhaps most surprisingly, radio traffic reports fulfil a social function. Based on traffic updates, motorists can inform people at their destination about their delayed arrival. Also the other way around, non-driving radio listeners sometimes inform motorists that they should expect a jam on their route. The meaning of radio traffic reports should therefore not exclusively be understood in terms of efficient monitoring and adjusting traffic flows on the road: they also affect people's social relationships and interactions.

In this chapter I thus illustrated the complex role of radio traffic reports and traffic information via other media, as part of drivers' search for uncongested roads and highways. Even if this goal cannot always be attained, motorists, once they are truly a captive audience inside their stationary cars in a traffic jam, will seek to find other ways to re-interpret their time on the road. They do so in ways that go beyond the economic model of travelling, in which time in the car is merely spent, rather than enjoyed (for critiques of this view, see Lyons and Urry, 2005; Mokhtarian, 2005). Scholars who investigated the role of sound and sound technologies as part of automobile habitation have helped to explain the reasons for people's preferential attitude towards car travel. In these discussions, auditory control is put forward as an important explanatory factor for clarifying the popularity of the car as our preferred means of transport (see Bull, 2001, 2004; Bijsterveld, 2010, 2014). My research builds on these works by zooming in on the apprehension of traffic information as one element of aural information - integrated into an entertaining radio programme - that helps to inform motorists, while it is at the same time part of an entertaining radio programme.

My study underlines the importance of sound technologies in motorists' search for sensorial solace on the (congested) road. Participants indicated various ways in which the sound technologies inside their car-from their car radio, to audiobooks, to their own music devices - help them to maintain a sense of control and autonomy while being physically stuck in a jam. That way, they seek to reappropriate their time, which is otherwise merely spent. A common strategy to cope with this lack of freedom is to change the station or type of media. Listening to audiobooks or making phone calls are other activities people take up, in order to 
spend their time inside the car more meaningfully. The final sound-related form of making productive use of travel time discussed in this chapter, which covers many but not all strategies people are likely to develop to this end, is to opt out of every form of sound and choose 'silence'. Motorists may enjoy the solitary time inside their vehicle as a moment to relax or think things over. This 'silence' is relative, however, because - as amply demonstrated in the participants' recordings - there is a continuous presence of sounds inside a car, even when all media devices are switched off. These examples illustrate the importance of the affective relationship between cars and their users. As such, my research supports elaborations by other scholars that detail people's affective motives for stepping into their car every single day-motives that go beyond merely rational trade-offs between time and resources. As mobility scholar Kent concluded:

the central proposition [is] that individual decisions to drive are not necessarily motivated by the desire to save time. Instead, automobility is sustained by appeals to flexibility and autonomy, as well as the interminable pull of the sensory experience provided by the cocoon of the car. (Kent, 2014, p. 103)

Radio traffic reports are generally part of motorists' automobile habitation, and as such they are intimately intertwined with the ways in which people listen to their sound technologies and make decisions regarding (the continuity of) their travel plans. For some participants, this evaluation process would even result in a temporary interruption of their trip altogether. By deciding to evade a traffic jam ahead, they may choose other, more meaningful ways to spend their time, such as shopping, eating out or visiting friends. This is a quite favourable choice, considering that these drivers and their cars do not contribute to even more build-up of traffic ahead. As such, this response is even compliant with the aim of traffic reports to change motorists' behaviour in favour of controlling traffic flows. At the same time, however, these motorists transform their commute into a genuine journey: one that is more recreational in nature and breaks away from the more rationalised commuting framework centred around saving time, flexibility and reliability (see Maxwell, 2001). This finding also demonstrates the wider relevance of radio traffic information that goes beyond the mere stimulus-response type of understanding that generally dominates discussions of traffic reports' use and importance.

Taking all these insights together, it becomes clear how radio traffic reports are part of a broad range of practices of automobile habitation. Its role in motorists' decision-making process with regards to their travel plans is highly dependent on the context of every single drive, and every motorist's personal habits and preferences. After having been broadcast for more than half a century, and despite the introduction of newer, advanced traffic information services, many motorists in my research indicated how radio traffic reports are still valuable for them during their everyday automobile travels. This value may not be the same as the objectives of policymakers, engineers or broadcasters, whose aims and strategies were discussed in the previous two chapters. Instead, in this chapter I have shown how the participating drivers in the Netherlands and Germany found additional ways in which they 
apprehend radio traffic reports, and allocate meaning to their automobile listening practices and the time they spend inside their vehicles. 



\section{Conclusion: Enriching the Debate about Automobility}

\section{Returning to the Research Objectives}

In this dissertation, I traced the technologies and organisational forms for gathering and transmitting radio traffic news, the ways in which these reports have been presented on the air, and how traffic information is appropriated by drivers as part of their overall listening while driving. These accounts allow me to show how and to what extent these practices evolved into practices expressing predominant traffic management and policy ideals: that of traffic information as an instrument for optimised traffic flow control. In this final part of the dissertation, I return to this issue by recapitulating how systems of collecting and transmitting radio traffic information developed differently and did not serve equally centralised traffic management purposes in the three countries studied; how radio traffic formats only gradually, and less so in the United States than in the Netherlands and Germany, came to express the bird's eye traffic control ideal; and how some of the drivers responded to traffic news by, at least temporarily, drawing on different concepts of travelling than efficiently moving from A to B. At the same time, I will use this chapter to zoom out in order to reflect more elaborately on the relation between sustainable mobility and radio traffic news and clarify how my historical-comparative and stakeholder-oriented research on radio traffic reporting in three different regions contributes to our understanding of past, present and future high-quality traffic information, as well as to do some modest suggestions for alternative modes of mobility.

A comparison between two recent versions of the Mobility for Growth work programme of the European Commission illustrates the changing role of traffic information in strategies towards more sustainable mobility. In 2014, European policymakers - as expressed in the Horizon2020 Mobility for Growth work programme (2014-2015) considered car radio to be a viable medium for traffic information and recognized its positive impact on more sustainable traffic and transportation. The programme states the ambition of a "smart, green and integrated" European transport system which, as I mentioned in the introduction of this thesis, should be "resource-efficient, climate- and environmentallyfriendly, safe and seamless for the benefit of all citizens, the economy and society" (2014, p. 5). In this definition of the ideal traffic and transport system, the three dimensions of sustainability - capturing ecological, economic and social concerns - all come to the fore. In the most recent version of the same programme (2018-2020), however, the concept of 'sustainability' returns on almost every page, but the positive contribution of radio traffic information as such is nowhere to be found in the programme's calls (European Commission, 2018).

Even though the Horizon2020 research agenda no longer refers to radio traffic information as part of the solution to congested roads, the objective of the call for action towards more sustainable traffic has largely remained the same; yet, rather than radio traffic information specifically, the agenda refers to information and communication technologies more widely. Research efforts should lead to "resource efficient transport that respects the 
environment" (2018, p. 7)-referring to ecological and economic dimensions of sustainability — and, secondly, to

better mobility, less congestion, more safety and security. The aim is to reconcile the growing mobility needs with improved transport fluidity, through innovative solutions for seamless, inclusive, affordable, safe, secure and robust transport systems that will make full use of modern information and communication technologies (ICT) capabilities. (2018, p. 7)

If the social component of sustainability is somewhat scattered across this statement, it becomes clear that new traffic and transport-related technologies should not only contribute to the expectations, safety, affordability and overall satisfaction of people when it comes to their mobility, but also limit its negative impact. Compared to the older version of the work programme, the recent one puts even more emphasis on the deployment of information and communication technologies. This illustrates the propensity of public authorities to trust in the capacity of ever more 'advanced' information and communication technologies to contribute to 'better mobility' in the future.

I would argue that more awareness of the social origin of strategies aimed at more 'sustainable mobility', and their connection to continuously evolving ideas and ideals about what such forms of mobility should entail, may help to explain - and potentially solve - a tension in the operationalisation of 'sustainable mobility'. Policy documents generally articulate a very broad understanding of what 'sustainability' in this context means. It refers first and foremost to the protection of the natural environment, emphasising the need for efficient use of resources and a reduction of pollutants, from air and water degradation to the problem of traffic-related noise (see "Mobility for Growth", 2018, p. 7; 2014, p. 5). At the same time, the four lines of activity proposed in the European Mobility for Growth work programme encompass very diverse kinds of measures in the mobility domain that should "create new opportunities for sustainable growth and development" (2018, p. 6).

This acknowledgement of the intertwinement and interdependencies beyond the mere economic domain in accomplishing desired, sustainable socio-technical change is commendable. However, this view on sustainable change from the present to the future is still lacking a crucial element: a thorough consideration of the ongoing relevance of the past. This is why I traced the main technological and organisational systems that have been developed in Germany, the Netherlands and the New York metropolitan area for distributing consistent, reliable and timely traffic information. This history, addressed in chapter two, shows how pre-existing practices in local contexts shape the development of (new) technological systems in those local environments. This principle was illustrated by my investigation of the developmental trajectory of the Autofahrer Rundfunk Information system (ARI) in Germany, which was a collaborative effort between the German motorist association ADAC, car radio company Blaupunkt, and several public authorities in the domain of radio 
and broadcasting. ARI was sold as a system to help motorists 'steer clear of traffic' promise that combined practical as well as idealistic, or romantic, imagery of automobility.

In the late 1970s and early 1980s, this potential was twinned with the new objective to improve the flow of road traffic through implicit and explicit regulation of traffic flows. Traffic reports thus became conceptualised as a means to control traffic, by directing drivers to roads with sufficient capacity. These aims were in fact well captured by the ARI system's preliminary name: ARI-Travelpilot (the German word Pilot meaning controller or guide). Users of the ARI-equipped car radio, so it was thought, would surely follow the instructions of their own, personal, travel guide. Indeed, after its launch, ARI quickly gained momentum. This can be explained by Blaupunkt's dominant position in the (German) car radio market at the time and the support the initiative received from influential European institutions like the European Broadcasting Union. As a result, ARI became the technical foundation for later technologies, like the Radio Data System and its special traffic-related feature called Traffic Message Channel. These systems, in turn, became worldwide standards for transmitting traffic information via radio.

The significance of local, pre-existing contexts - and the technological trajectories that draw on these contexts - was underlined by my study of Blaupunkt's attempt to export the ARI technology to the United States. There, the most popular radio stations already had a longstanding tradition of aerial traffic reporting, supported by either their own reporters or the services of Shadow Traffic, a commercial party. Even though Blaupunkt's liaisons were able to set up several collaborations with radio stations, the lack of institutional support, centralised radio and traffic policy, and standardised radio transmission protocols obstructed the rapid growth of the ARI system in the New York metropolitan area. Moreover, the technology upon which ARI operated was soon superseded by RDS, which used the same frequency as ARI - and therefore could not be operational at the same time-yet allowed for more technical features than its predecessor.

My historical study of the socio-technical systems for transmitting traffic information is both empirically and theoretically a reminder of what David Edgerton called 'the Shock of the Old'. Specifically, my analysis of the different traffic reporting practices, using the relatively old theoretical concepts of 'trajectory' and 'momentum', reveals how technological innovations build on prior practices and uses of available technologies, both technically and in terms of the underlying motivations. More broadly, my comparativehistorical research on changing socio-technical systems is not solely relevant for our knowledge of technological developments in the past. The concepts of trajectory and momentum help to create a sensitivity for the continued effect that past and current problems and solutions have on the way contemporary problems and strategies are defined and acted upon. Like Edgerton, I therefore favour increased awareness of this relevance of local, historical contexts for the development of new technologies amongst the technicians, policymakers and stakeholders involved in innovation.

Such an approach potentially has a lot to contribute to the conceptualisation and operationalisation of rather implicitly used, broad concepts in policy documents like

\footnotetext{
${ }^{82}$ Bosch Company Archives, unsorted files held by Mr. Kuhlgatz, document reference A/02/86/05/SM8, Blaupunkt Press Release "ARI Erfolgreich auch in den USA. Verkehrsfunk-Service schon von 24 UKW-FM-Sendern in Nordamerika", May 1986, p. 1.
} 
'sustainability'. Rather than taking such concepts at face value, or suggesting definitions that are considered incorrect or unproductive by some relevant stakeholder(s), historical research such as reported in this dissertation can help policymakers, engineers and strategists to find a solid basis for future plans and projects which inevitably have to reckon with the legacy of past plans and projects.

\section{Zooming in on the Meaning of Traffic Reports in Practice}

As argued in this study, radio traffic reports are intended to help construct a sense of flow in two ways. On the road, the reliance on traffic information by drivers should lead to better control of traffic flows. Together, hosts and reporters have to balance the objectives of informing and entertaining their listeners, while also inviting drivers' compliance with implicit or explicit travel suggestions that are aimed at distributing traffic in accordance with continuously changing road capacity. The emphasis on flow also became apparent in discussions on the role of traffic news as part of the overall radio programme. As we have seen, radio hosts and traffic reporters tried hard to integrate traffic updates smoothly into the overall show, and they increasingly had to present their information in less and less airtime, in order not to lose their listeners' attention.

This point was repeated several times during the two expert meetings organised in the fall of 2018, at the end of the research project. In these meetings — attended by radio host Jurgen van den Berg, traffic psychologist Karel Brookhuis and a team of ANWB radio traffic reporters managed by Arnoud Broekhuis. Broekhuis is a traffic information veteran who has been working at the ANWB for 38 years, and 35 years at its traffic information centre. We reflected on my main findings, while also discussing the contemporary relevance of radio traffic reports for their respective professions. All participants in these meetings, irrespective of their specialisation, were very explicit about the crucial role of retaining the attention of the listeners. Van den Berg, host of the Dutch public Radio 1 morning programme, concluded that "you want to keep people tuned in. That is really what you want." This forces him to be incessantly engaged in a quest to avoid so-called "drop-out moments", when listeners turn their radio off or switch to another station (Van den Berg, September 28, 2018).

This is an important consideration for broadcasters operating in a highly competitive market, in which listener ratings play an important role in the financial appraisal of a radio station. Brookhuis even declared somewhat grudgingly how the most important concerns and proposed solutions - regardless of the particularities of the question at hand-always come down to some kind of economic valuation, or, in one word, money (Brookhuis, September $28,2018)$. This implies for Dutch traffic reporters, as explained by Broekhuis, that they have to tailor the content as well as the form of their reports to each of the stations airing their updates. Servicing the stations that way, Broekhuis and Van den Berg agreed, is one additional strategy reporters and hosts have had to develop in order to make the airtime of traffic reports as valuable as possible for their listeners - thus also trying to secure the sustainability of their own professions (Broekhuis, November 2, 2018).

But all these various concerns about flow on the road and on the radio, no matter how pressing today, appear to have been of less importance in the past, and a reconstruction of this discourse in a broader context indicates the interrelation between shifts in traffic 
reporting practices, more competition for listeners amongst radio stations, and the rise of privatised mobility. To understand the continued support for radio traffic updates, the latter is most important. The notion of 'radio flow' was developed at around the time when the problem of congested roads started to become increasingly urgent, while environmental concerns also began to gain momentum. The content of traffic reports thus appears to mirror those evolving trepidations. In fact, very early traffic reports were not about efficient traffic flows at all, nor were they deliberately presented in order to keep the listeners' attention. Instead, early broadcasts for motorists were primarily concerned with traffic safety: warning drivers about the danger of slippery roads, local areas with dense fog or sites of accidents which were still being cleared by the police. It is therefore not surprising that traffic safety featured so prominently in the discourse on radio traffic information in the 1970s. Once the reports evolved into a frequently recurring item and traffic jams became an everyday event, the issue of safety gradually had to compete with new problem definitions and solutions - a process in which concerns about traffic safety gradually receded to the background, to be replaced by objectives that relate to traffic efficiency and flow control.

It is noteworthy to recall how in this evolution of traffic reports' form and content the perspective of traffic reporters changed along. Over time, the detailed and cautionary content of the reporters' updates, in which the reporter almost seemed to accompany the drivers inside their cars, developed into more standardised and abstract summaries of the main problems in terms of traffic flow. In this process the perspective of the reporter shifted from the so-called frog perspective to a bird's eye view on the biggest problems on the roads down below. This broader perspective was in part an effect of the introduction of automated technological systems for gathering and processing traffic information. Because of the availability of more traffic data across a wider geographical region, reporters had more information to refer to in their reports. At the same time, they were increasingly pressed to shorten the length of the reports. As a result, reporters chose to mention only the largest or most striking jams or specific safety hazards on the road. Consequently, the reports - with a few exceptions - became more generic, but the availability of more information also enabled reporters to compare traffic flows and offer suggestions for alternative routes around heavily congested areas. This way, they could contribute more purposely to the improvement of traffic flows.

Of course, the form and content of traffic reports, as well as of traffic information communicated via other means like RDS, websites or other digital applications, will affect the ways in which motorists apprehend and respond to such updates. My study of motorists' listening-while-driving and their comprehension of traffic news has demonstrated how drivers use this information in a variety of ways and for a variety of ends. Surely, they use it to calculate their chance of reaching their destination on time, or they take the information into account when contemplating possible alternative routes. In this respect, timely and precise traffic news may spark some new hope for an enjoyable trip after all.

But in the era of mobile phones, drivers turn to traffic news to coordinate their social relations as well. They may inform others of their delayed arrival, engage in phone calls to spend the extra time in their car productively, or they may decide to change their travel plans altogether and visit other places or people as a substitute to joining or evading a reported jam. Some motorists even argued that traffic news helps to create a sense of community amongst 
listeners, in particular those who are on the road - an observation also put forward for radio listening in general (e.g. Douglas, 1999). Media scholar Michelle Hilmes similarly concluded that "radio has worked most powerfully inside our heads, helping us create internal maps of the world and our place in it, urging us to construct imagined communities to which we do, or do not, belong" (2002, p. 5). I would claim that the locally specific content of radio traffic reports and the easy relatability of the reported problems on the road indeed has the potential to lead to empathy for the people who are stuck out there.

Finally, obtaining traffic information appears to have become part of the practice of automobile driving more generally. As claimed by many participants in this study, obtaining traffic information, through car radio or other information and communication technologies, is part of the everyday practice of preparing and doing their commute, and they generally appreciate their familiarity with the item on the radio or the ease with which they can obtain traffic information via other means. Once informed, participants agreed that they have the possibility to adjust their plans accordingly. The analysis of motorists' experiences additionally shows that, even if the options for alternative travel plans or social interactions from within the car are not explored, car radio and traffic reports are appreciated as sources of aural solace on the road. They enable drivers to re-appropriate their time, for example through listening to music, audiobooks or other types of self-selected media.

In sum, motorists' understanding of traffic reports and their response to them can lead to a wide variety of behaviour. Sometimes, drivers indeed show the desired, controlling effect of traffic information, according to its promotors, and change routes or travel at a different time of day. In those cases, their commute will simply remain their commute. As demonstrated, however, having adequate traffic information can also prompt motorists to redefine the conceptualisation of their time on the road, and turn their trip into a journey. In light of the broad 'sustainable mobility' objectives in contemporary policy documents that draw on the optimal efficiency of automobile travelling, this observation can support us in reconceptualising the relation between traffic news, automobility, and idea(1)s about mobility in the future. This concern will be explored in the section below.

\section{Envisioning New Trajectories}

As I mentioned above, much discourse on the role of traffic information currently centres around developments in telecommunications, and the (possible) influence of these technologies on future strategies for more sustainable traffic. Those strategies are not without some inherent ambiguity, however. In 2012, urban mobility and sustainability researchers Maja Essebo and Guy Baeten published The Contradictions of 'Sustainable Mobility' - the Illogic of Growth and the Logic of Myth, in which they explain the conundrum that is present in discussions on the future of mobility. As they conclude:

The myth of sustainable mobility is a merger of the myth of development as quantitative growth (including mobility growth) and the discourse of sustainability. It draws its power from our fears of the alternative - economic collapse, environmental degradation, ... - while at the same time finding a solution which gives us hope and justifies our behaviour. (2012, p. 563) 
According to Essebo and Baeten there is profound confusion about the meaning and use of the concept of sustainability in any discussion about 'sustainable mobility'. In my view, this does not need to undermine all efforts aimed at generating initiatives to try and change the trajectories on which we currently find ourselves. As Essebo and Baeten indicate, many researchers, engineers, policymakers and private individuals are in search of better, less harmful modes of mobility in the future.

Along with the louder call for improved mobility and the shift away from car radio as a medium for facilitating optimal traffic flows, researchers in various disciplines - ranging from behavioural psychology and civil engineering to computing - have begun to explore the positive relationship between information and communication technologies and the ways in which those technologies can contribute to a more sustainable mobility system. Exemplary work in this domain is that by informatics and sustainability scholar Lorenz Hilty (e.g. Hilty, Lohmann \& Huang, 2011), who promotes research into 'environmental informatics' and 'green information systems'. Some of this research is deeply concerned with ways to persuade individuals to choose for more ecologically sustainable travel options. These studies commonly include an evaluation of real-life trials with new traveller information systems, or an evaluation of the affordances of existing systems that should inform travellers about the most optimal travel option (e.g. Adler \& Blue, 1998).

There is also more attention for other kinds of mobility, however. Researchers are investigating how motorists can be persuaded to use alternative modes of transportation, such as public transport, ridesharing, cycling or a combination thereof (e.g. Kramers, 2014). Psychologists Wokje Abrahamse, Linda Steg, Robert Gifford and Charles Vlek (2009) mapped the thought processes of people when deciding whether or not to use their car. Some scholars have provocatively asked questions about mobility 'after the car' (Dennis \& Urry, 2009). In their edited volume on Automobility in Transition? A Socio-Technical Analysis of Sustainable Transport (2012), transition scholars Frank Geels, René Kemp, Geoff Dudley and Glenn Lyons are less inclined to "take for granted that a transition to sustainable transport will happen," which is why they keep a question mark in the title of their book. Instead, they aim to offer "a socio-technical 'transition theory', which indicates how transitions come about through co-evolutionary processes and multi-level alignments" (p. xiv). Accordingly, the research presented in Automobility in Transition? builds on the premise that automobility is likely to maintain its dominant position within our mobility systems in the foreseeable future. This is why many scholars, myself included, aim to understand why people continue to choose their car as preferred means of transport, even though there is much public concern about the (un)sustainability of this practice.

In a 2018 publication, sociologist Judith Green and her colleagues contributed to this field of research by exploring the motivations and expectations of drivers-to-be-young adults between ages 16 and 21 - concerning automobility before they are allowed to drive. Their conclusion is that they valued the car mostly for non-instrumental reasons, as a personal space, rather than as a vehicle that helps to get you to a destination. Almost as an aside, the authors mention that "environmental sustainability was notably absent from [their] discussions" (2018, p. 14). In these studies it thus becomes clear that the sustained-if not very sustainable - reliance on the car can be explained only when including people's attachment to their car as a personal space. This explains why people are hesitant to choose 
other modes of mobility, even when they have alternative options and are aware of the positive effects of less automobility on fossil fuel use or the emission of greenhouse gasses.

To be able to propose alternative mobility practices, we need detailed descriptions of those practices and the underlying motivations that constitute our everyday mobility. This does not mean that researchers should operate with a narrow focus. On the contrary, if we seek to successfully introduce new mobility practices we must investigate how proposed innovations are compatible with prevailing ways of living our life (or can be made to be so). As proposed by social science scholars Elizabeth Shove and Gordon Walker, we can then discuss ways in which those transitions towards more sustainable everyday routines can be shaped (2010). In many disciplines and for many decades, scholars have been working towards such understandings. To progress into new, more sustainable mobility practices it is now important to combine those insights, approaches and methods. That way we may be able to mediate between the fears of economic downfall, the ideals of environmental sustainability, and the self-interests that are part of our everyday mobility-related choices.

How can my study help further our thinking about the conceptualisation of everyday routines of sustainable mobility? On the basis of my research I will present three short propositions to contribute to this debate. First, traffic information is currently framed within a rather narrow conceptualisation of automobile travelling. People want to go somewhere, and traffic news may help them to realise that objective. In doing so, however, traffic information exclusively focusses people's attention on the route between their point of departure and their intended destination. To relieve the simultaneous, mass traffic on the main roads, it may also be productive to inform drivers about places in their vicinity where they can spend some time and experience something new, like a small village museum, a farmers market or a freely accessible but somewhat hidden sculpture garden. If the popularity of private automobility continues to grow, such information - which is another form of nudging indeed - could help to lower the traffic density in particular areas and at the same time enrich people's experience of their surroundings. This involves, in other words, the act of transforming their commute into a journey, just as some of my respondents at times claimed to do already.

A second reconfiguration of people's everyday automobility can be stimulated by facilitating social engagement amongst drivers on the road, or between drivers and their own social network. For example, navigation systems and smartphone applications can be deployed to notify motorists about the presence of friends, family or acquaintances along the same route, in line with the aural solace that radio has often provided. That way, people might be encouraged to invigorate real-life social contacts that, according to recent publications on media use, happiness and loneliness, are currently under strain (see Freitas, 2017; Wadhwa $\&$ Salkever, 2018). Of course, the inclusion and display of such information comes with particular concerns, such as privacy. Still, from the angle of the need to reduce traffic density, such applications may harbour promising options.

Thirdly, we can think of ways to reconceptualise mobility altogether. The need for commuting could be sized down if the distance between people's homes and workplaces would decrease. Additionally, commuters may (need to) consider alternative modes of mobility. Here we enter the domain of many researchers in the field of information and communication technologies aimed at improving multimodal mobility in order to disrupt the 
massive use of private cars. One example from this field of research is the study by Anna Kramers (2014), who suggests the possibility of integrating information about public transport in car traffic information systems. Another suggestion she offers on the basis of her qualitative study intro travel information is to provide travellers with quantitative information about the carbon footprint of various mobility options. These alternative forms of 'traffic information' may help to persuade car commuters to leave their automobile at home for a day. Some of the participants in my study in fact claimed that they would welcome such information technologies, and some of them spontaneously hypothesised similar ways that would encourage them not to use their car.

Whichever new strategies will be developed, I call upon scholars and policymakers who are concerned with automobility, traffic information, and the management of traffic flow, to take the aural environment of motorists into account when evaluating the possible impact of any proposed measures. This includes studies on the efficacy of radio traffic reports and other forms of in-car traffic information. Each of the audio recordings of the twenty participants in my study in fact revealed a different soundscape. While there may be no way to account for those differences in discussions on the strategic communication or efficacy of traffic information, the sounds motorists are surrounded by will affect the ways in which they can process and respond to the aurally presented information. This does not only apply to the perception of aural information; a driver is always confronted with both sonic and visual input. As visuals are notorious for impeding people's attention on the road in front of them, I would argue that developers of new, 'advanced' information technologies should stay attuned to people's sense of hearing as well.

\section{Conclusion: Where the Past, Present and Future Meet, Again}

Once I started researching the phenomenon of radio traffic information and its relation to ideas about mobility and people's individual mobility practices, I was frequently reminded that the meaning of the word 'mobility' transcends preliminary associations with the ability to physically 'be mobile'. My own academic endeavours also implied constant movement: physically, but especially mentally. I managed to find my way through ever-growing numbers of sources, evolving ideas, new (or re-gained) insights, and of course I tried to communicate part of the knowledge I acquired to other audiences.

Based on the approach and source materials selected, this study is a contribution to our collective knowledge about the phenomenon of radio traffic information. Of course, as my research progressed I continuously had to make decisions on the insights, observations, representations of sounds, and reflections that I wanted to present and connect, or leave out. This process reminded me of the poem "The Road Not Taken" by Robert Frost (1916). The first stanza starts with the following line: "Two roads diverged in a yellow wood, and sorry I could not travel both." In the second part of the poem, the protagonist looks down both roads, and decides to take the one of the two. He then reminisces: "Yet knowing how way leads on to way, I doubted if I should ever come back." The poem ends with the following lines: 
I shall be telling this with a sigh

Somewhere ages and ages hence:

Two roads diverged in a wood, and I-

I took the one less travelled by,

And that has made all the difference.

"The Road Not Taken" is one of the most popular poems of all time. According to poetry expert David Orr, it is also the "most misread poem in America" (Orr, 2015). A popular, positive reading of the four verses results in a romantic celebration of venturing into the unknown: "I took the [road] less travelled by, and that has made all the difference." The opposite, however, is also possible: in those last lines the protagonist is perhaps lamenting the decision made, and ponders over what could have been otherwise had he taken the other road.

In this dissertation, I have 'talked you through' important parts of the rich and complex history of radio traffic broadcasting and the listening practices of motorists since the 1950s. The last lines of "The Road Not Taken"-notwithstanding the ambiguity about their meaning or interpretation, or precisely because of this ambiguity - can represent the processes in which people who are concerned with and use radio traffic reporting continuously make decisions about what is the best route - figuratively as well as literallyto follow. All protagonists in this study have made decisions that have affected the encompassing socio-technical system of traffic reports, and they will continue to do so in the future no matter how our modes of mobility will evolve. This knowledge about the seemingly mundane phenomenon of radio traffic reports can be used as a source of inspiration for investigating important discussions about changes in our mobility system and our ideals for a more sustainable future in new ways. 
Conclusion 



\section{Bibliography}

Abrahamse, W., Steg, L., Gifford, R., \& Vlek, C. (2009). Factors influencing car use for commuting and the intention to reduce it: A question of self-interest or morality? Transportation Research Part F: Traffic Psychology and Behaviour, 12(4), 317-324.

ADAC (2018). Staubilanz 2017. Retrieved November 28, 2018, from https://www.adac.de/_mmm/pdf/statistik_staubilanz_231552.pdf

Adler, J. L., \& Blue, V. J. (1998). Toward the design of intelligent traveler information systems. Transportation Research Part C: Emerging Technologies, 6, 157-172.

Akerboom, S. P. (1988). Het gebruik en effect van (radio)verkeersinformatie: Een schriftelijk vragenlijstonderzoek. Leiden: Rijksuniversiteit Leiden.

Akerboom, S. P. (1989). Het begrijpen en onthouden van radioverkeersinformatie. Een onderzoek naar het optimaliseren van verkeersinformatie. Leiden: Faculteit der Sociale Wetenschappen, Werkgroep Veiligheid.

Akker, P. van den (2015). Nederland staat stil bij 60-jarige file. Retrieved November 6, 2018, from https://www.bnr.nl/nieuws/mobiliteit/10041972/nederland-staat-stil-bij-60-jarige-file.

Allan, S. (2010). News Culture (3 ed.). Maidenhead [etc.]: McGraw-Hill Open University Press.

Angus, R., \& Harrys, M. (1983). Tuning in on traffic. Citizen-Register(October 23), 58-59.

Bartsch, H. (1997). Der automatische, digitale Informationsfluß im Verkehr. POLIZEI-Heute(5), 134138.

Baudrillard, J. (1989). America. London: Verso Books.

Beale, T., \& Kopitz, D. (1993). RDS in Europe, RBDS in the USA - What are the differences and how can receivers cope with both systems? EBU technical review(Spring), 5-11.

Beerling, J. (1989) RDS: A Revolution for Radio. EBU Review, Programmes, Administration, Law, 11(2), 30-32.

Belt, H. van der, \& Rip, A. (1987/2012). The Nelson-Winter-Dosi Model and Synthetic Dye Chemistry. In W. Bijker, T. P. Hughes, \& T. Pinch (Eds.), The Social Construction of Technological Systems, 129-153. Massachusetts: MIT Press.

Ben-Elia, E., Pace, R. di, Bifulco, G. N., \& Shiftan, Y. (2013). The impact of travel information's accuracy on route-choice. Transportation Research Part C - Policy and Advice, 26, 146-159.

Bijker, W. E. (1995). Of bicycles, bakelites, and bulbs: Toward a theory of sociotechnical change: MIT press.

Bijsterveld, K. (2010). Acoustic cocooning: How the car became a place to unwind. Senses \& Society, $5(2), 189-211$.

Bijsterveld, K., Cleophas, E., Krebs, S., \& Mom, G. P. A. (2014). Sound and Safe. A History of Listening Behind the Wheel. Oxford: Oxford University Press.

Bijsterveld, K. \& Dieker, M. (2015). A Captive Audience: Traffic Radio as Guard and Escape. Journal of Radio \& Audio Media, 22(1), 20-25.

Blokpoel, A., \& Niet, M. de (2000). Spookrijders en frontale botsingen op autosnelwegen. Omvang en ontwikkeling van de onveiligheid door het rijden in de verkeerde rijrichting in de periode $t / m$ 1998. Leidschendam: Stichting Wetenschappelijk Onderzoek Verkeersveiligheid SWOV.

Blomkvist, P. (2004). Transferring Technology--Shaping Ideology: American Traffic Engineering and Commercial Interests in the Establishment of a Swedish Car Society, 1945-1965. Comparative technology transfer and society, 2(3), 273-302. 


\section{Bibliography}

Bogner, G. (1979). Broadcasts for motorists: European cooperation between radio stations. EBU Review, 6, 17-19.

Bogner, G. (1981). Radio on European Routes. EBU Review, 32(2), 12-13.

Boon, L. (2015, June 8). 'We staan al zestig jaar in de file'. NRC. Retrieved November 23, 2018, from https://www.nrc.nl/nieuws/2015/06/08/we-staan-al-zestig-jaar-in-de-file-a1496197

Bornstein, R. (1983). Levy, Schwartz get new posts at Shadow Traffic. Billboard, 12(10), 13.

Bosch, A., \& Ham, W. van der (1998). Twee eeuwen Rijkswaterstaat 1978-1998. Zaltbommel: Europese Bibliotheek.

Brägas, P. (1973). Verkehrsrundfunk. Bosch Technische Berichte, 4(5), 179-189.

Brägas, P. ([1974]). Verkehrsrundfunk und elektronische Verkehrslenkung. Techniken der Zukunft, special edition for the Blaupunkt Werke $\mathrm{GmbH}, 1-8$.

Brodsky, W. (2002). The effect of music tempo on simulated driving performance and vehicular control. Transportation Research Part F: Traffic Psychology and Behaviour, 4, 219-241.

Brown, I.D., \& Poulton, E. (1961). Measuring the spare 'mental capacity'of car drivers by a subsidiary task. Ergonomics, 4(1), 35-40.

Brown, I. D. (1965). Effect of a car radio on driving in traffic. Ergonomics, 8(4), 475-479.

Brown, B. J., Hanson, M. E., Liverman, D. M., \& Merideth, R. W. (1987). Global sustainability: toward definition. Environmental management, 11(6), 713-719.

Buiter, H., \& Volkers, K. (1996). Oudenrijn: de geschiedenis van een verkeersknooppunt. Utrecht: Matrijs.

Bull, M. (2001). Soundscapes of the car: A critical study of automobile habitation. In D. Miller (Ed.), Car Cultures, 185-202. Oxford [etc]: Berg.

Bull, M. (2004). Automobility and the power of sound. Theory, Culture and Society, 21(4-5), 243-259.

CBS (2000). Aantal verkeersdoden daalt gestaag. 2018(April 20). Retrieved July 17, 2018, from https://www.cbs.nl/nl-nl/nieuws/2000/39/aantal-verkeersdoden-daalt-gestaag.

CBS (2018). Meer kilometers dan ooit door Nederlandse wegvoertuigen. Retrieved November 29, 2018, from https://www.cbs.nl/nl-nl/nieuws/2018/45/meer-kilometers-dan-ooit-doornederlandse-wegvoertuigen.

Chorus, C. G., Molin, E. J. E., \& Wee, B. van (2006). Use and effects of Advanced Traveller Information Services (ATIS): A review of the literature. Transport Reviews, 26(2), 127-149.

Coutard, O. (1999). The Governance of Large Technical Systems. London: Routledge.

Crisell, A. (1994). Understanding Radio (2nd ed.). London: Routledge.

Crisell, A. (2012). Liveness and Recording in the Media. Basingstoke: Palgrave Macmillan.

Dammen, R. M. C. van, \& Overste, A. M. (1976). Filevorming bij Oudenrijn. Hilversum: Nederlandse Omroep Stichting, afd. Kijk- en Luisteronderzoek.

Dennis, K., \& Urry, J. (2009). After the Car. Cambridge: Polity Press.

Dibben, N., \& Williamson, V. J. (2007). An exploratory survey of in-vehicle music listening. Psychology of Music, 35(4), 571-589.

Dieker, M. (2016, 28 september). Er is verkeersinformatie... [edited radio interview]. In: M. Beekhuis (producer), Wetenschap Vandaag. Amsterdam: BNR Nieuwsradio. Retrieved February 9, 2019, from http://www.bnr.nl/radio/wetenschap-vandaag/10311517/er-isverkeersinformatie

Dieker, M. (2018). Keep Moving, Stay Tuned: the construction of flow in and through radio traffic reports. Transfers: interdisciplinary journal of mobility studies, 8(2), 67-86.

Dosi, G. (1982). Technological paradigms and technological trajectories. A suggested interpretation of the determination and directions of technical change. Research Policy, 11, 147-162. 
Dosi, G., \& Nelson, R. R. (1994). An introduction to evolutionary theories in economics. Journal of Evolutionary Economics, 4(3), 153-172.

Douglas, S. J. (1999). Listening In: Radio and the American Imagination, from Amos ' $n$ ' Andy and Edward R Murrow to Wolfman Jack and Howard Stern. New York: Times Books.

Edgerton, D. (2006). The Shock of the Old. Technology and Global History since 1900. London: Profile Books.

Eichengreen, B., Uzan, M., Crafts, N., \& Hellwig, M. (1992). The Marshall Plan: Economic Effects and Implications for Eastern Europe and the Former USSR. Economic Policy, 7(14), 14-75.

Ellis, J. (1982). Visible Fictions. Cinema, Television, Video. London: Routledge.

Emmerink, R. H. M., Nijkamp, P., Rietveld, P., \& Ommeren, J. N. van (1996). Variable message signs and radio traffic information: an integrated empirical analysis of drivers' route choice behaviour. Transportation Research Part A: Policy and Practice, 30(2), 135-153.

Emmerink, R. H. M., \& Nijkamp, P. (Eds.). (1999). Behavioural and Network Impacts of Driver Information Systems. London: Ashgate.

Ettema, D., \& Timmermans, H. J. P. (2006). Costs of travel time uncertainty and benefits of travel time information: Conceptual model and numerical examples. Transportation Research Part C - Policy and Advice, 14(5), 335-350.

European Broadcasting Union (1998). RDS-TMC. What is it all about? Geneva: EBU/EUR.

European Commission (2014). Horizon2020 work programme 2014-2015, Part 11: Smart, green and integrated transport. Call - Mobility for Growth.

European Commission (2018). Horizon2020 work programme 2018-2020, Part 11: Smart, green and integrated transport. Call - Mobility for Growth.

Everts, K., Olberding, M., \& Schneider, H.-W. (1994). BEssere VErkehrsInformation Fedversuch mit RDS-TMC. Zusammenfassender Schlussbericht. Projectbur BEVEI, report number TV91079110, 9354.

Fein, M. R., (2007). New York State road networks and the transformation of American federalism. In G. P. A. Mom \& L. Tissot (Eds.), Road History. Building, Planning and Use, 63-75. Neuchâtel: Alphil.

Flink, J. J. (1988). The Automobile Age. Cambridge, MA: MIT Press.

Forgber, H. (1972). So funktioniert der Autofahrerfunk. Motorwelt, 25(10), 40-47.

Freitas, D. (2017). The Happiness Effect: How Social Media is Driving a Generation to Appear Perfect at Any Cost: Oxford University Press.

Frost, R. (1916). The Road Not Taken. In Mountain Interval. New York: Henry Hold and Company.

Fuller, K. L., \& Lambell, A. J. (1970). Analyse van verkeersstromen met behulp van radar. Philips Technisch Tijdschrift, 31(1), 18-24.

Gan, H.-C., Bai, Y., \& Wei, J. (2013). Why do people change routes? Impact of information services. Industrial Management \& Data Systems, 113(3), 403-422.

Gecoördineerde verkeersinformatie (1969). De Kampioen (January), 15.

Geels, F. W. (2002). Technological transitions as evolutionary reconfiguration processes: a multilevel perspective and a case-study. Research Policy, 31(8-9), 1257-1274.

Geels, F. W., Kemp, R., Dudley, G., \& Lyons, G. (2012). Automobility in Transition? A Socio-Technical Analysis of Sustainable Transport. London: Routledge.

Gould, P., \& White, R. (2012). Mental maps. London: Routledge.

Green, J., Steinbach, R., Garnett, E., Christie, N., \& Prior, L. (2018). Automobility reconfigured? Ironic seductions and mundane freedoms in 16-21 year olds' account of car driving and ownership. Mobilities, 13(1), 14-28.

Gripsrud, J. (2002). Understanding Media Culture. London: Arnold. 


\section{Bibliography}

Gross, J. (1985). Radio programming and production: ARI gives radio traffic a "boost." Broadcast Management \& Engineering, 21(5), 27-30.

Hendriks, R. (1979). Binnenkort radio-verkeersinfo-systeem in Nederland? De Kampioen(December), 1135-1137.

Hendy, D. (2000). Radio in the Global Age. Oxford: Polity Press.

Henrich-Franke, C. (2016). Broadcasts for Motorists: Traffic Radio and the Transnationalisation of European Media Cultures. Spiel, 2016(1), 91-105.

Hilft-Autofahrern unterwegs. (1976). Bosch Zünder, 56(3), 2.

Hilmes, M. (2002). Rethinking radio. In M. Hilmes \& J. Loviglio (Eds.), Radio Reader: Essays in the Cultural history of Radio, 1-19. New York: Routledge.

Hilty, L., Lohmann, W., \& Huang, E. (2011). Sustainability and ICT-an overview of the field. Politeia, 27(104), 13-28.

Hinlopen, H. (1971). Uw auto en de electronica. Deventer: Kluwer.

Hommels, A. (2001). Unbuilding Cities: Obduracy in Urban Sociotechnical Change. (PhD dissertation), Maastricht University, Maastricht.

Hounshell, D. A. (1995). Hughesian history of technology and Chandlerian business history: Parallels, departures, and critics. History and Technology, an International Journal, 12(3), 205-224.

Hughes, T. P. (1993). Networks of power: electrification in Western society, 1880-1930: JHU Press.

Hughes, T. P. (1987/2012). The Evolution of Large Technological Systems. In W. Bijker, T. P. Hughes, \& T. Pinch (Eds.), The Social Construction of Technological Systems. New Directions in the Sociology and History of Technology, 45-76. Massachusetts: MIT Press.

Hütter, A. (2013). Verkehr auf einen Blick. Wiesbaden: Statistischer Bundesamt. Report number 0080006-13900-1.

INRIX (2015). Verkeer in Nederland dealt terwijl economie en arbeidsmarkt langzaam aantrekken; Blijft tweede land van Europa met hoogste filedruk. Retrieved January 25, 2018, from http://inrix.com/press-releases/scorecard-nl/

INRIX (2018). Los Angeles Tops INRIX Global Congestion Ranking. Retrieved June 15, 2018, from http://inrix.com/press-releases/scorecard-2017/

Jacobs, F. (2015, November 17). The beginning of the end for radio traffic reports? [blog post] Retrieved July 17, 2018, from http://jacobsmediablog.com/2015/11/17/stay-tuned-fortraffic-and-weather-on-my-iphone/

Jenkins, H. (2006). Convergence Culture. Where Old and New Media Collide. New York: NYU press.

Joerges, B. (1988). Large technical systems: Concepts and issues. In R. Mayntz \& T. P. Hughes (Eds.), The Development of Large Technical Systems, 9-36. Frankfurt am Main: Campus Verlag.

Kaufmann, V. (2009). Mobility: Trajectory of a concept in the social sciences. In G. Mom, G. Pirie, \& L. Tissot (Eds.), Mobility in History: The State of the Art in the History of Transport, Traffic and Mobility. Neuchâtel: Alphil.

Keen, K., \& Murphy, E. (1992). DRIVE '92. Research and Technology Development in advanced Road Transport Telematics in 1992. Brussels: Commission of the European Communities.

Kemp, R., Rip, A., \& Schot, J. (2001). Constructing transition paths through the management of niches. In R. Garud \& P. Karnoe (Eds.), Path Dependence and Creation, 269-299. Mahwah, NJ [etc]: Lawrence Erlbaum.

Kent, J. L. (2014). Driving to save time or saving time to drive? The enduring appeal of the private car. Transportation Research Part A: Policy and Practice, 65, 103-115.

Kent, J. L. (2015). Still feeling the car. The role of comfort in sustaining private car use. Mobilities, 10(5), 726-747.

Kerncijfers Mobiliteit 2018. (2018). Den Haag: Kennisinstituut voor Mobiliteit. 
Kinnear, N., \& Stevens, A. (2015). The battle for attention. Driver distraction - a review of recent research and knowledge. London: Institute of Advanced Motorists

Kirschfink, H., Poschmann, M., \& Ziegler, U. (2002). Verkehrsinformationszentrale: Rolle und Konzeption dargestellt am Beispiel der VIZ NRW. Straßenverkehrstechnik, 46(12).

Klijnhout, J. J. (1972). Auditieve signalering. Verkeerstechniek, 23(6), 286-289.

Kopitz, D., \& Marks, B. (1999). RDS: The Radio Data System. London: Artech House.

Kramers, A. (2014). Designing next generation multimodal traveller information systems to support sustainability-oriented decisions. Environmental Modelling \& Software, 56, 83-93.

Kranker Verkehrsfluss. (1952). Motorwelt, 5(11), 10.

Lamm, R., Psarianos, B., Choueiri, E. M., \& Mailaender, T. (1993). Interchange Planning and Design: An international perspective. Transportation Research Record (1135), 69-83.

Laurier, E., Lorimer, H., Brown, B., Jones, O., Juhlin, O., Noble, A., . . . Strebel, I. (2008). Driving and 'passengering': Notes on the ordinary organization of car travel. Mobilities, 3(1), 1-23.

Leisch, J. P. (1993). Freeway and Interchange Design: A Historical Perspective. Transportation Research Record(1135), 60-68.

Lupton, D. (1999). Monster in metal cocoons: 'road rage and cyborgs'. Body and Society, 5(1), 57-72. Lynch, K. (1960). The Image of the City. Massachussets: MIT press.

Lyons, G., \& Urry, J. (2005). Travel time use in the information age. Transportation Research Part A: Policy and Practice, 39(2-3), 257-276.

MacFarquhar, N. (1997, 3 July). Most Radio News of Roads Comes From 2 Services. The New York Times. Retrieved February 21, 2019, from ttps://www.nytimes.com/1997/07/03/nyregion/ most-radio-news-of-roads-comes-from-2-services.html

Maxwell, S. (2001). Negotiations of car use in everyday life. In D. Miller (Ed.), Car Cultures, 203-222. Oxford [etc]: Berg.

Mayntz, R., \& Hughes, T. P. (Eds.). (1988). The development of large technical systems: Frankfurt am Main: Campus Verlag.

McLeish, R. (1994). Radio Production. Oxford: Focal Press.

McShane, C. (1997). The Automobile. A Chronology of its Antecedents, Development, and Impact. London: Fitzroy Dearborn.

Merriman, P. (2009). Automobility and the geographies of the car. Geography Compass, 3(2), 586599.

Merriman, P., \& Pearce, L. (2017). Mobility and the humanities. Mobilities, 12(4), 493-508.

Meyer, L. (1999). Thema des Monats: Verkehrsfunk. Bosch Zünder, 78(8/9).

Miller, D. (Ed.) (2001). Car Cultures. Oxford [etc]: Berg.

Ministeriële Werkgroep Radioverkeersinformatie (1982). Radioverkeersinformatie. Den Haag: Ministerie van Verkeer en Waterstaat.

Mokhtarian, P. L. (2005). Travel as a desired end, not just a means. Transportation Research Part A: Policy and Practice, 39(2-3), 93-96.

Mom, G. P. A., \& Filarski, R. (2008). Van transport naar mobiliteit: De mobiliteitsexplosie (19002000). Zutphen: Walburg Press.

Mom, G. P. A., Schot, J. W., \& Staal, P.-E. (2002). Werken aan mobiliteit: de inburgering van de auto. In J. W. Schot \& A. A. Albert de la Bruhèze (Eds.), Techniek in Nederland in de twintigste eeuw (Vol. 5, pp. 45-74). Zutphen: Walburg Pers.

Moores, S. (1993). Television, geography and 'mobile privatization'. European Journal of Communication, 8, 365-379.

Nelson, R. R., \& Winter, S. G. (1977). In search of a useful theory of innovation. Research Policy, 6, 36-76. 


\section{Bibliography}

Nissan (2014) Raising Fuel Efficiency. Eco-Drive Support Technology. Retrieved February 25, 2015 from http://www.nissan-global.com/EN/ENVIRONMENT/CAR/FUEL_COST/GASOLINE/

Oei, H.-L. (1976). Informatiesysteem in het wegverkeer. Verkeerskunde, 27(5), 252-255.

Orr, D. (2015, September 11). The Most Misread Poem in America [blog]. Retrieved January 17, 2019, from https://www.theparisreview.org/blog/2015/09/11/the-most-misread-poemin-america/

Ory, D. T., \& Mokhtarian, P. L. (2005). When is getting there half the fun? Modeling the liking for travel. Transportation Research Part A: Policy and Practice, 39(2-3), 97-123.

Oswald, K., \& Packer, J. (2012). Flow and Mobile Media: Broadcast Fixity to Digital Fluidity. In J. Packer \& S. B. Crofts Wiley (Eds.), Communication Matters: Material Approaches to Media, Mobility and Networks, 276-287. London: Routledge.

Packer, J., \& Oswald, K. F. (2010). From windscreen to widescreen: screening technologies and mobile communication. The Communication Review, 10(4), 309-339.

Pinch, T. J., \& Bijker, W. E. (1987/2012). The social construction of facts and artifacts: Or how the sociology of science and the sociology of technology might benefit each other. In W. E. Bijker, T. Hughes, \& T. J. Pinch (Eds.), The Social Constructions of Technological Systems: New Directions in the Sociology and History of Technology (pp. 11-43). Cambridge: MIT Press.

Politiedeskundigen in Eindhoven bestudeerden verkeer per TV. (1957, October 11). Haagsche Courant.

Preis für das ARI-System. (1975). Bosch Zünder, 55(4), 1.

Radioprogramm für Autofahrer. (1970). Bosch Zünder, 50(9), 224.

Randell, R. (2017). The microsociology of automobility: The production of the automobile self. Mobilities, 12(5), 663-676.

Recommendations of EUROTRAVEL '88 (1989) EBU Review. Programmes, Administration, Law, 11(2), 35.

Rees, R. van (1995). TMC voor buitenlands verkeer. Directe verkeersinformatie in je moerstaal. Verkeersknooppunt: Tijdschrift van de Verkeersschool van het Korps Rijkspolitie (5), 16-17.

Renn, A. M. (2016, Released online June 1, 2016). When New York City tried to ban cars - the extraordinary story of 'Gridlock Sam'. The Guardian. Retrieved June 15, 2018, from https://www.theguardian.com/cities/2016/jun/01/new-york-city-ban-cars-gridlock-samschwartz-manhattan

Riley, J. L., \& McParland, A. K. (1991). RDS-ALERT: A proposed Traffic Message Channel (TMC) feature for the Radio Data System (RDS). London: British Broadcasting Corporation, research department, engineering division.

Sabo, W. (1997). Treating traffic as a top priority. Radio \& Records (November 21), 32.

Salomon, I., \& Mokhtarian, P. L. (1998). What happens when mobility-inclined market segments face accessibility-enhancing policies? Transportation Research Part D: Transport and Environment, 3(3), 129-140.

Schneider (1952). Straßenwetterdienst als Beitrag zur Verkehrssicherheit. Motorwelt, 5(1), 15.

Schneider, R. (1973). Einheitlicher Verkehrsfunk noch in weiter Ferne. Bild der Wissenschaft (october), no page.

Sheller, M. (2004). Automotive emotions: feeling the car. Theory, Culture and Society, 21(4-5), 221242.

Sheller, M., \& Urry, J. (2006). The new mobilities paradigm. Environment and Planning A, 38(221242).

Sheller, M. (2014). The new mobilities paradigm for a live sociology. Current Sociology, 62, 789-811. 
Shove, E., \& Walker, G. (2010). Governing transitions in the sustainability of everyday life. Research Policy, 39(4), 471-476.

Siedenbiedel, C. (2014, 24 August). Im Stau. Frankfurter Allgemeine Sonntagszeitung.

Silverstone, R. (2003). Preface to the Routledge Classics Edition. In R. Williams (Ed.), Television: Technology and Cultural Form (pp. vii-xiii). New York: Routledge.

Simmel, G. (1997). The Metropolis and Mental Life. In D. Frisby \& M. Featherstone (Eds.), Simmel on Culture, 174-186. London: Sage.

Smids, J. (2012). The voluntariness of persuasive technology. In Bang, M. \& Ragnemalm, E. (Eds.) Proceedings of Persuasive Technology. Design for Health and Safety Conference, 123-132. Springer.

Sovacool, B. K., Lovell, K., \& Ting, B. (2018). Reconfiguration, Contestation and Decline: Conceptualizing Mature Large Technical Systems. Science, Technology \& Human Values, online, 1-32.

Space Speaks. Wireless on Taxi Cabs. (1929, June 29). The Sun.

Staudenmaier, J. (1985). Technology's Storytellers: Reweaving the Human Fabric. Cambridge, MA: The Society for the History of Technology and the MIT Press.

Subsidiary Communications Authorization. (2010). In C. H. Sterling \& C. O'Dell (Eds.), The Concise Encyclopedia of American Radio. New York: Routledge.

Suchman, E. A. (1939). Radio listening and automobiles. Journal of Applied Psychology, 23(1), 148157.

Summerton, J. (1994). The Systems Approach to Technological Change. In J. Summerton (Ed.), Changing Large Technical Systems, 1-24. Boulder: Westview Press.

Thaler, R. H., \& Sunstein, C. R. (2008). Nudge: Improving Decisions About Health, Wealth and Happiness. New Haven: Yale University Press.

Tseng, Y.-Y., Knockaert, J., \& Verhoef, E. T. (2013). A revealed preference study of behavioural impacts of real-time traffic information. Transportation Research Part C: Emerging Technologies, 30, 196-209.

Ünal, A. B., Waard, D. de, Epstude, K., \& Steg, L. (2013). Driving with music: Effects on arousal and performance. Transportation Research Part F: Traffic Psychology and Behaviour, 21(0), 52 65.

Urry, J. (1999). Automobility, car culture and weightless travel: A discussion paper. Retrieved July 17, 2018, from http://www.comp.lancs.ac.uk/sociology/papers/Urry-Automobility.pdf.

Urry, J. (2000) Sociology beyond Societies: Mobilities for the Twenty-first Century. London: Routledge Urry, J. (2004). The 'system' of automobility. Theory, Culture \& Society, 24(4-5), 25-39.

Urry, J. (2006). Inhabiting the Car. The Sociological Review, 51(S1), 17-31.

Urry, J. (2007). Mobilities. Cambridge: Polity Press.

Vleuten, E. van der, \& Kaijser, A. (Eds.) (2006), Networking Europe: transnational infrastructures and the shaping of Europe 1850-2000. Sagamore Beach: Science History Publications.

Vleuten, E. van der (2006). Understanding network societies: Two decades of large technical system studies. In E. Van der Vleuten \& A. Kaijser (Eds.), Networking Europe: transnational infrastructures and the shaping of Europe 1850-2000, 279-314. Sagamore Beach: Science History Publications.

Vanderschuren, M. J. W. A., \& Sijtsema, A. (2000). The future of the Dutch traffic information centre. Paper presented at the 7th World Congress on Intelligent Transport Systems, Turin.

Verbeek, P.-P. (2006). Persuasive Technology and Moral Responsibility Toward an ethical framework for persuasive technologies. Persuasive, 6, 1-15.

Verkeersinformatie. (1983). De Kampioen (June), 32-33. 


\section{Bibliography}

Verkeersinformatie in Nederland. (1975). De Kampioen (May), 344-345.

Vogel, H. W. (1875). Handbook of the Practice and Art of Photography. Philadelphia: Sherman \& Co.

Volek, T. W. (1993). Examining the emergence of broadcasting in the 1920s through magazine advertising. Journal of Radio Studies, 2(1), 99-122.

Wadhwa, V., \& Salkever, A. (2018). Your Happiness Was Hacked: Why Tech Is Winning the Battle to Control Your Brain And How to Fight Back. Oakland: Berrett-Koehler Publishers.

Walbeehm, T. B. (1959). De psycholoog en zijn arbeidsterrein met betrekking tot automobilisten en wegverkeer. Tijdschrift voor Verkeerstechniek, 10(1), 6-8.

Wassens, R. (2019, January 22). ANWB: sneeuwval leidt tot absoluut filerecord. NRC. Retrieved May 22, 2019, from https://www.nrc.nl/nieuws/2019/01/22/anwb-sneeuwval-leidt-totabsoluut-filerecord-a3651274.

Weber, H. (2008). Das Versprechen mobiler Freiheit. Zur Kultur- und Technikgeschichte von Kofferradio, Walkman und Handy. Bielefeld: Verlag.

Weber, H. (2011). Mobile electronic media: Mobility history at the intersection of transport and media history. Transfers, 1(1), 25-49.

Wer hört, fährt besser... Autoradio dient der Sicherheit. (1969). Bosch Zünder, 49(7), 179-180.

Wilkins, G. (1973, January 21). The Observer, 25.

Williams, R. (1999). Programming as Sequence or Flow. In P. Marris \& S. Thornham (Eds.), Media Studies: A Reader, 231-237. Edinburgh: Edinburgh University Press.

Williams, R. (1974/2003). Television: Technology and Cultural Form. London: Routledge.

Zo werkt de radio-verkeersinformatie. (1978). De Kampioen (September), 824.

Zukunftsmusik für Autofahrer. (1968). Bosch Zünder, 48(1), 18-19.

Zwaag, M. van der (2012). Music Directs Your Mood. Rijksuniversiteit Groningen, Groningen.

Zwaag, M. van der, Dijksterhuis, C., Waard, D. de, Mulder, B. L. J. M., Westerink, J. H. D. M., \& Brookhuis, K. A. (2012). The influence of music on mood and performance while driving. Ergonomics, 55(1), 12-22. 
Bibliography 



\section{Archives, Field Visits, Interviews and Correspondences}

\section{Corporate and institutional archives:}

Philips Company Archives, Eindhoven, the Netherlands.

Bosch Company Archives, Stuttgart, Germany.

Nederlands Instituut voor Beeld en Geluid, Hilversum, the Netherlands.

SWR Archives, Stuttgart, Germany.

Paley Center for Media, New York, United States of America.

Rodgers and Hammerstein Archives of Recorded Sound, New York, United States of America.

\section{Field visits:}

ANWB traffic information center. June 15, 2015 + November 2, 2018, The Hague, the Netherlands. Landesmeldestelle für den Verkehrswarndienst Stuttgart. February 6,2017, Stuttgart, Germany. NPO Radio 1. June 22, 2017, Hilversum, the Netherlands.

Port Authority of New York and New Jersey. March 14, 2018, New Jersey, United States of America. SWR 1, February 23, 2016 + February 23, 2017, Stuttgart, Germany.

Total Traffic and Weather, March 12, 2018. New Jersey, United States of America.

WCBS880, March 5, 2018. New York, United States of America.

1010WINS, March 15, 2018. New York, United States of America.

\section{Expert interviews:}

Jurgen van den Berg, radio host Radio 1. April 13, 2017 (telephone) + June 22, 2017 (Hilversum, the Netherlands) + September 28, 2018 (Maastricht, the Netherlands).

Peter Brägas, former engineer and consultant at Blaupunkt. March 24, 2016. Hildesheim, Germany. Arnoud Broekhuis, manager ANWB traffic information center. June 15, 2015 + November 2, 2018. The Hague, the Netherlands. Additionally, June 8, 2016 via telephone.

Karel Brookhuis, expert traffic psychology \& professor traffic and transport (Rijksuniversiteit Groningen \& TU Delft, the Netherlands). September 28, 2018. Maastricht, the Netherlands.

Wayne Cabot, radio host WCBS880. March 5, 2018. New York, United States of America. Kelly Dillon, traffic reporter WCBS880. March 5, 2018. New York, United States of America.

David Fein, former traffic reporter at Shadow Traffic, New York. March 13, 2018. New Jersey, United States of America.

Anthony Gatti, manager traffic operations 1010WINS. March 15, 2018. New York, United States of America.

Erwin de Hart, traffic reporter ANWB. November 2, 2018. The Hague, the Netherlands.

Jerry Lebow, former WCBS newsroom technician and involved in the introduction of ARI in the United States. December 5, 2018. Interview via telephone.

Theo Kamalski, manager regulatory affairs and patent engineering business unit Automotive at TomTom. July 3, 2015. Eindhoven, the Netherlands.

Tom Kaminski, traffic reporter WCBS880. March 5, 2018. New York, United States of America.

Bernd Mayershofer, police officer at Landesmeldestelle für den Verkehrswarndienst, Stuttgart. February 6, 2017. Stuttgart, Germany.

John McLaughlin, traffic reporter and traffic producer WCBS880. March 5, 2018. New York, United States of America.

Dennis Mooij, traffic reporter ANWB. November 2, 2018. The Hague, the Netherlands.

René Passet, traffic reporter ANWB. November 13, 2018. Interview via telephone. 
Janet Pollok, radio host SWR 1. April 24, 2017. Interview via telephone.

Cees Quax, traffic reporter ANWB. November 2, 2018. The Hague, the Netherlands.

Hans van Raaij, producer morning show Radio 1. June 22, 2017. Hilversum, the Netherlands.

Julia Raizner, traffic reporter SWR. February 23, 2016 + February 23, 2017. Stuttgart, Germany.

Lara Rense, radio host Radio 1. June 22, 2017. Hilversum, the Netherlands.

Greg Rice, traffic reporter 1010WINS. March 15, 2018. New York, United States of America.

Frits 'Spits' Ritmeester, radio host Radio 1. June 22, 2017. Hilversum, the Netherlands.

Thomas Schmidt, radio host SWR 1. April 20, 2017. Interview via telephone.

Steve Scott, radio host WCBS880. March 5, 2018. New York, United States of America.

Jochen Stöckle, radio host SWR 1. April 20, 2017. Interview via telephone.

Corvin Tondera-Klein, traffic reporter SWR. February 23, 2016. Stuttgart, Germany.

Jolanda van der Velden, traffic reporter ANWB. November 2, 2018. The Hague, the Netherlands.

Birgit Wächter, traffic reporter SWR. February 23, 2017. Stuttgart, Germany.

Bernie Wagenblast, traffic information communication expert and former traffic reporter at Shadow Traffic, New York. 14 November, 2013 (Google chat) + March 6, 2018. New Jersey, United States of America.

Michael Wallace, radio host WCBS880. March 5, 2018. New York, United States of America.

Matt Ward, traffic reporter at Total Traffic and Weather. March 12, 2018. New Jersey, United States of America.

Mike Weinstein, project manager at Agency Operations Center, Port Authority of New York and New Jersey. March 14, 2018. New Jersey, United States of America.

Participant driver interviews:

Netherlands:

Andrew, male, age 34. November 8, 2016.

Benjamin, male, age 58. January 21, 2017.

Cathy, female, age 48. April 21, 2017.

Chris, male, age 37. November 8, 2016.

Harold, male, age 60. November 7, 2016.

Jessica, female, age 25. November 28, 2016.

Maud, female, age 44. January 21, 2017.

Phoebe, female, age 28. December 10, 2016.

Robin, male, age 29. December 21, 2017.

William, male, age 50. December 152016.

\section{Germany:}

Aubrey, female, age 47. February 26, 2017.

Alex, male, age 51. February 23, 2017.

Alice, female, age 52. January 11, 2018.

Ethan, male, age 36. April 2, 2018.

Edward, male, age 56. February 26, 2017.

Jim, male, age 41. April 7, 2017.

Mira, female, age 47. February 16, 2018.

Paul, male, age 32. February 27, 2017.

Shane, male, age 51. March 13, 2017.

Uri, male, age 40. April 4, 2017. 
New York metropolitan area:

Tony, male, age 30. March 6, 2018.

Vivian, female, age 39. April 5, 2018.

Quoted personal correspondences

Kelly Dillon, traffic reporter WCBS880. September 26, 2018.

Bob Gilmore, New York radio enthusiast and collector of airchecks. September 11, 2018.

Ed Salvas, former traffic reporter in the New York region and radio enthusiast. July 24, 2018. 



\section{Illustrations}

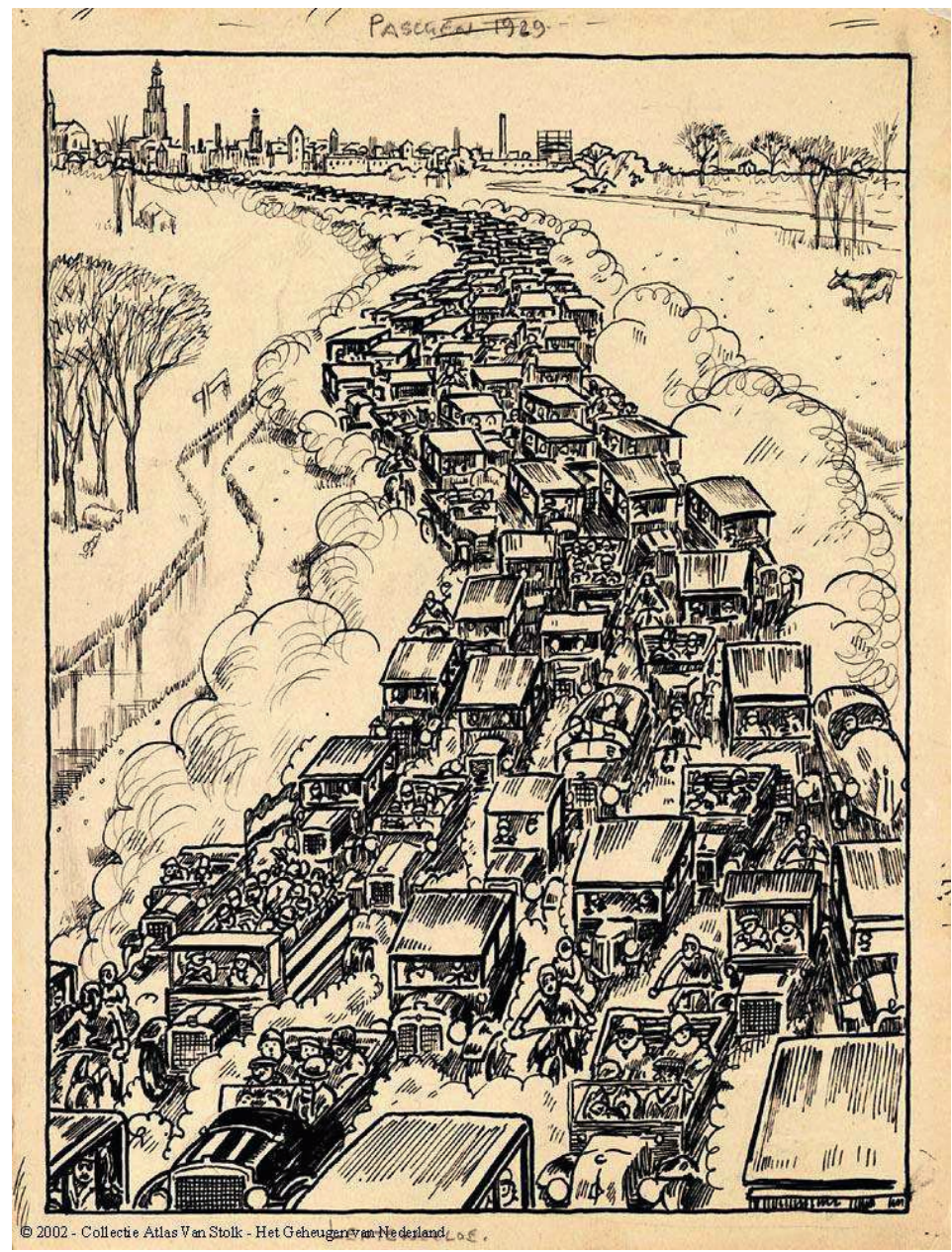

\section{Illustration 1.1}

Cartoon by Leo Jordaan in newspaper De Groene Amsterdammer (March 30, 1929) titled Paschen, 1929 - Lenteweelde [Easter 1929 - Springtime].

The image shows a cartoon of a rush of traffic aiming to exit the city of Amsterdam for the Easter Holiday. It illustrates how concerns about heavy traffic around holiday periods are almost a century old.

From: Collectie Atlas Van Stolk.

Reprinted with kind permission of Atlas van Stolk, Rotterdam. 


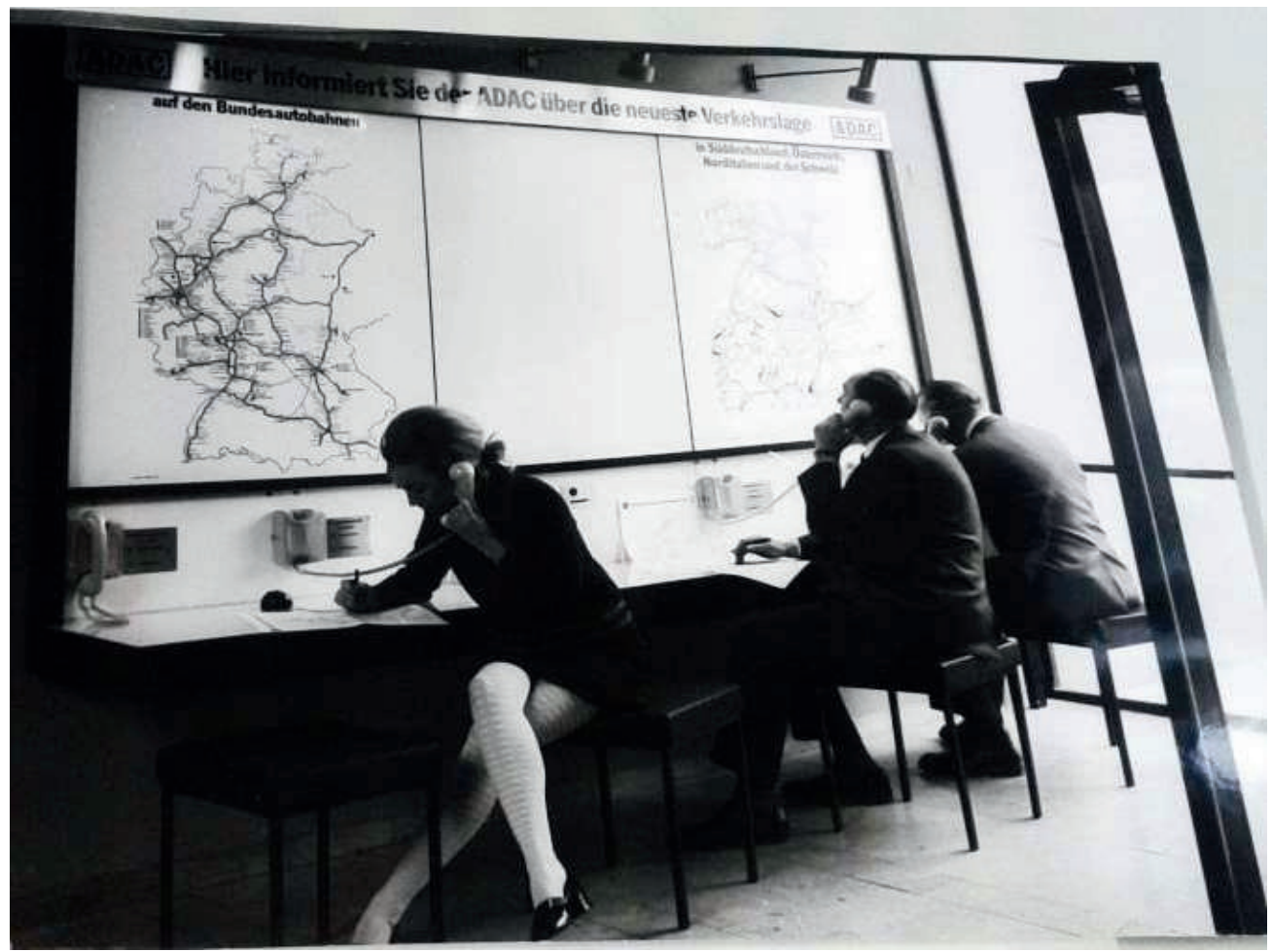

\section{Illustration 2.1}

Promotion photo ADAC Infothek München.

Caption (translated from German): "This is what the first Infothek for motorists looks like, which the ADAC has now installed at their headquarters in Munich. Via the telephone and the touch of a button, drivers always get the latest announcements about the situation on the roads at the borders and in the Alps.

The ADAC intends to install a series of these Infotheken in service areas alongside the motorways from South to North by 1972."

Bosch Company Archives, file folder "ARI 70-73," unnumbered documentation, photo. Reprinted with kind permission of the Bosch Company. 


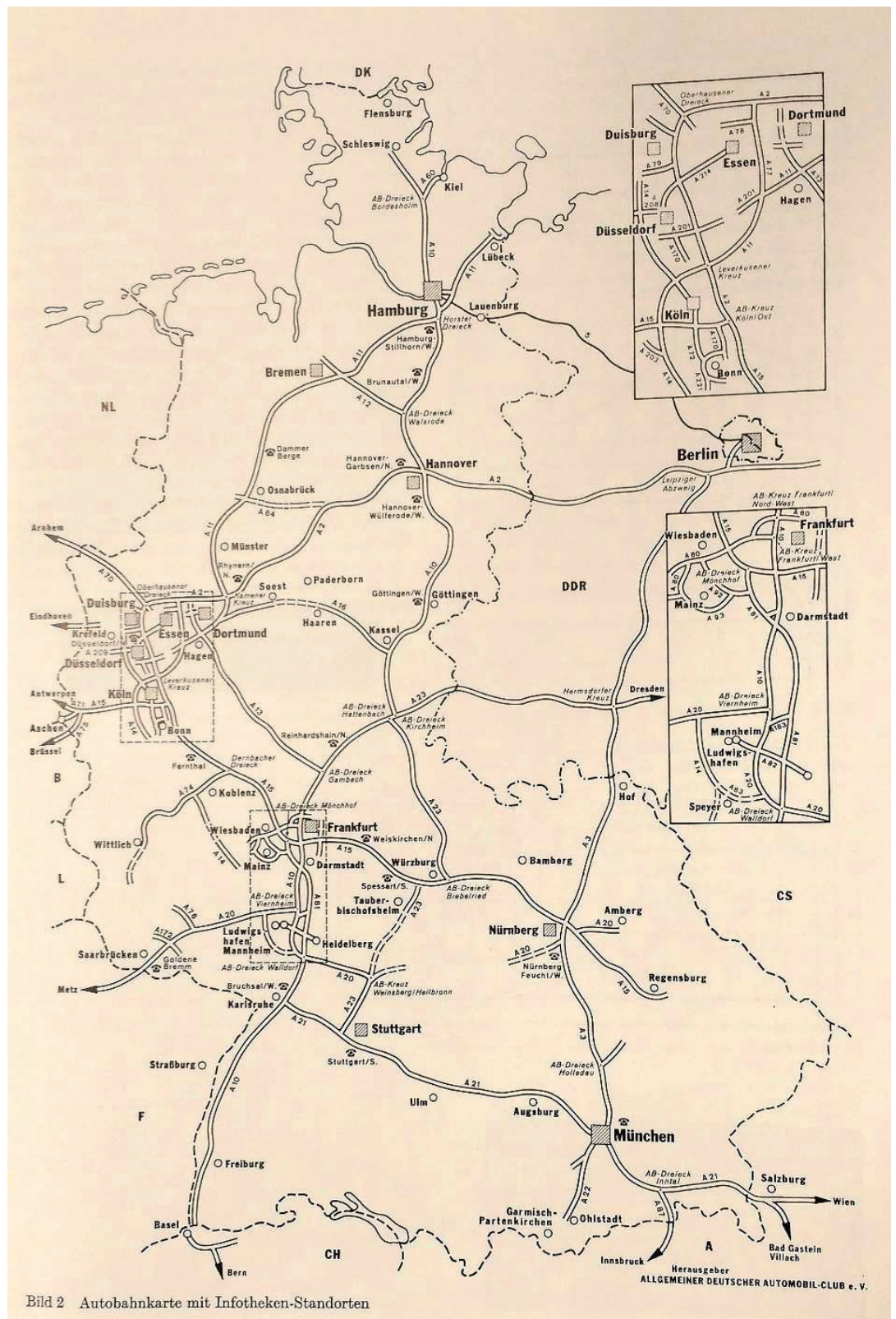

\section{Illustration 2.2}

A map of the various locations of ADAC Infotheken, indicated with squares next to frequently travelled highways and inside the ADAC office in Munich.

Brägas, P. (1973) Verkehrsrundfunk. In: Bosch Technische Berichte, vol. 4(5), p. 181.

Reprinted with kind permission of the Bosch Company. 

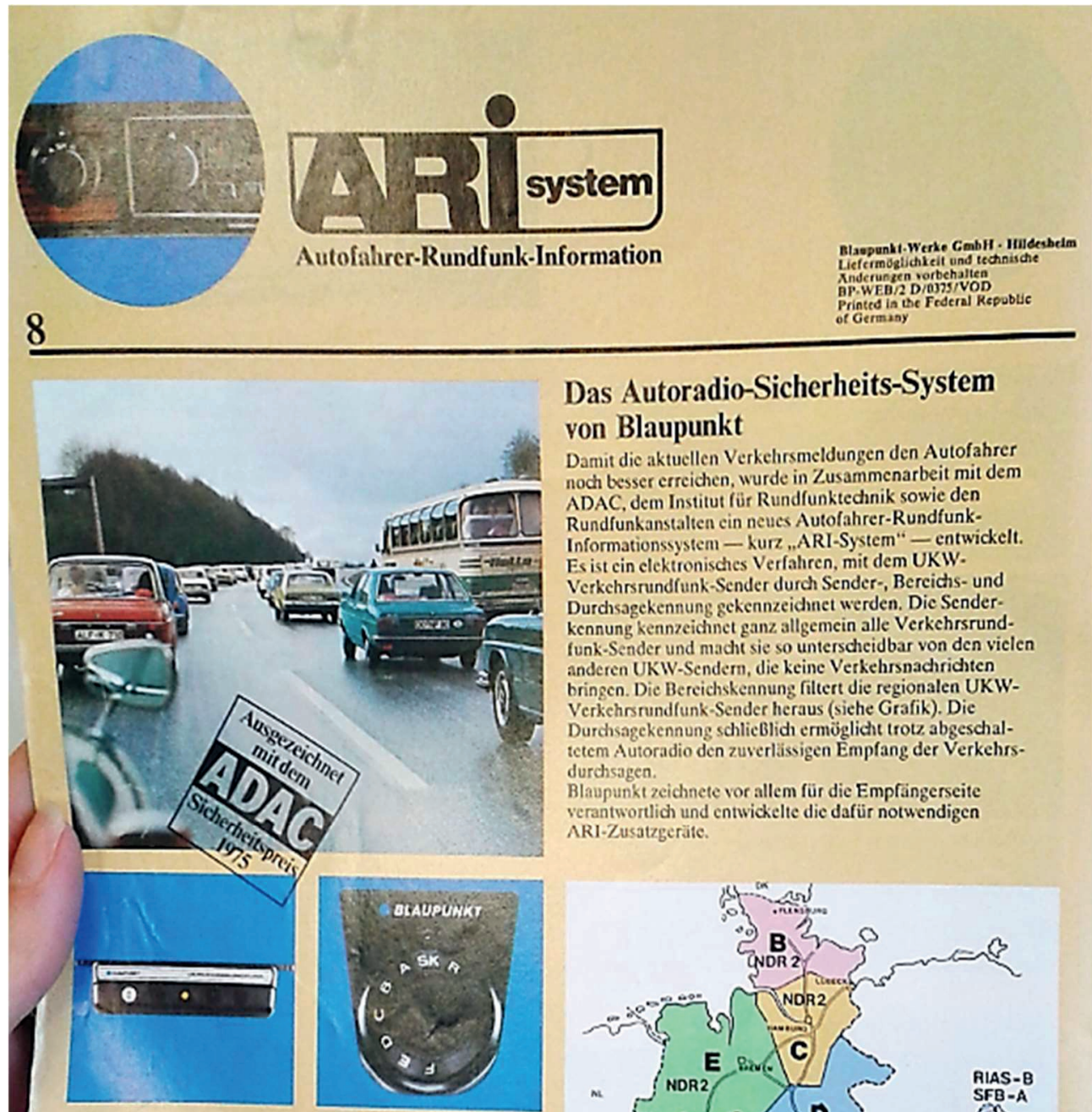

\section{Blaupunkt-}

Verkehrslotse

\section{(ARI SK)}

\section{zur Senderkennung}

Alle UKW-Sender mit Verkehrsnachrichten sind mit ciner unhörbaren Kenn-

frequenz gekennzeidinet. Auf diesen Pilotton spridit der

Verkehrslotse (SK) an. Wenn also cin Sender, der Verkehrsmeldungen ausstrahlt, eingestellt ist, wird das optisch durch Aufleuchten der Kontrollampe angezeigt. Bei gedrüdzter Einrast-Taste werden alle Nicht-Verkehrsrundfunk-Sender stummgeschaltet. Man hört dann nur noch die Sender, die Verkehrsmeldungen bringen.

\section{Das Autoradio-Sicherheits-System von Blaupunkt}

Damit die aktuellen Verkehrsmeldungen den Autofahrer noch besser errecichen, wurde in Zusammenarbeit mit dem ADAC, dem Institut für Rundfunktechnik sowie den Rundfunkanstalten ein neues Autofahrer-RundfunkInformationssystem - kurz „ARI-System" - entwickelt. Es ist ein elektronisches Verfahren, mit dem UKW. Verkehrsrundfunk-Sender durch Sender-, Bereichs- und Durdhsagekennung gekennzeidhnet werden. Die Senderkennung kennzeidinet ganz allgemein alle Verkehrsrundfunk-Sender und madit sie so unterscheidbar von den vielen anderen UKIV-Sendern, die keine Verkehrsnachrichten brinsen. Die Bercichskennung filtert die regionalen UKWVerkehrsrundfunk-Sender heraus (siehe Grafik). Die Durchsagekennung schließlid ermöglicht trotz abgeschaltetem Autoradio den zuverlässigen Empfang der Verkehrsdurchsagen.

Blaupunkt zeichnete vor allem für die Empfängerseite verantwortlich und entwickelte die dafür notwendigen ARI-Zusatzgerätc.

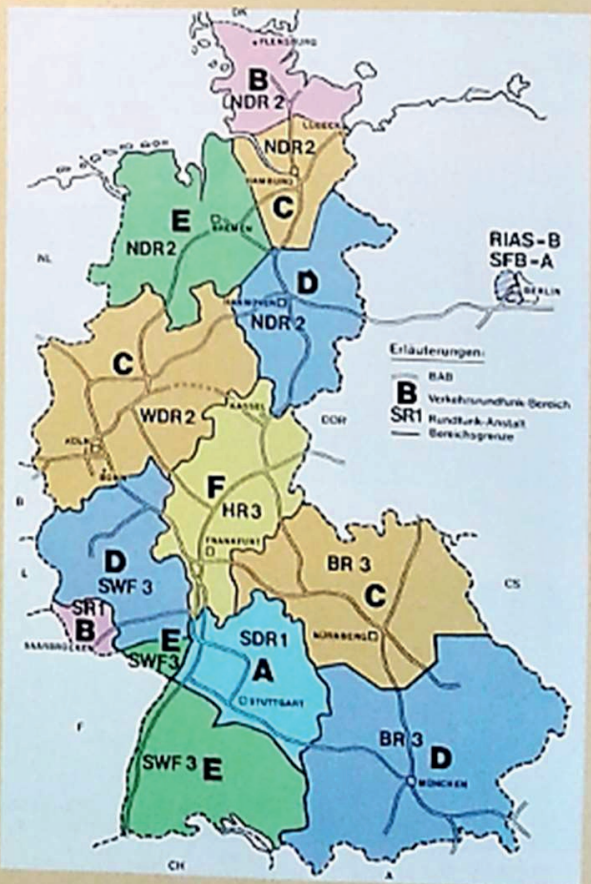




\section{$\underline{\text { Illustration } 2.3}$}

ARI information leaflet showing two add-on ARI decoders. On the map of Western Germany we see a directory for the use of the Bereichskennung decoder. Each coloured region has its own letter code and no two adjacent regions have the same code. The colour coding helps the viewer to recognise quickly which regional station s/he should tune in to for the most local traffic news.

Bosch Company Archives, file 1601 078-I Autoradio 1975-1976, unnumbered documentation, brochure "ARI-System."

Reprinted with kind permission of the Bosch Company. 


\section{Informationsfluß beim Verkehrswarnfunk}

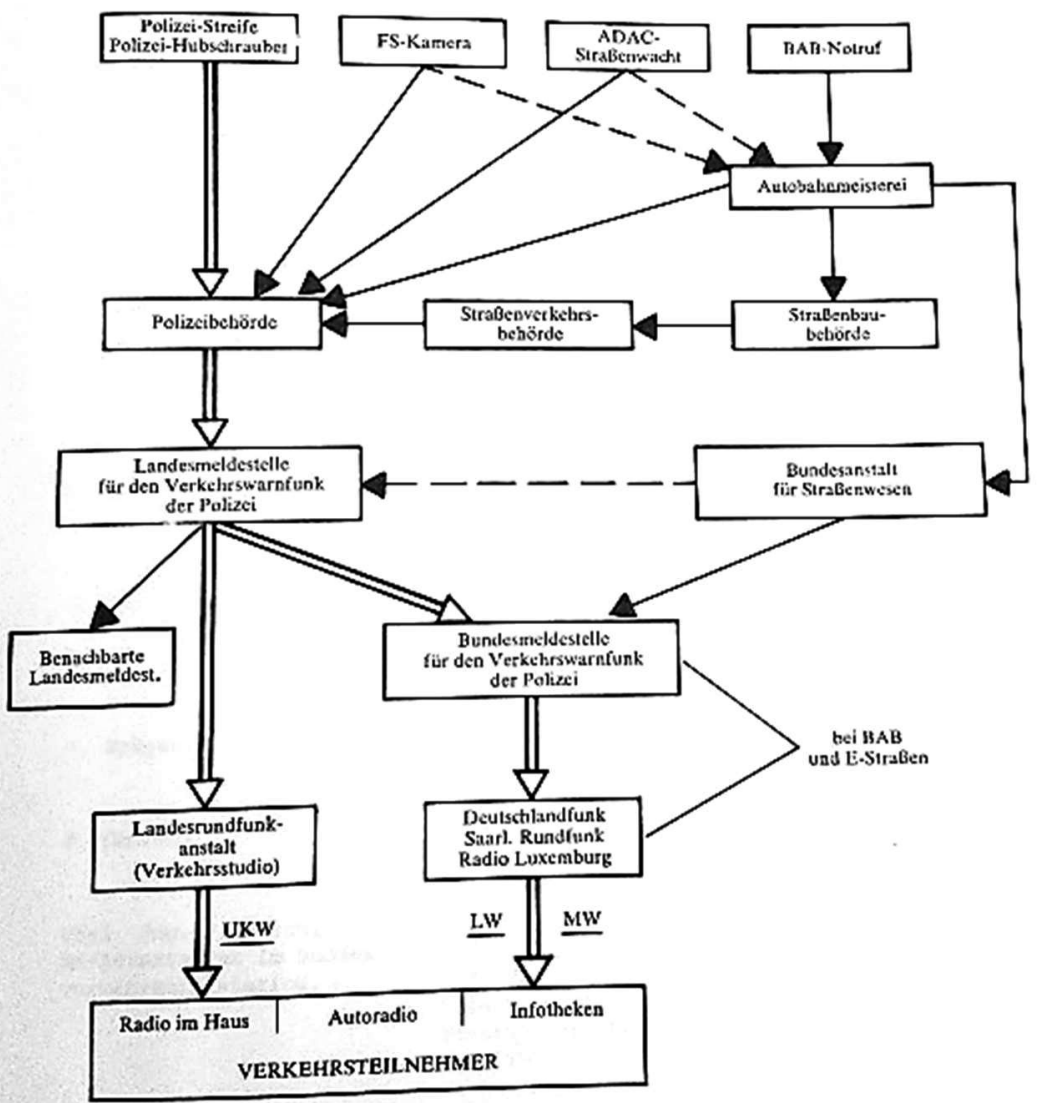

\section{Illustration 2.4}

Visual overview of the information flow.

Bosch Company Archives, unsorted files held by Mr. Kuhlgatz, unnumbered documentation, report "Radio Traffic Broadcast Systems: A detailed description of ARI," 1977, p. 18.

Reprinted with kind permission of the Bosch Company. 


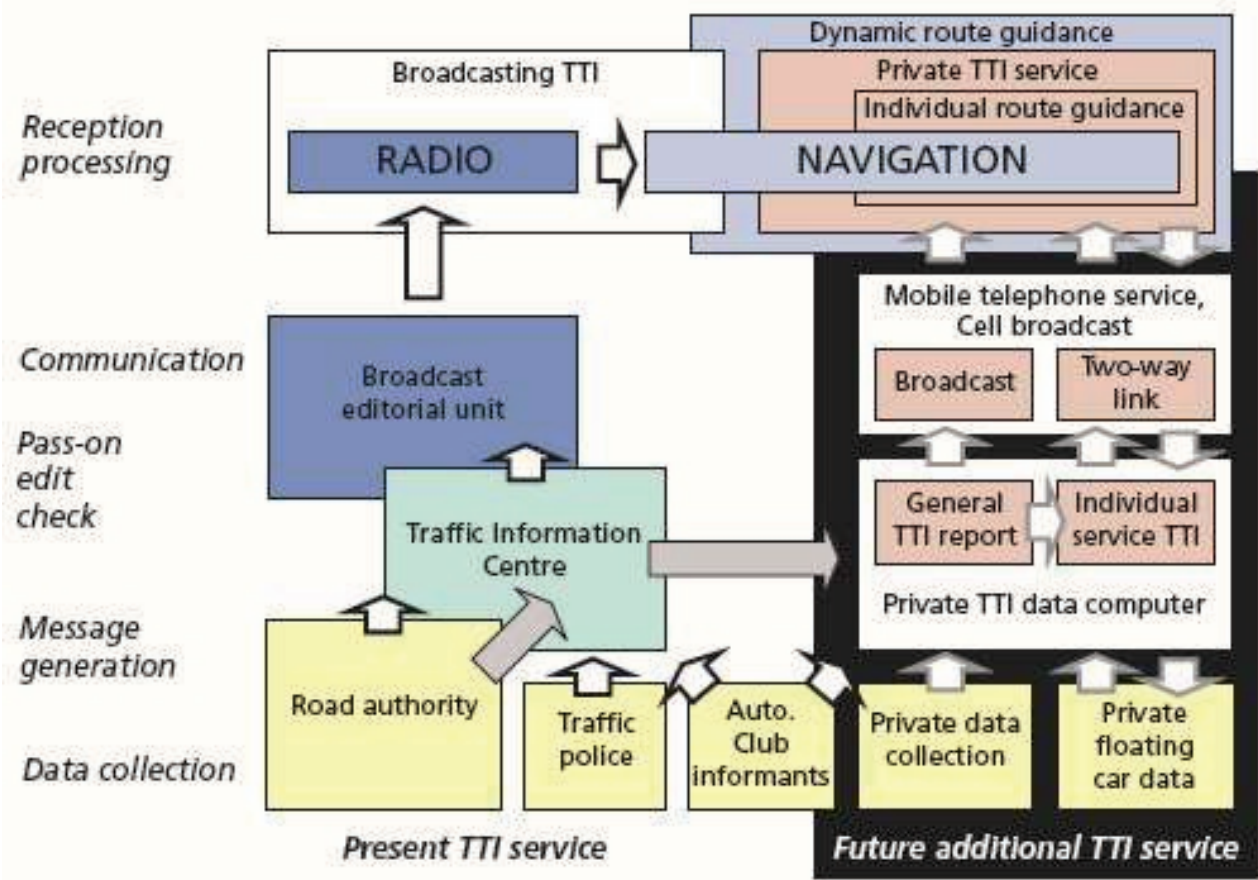

Figure 1

The competitive TTI environment: new information sources, new delivery mechanisms and enhanced services.

\section{Illustration 2.5}

The competitive TTI [Traffic and Transport Information] environment: new information sources, new delivery mechanisms and enhanced services.

Kopitz \& Marks (1999) Traffic and travel information broadcasting: Protocols for the $21^{\text {st }}$ century. In: EBU Technical Review, spring 1999, p. 2. 
The New England to Washington, $D C$ traffic corridor showing several connecting ARI areas. Zone numbers are repeated in ARI zones which are far enough away from each other.

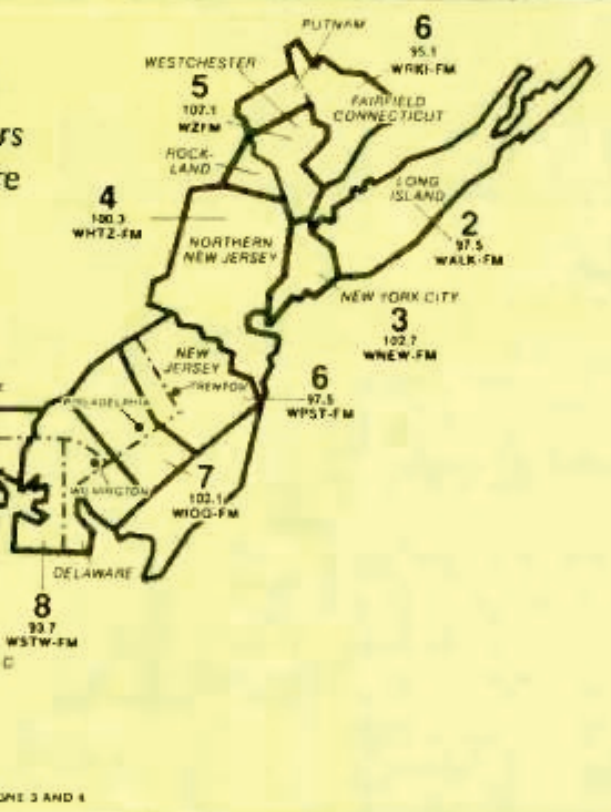

$\underline{\text { Illustration } 2.6}$

A map of the ARI broadcasting regions, indicated by number instead of letters, along the Eastern shore of the United States.

Gross, J. (1985). Radio programming and production: ARI gives radio traffic a "boost." Broadcast Management \& Engineering, 21(5), 27-30, here p. 29. 


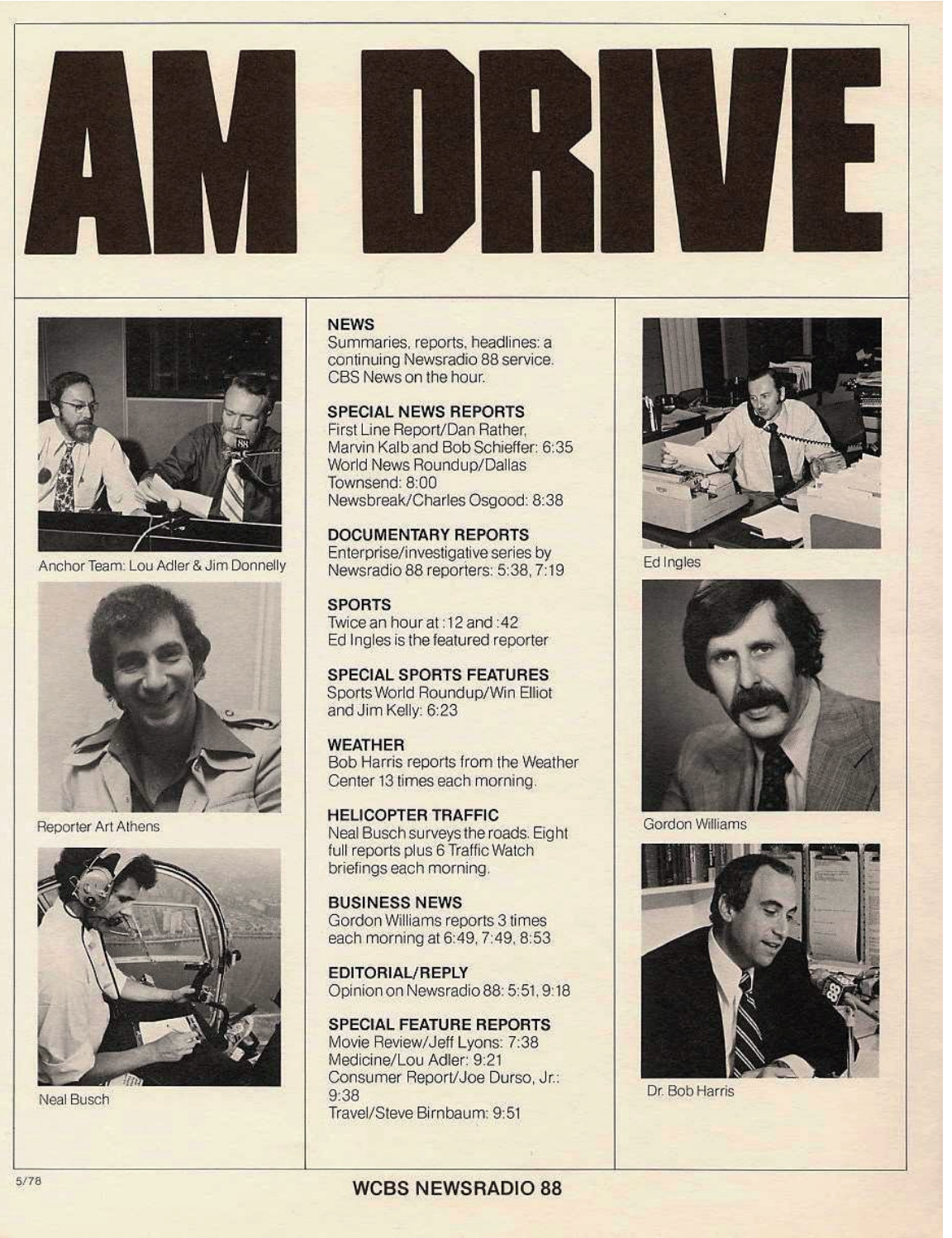

\section{Illustration 3.1}

Programme flyer of WCBS880, then known as WCBS Newsradio 88. Publication dates likely from 1978. The image of Neil Busch that can be seen on the left bottom corner shows Mr. Busch with the collective (the helicopter's 'steering wheel') and a notepad on which he keeps track of increasing and dissolving congestions on the roads below.

Retrieved August 30, 2018, from

http://www.nyradionews.com/wcbs/images/wcbs.amdrive.flyer.full.jpg.

Reprinted with kind permission of WCBS880. 


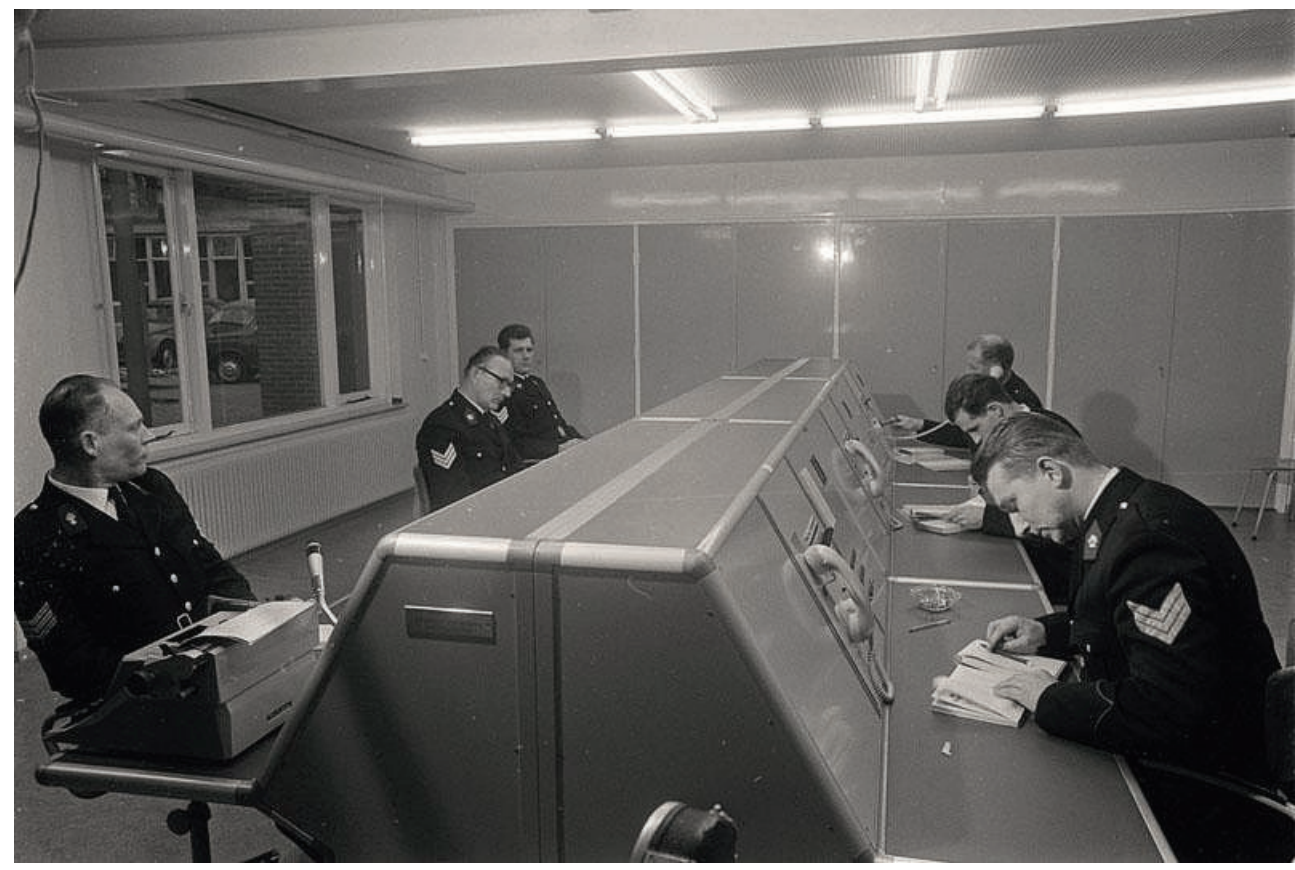

Illustration 3.2

The Police Traffic Centre in Driebergen, 1968. Photo by Ruud Hoff

From: ANP Historisch Archief, ANP Foundation, collection Algemeen Nederlands Persbureau - Fotoarchief, 1963-1986, item number 13857059.

Reprinted with kind permission of the ANP. 


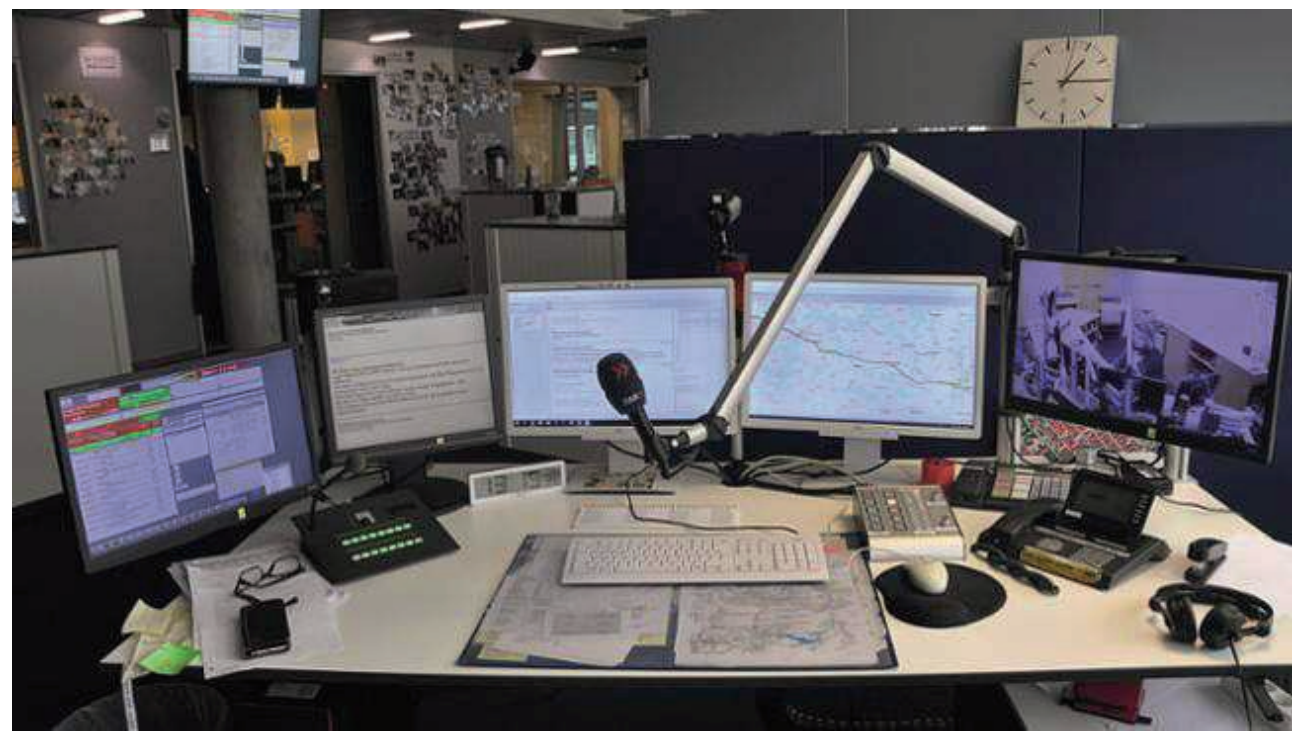

\section{Illustration 3.3}

The workspace of a SWR traffic reporter. The screens display the systems that connect with the regional traffic centre where all traffic data is gathered and processed; the system for selecting relevant notifications and putting those together for the next traffic report; the live traffic overview of Google Maps; and a view on the studio where the show host is working. On the table there is an additional microphone to communicate with the radio show's presenter and producers off air, a paper map of the Bundesland of BadenWürttemberg, and on the right there is a panel to switch the microphone and the ARI signal on and off.

Retrieved September 6, 2018, from https://www.swr.de/swr1/bw/programm/diearbeitsweise-der-verkehrsredakteure-raus-aus-dem-stau-mit-swr1/-/id=446250/did= 20993204/nid=446250/yfbrua/index.html.

Reprinted with kind permission of the SWR. 



\section{The Valorisation Addendum}

\section{Sharing Expertise and Experience}

It is mid-July 2019, and millions of Europeans are travelling far and wide to enjoy their holiday away from home and the workplace (Graafland, 5 July 2019). Many of these people go by car. According to Statistics Netherlands, in 2017, 43 per cent of the Dutch citizens travelling abroad for their summer holiday did so by car, and close to 90 per cent of the Dutchmen who spent their holidays in the Netherlands used a car to reach their destination (CBS, 2018). It is therefore not surprising to find discussions about automobile travelling in the media around this time of year. Recently, a Dutch journalist contacted me to contribute to such feature. She asked about my knowledge of in-car technologies and assumed that new information and communication systems had made older technologies redundant and consequently changed the character of long car journeys: the paper map, so she argued, had been substituted by real-time updated navigation systems and people no longer listened to (foreign) radio and traffic news but turned to their own playlists.

While this story sounds convincing, I replied that so-called 'old-fashioned' technologies rarely disappear the moment new technologies are introduced. The continuing use of radio traffic reports is a case in point: accessibility of new information and communication technologies inside automobiles has not resulted in an instantaneous change in people's listening, navigating, or driving practices. To illustrate this, I presented several examples from my qualitative and exploratory research into people's experiences with listening as part of their automobile habitation; findings I discuss in chapter 4 of this dissertation. These examples contradict a linear view of technological progression, and support David Edgerton's "shock of the old" premise; a discussion I introduce in chapter 1. I ended the interview hoping that my contribution to the article would leave the journalist as well as readers with a slightly broader understanding of technological innovations in the realm of automobility.

The persisting attention for automobile travelling, traffic news, and the linear view of technological development brings me to the topic of this addendum: the valorisation of my $\mathrm{PhD}$ research. For those unaware of recent discussions and changes in the scholarly domain, 'knowledge valorisation' is officially the third main task of Dutch universities, after teaching and research (see VSNU, 2019). The definition of the term valorisation, adopted by the Landelijke Commissie Valorisatie (National Commission on Valorisation) in 2011, reads: "The process of creating value from knowledge through making knowledge suitable and/or available for economical and/or societal usage and to translate into competitive products, services, processes and new businesses" (Van Drooge \& Vandeberg et al., 2011, p. 8).

While I strongly support efforts for making research outcomes accessible to the general public, I would like to express my discontent about the explicit demand for the commodification of research. The position paper of the collective Science in Transition (Science in Transition, 2013) or the report by Van Drooge and De Jong (2015) present lengthier critiques of the problems with the current definition and indicators of knowledge valorisation. A common other issue of critique, which I support, is that explicit pressure on 
researchers to evaluate the impact of their efforts principally in economic or other quantitative 'quality measurement' criteria undermines the wealth of possibilities scholars (ought to be able to) explore to share and valorise their research findings.

In my own $\mathrm{PhD}$ project, plans to communicate about my research were developed at the very beginning of the process, and I am happy about the outcomes of those efforts. I experienced first-hand how my research was positively valued by external audiences, and how fun valorisation activities can be. In this addendum I will reflect on the relevance of my thesis for other scholarly domains, what opportunities I seized for sharing my research findings, and how I intend to communicate about my $\mathrm{PhD}$ research in the nearby future. With this overview I aim to show that 'valorisation' can be done throughout a project, not only at the very end. In fact, my experience has been that a sensitivity for outreach activities can have a positive influence on the research process. Reaching out to others and communicating about my project helped me to stay informed, engaged and inspired throughout the project. This is why, personally, I welcome a broad definition of knowledge valorisation and would invite every colleague to experiment with different outreach activities. At the end of this addendum, then, I will highlight three ways in which my $\mathrm{PhD}$ affects my current research and educational activities.

\section{Explicating the Relevance of my Research}

The design of my project-studying developments in three different countries, over approximately 70 years' time, from three different vantagepoints, while keeping an eye on the evolving discussions about sustainable mobility-necessitated an interdisciplinary research approach, combining different methods and theoretical frameworks. Additionally, my research implied data collection from a highly diverse range of sources. Consequently, I encountered people having varying backgrounds: engineers and traffic reporters, radio hosts and archivists, drivers from all ages, scholars from various academic disciplines, and countless other individuals who had a relation with my topic in one way or another. In this section I will highlight the most innovative ways in which my thesis returns new knowledge to these stakeholders.

First, my research is relevant for the professionals I have studied: traffic reporters, people and organisations in radio broadcasting, manufacturers of information technologies and radio systems, policymakers, and experts in the field of traffic management. For these professionals, my thesis illuminates how all their efforts and operations are connected, and explains several of the historical shifts in the practices and underlying sociotechnical systems within which they operate. This broad yet thorough discussion of the system of traffic reporting can help the relevant professionals to reflect on their own role and expertise in this system and seek new or closer alliances with other stakeholders in the same field. The benefit of knowing and meeting with people in the same sector was also underlined by the participants in my expert meetings. Two of them were especially positive about the opportunity my research had provided to share experiences with co-workers in other parts of the traffic reporting sector. The study that is presented in this thesis can therefore be used as an incentive for more or closer relations between the various organisations that are involved in the sociotechnical traffic reporting system. As such, this study has the potential to reduce 
fragmentation of knowledge in the field of traffic reporting, and may help to shape new strategies for addressing important challenges in the future.

Second, this thesis enlarges our knowledge concerning one of the grand challenges of our time: the negative externalities of the increasing number and length of traffic jams. Compared to past and present research on the effects of automobility and traffic management, my exploration of traffic reports as part of motorists' overall listening-while-driving experiences adds more knowledge about the social character of traffic news. This social nature firstly pertains to the broadcasters of the information. Traffic reports are allocated significant amounts of airtime and reporters play an important role in radio shows. As a result, listeners gradually become used to the reporters and the form and content of the reports. Additionally, participants referred to radio traffic reports as an intermediary between them and their family, friends, colleagues and acquaintances. Such qualitative user experiences complement studies on the influence of traffic news on traffic flows, and should therefore be included in discussions about the value of radio traffic news.

In the literature reviews in chapters one to four of this thesis I have already explicated the relation between my research and earlier studies in the scholarly fields this study aims to contribute to Science, Technology and Society studies (STS), media studies, and mobility studies. Because of the width of my study, however, the findings may also provide interesting details or ideas for further research to scholars in other disciplines. To scholars concerned with the efficacy of traffic news, my study of people's automobile habitation underlines the importance of the senses, and particularly the aural environment, for the apprehension of traffic information while driving. I invite scholars in this field to include this sensitivity for the senses more explicitly in their research Additionally, people concerned with organisation theory and development, political theorists, or innovation scholars, may use this thesis to study the process in which a single technological innovation gets momentum, investigate the importance of governmental and non-governmental organisations in the development of a sociotechnical system, or identify the connections between (evolutions in) sociotechnical systems and the experiences of professionals and users of radio traffic news.

\section{Past and Planned Dissemination and Outreach Activities}

During my PhD, I have published several items to communicate with scholars in the various areas of study I engage with in my research. In a professional publication I co-authored with Karin Bijsterveld, published in the Journal of Radio and Audio Media in 2015, I contemplated on the role of traffic reports in drivers' experiences of traffic jams. We argued that traffic reports are at once part of the strategies to keep people tuned in to the radio, while at the same time offering clues for an escape or bypass of impending traffic jams. This publication was especially relevant for people in the field of media and mobility studies, because it presented traffic news as a novel starting point for investigating the nexus of the media and mobility domains. I advanced this part of my research in chapters 3 and 4 of this thesis.

When the analysis of the Dutch traffic reports was completed, I presented my methods and findings at the 4S-EASST conference in Barcelona, Spain, in 2016. This paper 
was then edited for publication in the interdisciplinary peer-reviewed journal Transfers (Dieker, 2018). In that article I discussed my methodologically innovative approach for studying traffic reporting: adapting Raymond Williams' theory of flow from media studies to the analysis of radio broadcasting, combined with mobility studies. In the fall of 2017, I also presented a paper, drawing on my research presented in chapter 4 of this thesis, at the Mobile Utopia conference in Lancaster, United Kingdom. In addition to these conferences, I presented my work during two seminars: at the Technology, Innovation \& Science group of the Technical University Eindhoven in December 2016, and at the Knooppuntcafé ('junction café': a recurring event where people with different backgrounds within media studies meet) at Beeld en Geluid in December 2017. At these conferences and seminars I spoke to scholars and professionals in STS, media studies, and mobility studies. The interdisciplinary nature of my project frequently proved an interesting addition to the research that was presented in the sessions I attended. For example, I added insights from media studies-Williams' theory of flow-to mobility research, and used theory from the history of technology on the evolution of large technological systems to explain the development of traffic reporting to media professionals. This way the interdisciplinary nature of my research enriches ongoing research in each of these domains.

Throughout my PhD I have also communicated my findings to general audiences. I published two blogs on the website of Beeld en Geluid in which I shared elements of my analysis of Dutch traffic reports as the research unfolded (Dieker, 2016b, 2016c). These blogs were primarily intended for people involved in radio studies, shedding some light on my research process from a methodological point of view, and people interested in Dutch radio history more widely. I could also draw on my research when I was approached by a journalist of the Dutch radio station BNR. He interviewed me in September 2016 and November 2017 about the development and relevance of radio traffic reports in contemporary radio programming and traffic management (Dieker, 2016a, 2017). A final public outreach activity I would like to mention here, was my pitch at the PhD pitch night that was part of the TEDxMaastricht event in September 2018 (Dieker, 2018). At this occasion, eighteen selected PhD's were asked to present their "idea worth sharing" in a five-minute presentation to a large lay audience of students are residents of Maastricht. In my pitch, I had the audience listen to two short excerpts of American traffic reports, from 1979 and 2018. These examples illustrated my takeaway message of that evening, that something as 'mundane' as traffic news in fact changes in form and content, and that we should take this awareness into account when discussing the problem of traffic congestion in the present and future.

In many instances, the interviews I conducted with my research participants and professionals in the field were also a form of valorisation. The invitation to participate in my research was an opportunity for the interviewees to sit back for a moment and reflect on their everyday activities, whether as professional involved in the creation of traffic news or as member of the reports' intended audience. Many of the participants in fact noted that they had never, or only marginally, thought about their own relation to radio traffic reports. For them, it was interesting to reflect on their own habits and preferences for gathering information prior to or during their commute. Several professionals whom I interviewed were especially interested in the methodology of project. They were for example curious to learn ow the international comparative aspect of my study, upon completion of the research, could 
provide an opportunity to reflect on their own professional practices. Conducting interviews, then, was a valuable means for reaching out throughout the $\mathrm{PhD}$ trajectory, making people more aware about their own relation to traffic news in the process.

My research also featured in my teaching at the Faculty of Arts and Social Sciences at Maastricht University. I taught a bachelor course in which the students learned about the 'networked' nature of our society, introducing them to several key concepts from Science, Technology and Society studies. In this course I could share my knowledge about information and radio systems. Also, at the masters level, I shared my experiences with research methods, and taught a skills course about qualitative interviewing. A special opportunity for teaching something about my research and academic training to a lay audience arose with the valedictory celebrations for Wiebe Bijker. As a gift, many of his (former) colleagues and students wrote short chapters for an introductory 'roadmap' to STS research for secondary school students. Together with two fellow graduates from the Cultures of Arts, Science and Technology master programme, of which Wiebe had been the co-founder and director, I wrote a fictional scenario in which 16-year-old pupils are taught some of the basic principles of social constructivism. My contribution to the chapter illustrated these principles on the basis of a short history of the technologies that enable the reception of traffic news on the road.

In the nearby future I will continue to share my knowledge about traffic information systems and sociotechnical change. In September 2019, I will give a guest lecture at the Athena Institute of the Vrije Universiteit, Amsterdam. In that lecture I will present different approaches to studying innovation, and explain how my historical study of evolving traffic information systems relied on a social constructivist understanding of the interrelations between scientific, technological, and societal change. In November 2019, I will present a new paper at the Dutch radio centenary conference at Beeld en Geluid. At that occasion I will add an international perspective to Dutch radio history, showing how traffic news featured prominently in the first attempts to develop a broadcasting system that was, technically, truly European. Finally, the Dutch motorist association ANWB has expressed interest in my research and has invited me to present a thorough overview of my research on the shifts of radio traffic reporting practices since the 1950s at the ANWB headquarters in The Hague.

In conversations about my topic, I have frequently said that radio traffic reports are a gratifying subject to study: virtually everybody is familiar with them, yet very little is known about them. Very often, I would receive positive responses to this observation (frequently involving one or two anecdotes about instances in which traffic reports had helped or not helped someone to evade a jam). Of course, the mere fact that people have personal experiences with traffic reports does not mean that my findings are also relevant to them. Nevertheless, the many engaging responses to my research have led me to believe that my study of traffic news could potentially be an interesting read to a wide audience. For this reason I will consider options to turn this manuscript in a (popular) science book after the thesis has been defended. 


\section{Traversing into new Trajectories}

In June 2019, I accepted a position as researcher and teaching coordinator at the HAN University of Applied Science in Arnhem, the Netherlands. Here, I am affiliated with the Automotive Research Department. Even though there was no vacancy, the heads of the department were interested in experimenting with more multidisciplinary researchers in their team. To validate the added benefit of such a strategy, I am currently valorising my knowledge of (auto)mobility, technology and society, sustainability, and my experience with qualitative research methods on a daily basis. To illustrate this, I will briefly mention three ways in which my past research and educational experiences feature in my new job. After all, this thesis is not the only means by which the knowledge I accumulated during my $\mathrm{PhD}$ research comes to fruition. In fact, many thoughts and details did not make it into this manuscript. Yet the experience of doing this $\mathrm{PhD}$ has shaped me as a researcher and as a person, and consequently I could argue that $I$ am the result of my research. So what am I doing with myself, professionally?

First, I have stepped into several ongoing research projects to which I contribute my knowledge and skills to the team's work. I am currently also (co-)authoring funding applications for new, interdisciplinary research in the area of automobility. As a researcher I am trying to stimulate interdisciplinary and multimethod enquiries, hoping to bring together knowledge and research skills that circulate in the scholarly and more applied sides of (auto)mobility and automotive research.

Second, I am adding some qualitative social science and humanities research, in particular from the field of STS and mobility studies, into the curriculum of the new specialisation 'Intelligent Mobility' that is part of the HAN Master of Engineering Systems. In short, I will introduce students of this programme to two STS mottoes that I believe are very relevant for future engineers: (1) we live in a 'technological culture' which means we cannot understand technology or society without including the one in the study of the other, and (2) because of the social dimension in technological innovation, technological trajectories could always have been otherwise if different decisions had been made in the past. The proposed additions to the current, primarily technical curriculum are thus intended to sensitise the students to the social nature of technological innovations, introduce them to some basic principles of responsible research and innovation, and, on a more practical level, make them reflect on the ways in which the mobility-related technologies they study and will themselves contribute to might affect the way we can be mobile.

Third, and perhaps most idealistically, I aim to narrow the gap between 'academic' and 'applied' research in the Netherlands. I believe that there can be a close(r) connection between research, education, and knowledge valorisation or (public) outreach efforts. However, for such synergies to become fruitful, it is important to be attentive towards the conduct, language and objectives of 'the other' and of oneself. Here, I am inspired by the positive response of the participants in the expert workshops I organised at the end of the $\mathrm{PhD}$. The participants appreciated the opportunity I had given them to talk to one another, and create more rapport between them. I aim to grow in my own capabilities to facilitate such exchanges and create new sustainable relationships. I intend to do so, at least, by maintaining my position in the academic community and actively participating in a network of nonacademic, local stakeholders like business, governments, knowledge institutes, and 
knowledge associations. The knowledge, experience and skills I have obtained during my studies and $\mathrm{PhD}$ will thus find their way into yet unknown places. 


\section{References}

ANWB (2019). "Verkeersdruktekalenders". Retrieved July 17, 2019, from: https://www.anwb.nl/verkeer/nederland/verkeersinformatie/verkeersdruktekalenders

Bijsterveld, K. \& Dieker, M. (2015). A Captive Audience: Traffic Radio as Guard and Escape. Journal of Radio \& Audio Media, 22(1), 20-25.

Breebaart, L. (2019, 6 July) Reizen anno 2019: Inpakken, wegwezen en lekker in je eigen bubbel blijven. Trouw. Retrieved July 17, 2019, from: https://www.trouw.nl/religiefilosofie/reizen-anno-2019-inpakken-wegwezen-en-lekker-in-je-eigen-bubbelblijven bf15048e/

CBS (2018) Twee derde zomervakanties geboekt via internet. Retrieved July 19, 2019, from: https://www.cbs.nl/nl-nl/nieuws/2018/30/twee-derde-zomervakanties-geboekt-via internet.

Dieker, M. (2016, 28 september). Er is verkeersinformatie... [edited radio interview]. In: M. Beekhuis (producer), Wetenschap Vandaag. Amsterdam: BNR Nieuwsradio. Retrieved February 9, 2019, from http://www.bnr.nl/radio/wetenschap-vandaag/10311517/er-isverkeersinformatie.

Dieker, M. (2016). Research blog for Beeld en Geluid: Radioverkeersinformatie: een onderzoek naar (weinig?) nieuws" (17 November). Retrieved from: http://www.beeldengeluid.nl/kennis/ blog/radioverkeersinformatie-een-onderzoek-naar-weinig-nieuws.

Dieker, M. (2016). Research blog for Beeld en Geluid: "Van uitstekende stenen naar bondige berichten over baanvakken" (19 December). Retrieved from: http://www.beeldengeluid.nl /kennis/blog/van-uitstekende-stenen-naar-bondigeberichten-baanvakken

Dieker, M., Diem, L. van \& Egher, C. (2017) Glances behind the scenes: the construction and dissemination of knowledge and technology in different times and spaces. In: Lente, $\mathrm{H}$. van; Swierstra, T., Wyatt, S. \& Zeiss, R. (Eds.) Wegwijs in STS - Knowing your way in STS, 205-216.

Dieker, M. (2018). Keep Moving, Stay Tuned: the construction of flow in and through radio traffic reports. Transfers: interdisciplinary journal of mobility studies, 8(2), 67-86.

Dieker, M. (2018, 12 September). Talking You Through - The hidden history of radio traffic reports. Pitch presented at the TEDxMaastricht PhD Pitch night, Maastricht.

Graafland, K. (2019, 5 July) Pas op: de zwarte en rode zaterdagen komen eraan. Algemeen Dagblad. Retrieved July 16, 2019, from: https://www.ad.nl/auto/pas-op-de-zwarte-en-rodezaterdagen-komen-eraan a231b25b5.

Science in Transition (2013) Why Science does not work as it should and what to do about it. Retrieved July 16, 2019, from: http://www.scienceintransition.nl/app/uploads/2013/10 /Science-in-Transition-Position-Paper-final.pdf.

Van Drooge, L. \& De Jong, S. (2015) Valorisatie: Onderzoekers doen al veel meer dan ze denken. DenHaag: Rathenau Instituut.

Van Drooge, L. \& Vandeberg, R. et al. (2011) Waardevol: Indicatoren voor Valorisatie. Den Haag: Rathenau Instituut.

VSNU (2019) “Valorisatie”. Retrieved July 17, 2019, from: https://www.vsnu.nl/valorisatie. 
Valorisation Addendum 



\section{Nederlandse Samenvatting}

"En dan gaan we nu door naar de verkeersinformatie." Dit type aankondiging wordt al decennialang door presentatoren op vele radiostations ter wereld uitgesproken om luisteraars te attenderen op het aankomende verkeersbericht. Voor de luisteraars die reeds ingeschakeld zijn op de nieuwszender is het filebericht een integraal onderdeel van het radioprogramma, en daarmee van de luisterervaring. Bij een deel van de automobilisten zal de autoradio op het moment van de aankondiging echter omschakelen naar de zender met het verkeersinformatiesignaal. Met behulp van deze techniek worden alle luisteraars die zijn geïnteresseerd in het laatste verkeersnieuws op de hoogte gehouden van de laatste ontwikkelingen op de weg. Op deze manier biedt verkeersinformatie, zo is de gedachte, iedereen met radio-ontvangst de mogelijkheid om files te ontwijken. Dit kan de automobilist doen door bij voorbeeld een andere route te kiezen of het moment van vertrek aan te passen. Deze inspanningen zouden via een betere en meer gecontroleerde spreiding van het verkeer over het wegennet moeten leiden tot minder files.

Hoewel de autoradio vergeleken met GPS-gestuurde navigatie- en communicatiemiddelen een relatief oud fenomeen is, wordt radioverkeersinformatie door onderzoekers en automobilisten zelf nog altijd belangrijk geacht. Het effect van verkeersinformatie op bestuurders hangt echter af van de manier waarop zij de informatie ontvangen en erop reageren. Daarbij is relevant dat de radioverkeersinformatie slechts één aspect is van de vele auditieve informatie- en entertainmentvoorzieningen die bestuurders tot hun beschikking hebben. De manier waarop de verkeersinformatie wordt verzameld, verwerkt en gepresenteerd aan automobilisten is per land echter veelal verschillend georganiseerd. Die praktijken zijn bovendien in de loop der tijd veranderd. In Talking You Through ("U er doorheen praten") onderzoek ik wat er achter deze observaties omtrent de radioverkeersinformatie schuil gaat. Die observaties hebben tot de volgende vraag geleid:

\section{Hoe en in welke mate zijn praktijken rondom het verzamelen, presenteren en beluisteren van radioverkeersinformatie veranderd in praktijken gericht op het sturen van verkeersstromen?}

In dit proefschrift onderzoek ik hoe radioverkeersinformatie in de tweede helft van de twintigste eeuw een vast onderdeel werd van een strategie voor mobiliteit die erop gericht was om automobilisten mondeling langs, en zo nodig door, de file te leiden. Na mijn introductie, waarin ik de aanleiding voor en opzet van dit onderzoek beschrijf, staat in de drie daaropvolgende hoofdstukken steeds één deelvraag centraal. Deze deelvragen luiden:

(1) Welke technologieën en organisatievormen zijn ontwikkeld voor het verzamelen en verzenden van radioverkeersinformatie?

(2) Hoe is de verkeersinformatie gepresenteerd en ingebed in radioprogramma's? 
(3) Hoe gaan hedendaagse automobilisten met radioverkeersinformatie om, en welke rol spelen andere luisteractiviteiten in de auto daarin?

In de antwoorden op de deelvragen bewegen we ons figuurlijk met de verkeersinformatie mee: van (1) haar ontstaansgeschiedenis, via (2) de presentatievormen op de radio, naar (3) de praktijken van de beoogde eindgebruikers. Deze kennis vormt de basis waarop ik in de conclusie van dit proefschrift reflecteer op de relatie tussen verkeersinformatie en strategieën voor meer duurzame automobiliteit, welke sinds de jaren ' 70 in hoge mate zijn gericht op het beheersen van verkeersstromen.

De bevindingen zijn het resultaat van een vergelijkende studie van Nederland (met name de Randstad), Zuid-Duitsland en de metropool New York in de Verenigde Staten, waarbij ik het historisch onderzoek start in het jaar 1950. De keuze voor deze landen, de regio's binnen deze landen en tijdsperiode is gebaseerd op de reeds bestaande kennis van de ontstaansgeschiedenis van de radioverkeersinformatie. Al in de jaren '30 van de vorige eeuw informeerde een radiostation in Newark, een stad ten westen van New York, vanuit een helikopter luisteraars over de toestand op de weg. Maar pas in de jaren ' 50 werd dergelijke verkeersinformatie in grote Amerikaanse steden een vast onderdeel van de programmering van veel zenders, en is dat tot vandaag gebleven. Om deze ontwikkeling te begrijpen richt ik mij daarom wat betreft de Verenigde Staten op de regio rond New York.

In Europa nam de automobiliteit pas enkele jaren na de Tweede Wereldoorlog sterk toe. Daarmee groeide, net als in de Verenigde Staten, het fileprobleem. In de Europese context onderzoek ik die problematiek en de ontwikkeling van de radioverkeersinformatie in Zuid-Duitsland en Nederland. In Zuid-Duitsland bevindt zich een groot deel van de invloedrijke Duitse auto-industrie, en ook de bekende radiofabrikant Blaupunkt en de Duitse automobielclub ADAC zijn in Zuid-Duitsland ontstaan. Nederland is aan de vergelijkende studie toegevoegd om te onderzoeken hoe de verkeersinformatie vorm kreeg in een land waar de auto relatief laat massaal werd aangeschaft, maar waar het wegennet, met name in de Randstad, een van de meest intensief bereisde infrastructuren ter wereld werd.

De vergelijking tussen deze geografisch en sociaal-technologisch verschillende gebieden illustreert goed hoe het werk van de betrokken partijen in elk gebied gebonden zijn aan hun lokale context. Dit geldt voor de technologische ontwikkelaars en organisaties die invloed hadden op de verdere invoering van de systemen voor radioverkeersinformatie, alsmede voor de radiomakers en de automobilisten die onderling verschillende gebruiken en wensen hadden met betrekking tot het uitzenden van het filenieuws. Om de praktijken van de verschillende betrokken partijen te doorgronden, benader ik de verkeersinformatie in elk hoofdstuk vanuit een andere invalshoek. Dit proefschrift is dan ook een voorbeeld van interdisciplinair onderzoek, waarin ik methoden en theoretische kaders heb toegepast uit wetenschap- en techniekonderzoek, mediastudies en mobiliteitsstudies, en gebruik heb gemaakt van verschillende soorten bronnen. Hieronder zal ik voor elk hoofdstuk de belangrijkste bevindingen uiteenzetten.

In hoofdstuk 2, "Mapping Mobility: Gathering, Processing and Broadcasting Traffic Information," zijn de bevindingen gebaseerd op archiefonderzoek bij twee belangrijke autoradiofabrikanten (Philips in Nederland en Bosch-Blaupunkt in Duitsland), publicaties van een reeks organisaties die in deze landen alsook in de regio New York van de Verenigde 
Staten betrokken waren bij de technologische ontwikkeling van radioverkeersinformatie systemen, interviews met experts op het gebied van radiotechniek, en een analyse van de tijdschriften De Kampioen (uitgegeven door de Nederlandse ANWB) en Motorwelt (uitgegeven door de Duitse automobielclub ADAC) in de periode 1950-2000. Om de ontstaansgeschiedenis van de radioverkeersinformatie te verklaren, maak ik gebruik van twee theoretische concepten die helpen de technologische en organisatorische veranderingen inzichtelijk te maken. Deze concepten, technological trajectory en momentum, helpen de gevolgen van vroege technologische oplossingen voor latere innovaties en organisatiestructuren te begrijpen.

In dit hoofdstuk staat de ontwikkeling van het Duitse Autofahrer Rundfunk Information (ARI) systeem centraal. Deze techniek maakte het begin jaren '70 mogelijk dat bestuurders via hun autoradio gemakkelijk in konden schakelen op een zender die verkeersinformatie uitzond. Die verkeersinformatie had destijds drie doelen: ze moest leiden tot meer verkeersveiligheid, het vermijden en daardoor verminderen van problemen als files en andere hindernissen op de weg, en het verbeteren van de gemoedstoestand van de automobilist. Na een succesvolle implementatie in Duitsland en enkele Duitstalige landen kreeg ARI momentum, en werd het opgevat als fundament voor de ontwikkeling van een verkeersinformatiesysteem dat in heel Europa zou worden geïntroduceerd. Ik laat vervolgens zien hoe, door toenemende belangstelling vanuit onder andere de European Broadcasting Union (EBU) en een positieve waardering door experts in Europese onderzoeks- en ontwikkelingsprojecten, er een opeenvolging — trajectory — kan worden geïdentificeerd in de technologische ontwikkeling van de vroege ARI-techniek naar het latere Radio Data System (RDS) en het Traffic Message Channel (TMC). Deze ontwikkeling vond plaats in een tijdsperiode waarin de filedruk sterk toenam, en het belang van verkeersregulatie middels beïnvloeding van de verkeersstroming steeds belangrijker werd geacht.

Ondertussen werd aan de andere kant van de Atlantische Oceaan ook met de ARItechniek geëxperimenteerd. Maar daar werd ARI niet met hetzelfde enthousiasme ontvangen als in Europa. Ik verklaar dit verschil door het sociaal-technologische systeem voor het verzamelen van de verkeersinformatie in de New York regio nader te bekijken, en concludeer dat, ondanks de eveneens hoge filedruk, de ARI-betrokkenen daar niet genoeg momentum konden opbouwen. Zowel de infrastructuur als de bestaande radio-industrie aldaar werden namelijk gekenmerkt door diepgewortelde commerciële belangen en gesegmenteerde organisatiestructuren, waardoor de context in New York niet ontvankelijk was het gestandaardiseerde ARI-systeem.

In hoofdstuk 3, "Broadcasting Flow: Presenting Traffic Information on the Air" schakel ik over op de presentatie en inbeddingsvormen van de verkeersinformatie in het radioprogramma. Ik heb hiervoor radio-opnames getranscribeerd van de belangrijkste nieuwszenders in elk van mijn regio's, te weten: Radio 1 in Nederland; SWF, SDR en (na hun fusie) SWR in Zuid-Duitsland; en WCBS880, 1010-WINS, en 77WABC in de regio New York. Omdat er in de periode tot 1960 heel weinig radio-opnames bewaard zijn gebleven, begint de historische analyse in de jaren '60 en loopt door tot de millenniumwisseling. Met betrekking tot de presentatie van de verkeersinformatie op de radio was ik in het bijzonder geïnteresseerd in de vorm en inhoud van de verkeersinformatie rubriek, en hoe deze in veertig jaar zijn veranderd. Om dit gestructureerd te onderzoeken heb 
ik een groot aantal opnames gecodeerd en geanalyseerd, waarbij ik de analyse theoretisch onderbouw met Raymond Williams' media-theoretische concept flow. Daarnaast heb ik radiopresentatoren, producers en verkeersreporters geïnterviewd om inzicht te krijgen in hun alledaagse ervaringen met de presentatie en inbedding van de radioverkeersinformatie, en kon ik gebruik maken van literatuur en historische bronnen.

In dit hoofdstuk laat ik zien hoe de veranderende vorm en inhoud van de verkeersinformatie een weerspiegeling vormen van het toenemende fileprobleem, de technologische innovaties voor het verzamelen en verwerken van de verkeersinformatie welke voortkwamen uit nieuw beleid en onderzoek op het gebied van verkeersmanagement zoals ik die heb geïllustreerd in hoofdstuk 2, en de oplopende druk op radiomakers om de aandacht van de luisteraar zo lang mogelijk vast te houden. Door die ontwikkelingen kom ik tot een ogenschijnlijk paradoxale observatie: terwijl de inhoud van de verkeersberichten in toenemende mate werd gestandaardiseerd en verschoof van een kikkerperspectief-waarin de automobilist in zijn reis werd begeleid — naar een vogelperspectief — waarbij de informatie abstracter en het hele land "overziend" werd weergegeven-werd de vorm van de berichtgeving juist steeds informeler en interactiever. Dit laatste blijkt onder meer door het gebruik van herkenbare achtergronddeuntjes en verbale aankondigingen die de luisteraars helpen attenderen op het filenieuws. Zo pogen radiomakers op twee manieren "flow" te creëren. Zij proberen luisteraars aan het programma gekluisterd te houden, en tegelijkertijd bij te dragen aan verbeterde doorstroming van het verkeer op de weg. Dit alles doen zij met een grote gevoeligheid voor de identiteit van de betreffende radiozender en de voorkeuren van luisteraars. De veranderingen in de vorm en inhoud van de verkeersinformatieberichten reflecteerden zo niet alleen de toenemende hoeveelheid gegevens over en gevoelde noodzaak tot een betere doorstroming van het verkeer, maar ook de druk om de automobilist te midden van steeds langere files en weinig opwekkende verkeersberichten in radioprogramma's geïnteresseerd te houden.

In hoofdstuk 4, getiteld "Listening while Driving: Apprehending Traffic Information on the Road" staan de luisterervaring en de verschillende strategieën die automobilisten hebben ontwikkeld voor het vergaren van verkeersinformatie centraal. Ik onderzoek hoe de verkeersinformatie onderdeel is van de algehele luisterervaring van automobilisten, en welke invloed de informatie heeft op hun beleving van woonwerkverkeer. Dit doe ik met behulp van het concept automobile habitation: hoe 'bewonen' mensen hun auto? Dit analytische begrip helpt inzicht te krijgen in de manieren waarop automobilisten hun ritten beleven en, bijvoorbeeld door het gebruik van verschillende soorten media, vormgeven. Om een goed beeld - een visuele metafoor, inderdaad—van de luisterervaringen van automobilisten te krijgen, is dit deel van het proefschrift gebaseerd op analyses van audio-opnamen van een werkweek aan autoritten van twintig onderzoeksparticipanten en interviews met elk van de deelnemers.

Het deelnemersonderzoek toont aan dat de betekenis van verkeersinformatie, verkregen via de radio of andere bronnen, in bredere termen moet worden begrepen dan alleen die van de reisplanning van de automobilist, verkeersstromen of verkeersveiligheid; de noties die in beleidsdocumenten en veel onderzoek naar verkeersinformatie domineren. Hierbij maak ik enkele kanttekeningen, waaronder dat automobilisten in de praktijk niet altijd de mogelijkheid hebben om hun route of reistijd te veranderen. Zij kunnen desalniettemin 
andere rollen aan verkeersinformatie toeschrijven; rollen met een hoog sociaal karakter. Ze gebruiken de verkeersinformatie bijvoorbeeld voor individueel verwachtingsmanagement als het gaat over de eigen kans op een ongehinderde rit. En soms delen zij de informatie met relaties om zo afspraken te verzetten, te bevestigen of nieuwe afspraken te maken zodat de reis voor hen interessanter wordt. Als de automobilist onverhoopt toch in een file terecht komt, zo bleek in het onderzoek, biedt de autoradio de mogelijkheid om binnen de fysiek beperkte ruimte van een stilstaande auto alsnog enige vorm van autonomie te ervaren, bijvoorbeeld door activiteiten als het luisteren naar muziek. Op die manier 'heroveren' de bestuurders hun gevoel van zelfbeschikking in de auto. Al dan niet up-to-date wat betreft het laatste filenieuws vinden automobilisten zo alsnog soelaas in een veelal ongewenste verkeerssituatie.

In hoofdstuk 5, "Conclusion: Enriching the debate about automobility" vat ik de bovengenoemde verschuivingen niet alleen samen, maar ga ik ook in op de relatie tussen verkeersinformatie en de huidige debatten en strategieën voor meer duurzame mobiliteit. Ik laat zien hoe in de afgelopen jaren de rol van de radio verkeersinformatie in de conceptualisatie van duurzaamheidsstrategieën in het mobiliteitsdomein is veranderd, waarbij de nadruk is komen te liggen op zogenaamde 'advanced traveller information technologies'. Deze informatietechnologieën zijn eveneens instrumenten voor het monitoren en reguleren van verkeersstromen. Het oude medium van de autoradio lijkt daar niet meer toe te worden gerekend, hoewel diezelfde autoradio nog wel wordt gebruikt in de alledaagse praktijk. In het licht van deze ontwikkeling, en in ogenschouw nemend hoe de verkeersinformatie sinds haar ontstaan continue heeft meebewogen met veranderingen in haar context, stel ik drie concrete mogelijkheden voor waarop het medium ook in de toekomst haar relevantie kan behouden. Deze drie alternatieve gebruikersmogelijkheden zijn gericht op het attenderen van automobilisten op plekken of activiteiten in de nabijheid die hun interesse kunnen wekken, het vergemakkelijken van sociale contactmomenten tussen mensen, en een nieuwe conceptualisatie van de autorit in het algemeen. Als de verkeersinformatie op dergelijke manieren verder wordt ontwikkeld, kan het mogelijk een duurzame bijdrage blijven leveren aan de veiligheid, mobiliteit, en het welzijn van automobilisten. 



\section{Curriculum Vitae}

Marith Dieker (Arnhem, 1990) obtained her BA cum laude in Arts \& Culture at the Faculty of Arts and Social Sciences (FASoS), Maastricht University, the Netherlands, in 2011. In this programme, she was enrolled in the specialisation Cultures of Knowledge and Technology, and focussed on innovation studies during a minor at the Maastricht Centre for Entrepreneurship. She continued her education in the Research Master programme Cultures of Arts, Science and Technology (CAST), also at Maastricht University, from which she graduated cum laude in 2013. During CAST she did a junior research internship at the NGO Dastkar Andhra in Hyderabad, India, where she contributed to research on the possibilities for sustainable livelihoods in rural Andhra Pradesh. After this internship, she shifted her attention to the sustainability of everyday practices in the West. In her master thesis, she explored the re-appropriation of 'waste' at a thrift shop and a recycling centre in the Netherlands.

After her master, Marith worked as research assistant for Professor Karin Bijsterveld at Maastricht University. She co-organised the Sonic Science Festival, which took place in January 2015. Upon being awarded a NWO research grant (grant file PGW-14-02), she continued working in Maastricht on her PhD research. Her project Talking You Through focussed on the history and contemporary practices of radio traffic reporting since the 1950s, and the relations between traffic reports and rising concerns about the environmental sustainability of our everyday automobility. As part of her training, Marith successfully finished the graduate training programme of the Dutch national graduate research school of Science, Technology and Modern Culture (WTMC). In addition to her teaching activities at the bachelor and master level, she was $\mathrm{PhD}$ representative in the FASoS Graduate School Advisory Board (2016-2018) and one of the founding members of the Central PhD Candidates Platform of Maastricht University. 

